Portland State University

PDXScholar

Fall 3-6-2017

\title{
Application of Numerical Modeling to Study River Dynamics: Hydro-Geomorphological Evolution Due to Extreme Events in the Sandy River, Oregon
}

Sarkawt Hamarahim Muhammad

Portland State University

Follow this and additional works at: https://pdxscholar.library.pdx.edu/open_access_etds

Part of the Civil and Environmental Engineering Commons, Geomorphology Commons, and the Hydrology Commons

Let us know how access to this document benefits you.

\section{Recommended Citation}

Muhammad, Sarkawt Hamarahim, "Application of Numerical Modeling to Study River Dynamics: HydroGeomorphological Evolution Due to Extreme Events in the Sandy River, Oregon" (2017). Dissertations and Theses. Paper 3478.

https://doi.org/10.15760/etd.5362

This Thesis is brought to you for free and open access. It has been accepted for inclusion in Dissertations and Theses by an authorized administrator of PDXScholar. Please contact us if we can make this document more accessible: pdxscholar@pdx.edu. 
Application of Numerical Modeling to Study River Dynamics:

Hydro-Geomorphological Evolution Due to Extreme Events in the Sandy River, Oregon

by

Sarkawt Hamarahim Muhammad

A thesis submitted in partial fulfillment of the requirements for degree of

Master of Science

in

Civil and Environmental Engineering

Thesis Committee:

David Jay, Chair

Stefan Talke

Saeed Moghimi

Portland State University

2017 
(C) 2016 Sarkawt Hamarahim Muhammad 


\section{Abstract}

The Sandy River (OR) is a costal tributary of the Columbia River and has a steep hydroshed 1316 square kilometers which is located on the western side of Mount Hood (elevation range $3 \mathrm{~m}$ to $1800 \mathrm{~m}$ ). The system exhibits highly variable flow: Its average discharge is $\sim 40 \mathrm{~m}^{3} / \mathrm{s}$, and the highest recorded discharge was $1739 \mathrm{~m}^{3} / \mathrm{s}$ in 1964 . In this study I model the geomorphic sensitivity of an $1800 \mathrm{~m}$ reach located the downstream of the former Marmot Dam, which was removed in 2007. The hydro-geomorphic response to major flood has implications for system management and aquatic life.

Studying hydro-geomorphic change requires a systematic approach. Here, I define flows and flood hydrographs for specified return interval based on the observed hydrologic record, and then examine potential hydro-geomorphic changes using a numerical model. A Pearson Type III distribution is used to calculate 100, 75, 50, 25, 10, and 2 year return periods. Extreme event hydrographs are derived by fitting derived and observed flood hydrographs to the gamma distribution curve. Sediment transport and geomorphology are then modeled numerically with $N a y s 2 \mathrm{DH}$, a solver that is part of iRIC software. Because the model is computationally intensive, I model the domain with five different spatial grid resolutions, to find proper grid resolution. The grid resolutions used are $1.5 \mathrm{~m}, 2 \mathrm{~m}, 3 \mathrm{~m}, 4 \mathrm{~m}$, and $5 \mathrm{~m}$. We choose $4 \mathrm{~m}$ as optimum grid resolution, based on the convergence of model results. The model is run for extreme event hydrographs with six above return periods. For result visualization and analysis, we focus on flow properties and bed elevation at peak flow and at the end of each event. For both times for each event, important flow and sediment transport parameters are visualized for 
the entire domain in plane form and eight cross-sections at $200 \mathrm{~m}$ intervals. Finally, we divide the geomorphic response into areas of erosion and deposition. Linear regression analyses of mean values of erosion and deposition at peak flow for all extreme events yield $\mathrm{R}^{2}$ of 0.981 for erosion and 0.986 for deposition. The mean erosion and deposition depth at the end of the events is modeled by nonlinear regression with correlation coefficient of 0.965 for erosion and 0.998 for deposition. The regression models provide direct understanding of impacts of different floods on the geomorphic response of the river domain. examination of the model as a whole suggest that the amount of erosion and deposition in the bed and banks is a function of channel geometry, bank and bed geology, riparian area condition and strongly depend on the amount of flow through the channel. 


\section{Dedication}

This study is dedicated to Shawnm. 
Acknowledgments

The author is deeply thankful to God for providing energy and ability to finish this work. I am seriously indebted to my advisor, Professor David Jay for his supervision and skillful guidance and encouragement. Also, I would like to thank Assistant Professor, Stefan Talke who helped me as the second advisor and Saeed Moghimi, who served on my thesis committee. Also, I thank Mackenzie Keith for providing DEM data in the USGS office, Portland, Oregon. Finally, I owe my regards and thanks to Professor Yangdong Pan, in the Department of Environmental Science and Management.

I would like to thank people in the Office of International Student Life, Jill Townely, Sponsored Student Program Administrator, Krista Kennedy, and Graduate Students Services Coordinator, Karen Popp. This work is impossible without encouragement and patience of my wife, Shawnm. Finally, my deepest gratitude is for my parents, brothers, sisters, and dear friend Hawkar Oagaz for their support and encouragements. 


\section{$\underline{\text { Table of Contents }}$}

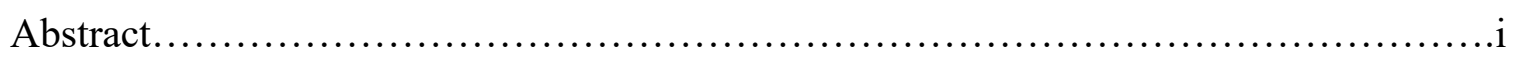

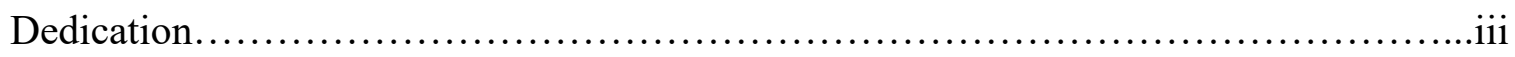

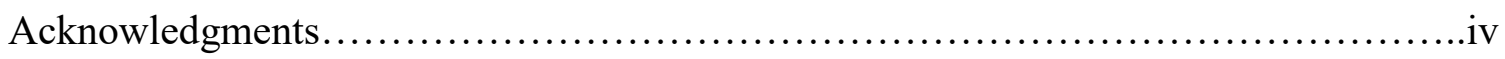

List of Tables.........................................................................

List of Figures...........................................................................

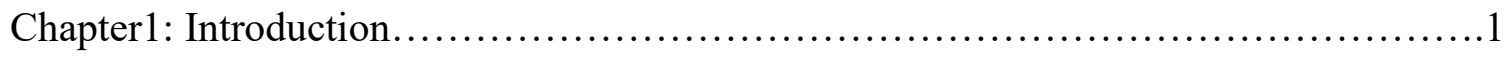

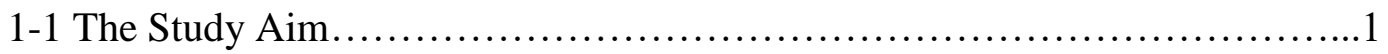

1-2 Sandy River Basin Characteristics.....................................2

1-3 Sandy River Climate and Metrology Condition.............................6

1-4 Climate Change and its Impacts on Sandy River Basin......................10

1-4-1 Long Term Variation.............................................11

1-5 Marmot Dam and its Removal......................................... 14

1-6 Study Area of the Sandy River......................................... 18

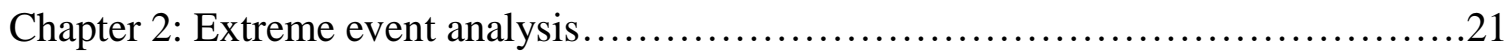

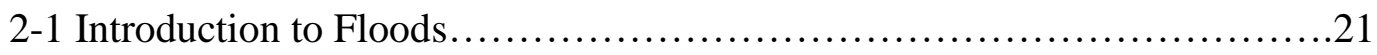

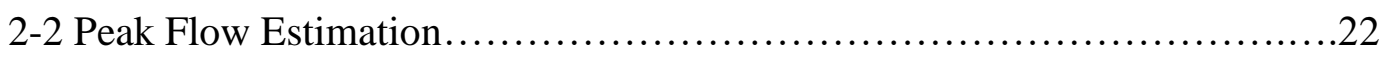

2-3 Extreme Event Hydrographs.............................................27

2-3-1 Base Flow Separation.......................................... 30

2-3-2 Base Time and Time to peak of extreme hydrographs...............31

2-3-3 Shape of Extreme Hydrographs...................................32

2-3-4 Ordinates of Extreme Event Hydrographs and Hydrograph Shapes

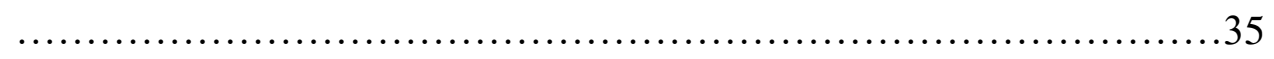

Chapter 3: Theory of the Numerical Model..........................................41

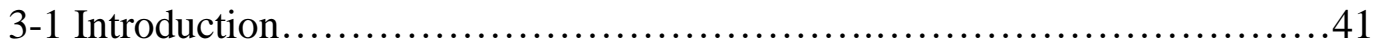

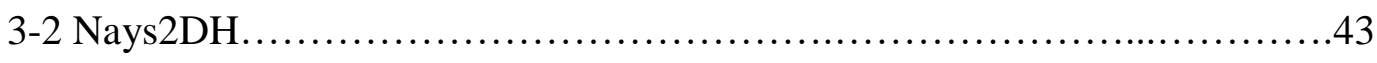

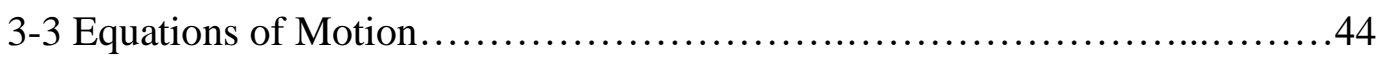

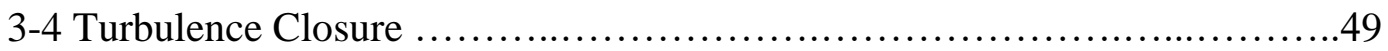

3-5 Sediment Transport Model Equations..................................50 
3-5-1 Shields Number (Non-Dimensioned shear stress) ..............50

3-5-2 Bed-Load Transport.....................................51

3-5-3 Near Bed Velocity................................................................52

3-5-4 vertical Flux of Suspended Load from River Bed.................52

3-5-4 Conservation of Suspended Load.............................53

3-5-4 Conservation of Sediment load and Exchange with the Bed........53

3-5-5 Bank Erosion Model.........................................54

Chapter 4: Numerical Grid Size Selection......................................57

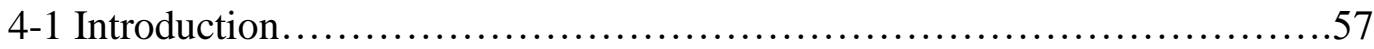

4-2 Models for Grid Selection............................................59

4-3 Grid Selection Models' Result.......................................61

4-4 Grid Resolution Selection............................................ 70

4-5 Model Specification for Extreme Events............................72

Chapter 5: The Result................................................... 74

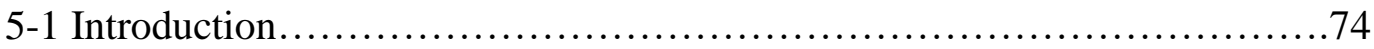

5-2 The Models Result................................................. 75

5-3 Sediment Transport Result........................................88

5-4 Prediction of Erosion and Deposition............................... 110

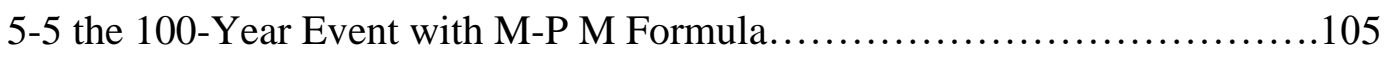

Chapter 6: Conclusion and Discussion...................................... 112

6-1 Conclusion and Summary....................................... 112

6-2 Future Climate Impacts.......................................118

6-3 Discussion of Model Limitation and Recommendation....................119

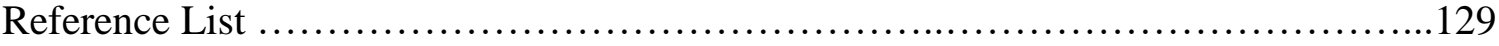

Appendix............................................................... 136 


\section{List of Tables}

Table 1-2-1 Size of the Sandy River basin and its watersheds ......................................

Table 1-3-1 The yearly range of precipitation in Sandy River basin watersheds ............7

Table 2-3-1 Return Periods and calculated peak flow events....................... 30

Table 2-3-1-1 Amount of base flow in each year events .......................... 30

Table 2-3-2-1 Base time and time to peak of direct runoff hydrographs for each year high

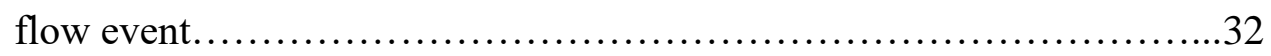

Table 2-3-3-1 $\mathrm{R}^{2}$ between observed direct runoff and gamma function curve............35

Table 2-3-4-1 Discharge, time rising and time lowering according to different percentages of peak flow for different years..........................37

Table 2-3-4-2 computed time ordinated for extreme event hydrographs................38

Table 4-2-1 Number of grids and grid resolution of each model.....................59

Table 4-3-1 the location of the cross-sections on the grids of the models..............66

Table 4-4-1 The requested time and average, 5\% and 95\% confidence interval of elevation change of the study domain of all models ....................72

Table 5-2-1 The spatial distribution of the cross-sections from upstream..............75

Table 5-3-1 Relations between bed-load and velocity........................... 106

Table 5-4-1 Mean erosion and deposition depth of the river reach for each return period and both flow conditions..................................... 107

Table 6-3-1 calculation of the amount of gravel accumulated inside the reservoir.....125 


\section{List of Figures}

Figure 1-1-1 Typical reservoir inflow and outflow hydrographs during a high flow event. This type of flow regulation reduces flood intensity. In the present Sandy River without flow regulation, flood time histories resemble the blue

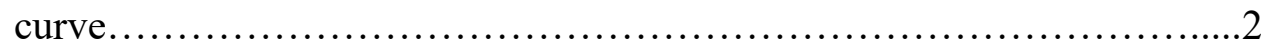

Figure 1-2-1 Geographic map of Sandy River basin and its watersheds ................5

Figure 1-3-1 Mean water year near Marmot dam station, 1911-2015..................8

Figure 1-3-2 Daily time series flow of Sandy River near Marmot Dam station, 19112016.

Figure 1-3-3 Three-dimensional hydrograph of water year of Sandy River; year day in October

Figure 1-4-1-1 Average and minimum winter temperature of the Sandy River basin from 1910 to 2016

Figure 1-4-1-2 Winter precipitation and snow depth of the Sandy River basin from 1910 to 2016 .

Figure 1-4-1-3 The history of the timber harvested in the Mount Hood (million board feet) and Oregon State (billion board feet).......................13

Figure 1-5-1 The Sandy River basin and locations of gage stations and Marmot Dam. 16

Figure 1-5-2 The Marmot Dam in two different situations, a- normal condition, and bduring demolition.

Figure 1-5-3 Cameras installed in and near Marmot Dam reservoir and cofferdam

Figure 1-6-1 Upstream, downstream extreme cross-sections, and longitudinal section of study reach of the Sandy River. 19

Figure 1-6-2 DEM of the study area of the Sandy River. Downstream of Marmot Dam 20

Figure 2-1-1 Transferring effective precipitation $\left(P^{*}\right)$ to flood hydrograph.... .22 
Figure 2-2-1 Maximum observed yearly flow in Sandy River at 14137000 station $\left(\mathrm{R}^{2}=\right.$

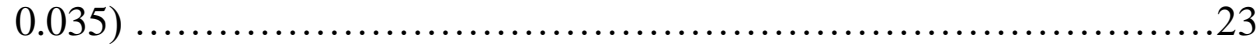

Figure 2-2-2 The result of the log-Pearson type III distribution of the Sandy river at

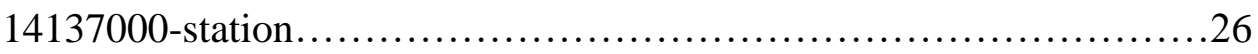

Figure 2-3-1 Time series (15 minute interval) data with discretized high flow events,

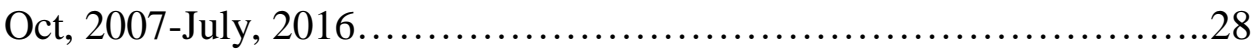

Figure 2-3-2 Discretized high flow events from time series data in different years.....29

Figure 2-3-3 Histograms of the discretized high flow events.......................29

Figure 2-3-1-1 Direct runoff of the high flow events in each years....................31

Figure 2-3-3-1 Effect of physiological conditions of watershed on shape of hydrograph........................................................

Figure 2-3-3-2 Typical Gamma Distribution curves; adapted from.....................34

Figure 2-3-3-3 plotted gamma distribution curve on the direct runoff of high flow

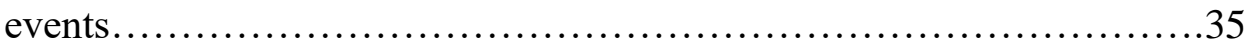

Figure 2-3-4-1 Division of direct runoff hydrograph according to peak flow.............38

Figure 2-3-4-2 Extreme direct runoff hydrographs for different return periods...........39

Figure 2-3-4-3 Extreme hydrographs of different return periods....................40

Figure 3-2-1 General structure of iRIC model f................................43

Figure 3-3-1 The horizontal moving boundary-fitted coordinate for non-dimensional ( $\xi$ and $\eta)$ and dimensional of $\tilde{\xi}$ and $\tilde{\eta}$ coordinates.....................46

Figure 3-5-5-1 the bank erosion model conceptualized diagram.....................55

Figure 3-5-5-2 the conceptualized slope collapse model..........................56

Figure 4-1-1 General outline of computational fluid dynamics......................58

Figure 4-2-1 the computational domain of the five models........................60

Figure 4-2-2 Manning's coefficient in river channel and riparian area.................61

Figure 4-3-1 Depth of water at the peak flow and at the end of the event..............62

Figure 4-3-2 Alteration of bathymetry at the time of peak flow and at the end of the

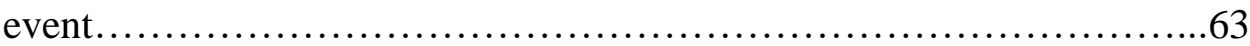


Figure 4-3-3 3 Histograms of distribution the bed elevation alteration for different model and flow situation (peak flow and the end of the event) ..............65

Figure 4-3-4 Locations of the cross-sections used for convergence evaluation...........66

Figure 4-3-5 $1.5 \mathrm{~m}$ resolution grid cross-sections looking upstream of initial bed elevation, water surface elevation, and evolution of bed elevation at peak flow and the end of the event flow condition. Cross-section locations are

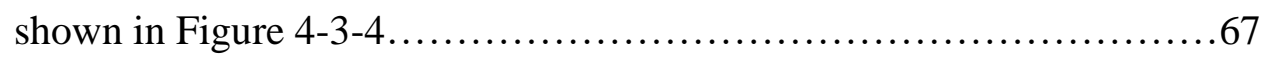

Figure 4-3-6 As in Figure 4-3-5, but for the $2 \mathrm{~m}$ grid resolution model ...............68

Figure 4-3-7 As in Figure 4-3-5, but for the $3 \mathrm{~m}$ grid resolution model ...............68

Figure 4-3-8 As in Figure 4-3-5, but for the $4 \mathrm{~m}$ grid resolution model ................69

Figure 4-3-9 As in Figure 4-3-5, but for the $5 \mathrm{~m}$ grid resolution model ...............69

Figure 4-4-1 The average elevation change of the entire domain for all grid sizes.......71

Figure 4-5-1 Movable and fixable bed of the domain.......................... 73

Figure 5-2-1 The spatial distribution of the cross-sections over the computational domain. .76

Figure 5-2-2 Water depth variations for all extreme events (For peak and final) flow conditions. .77

Figure 5-2-3 The water velocity distribution for all extreme events (For peak and final) flow conditions.

Figure 5-2-4 The spatial distribution of elevation change for all extreme events (For peak and final) flow conditions (Note the peak flow condition is normalized to $2.5 \mathrm{~m}$ to $2.5 \mathrm{~m}$, but the final condition normalized to $-3 \mathrm{~m}$ to $3 \mathrm{~m}$ )........80

Figure 5-2-5 Figure 5-2-5 The cross-sectional variation of bed and bank evolution with water surface elevation for the 2-year event (For peak and final) flow conditions. IniE is initial elevation, peak WSE is water surface elevation at peak flow, peak BE is the bed elevation condition at peak flow, end WSE is the water surface elevation at the end of the event, end $\mathrm{BE}$ is the bed elevation at the end of the event, and XS is cross-section .81

Figure 5-2-6 As in Figure 5-3-5, but for the 10-year event .82 
Figure 5-2-7 As in Figure 5-3-5, but for the 25-year event ....................... 83

Figure 5-2-8 As in Figure 5-3-5, but for the 50-year event ......................84

Figure 5-2-9 As in Figure 5-3-5, but for the 75-year event........................ 85

Figure 5-2-10 As in Figure 5-3-5, but for the 100-year event .......................86

Figure 5-2-11 Normal distribution fits to the histogram of elevation change for all extreme events (For peak and final) flow conditions..................87

Figure 5-3-1 The shear stress distribution for all extreme events (For peak and final) flow

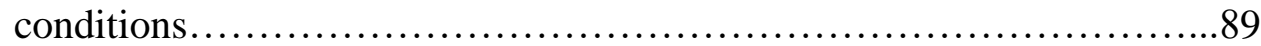

Figure 5-3-2 The Non-dimensional shear stress (Shields Number) distribution for all extreme events (For peak and final) flow conditions..................................................... 90

Figure 5-3-3 The bed-load flux distribution for all extreme events (For peak and final) flow conditions.............................................91

Figure 5-3-4 Figure 5-3-4 The suspended-load distribution for all extreme events (For peak and final) flow conditions..................................................... 92

Figure 5-3-5 Cross-sections of horizontal velocity and bedload transport for the 2-year return period, for the peak flow condition.........................93

Figure 5-3-6 As in Figure 5-3-5, but for the final flow condition ...................94

Figure 5-3-7 As in Figure 5-3-5, but for the 10-year event .......................95

Figure 5-3-8 As in Figure 5-3-5, but for the 10-year event, the final flow condition .....96

Figure 5-3-9 As in Figure 5-3-5, but for the 25-year event ....................... 97

Figure 5-3-10 As in Figure 5-3-5, but for the 25-year event, the final flow condition ...98

Figure 5-3-11 As in Figure 5-3-5, but for the 50-year event ......................99

Figure 5-3-12 As in Figure 5-3-5, but for the 50-year event, the final flow condition.............................................. 100

Figure 5-3-13 As in Figure 5-3-5, but for the 75-year event .....................101

Figure 5-3-14 As in Figure 5-3-5, but for the 75-year event, the final flow condition 102 
Figure 5-3-15 As in Figure 5-3-5, but for the 100-year event 103

Figure 5-3-16 As in Figure 5-3-5, but for the 100-year event, the final flow condition 104

Figure 5-3-17 Fitted bed-load vs. velocity for all extreme event scenarios and both flow conditions. .105

Figure 5-4-1 Mean erosion depth for the peak flow condition ......................108

Figure 5-4-2 Mean deposition depth at peak flow condition .......................... 108

Figure 5-4-3 Mean erosion depth at end of the events flow condition (return periods)

Figure 5-4-4 Mean deposition depth at end of the events flow condition (return periods).

Figure 5-5-1 Elevation change of 100 year return period for both Ashida and Michiue formula and Meyer-Peter and Müller formula at peak and end of the event flow condition. 110

Figure 5-5-2 The erosion and the deposition spatial distribution for the 100 year return period scenario for the Ashida and Michiue formula and the Meyer-Peter and Müller formula, for peak and final flow condition 111

Figure 6-1-1 1964 flood in the Sandy at the upstream of the study area...............112

Figure 6-1-2 2011 flood, same location in two different times......................113

Figure 6-1-3 2011 flood in other locations.................................. 113

Figure 6-1-4 Cross-sectional hysteresis of suspended and bed-load for 100 year flood return period which is taken from $450 \mathrm{~m}$ from upstream face of the study

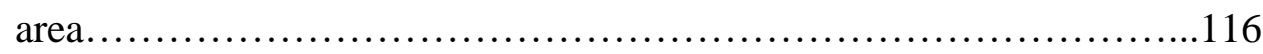

Figure 6-1-5 Cross-sectional hysteresis of suspended and bed-load for 10 year flood return period which is taken from $450 \mathrm{~m}$ from upstream face of the study

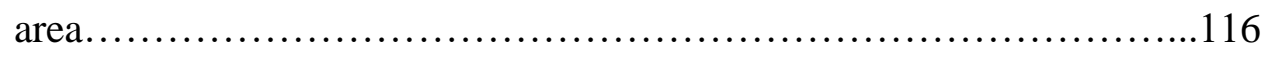

Figure 6-1-6 Cross-sectional bedslope change with time for 100 and 10 years flood return periods which are taken from $450 \mathrm{~m}$ from upstream face of the study area................................................. 
Figure 6-2-1 Watersheds of Columbia River basin for projected climate change

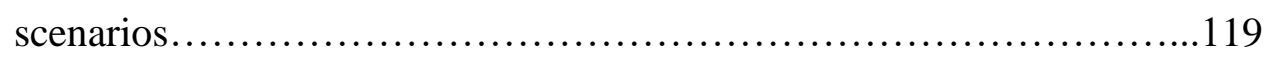

Figure 6-3-1 Shields diagram for initiation of sediment particle movement............123

Figure 6-3-2 the bed-load hysteresis of different return period floods................126

Figure 6-3-3 The inlet of the computational domain before and after deleted points on the shoulders of the valley at upstream face of the domain ................128 


\section{Chapter 1: Introduction}

\section{1-1 The Study Aim}

The main purpose of this study is to investigate how the river bed and banks respond to high flows and floods in a study reach of the Sandy River. The hydrogeomorphic response of the rivers affects future flow and sediment transport and bed characteristics, and extreme event flow exerts substantial forces that alter the bed and banks of the river. The Sandy River is a dynamic stream with a range of annual average maximum $\left(470.3 \mathrm{~m}^{3} / \mathrm{s}\right)$ to minimum $\left(5.5 \mathrm{~m}^{3} / \mathrm{s}\right)$ flow ratio of 85.5 and a daily average flow that varies by a factor of 213 within the observed record (1911 to date). Extreme events in the system have both human and habitat impacts. A major flood in 2011, for example, damaged roads and destroyed houses upstream of the study reach. While the study reach and the Sandy River Gorge downstream are not heavily developed, they are used for habitat, and affected by forestry and (to a minor extent) agriculture. Thus, it is useful to inquire how the stream may evolve in the future, given that Sandy River flows and sediment transport are no longer constrained by Marmot Dam. Because of the relatively coarse material found in the system, most sediment transport occurs under the highest flow conditions (Chapter 5), so modeling these conditions is vital. However, extreme events occur randomly and have a distribution of properties, so the hydrographs used to force the numerical model should be derived based on the shape and distribution of the past flood events. A numerical model can then be used to evaluate hydro-geomorphic evolution during extreme event for different return periods. 
Sandy River flows have not been regulated since October 2007, and there is no structure to reduce peak floods or prolong the flooding time (Figure 1-1-1). Thus, the flood hydrograph in the study reach reflects upstream flows, and the same flows are passed downstream to further sections. Although the study area used in this research was kept relatively short to facilitate modeling, it should still show the physical characteristics of the river's hydro-geomorphic response during floods, at least for the part of the system with coarse sediment. Results of this study should assist decision makers in analysis risk management policy during high floods for the river habitat and riparian areas.

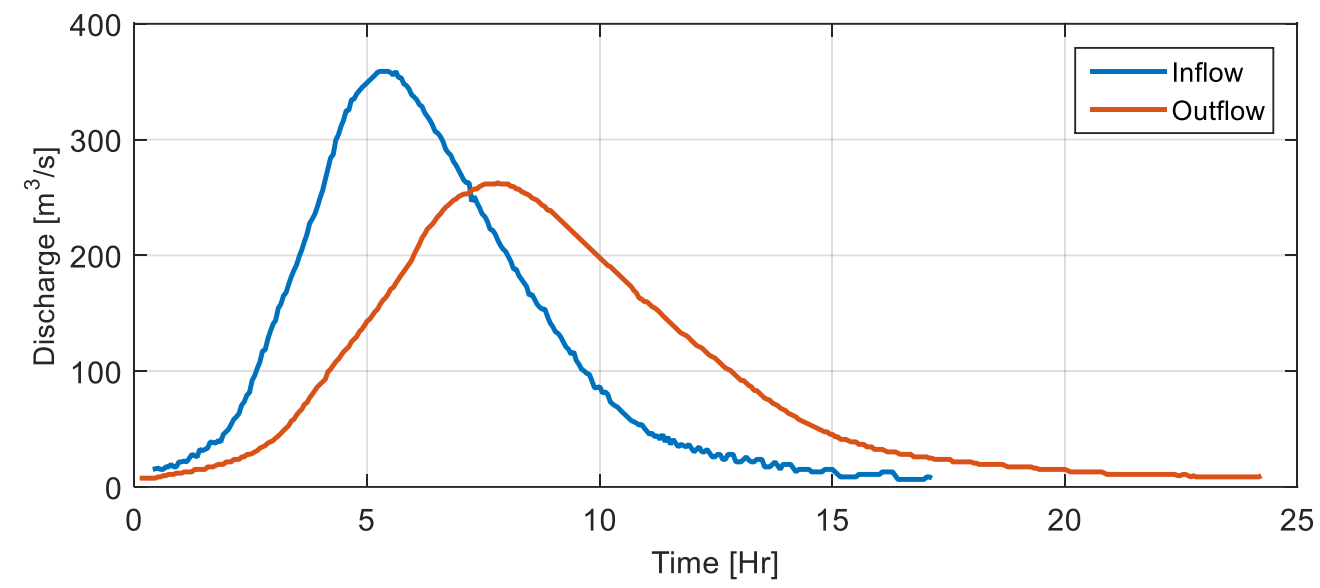

Figure 1-1-1 Typical reservoir inflow and outflow hydrographs during a high flow event. This type of flow regulation reduces flood intensity. In the present Sandy River without flow regulation, flood time histories resemble the blue curve.

\section{1-2 Sandy River Basin Characteristics}

The Sandy River, Oregon, is one of the tributaries of the Columbia River. It arises from the west-southwest slopes of Mount Hood at an elevation of $\sim 1800 \mathrm{~m}$, below the Reid and Sandy glaciers (Keith, 2012). The river basin area is $1316 \mathrm{~km}^{2}\left(508\right.$ mile $\left.^{2}\right)$ (Figure1-2-1); its length is about $90 \mathrm{~km}$ (56 mile), and it reaches the Columbia River near 
the City of Troutdale at elevation of $\sim 3 \mathrm{~m}$ at Columbia River kilometer 194 (river mile120.6). The Sandy River's basin area is about $0.2 \%$ of the Columbia River Basin. The Sandy River basin can be divided into six sub-watersheds, (Table1-2-1), all of which are located in Multnomah and Clackamas counties of Oregon State (Shankland, 2005). The upper portion of Sandy River basin is steep with high a density of trees. The river passes through a $4 \mathrm{~km}$ long steep, narrow canyon from its source, after which its valley widens to $800 \mathrm{~m}$ width, and the bed slope becomes $0.05 \mathrm{~m} / \mathrm{m}$ until it reaches the Zigzag River on the left and Clear Creek on the right. Where the Salmon River enters the Sandy River near Brightwood, it becomes moderately narrower (200 m average width). Before reaching "the Marmot Dam Reservoir" approximately $35 \mathrm{~km}$ from headwaters, the channel narrows again. The reservoir was impounded by Marmot Dam, which existed from 1913 to October 2007, though the modern structure was not constructed until 1927.

Table 1-2-1 Size of the Sandy River basin and its watersheds; (Shankland, 2005).

\begin{tabular}{lcc}
\hline Basin and Watersheds & Area (Sq. miles)* & Area (Sq. km) \\
\hline Sandy River Basin & 508 & 1316 \\
Upper Sandy River Watershed & 64 & 166 \\
Middle Sandy River Watershed & 54 & 140 \\
Lower Sandy River Watershed & 72 & 186 \\
Salmon River Watershed & 59 & 153 \\
Bull Run River Watershed & 139 & 360 \\
Zigzag River Watershed & 114 & 295 \\
\hline
\end{tabular}

*Watershed areas were calculated by GIS

Just upstream of "Marmot Dam Reservoir" the Sandy River is joined by Whisky Creek (Keith, 2012). Downstream of the former Marmot Dam, the river channel is relatively wide for about $0.3 \mathrm{~km}$, after which the river flows through Sandy River gorge for about $6.4 \mathrm{~km}$. Below the gorge Bull Run River enters the Sandy River at Dodge Park, about 
29.8 river kilometer from the Columbia River. The name "Sandy River" comes from the delta where the river flows into the Columbia River, a sandy area about $10 \mathrm{~km}^{2}$ extending into the Columbia River (Shankland, 2005). The location of each sub-watershed inside the basin is shown in the Figure1-2-1. 


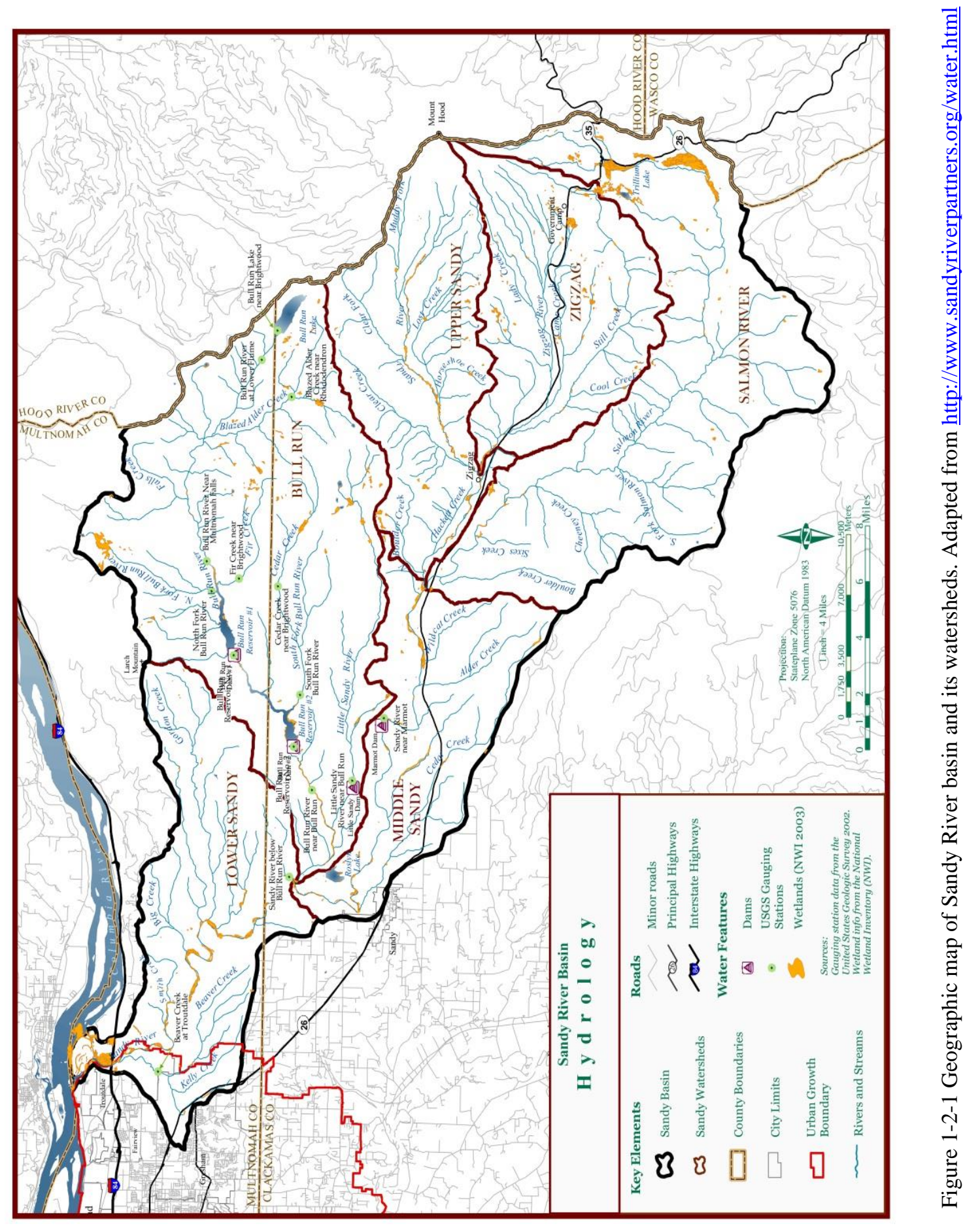




\section{1-3 Sandy River Climate and Metrology Condition}

The Sandy River's climate is maritime, with wet, cool winters and dry, relatively warm summers. At the former Marmot Dam site, the average annual high and low temperatures are $15.6^{\circ} \mathrm{C}$ and $5^{\circ} \mathrm{C}$ respectively. The amount of precipitation is a function of both geographical location and the elevation. The quantity of precipitation rises with increasing elevation. Thus the average annual precipitation near mouth of the Sandy River (3 m elevation) is $700 \mathrm{~mm}$; and $2700 \mathrm{~mm}$ at $1800 \mathrm{~m}$ (headwaters); It is about 1970 $\mathrm{mm}$ at the dam former site (Keith, 2012). Table 1-3-1 presents the high and low yearly precipitation for each sub-watershed of the basin. The precipitation also varies seasonally, with a maximum between November and January and a minimum in July and August. The type of precipitation is varies with elevation. In the lower elevations, it is almost all rain, but near the headwaters the precipitation is mostly snow. The snow pack glaciated of Mount Hood usually does not melt entirely until the end of the summer, because the mean annual snowfall in Mount Hood is more than 7620 mm (300 inches) (Shankland, 2005).

Daily flow data are available for multiple gage stations from the U.S. Geological Survey website; for this research, the most important gage station is (USGS 14137000 SANDY RIVER NEAR MARMOT, OR), with daily data available from September 1, 1911to the present. 
Table 1-3-1 The yearly range of precipitation in Sandy River basin watersheds. (Shankland, 2005).

\begin{tabular}{|c|c|c|c|c|}
\hline \multirow{3}{*}{ Watersheds } & \multicolumn{4}{|c|}{ Annual Precipitation Range } \\
\hline & \multicolumn{2}{|r|}{ Low } & \multicolumn{2}{|r|}{ High } \\
\hline & $\mathrm{mm}$ & inch & $\mathrm{mm}$ & inch \\
\hline $\begin{array}{l}\text { Lower Sandy } \\
\text { River }\end{array}$ & 762 & 30 (at Troutdale) & 1575 & 62 \\
\hline $\begin{array}{l}\text { Middle Sandy } \\
\text { River }\end{array}$ & 2311 & 91 & 3226 & 127 \\
\hline $\begin{array}{l}\text { Upper Sandy } \\
\text { River }\end{array}$ & 1778 & 70 (at the west end) & 3556 & $\begin{array}{l}\text { 140 (near Mount } \\
\text { Hood Summit) }\end{array}$ \\
\hline Salmon River & 889 & 35 (at the east end) & 3302 & 130 (at its source) \\
\hline Bull Run River & 1321 & 52 & 3632 & 143 \\
\hline Zigzag River & 1651 & $\begin{array}{c}65 \text { (at the upper Still Creek } \\
\text { drainage) }\end{array}$ & 3302 & 130 \\
\hline
\end{tabular}

The gage station is located in Clackamas County, Oregon, hydrologic unit 17080001; its latitude and longitude are $45^{\circ} 23^{\prime} 59^{\prime \prime}, 122^{\circ} 08^{\prime} 10^{\prime \prime}$ respectively. The average daily flow at the gage station is $39.8 \mathrm{~m}^{3} / \mathrm{s}$. The highest daily flow $1172.3 \mathrm{~m}^{3} / \mathrm{s}$ took place in December 22, 1964 while the lowest flow on October 13, 1994 was $5.5 \mathrm{~m}^{3} / \mathrm{s}$ (U. S. Geological Survey, 2016). The annual average water year flows for the Near Marmot station suggest that there is no trend in average flow over the last century (Figure 1-3-1). The daily recorded time series flow is shown in Figure 1-3-2. From 1911 up to the 1950s, interannual flow variations were fairly small (Figure 1-3-2) e.g., the highest flows are about $350 \mathrm{~m}^{3} / \mathrm{s}$ and mean of floods were $375.5 \mathrm{~m}^{3} / \mathrm{s}$. But variability then increased, so that the mean of flood events were $516 \mathrm{~m}^{3} / \mathrm{s}$. Figure 1-3-3 shows water year hydrograph based on daily flow discharge in three-dimensional view; it is obvious that the flow very rapidly advances to peak, especially for the two highest flows in 1964 and 1996, because 
the flow comes from combined heavy rainfall and snow melt in the headwaters of Sandy River. In general, the highest flows occur when rainfall falls on the Mount Hood snow pack, usually in December to February or due to melting snow in spring.

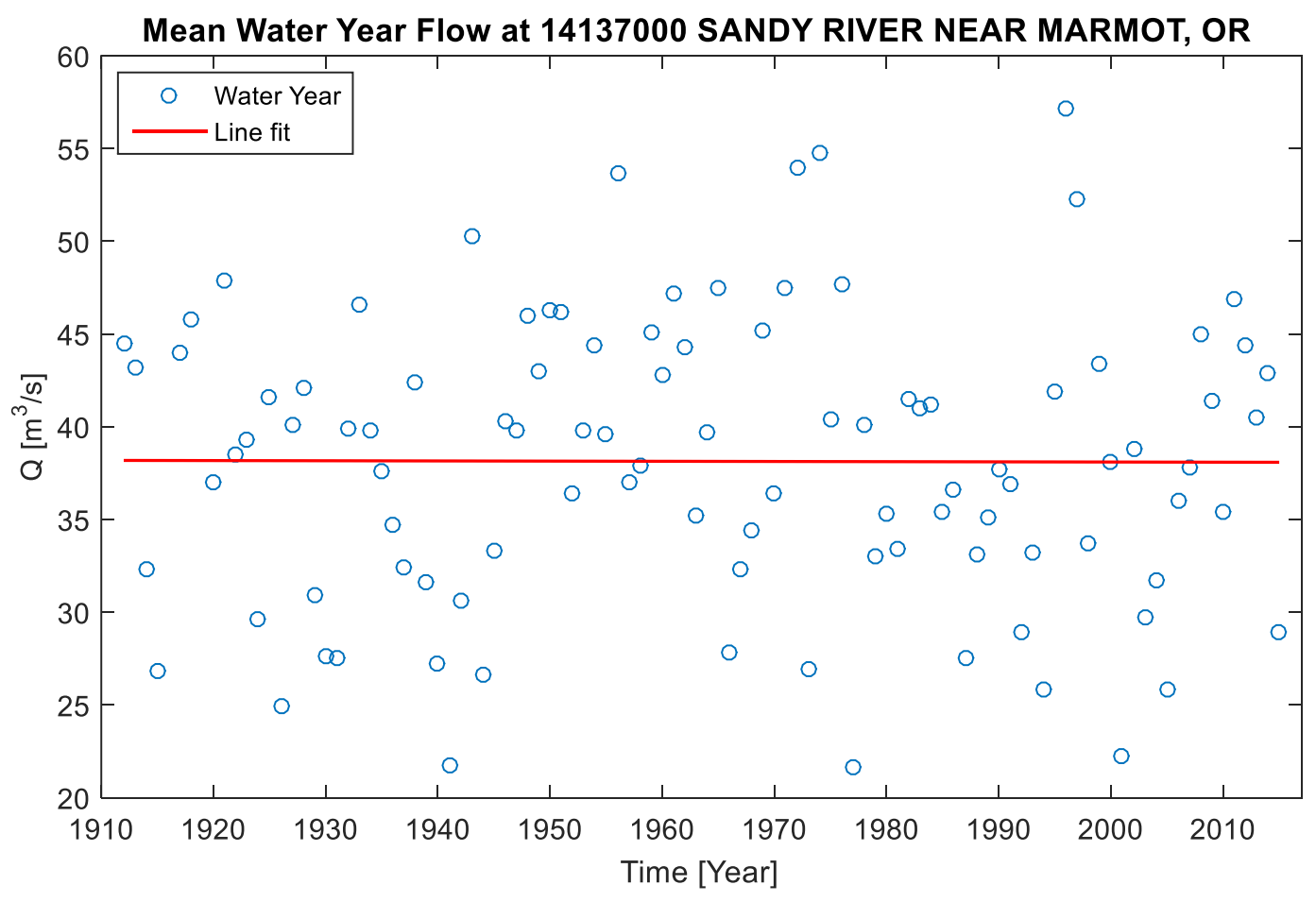

Figure 1-3-1 Mean water year near Marmot dam station, 1911-2015

But this pattern varies between sub-watersheds. For example, in the Upper Sandy River and Bull Run watersheds, the flow is lowest in August and September and highest between October to April due to rainfall; on the other hand, the Zigzag River flows usually are highest between May and June because of runoff due to melting snow, but the high flows in Zigzag River in December and January are due to rain on snow. On the other hand the mean stream flow of Salmon River is markedly impacted by snowmelt in its watershed (Shankland, 2005). 


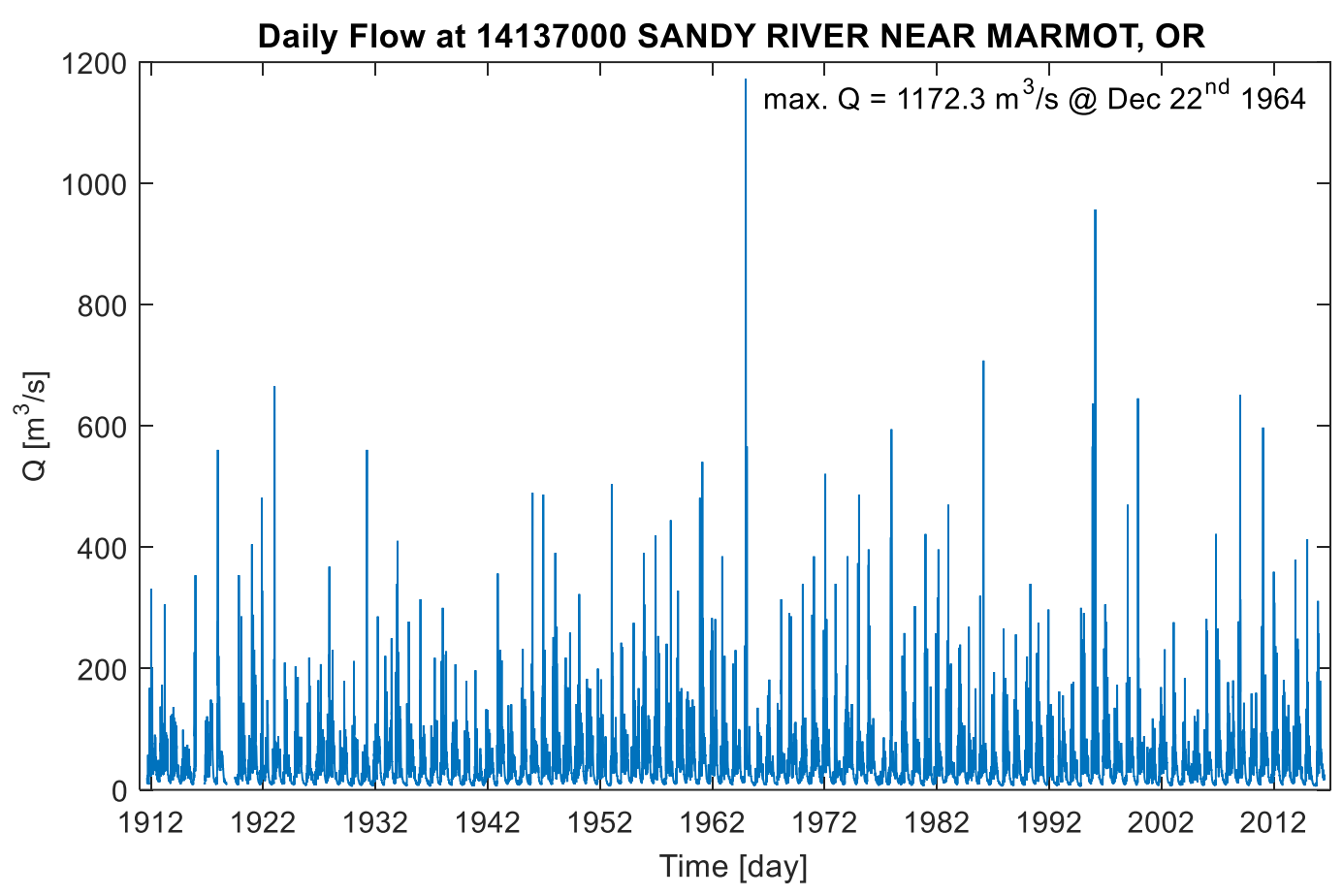

Figure 1-3-2 Daily time series flow of Sandy River near Marmot Dam station, 1911-2016 


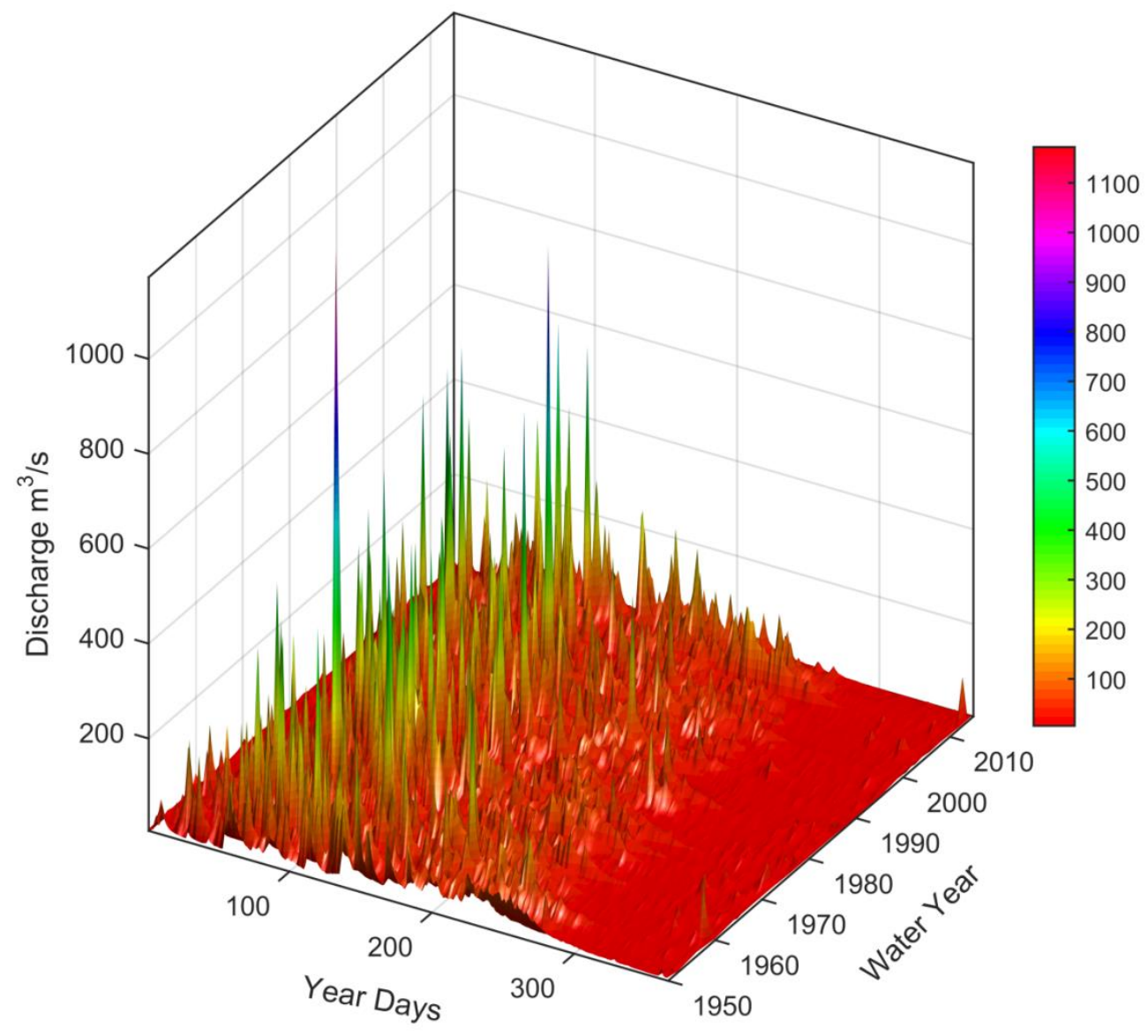

Figure 1-3-3 Three-dimensional hydrograph of water year of Sandy River; year day in October

\section{1-4 Climate Change and its Impacts on the Sandy River Basin}

Climate change is a global issue and that is of concern to most environmental research communities. Because the Sandy River Basin is a relatively small basin, research related to climate change in this basin has been very limited. Most Pacific Northwest research related to hydrologic change has been conducted in the Columbia River basin, because it is much larger and much more important relative than the Sandy River. According to (Brekke et al., 2010) the annual average temperature of the Pacific 
Northwest is likely to increase by $2.0^{\circ} \mathrm{F}, 3.2^{\circ} \mathrm{F}$, and $5.3^{\circ} \mathrm{F}$ in $2020 \mathrm{~s}, 2040 \mathrm{~s}$, and $2080 \mathrm{~s}$ respectively, in comparison to 1970-1999. This occurrence will impact all climatic and metrological aspects of the Sandy River basin by altering rainfall timing, duration, and intensity. Also, it impacts the amount and timing of snow fall, and snow-dominant basins are likely to become rainfall dominant. Seasonal timing will change high flows occurring earlier in the year. Stream flow is likely to become very high in winter and very low in summer, making difficulties for water management, especially in hot years. Mount Hood is the source of the Sandy River, and it has lost 34\% of its seven glaciers between 1907 to 2004, because of increasing average annual temperature (Oregon Climate Change Research Institute, n. d.). Loss of glacial area feeding the Sandy River will likely reduce base flow considerably.

\section{1-4-1 Long Term Variation}

According to the data observed in the Sandy River basin, floods before and after the 1960s are different. Floods after the 1960s are more extreme in term of volume and duration. There are long-term reasons for this, including natural factors and human influences. Changing climate factors (e.g., trends in maximum precipitation, snow, and temperature) and, on the other hand, logging as a human activity has all impacted the Sandy River basin flow conditions. National Oceanic and Atmospheric Administration (NOAA) climate data for a station in the Sandy River basin (USC00353770) provide closer look at this variations. Figure 1-4-1-1 shows average and minimum winter temperature before and after 1960. Figure 1-4-1-2 shows precipitation and snow fall before and after 1960. Before 196, minimum and average temperature decreased 
moderately, though this decrease is likely influenced by the cold Pacific Decadal oscillation period that began at 1947 (Mantua et al., 1997). Since 1960, minimum winter temperatures have increased sharply, and average temperatures have increased modestly.
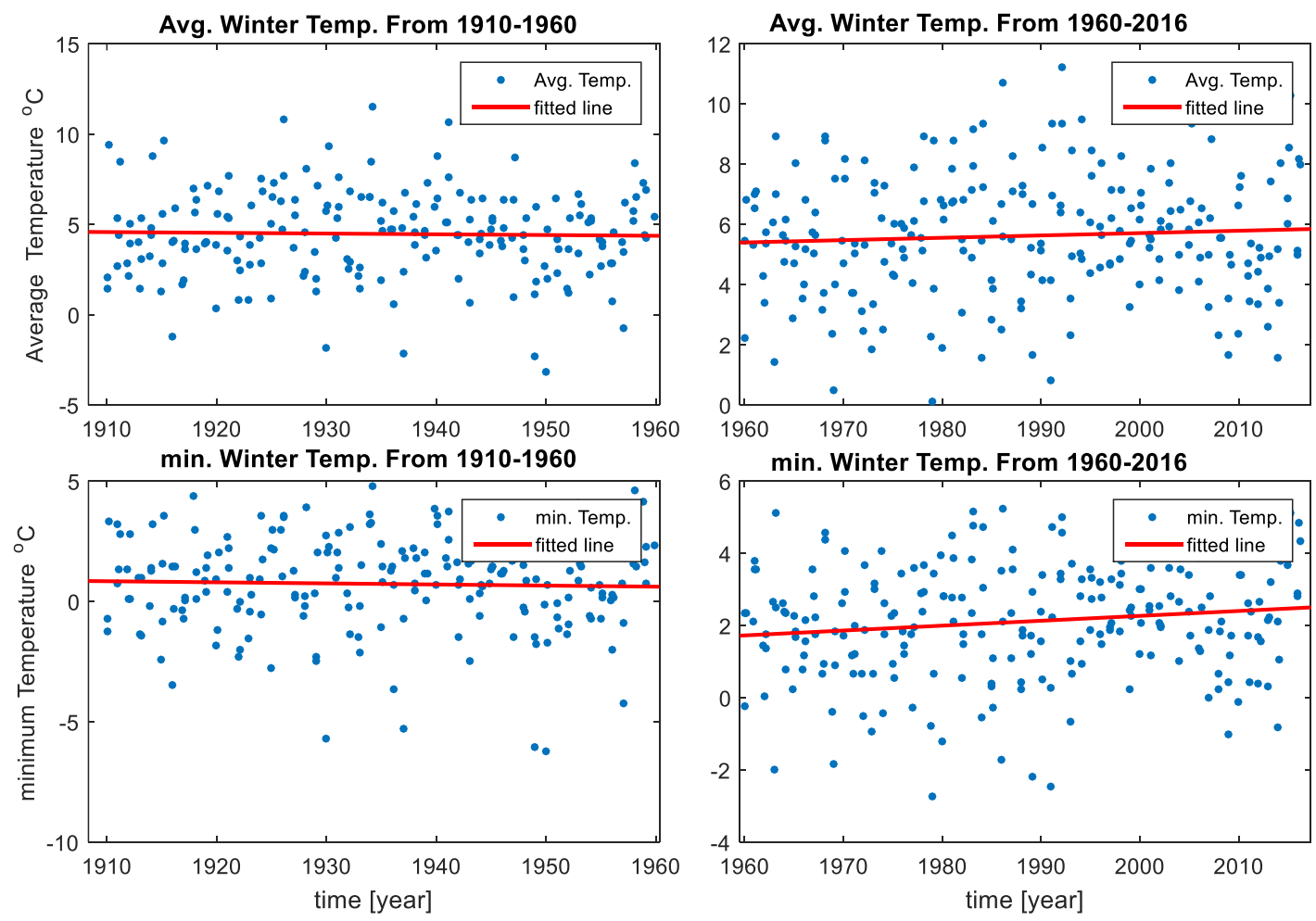

Figure 1-4-1-1 Average and minimum winter temperature of the Sandy River basin from 1910 to 2016, (NOAA, Climate) 

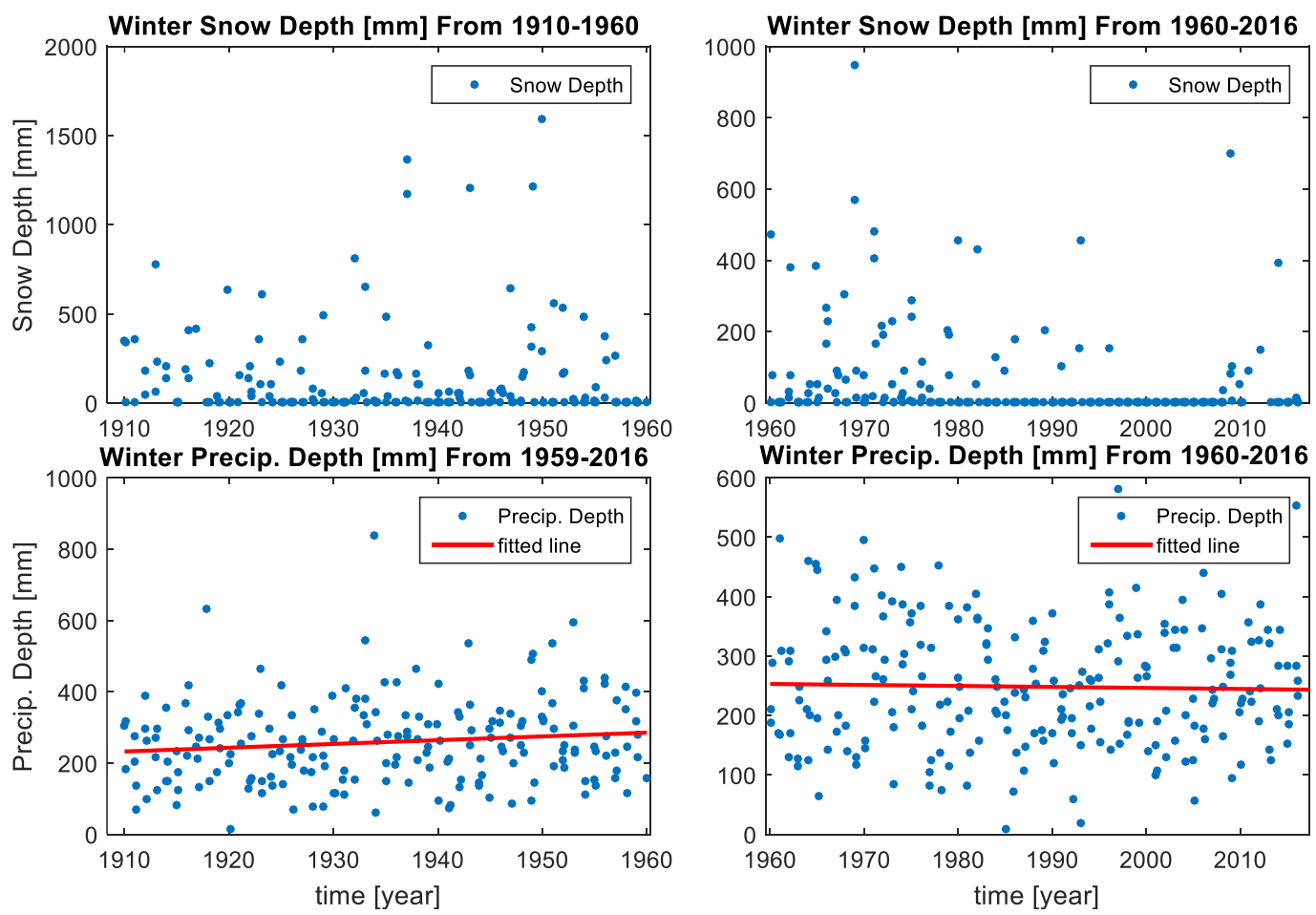

Figure 1-4-1-2 Winter precipitation and snow depth of the Sandy River basin from 1910 to 2016, (NOAA, Climate)

A logging history can be derived from timber harvest in the forests of the Sandy River basin. The timber harvesting in the Mount Hood National Forest is a good indicator for logging in the basin. Increased logging after 1960 is considered a sign for an increasing incidence of extreme floods after 1960, particularly because winter temperature rises (especially winter minimum temperature), and logging activity increased more or less simultaneously. Figure 1-4-1-3 shows the history for volume of timber harvesting in the Mount Hood forests and Oregon (Kay et al., 2007, Brandt et al., 2006). Clearly, timber harvest near Mt Hood increased dramatically in the late 1950s and continued at high levels for about 30 years. This deforestation likely had several effects: a) flood flows typically rise more rapidly in river basins after deforestation; b) sediment loads likely 
increased due to increased erosion, c) evapotranspiration may have decreased, and d) spring snow melt likely occurred at an early date than in earlier years with similar temperature histories (Mattheussen et al., 2000, Coe et al., 2011).
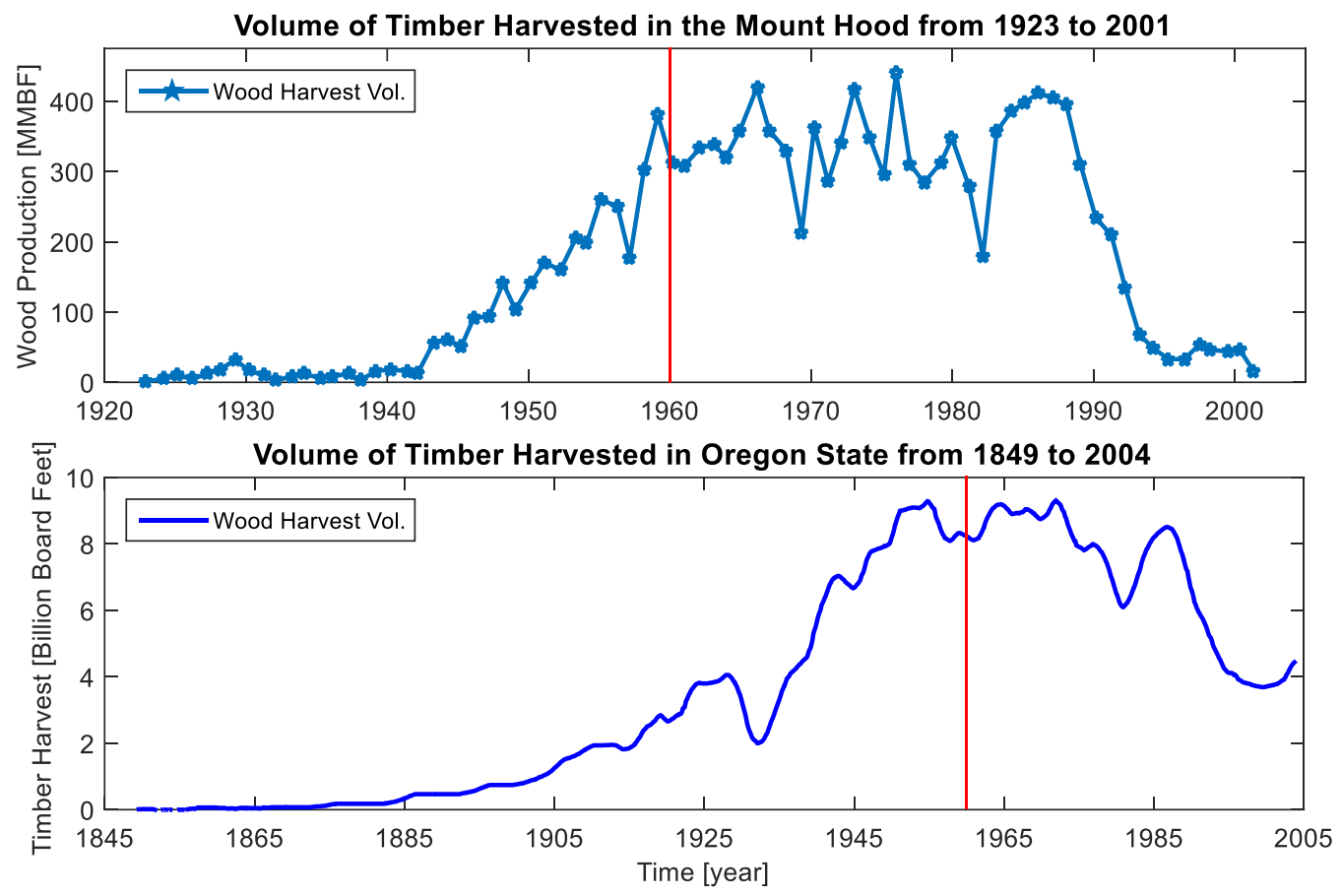

Figure 1-4-1-3 The history of the timber harvested in the Mount Hood National Forest (million board feet) and Oregon State (billion board feet), (USDA)

\section{1-5 Marmot Dam and its Removal}

The Marmot Dam (Figure 1-5-1) was built on Sandy the River at river kilometer 48 (river mile 30) in Clackamas County, Oregon; it was originally constructed of timber and was installed in 1913. In 1927, a concrete dam was built, and in 1989 the dam was upgraded. Marmot Dam's drainage area (above the study area) was $680 \mathrm{~km}^{2}$ (Keith, 2012). The dam was $14.3 \mathrm{~m}$ high and L-shaped (105 m length) in plan. The dam was used to divert water from the Sandy River to the Little Sandy River by tunnel and canal.The 
reservoir was filled by sediment (sand to coarse gravel), and this sediment deposition filled the channel for $3 \mathrm{~km}$ to $3.5 \mathrm{~km}$ upstream of Marmot Dam. In 2004 the hydropower license of Marmot Dam expired, and its owner (Portland General Electric) PGE did not ask for license renewal from the Federal Energy Regulatory Commission (FERC). Instead PGE requested removal it because of the high cost of operation and maintenance of the dam (Shankland, 2005; Keith, 2012; Major et al., 2010). Building and later Demolishing Marmot Dam (Figure 1-5-2) was perhaps the largest human disturbance in the history of the Sandy River, but the watershed has been previously altered by logging. The process of removal was planned by 23 collaborating governmental agencies and nonprofit organizations. Before removing the main dam, two coffer dams were built upstream and downstream of main dam, and water was diverted to downstream of the lower coffer dam, to facilitate removal (Keller, 2010). After Marmot Dam was removed, the $90 \mathrm{~km}$ Sandy River became free from the headwaters of the Mount Hood to the outlet at Columbia River, after almost a century of confinement (Major et al., 2010). At 08:05 Pacific daylight time (PDT) of 19 October 2007, the upper coffer dam breached and about 730,000 $\mathrm{m}^{3}$ of accumulated sediment in the reservoir was released (Keith, 2012; Major et al., 2012; Major et al., 2010; Major et al., 2008) 


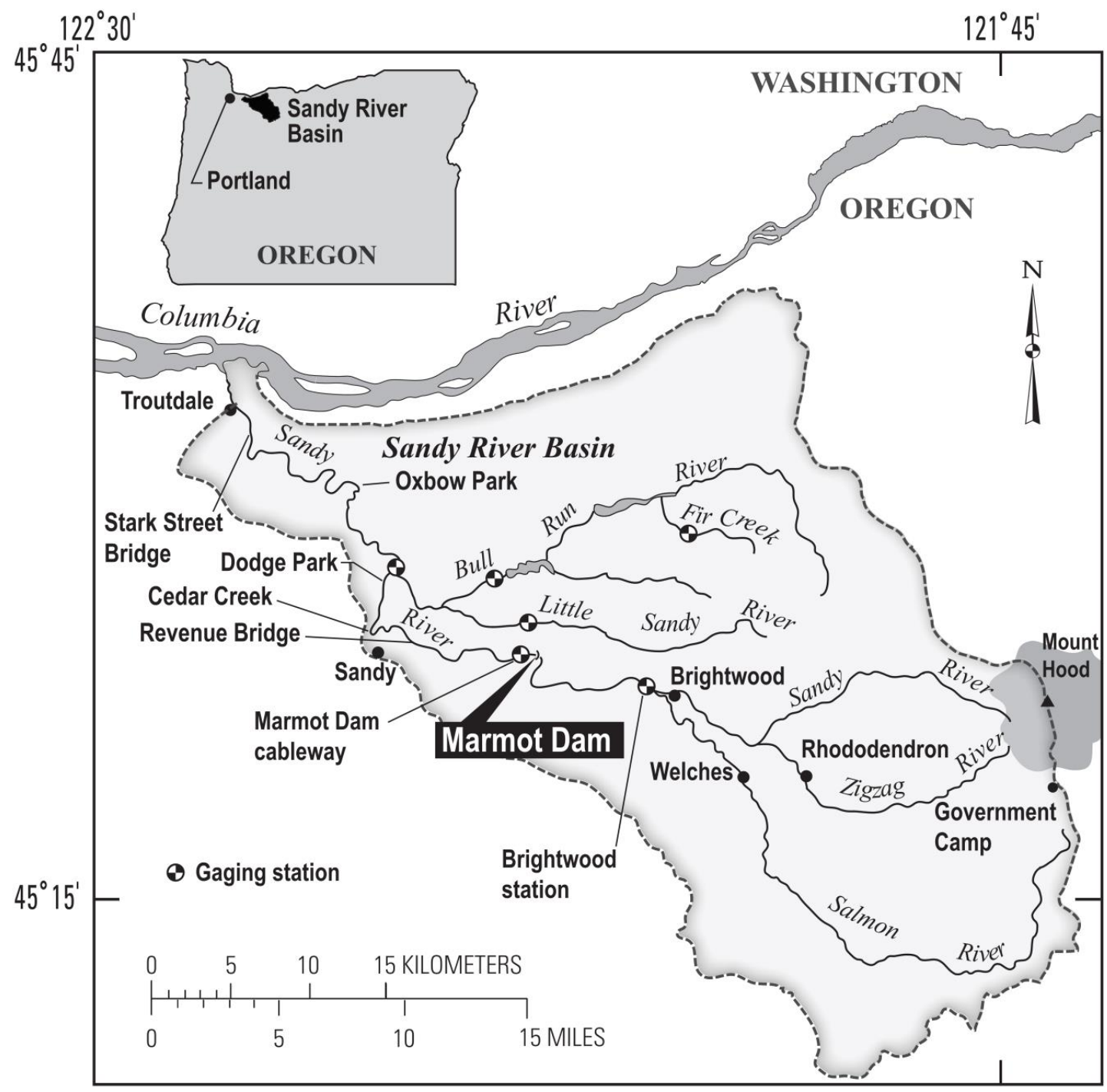

Figure 1-5-1 The Sandy River basin and locations of gage stations and Marmot Dam. Adapted from (Major et al. 2012) 


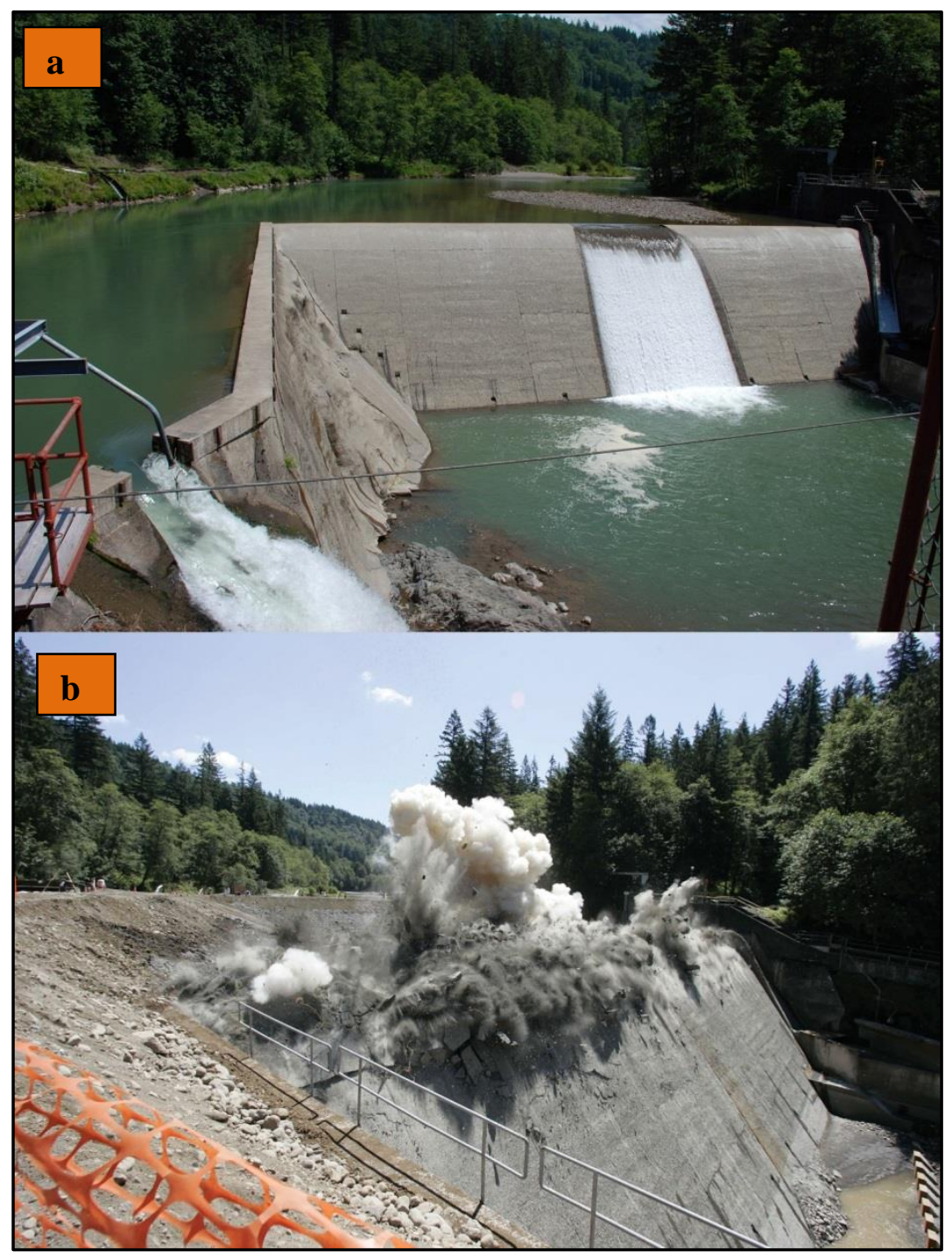

Figure 1-5-2 The Marmot Dam in two different situations, a- normal operation, and b- during demolition. Adapted from (Keller, 2010)

The process of removing Marmot Dam precisely pre-tested and monitored. A physical model of the demolition was created by the National Center for Earth Surface Dynamics (NCED) (Grant et al., 2008), it was modeled numerically by Stillwater (2002b), and cameras were installed around the coffer dam and reservoir (Figure 1-5-3) to take time series of images from different angles (Major et al., 2010). Direct observations during the 
demolition process included flow and sediment transport observations, a light detection and ranging (LiDAR) bathymetric survey, and photogrammetry (Major et al., 2012). Monitoring the transport of the large amount of sediment deposited inside the reservoir was very important, because it had altered the geomorphic of the Sandy River channel. Monitoring continued irregularly after demolition to check for deposition and erosion of sediment material seasonally and during events.

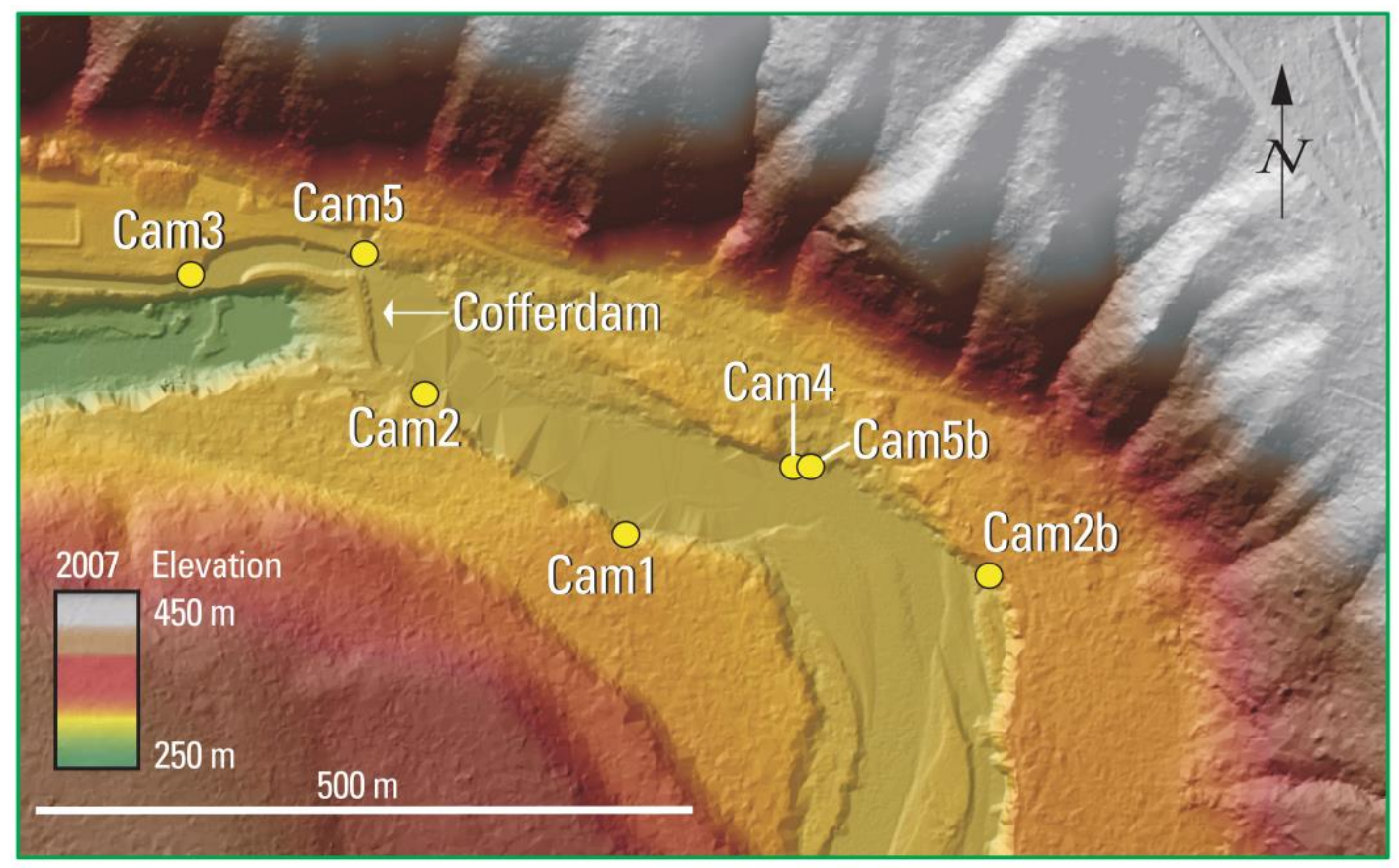

Figure 1-5-3 Cameras installed in and near Marmot Dam reservoir and cofferdam; adapted from (Major et al., 2010)

\section{1-6 Study Area of the Sandy River}

The part of the Sandy River used for this study is a short reach located downstream of the former Marmot Dam location. This reach was selected because of the location of a stream gage (Sandy River Near Marmot Gage USGS 14137000) used for definition of an upstream boundary flow condition for numerical modeling. The reach 
(figure 1-5-2) is about $1.8 \mathrm{~km}$ length; the lowest point elevation in the most upstream cross-section (figure 1-5-1) of the reach is $210.4 \mathrm{~m}$ above NAVD88, and the lowest point in the downstream cross-section (figure 1-6-1) was $194.5 \mathrm{~m}$. Thus the average reach slope is about $0.009 \mathrm{~m} / \mathrm{m}$. However, this slope is not uniformly. The first $600 \mathrm{~m}$ have an average slope of $0.0023 \mathrm{~m} / \mathrm{m}$, while the remaining $1200 \mathrm{~m}$ is steeper, with a slope of $0.012 \mathrm{~m} / \mathrm{m}$. The increase in slope is caused by confinement of the stream in the approach to the Sandy River gorge, just downstream of the studied section
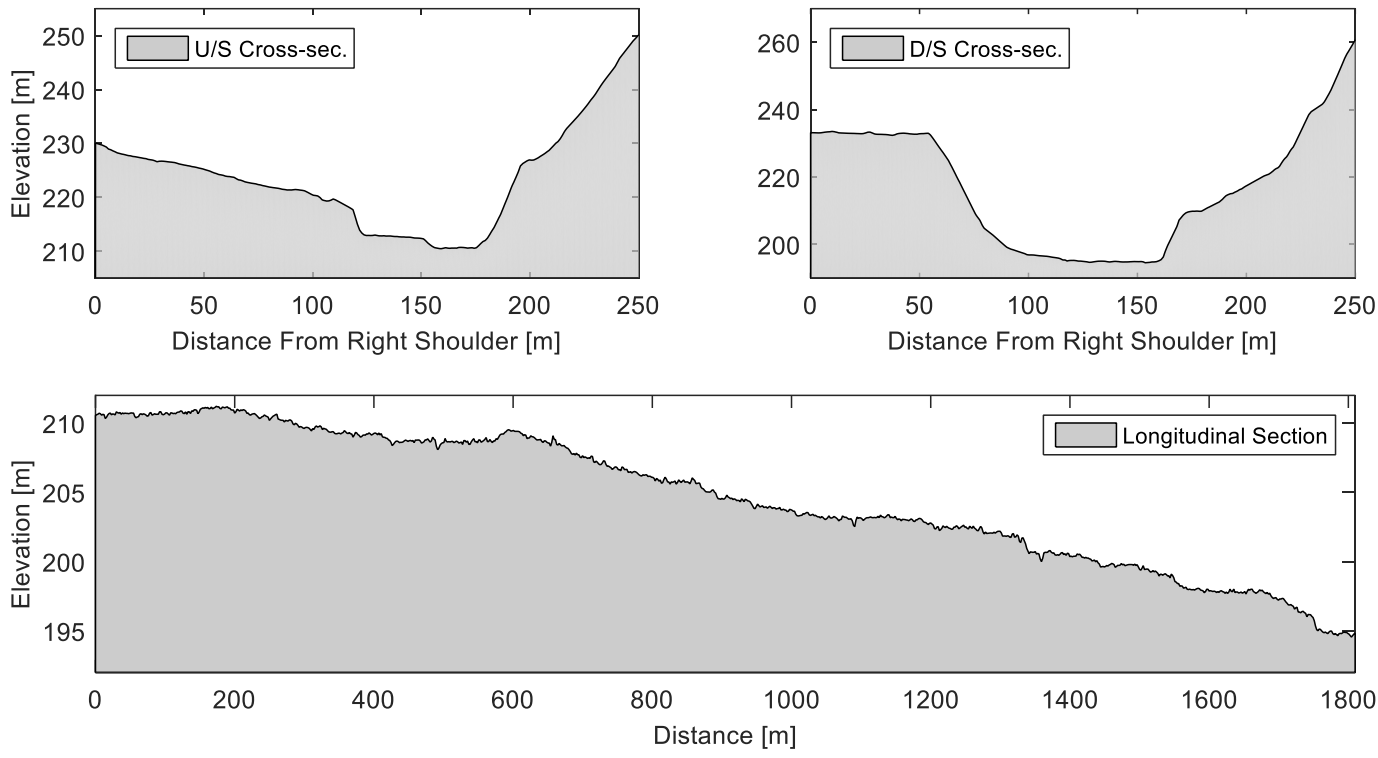

Figure 1-6-1 Upstream, downstream extreme cross-sections, and longitudinal section of study reach of the Sandy River

A Digital Elevation Model (DEM) and LiDAR imagery were obtained from USGS Water Resources office in Portland, Oregon. The DEM has high resolution $(1 \times 1 \mathrm{~m})$, and it was already integrated with bathymetry survey of the river (Figure 1-6-2). The DEM was 
created in 2012, so everything in this research related to bed topography is derived from the 2012 DEM data.

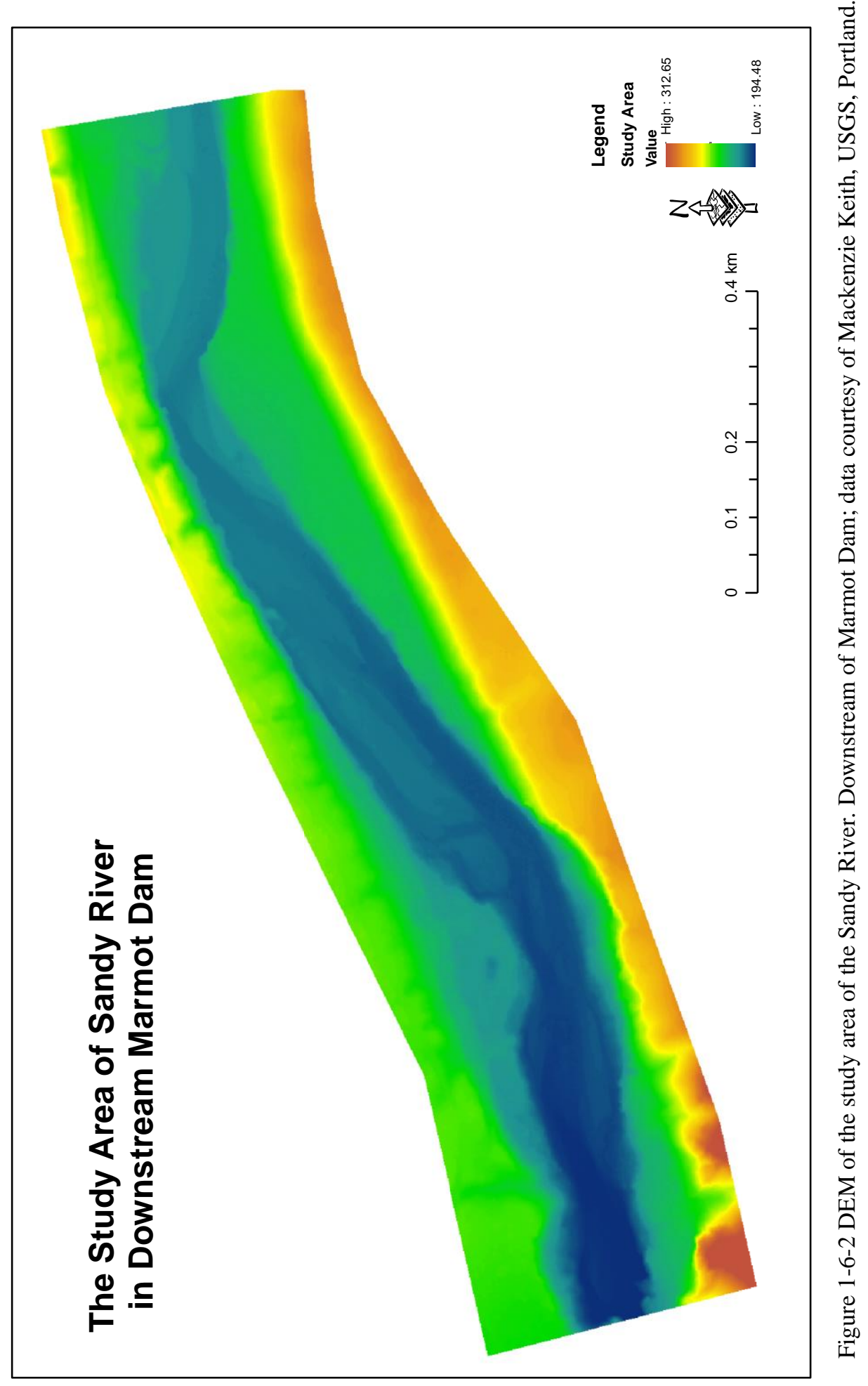




\section{Chapter 2: Extreme event analysis}

\section{2-1 Introduction to Floods}

A flood is large pulse of water with unusually high water levels that passes through a hydro-system, with or without flow over the banks (Hingray et al., 2015). Floods can causes destruction in inundated private and public property areas and lead to loss of life. Flood and extreme event analysis provide information for management purposes and for designing hydraulic structures, like bridges, flood walls, culverts, and spillways (Subramanya, 2013). Multiple processes acting individually or together may contribute to generating a flood, for instance, extraordinary rainfall (Figure 2-1-1) with high intensity and duration, rapid snow-melting due to warm weather in spring, and abnormal snow melting due to external force like rainfall over a snow pack. In contrast, a flood may take place due to dam break, a landslide into a river or reservoir or large snow avalanche (Hingray et al., 2015).

The history of a flood is vital for geomorphological changes. Figure 2-1-1 shows a conceptual view of transfer of rainfall event over the watershed to stream flow. The rainfall hyetograph is divided into two parts, the hatched area $\left(P^{*}\right)$ is the effective precipitation that leads to runoff, whereas the blank area represent losses due to evaporation, infiltration and percolation. The $q^{*}$ is direct runoff of stream flow which comes from effective precipitation $\left(P^{*}\right)$ and the watershed works as a transfer function to transfer the effective precipitation to the direct runoff as stream flow. 


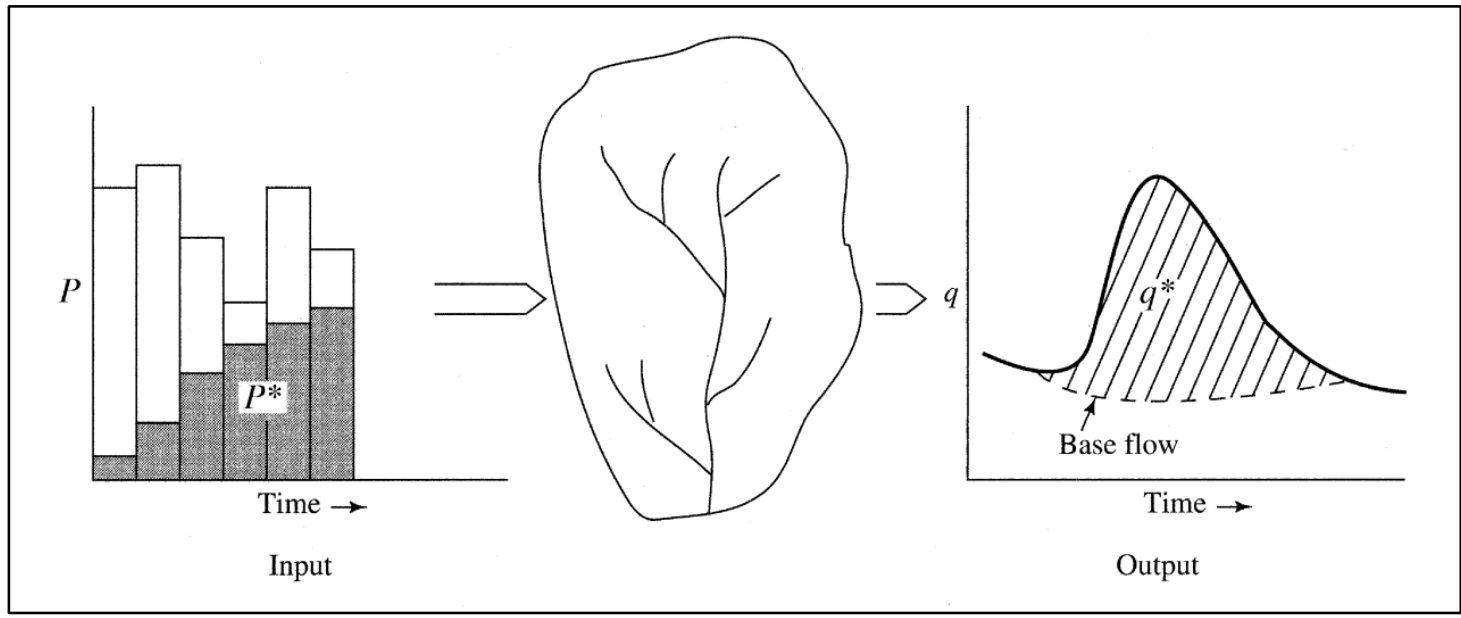

Figure 2-1-1 Transferring effective precipitation $\left(P^{*}\right)$ to a flood hydrograph. Adapted from (Dingman, 2015)

\section{2-2 Peak Flow Estimation}

The term "peak flow" denotes the locally highest flow value relative to the previous and following flows in a time series of flow measurements (NOAA, n. d.). Because flood occurrence and volume are random, statistical techniques designed for random variable analysis can be used to analyze peak flows. In a given time series, the yearly maximum floods are typically considered to be independent (Hingray et al., 2015). A statistical study of annual flood discharge can be used to compute a return period of the maximum recorded annual discharge of the river (Figure 2-2-1). The return period can be defined for the n-year return event in an n-year time scale as having an expected value of one (Cooley, 2013). Under certain linearity assumptions, the return period is equivalent to the inverse of exceedance probability of an event (Meylan et al., 2011; Dingman, 2015; Chow et al., 1988; Subramanya, 2013). 


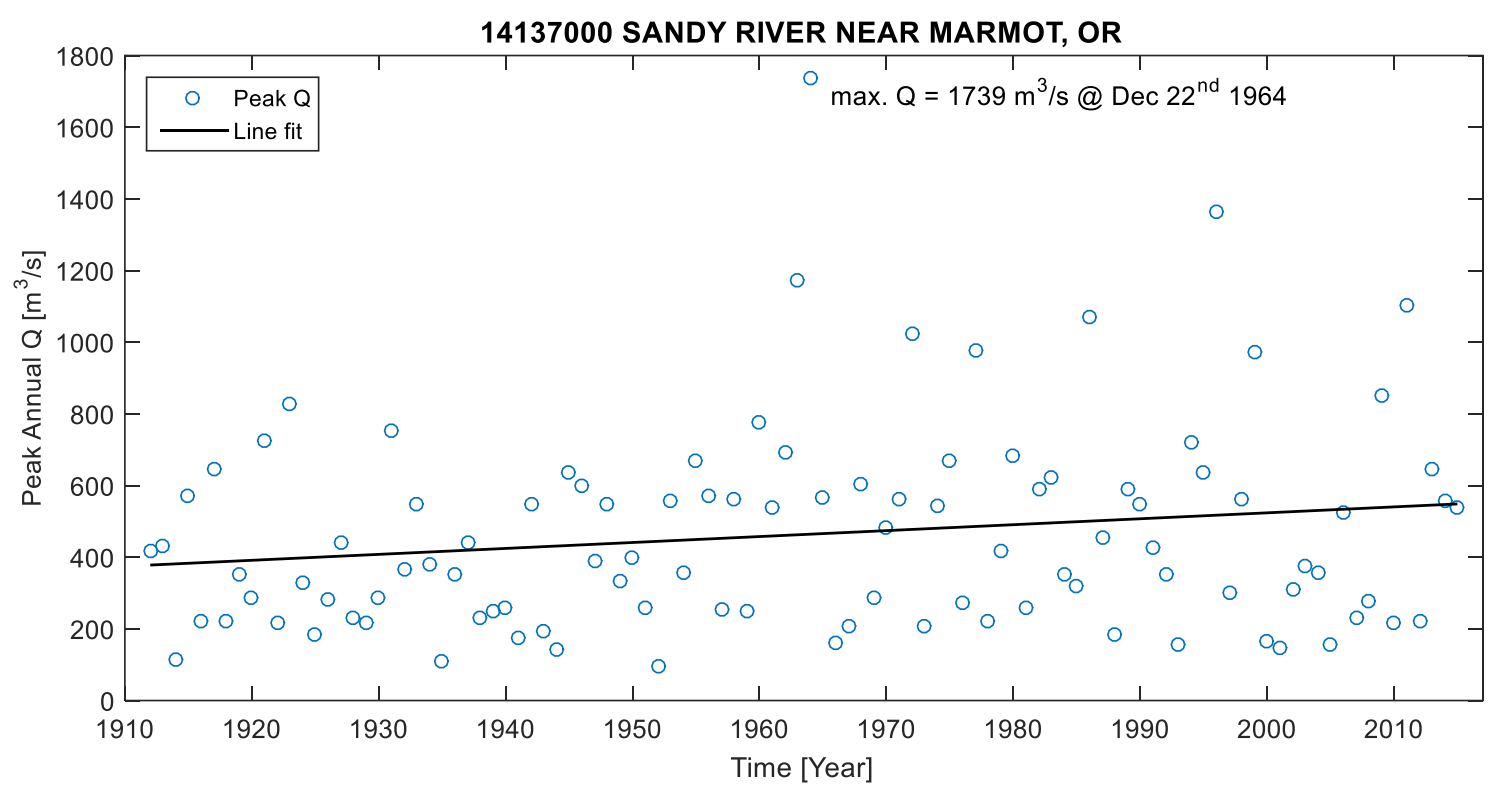

Figure 2-2-1 Maximum observed yearly flow in Sandy River at 14137000 station $\left(R^{2}=0.0308\right)$

A peak flow analysis is also called an extreme event analysis, a statistical computation based of a different approach. Extreme event probabilities can be computed for lowest flows (drought events) or for floods. Several different probability distributions have been utilized for extreme event analysis, e.g., Gumbel, Pearson Type III, LogPearson Type III, Weibull, Generalized Extreme Value (GEV), and Generalized Pareto distribution (GPD) (Chow et al., 1988; Vogel \& Wilson, 1996). The distribution used in this study for extreme flood analysis is Log-Pearson Type III, based on U.S. Water Resources Council (1981, revised 1982). The log-Pearson type III distribution is widely utilized for hydrologic analysis, especially for flood frequency determination. It is recommended by the U. S. Water Resources Council (Bobée, 1975; Griffis \& Stedinger, 2007; Subramanya, 2013). The log-Pearson type III is a one of the Pearson Type families and it is suggested for modeling of random variables (Griffis \& Stedinger, 2007). The U.S. Water Resources Council recommended method of moments for evaluating 
parameter of distributions. The method uses the base 10 logarithm of maximum peak flow in individual years of records data. The equations which are suggested by U.S. Water Resources Council are as follow:

$$
\begin{aligned}
& \log Q=\bar{X}+K S \\
& \bar{X}=\frac{\sum X}{N} \\
& S=\left[\frac{\sum(X-\bar{X})^{2}}{(N-1)}\right]^{0.5} \\
& =\left[\frac{\left.\left(\sum X^{2}\right)-\frac{\left(\sum X\right)^{2}}{N}\right]^{0.5}}{(N-1)}\right]^{-5} \\
& G=\frac{N \sum(X-\bar{X})^{3}}{(N-1)(N-2) S^{3}} \\
& K=\frac{2}{G}\left[\left[\left(K_{n}-\frac{G}{6}\right) \frac{G}{6}+1\right]^{3}-1\right] \\
& =\frac{N^{2}\left(\sum X^{3}\right)-3 N\left(\sum X\right)\left(\sum X^{2}\right)+3\left(\sum X\right)^{3}}{N(N-1)(N-2) S^{3}}
\end{aligned}
$$

Equation 2-2-5 
Where: $\bar{X}$ is mean logarithm, $K$ is a factor which is a function of the skew coefficient $X$ (its values tabulated in the $17 \mathrm{~b}$ Bulletin), $S$ is standard deviation of logarithms, $X$ is logarithm of flood flow, $N$ is number of observed data and $G$ is a logarithm skew coefficient. $K_{n}$ is the standard normal deviation of desired probability of exceedance. Equation 2-2-3b and equation 2-2-4b are recommended for a precise calculation with a number significant digits but Equation 2-2-3a and equation 2-2-4a can be used for lower precise result (U.S. Water Resources Council, 1982). For short records, the skew coefficient cannot be accurately estimated because of its sensitivity for extreme values; for resolving this issue the U.S. Water Resources Council recommends use of a generalized skew coefficient defined from a weighted average value of surrounding stations. The generalized skew coefficient should be based at least 40 stations within 161 $\mathrm{km}$ (100 mile) radius, and all stations should have at least 25 year of recorded data.

Peak flow data available for Sandy River at 14137000 station from 1912 to 2015 (Figure 2-2-1) and these data were used to calculate peak flow for different return periods. Burkey, (2009) prepared software available from the MATLAB Central File Exchange website for computing and plotting probability exceedance and return period versus peak flow discharge based on Bulletin 17 U.S. Water Resource Council (1982). Here, the software was used to compute and plot extreme event floods. Figure 2-2-2 presents result of the log-Pearson type III distribution of Sandy River at 14137000-station the calculations and figure are based on cubic feet per second (cfs) as flow measurement unit. 

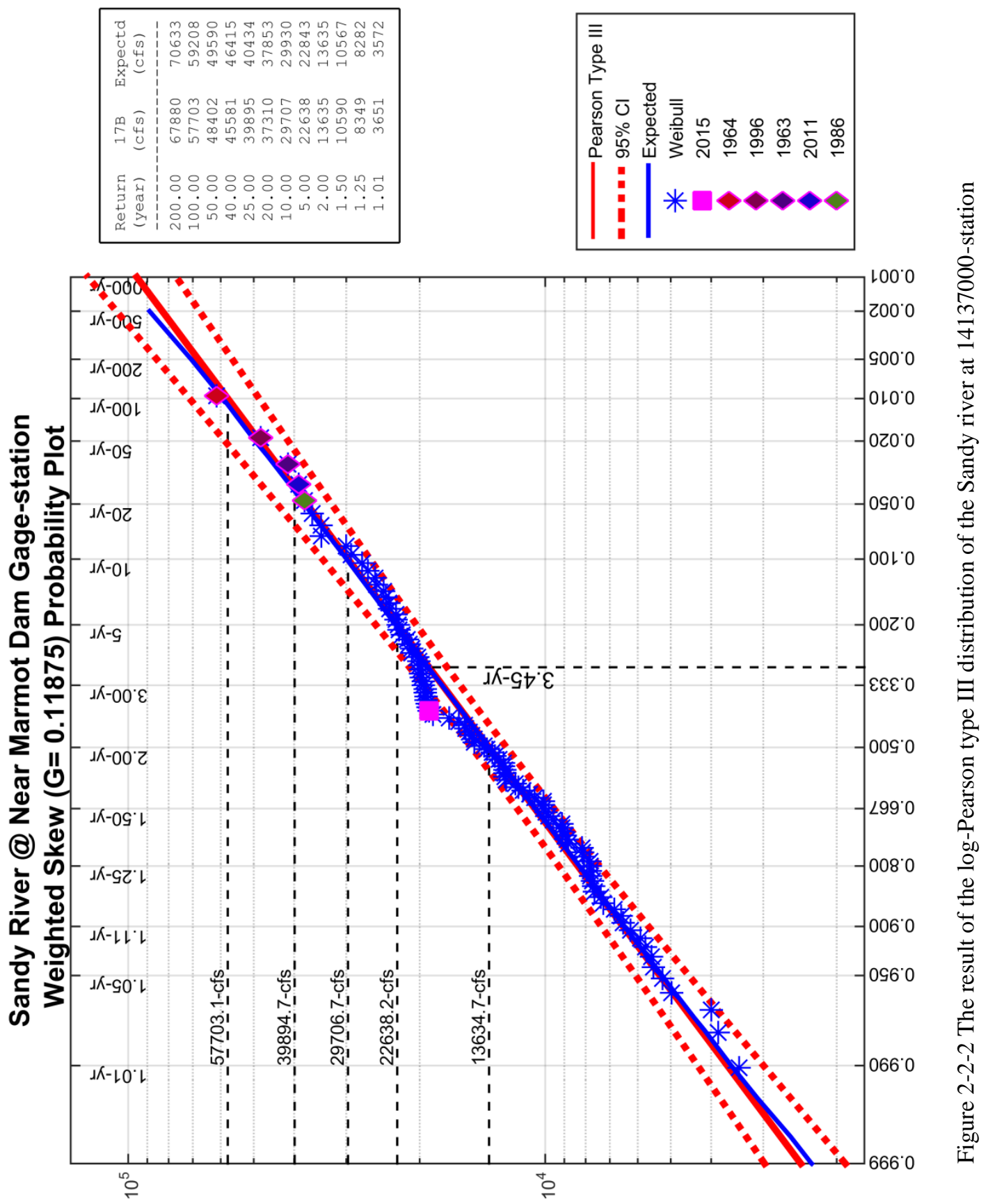

(sı) әэеу M이 jenuu 


\section{2-3 Extreme Event Hydrographs}

A flood, like many other environmental phenomena, takes place randomly. Thus, the hydrograph that represents the rate of flow per unit time has peaks that are randomly distributed in time (Xiao et al., 2009). Also a hydrograph has a base flow and base flow time, a peak flow and a time to peak from base for each event, a variable shape, and variable distributions of flow over rising limb and falling limb of varies flow events. When base flow is subtracted from a hydrograph, the result is called the direct runoff hydrograph (Subramanya, 2013; Chow et al., 1988).

Several approaches have been developed for constructing a flood hydrograph, based on various statistical or analytical approaches. Ronen-Eliraz et al. (2016) used a one parameter distribution to model the recession limb of the flood hydrograph for ephemeral stream in Israel. Bhunya et al. (2003) utilized a two-parameter gamma distribution to model the unit hydrograph, and they presented four different derivations, based on available data. Yue et al., (2002) suggested two-parameter beta probability distribution function for describing flood hydrographs; this approach requires flood discharge, water volume, and duration from observed data.

In this study, I derive representative flood hydrographs, based on time series observed data of the Sandy River and some non-dimensionalized factors to discretized flood events in seven different years. The dataset used in this analysis is the 15-minute interval time series discharge data (U.S. Geological Survey, 2016) for the Sandy River Near Marmot Dam gage station, available beginning October 1, 2007 (after removal of the dam). These time series data (Figure 2-3-1) show the changing flow in a very precise 
way. The most obvious floods in this time series are used to model extreme event hydrographs. Figure 2-3-2 shows discretized high flow events for 2008, 2010, 2011, 2012, 2013, 2014, and 2015. The water year 2007 and 2016 are not included because 2007 was an abnormal year (due to removal of the Marmot Dam) and the 2016 water year is not yet complete. The high flow event distributions (histograms) are shown in figure 2-3-3. Based on figure 2-2-2 we select six different return periods to model their hydrograph and to run our numerical model. The return periods and their flows which are used for this study are tabulated in Table 2-3-1. The expected extreme event hydrographs for each return period will be created by using the data in Table 2-3-1 and observed data that plotted in Figure 2-3-2. The procedure for derivation of extreme event hydrographs is described in the following sections.

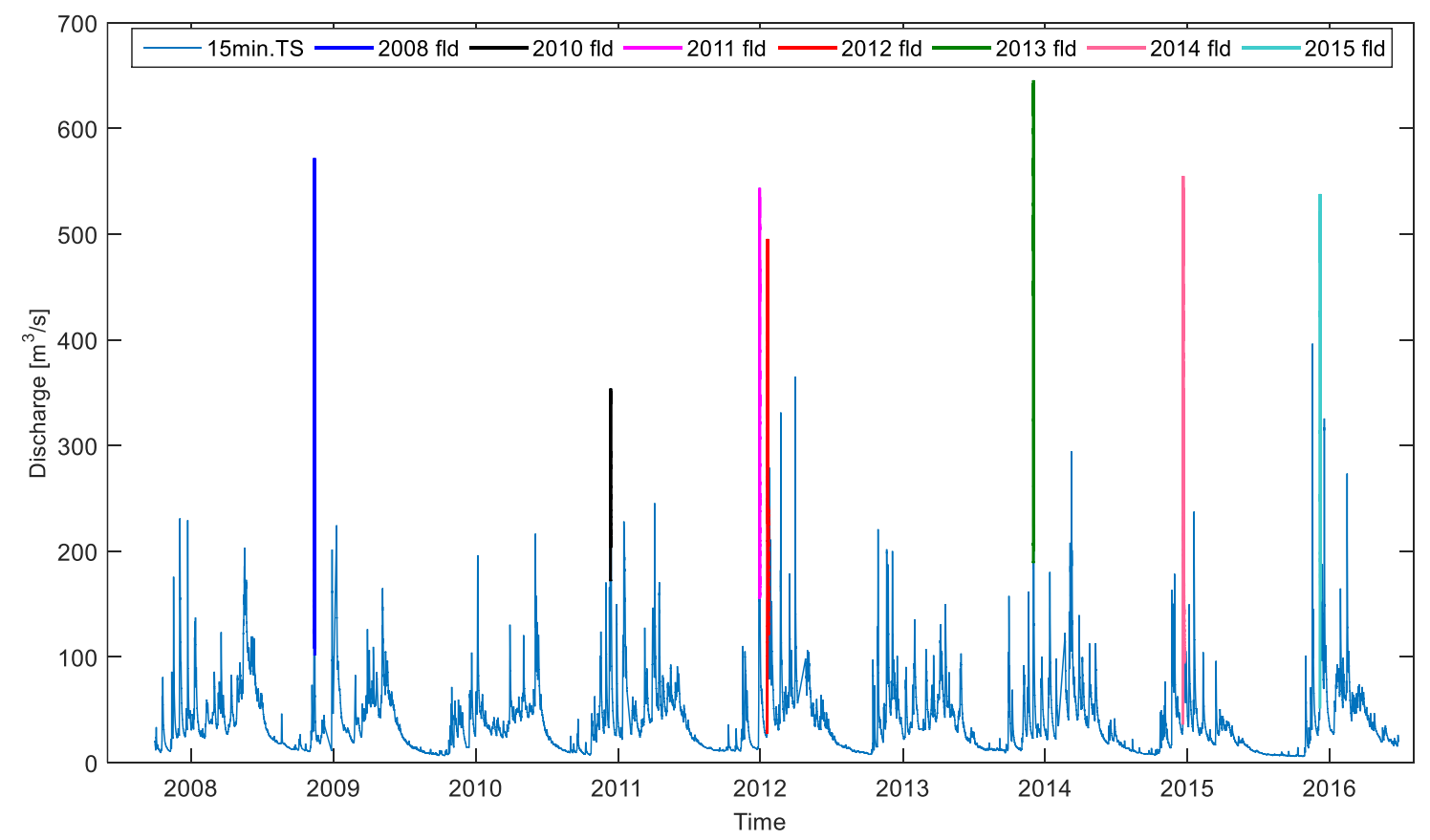

Figure 2-3-1 Time series (15 minute interval) data with discretized high flow events, Oct, 2007-July, 2016 

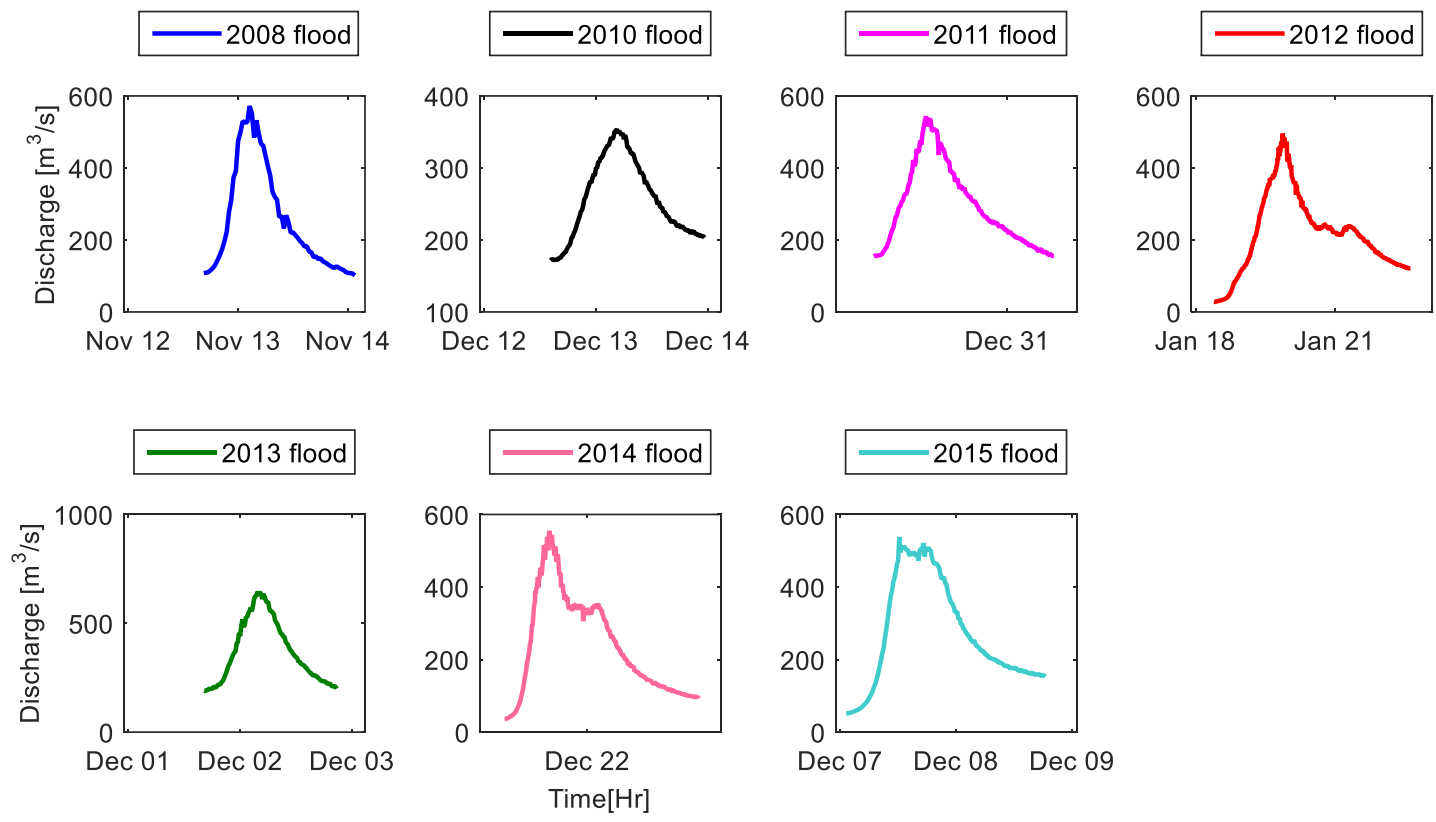

Figure 2-3-2 Discretized high flow events from time series data in selected years
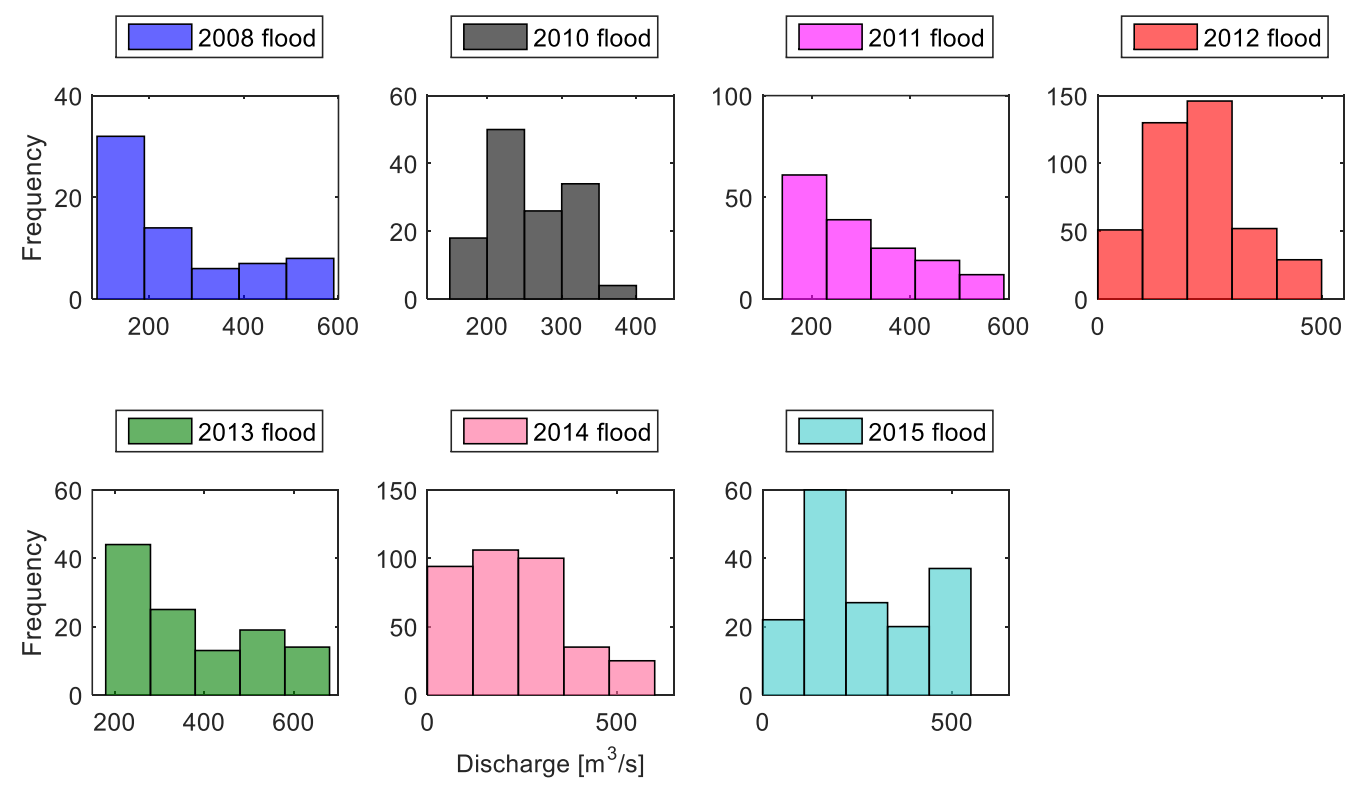

Figure 2-3-3 Histograms of the discretized high flow events 
Table 2-3-1 Return Periods and calculated peak flow events

\begin{tabular}{ccc}
\hline Return Periods [Year] & Peak Flow [cfs] & Peak Flow $\left[\mathrm{m}^{3} / \mathrm{s}\right]$ \\
\hline 2 & 13635 & 386.1 \\
10 & 29707 & 841.2 \\
25 & 39895 & 1129.7 \\
50 & 48404 & 1370.6 \\
75 & 53053 & 1502.3 \\
100 & 57703 & 1634.0 \\
\hline
\end{tabular}

\section{2-3-1 Base Flow Separation}

Several different approaches can be used for separation base flow of hydrograph from direct runoff (Subramanya, 2013; Chow et al., 1988; Dingman, 2015). The easiest approach is to define a straight line between starting point of rising limb to the end of the recession limb; this method is used in this study. The base flow for each year event in (Table 2-3-1-1) and the average of base flows are used as base flow of extreme hydrographs. When the base flow is subtracted from the hydrograph ordinate, the residual part is direct runoff. The direct runoff of each year event is shown in figure 2-3-1-1.

Table 2-3-1-1 Amount of base flow in each year events

\begin{tabular}{ccc}
\hline Event year & Base flow $[\mathrm{cfs}]$ & Base flow $\left[\mathrm{m}^{3} / \mathrm{s}\right]$ \\
\hline 2008 & 3579 & 101.3 \\
2010 & 6059 & 171.6 \\
2011 & 5470 & 154.9 \\
2012 & 971 & 27.5 \\
2013 & 6670 & 188.9 \\
2014 & 1270 & 36.0 \\
2015 & 1810 & 51.3 \\
\hline mean & 3690 & 104.5 \\
\hline
\end{tabular}



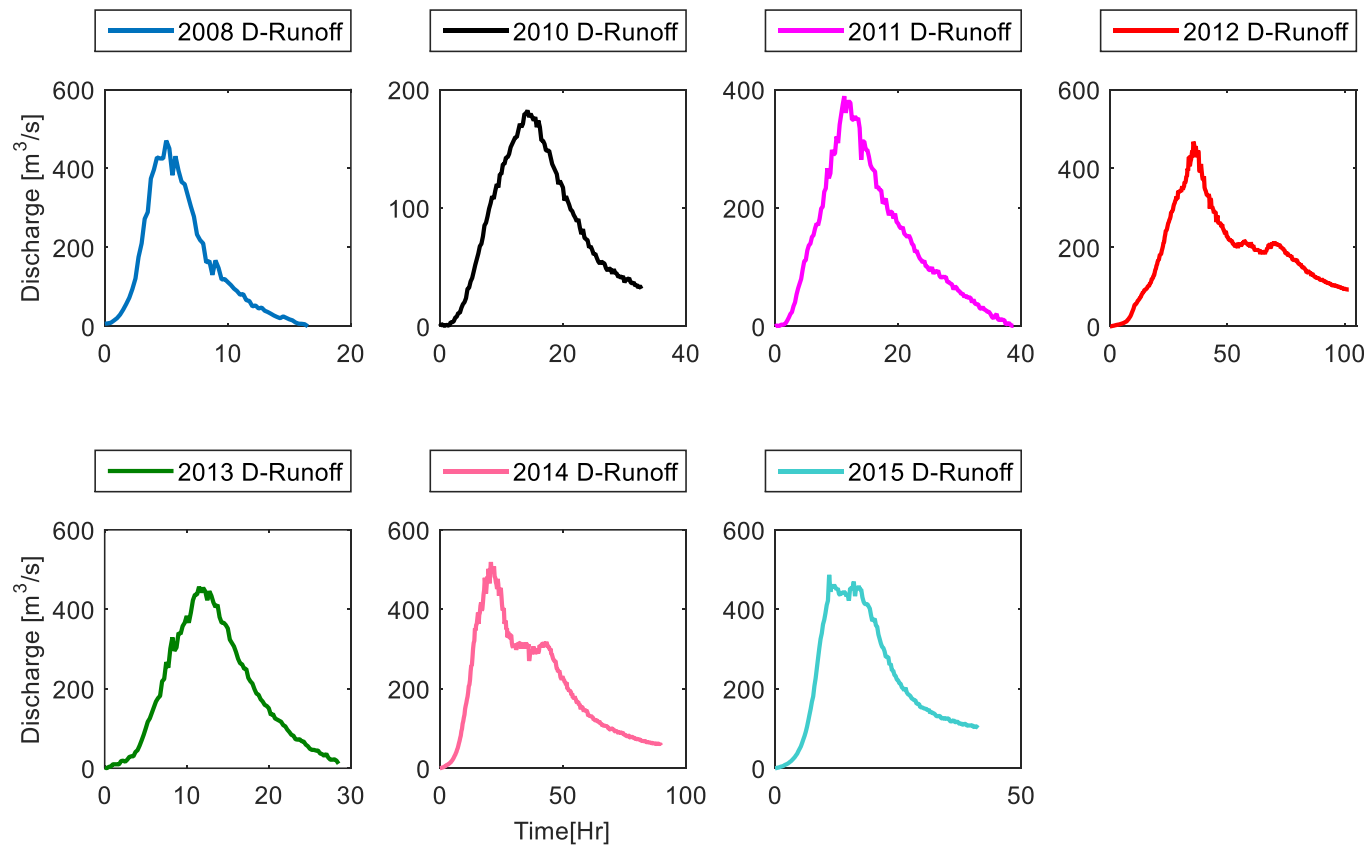

Figure 2-3-1-1 Direct runoff of the high flow events in each years

\section{2-3-2 Base Time and Time to peak of extreme hydrographs}

Dimensionless factors are important and widely used in fluid mechanics problem as well as in hydrology, because they are thought to characterize processes in a useful manner. To define dimensionless factors that describe extreme event hydrographs, we have to study actual observed hydrographs of the river. As mentioned before, Time-toPeak (PT) and Base-Time (BT) are two characteristics of hydrograph. Dividing PT by BT gives a Time Ratio (TR). PT, BT, and TR for each year are tabulated in table 2-3-2-1. 
Table 2-3-2-1 Base time and time to peak of direct runoff hydrographs for each year high flow event

\begin{tabular}{cccccc}
\hline Year & $\begin{array}{c}\text { Base Time } \\
\text { (TB) }[\text { Min] }\end{array}$ & $\begin{array}{c}\text { Base Time } \\
\text { (TB) }[\mathrm{Hr}]\end{array}$ & $\begin{array}{c}\text { Time to Peak } \\
\text { (PT) }[\text { Min }]\end{array}$ & $\begin{array}{c}\text { Time to Peak } \\
\text { (PT) }[\mathrm{Hr}]\end{array}$ & $\begin{array}{c}\text { Time Ratio } \\
\text { (TR) }=\text { PT/BT }\end{array}$ \\
\hline 2008 & 990 & 16.5 & 300 & 5.0 & 0.303 \\
2010 & 1965 & 32.8 & 850 & 14.2 & 0.433 \\
2011 & 2325 & 38.8 & 675 & 11.3 & 0.290 \\
2012 & 6105 & 101.8 & 2130 & 35.5 & 0.349 \\
2013 & 1710 & 28.5 & 690 & 11.5 & 0.404 \\
2014 & 5385 & 89.8 & 1245 & 20.8 & 0.231 \\
2015 & 2475 & 41.3 & 675 & 11.3 & 0.273 \\
\hline Mean & 2993.6 & 49.9 & 937.9 & 15.6 & 0.326 \\
\hline
\end{tabular}

The base time of the 2012 and 2014 were large and the shapes of their hydrograph were abnormal (Figure 2-3-1-1), because both years had extended nearly steady flows after the peak; which prolonged the hydrograph tail. If these two cases are dropped from calculation, the mean of time base is 31.6 hours. For this study, a $30 \mathrm{hr}$ base time is chosen. Possible reasons for such a short base time for Sandy River basin, include the small basin size, a steep basin slope, high precipitation, average winter temperature near $0^{\circ} \mathrm{C}$ (allowing rapid snow melt), frequent heavy rainfall over snow, and recent deforestation. Severe climate change scenarios may alter this base-time however. In summary, some of the most important factors for creating a synthetic hydrograph are available, e.g., peak flow, base time, base flow, and time to peak.

\section{2-3-3 Shape of Extreme Hydrographs}

The shape of the hydrograph is a function of basin or watershed physiography (Figure 2-3-3-1) and is crucial to defining extreme flow hydrographs. The Gamma Distribution function has been extensively used to represent flood hydrographs (Ji, 2011; 
Bhunya et al., 2003; Sade. 2011; Bhunya et al., 2008; Aron and White. 1982), because it can reproduce the asymmetry between the rising and falling limbs of a hydrograph. Here the two-parameter Gamma Distribution (Equation 2-3-3-1and Figure 2-3-3-3) was used as a means to summarize the hydrograph derived from data; the procedure for this is explained in the next section hydrographs. Observed high flow events that are fitted on gamma distribution are plotted in Figure 2-3-3-3 and the $\mathrm{R}^{2}$ between observed and Gamma Distribution curve for years events are shown in Table 2-3-3-1. Note that for the two years with prolonged peaks (2012 and 2014) the fit of the Gamma Distribution to the hydrograph is less precise, particularly in representation of the peak flow. Thus, the actual hydrographs where used in most model simulations, as described in the next section.

The Gamma Function representation of the hydrograph is :

$$
\begin{aligned}
& f(x)=\frac{1}{\text { scale }^{\text {shape }} \times \Gamma(\text { shape })} x^{(\text {shape }-1)} e^{-\left(\frac{x}{\text { scale }}\right)} \\
& f(x)=\frac{1}{b^{a} \times \Gamma(a)} x^{(a-1)} e^{-\left(\frac{x}{b}\right)}
\end{aligned}
$$

Where $f(x)$ is the value of the distribution, $\Gamma$ is the Gamma function, it formally is $\Gamma(s)=\int_{0}^{\infty} t^{s-1} e^{-t} d t, s>0$, and for integers is $\Gamma(s)=(s-1)$ ! 


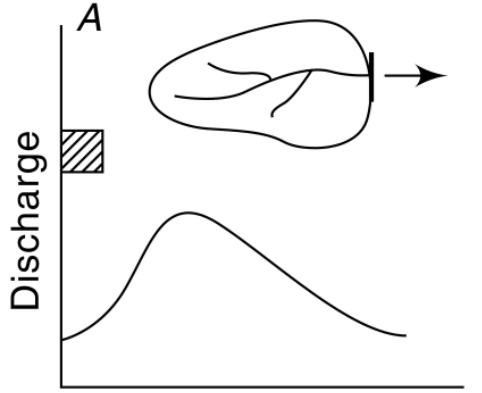

Time

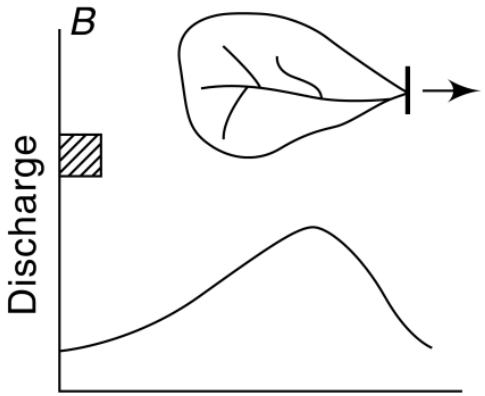

Time

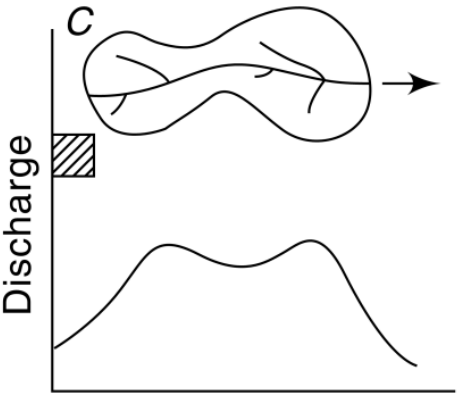

Time

Figure 2-3-3-1 Effect of physiological conditions of watershed on shape of hydrograph; adapted from (Subramanya, 2013)

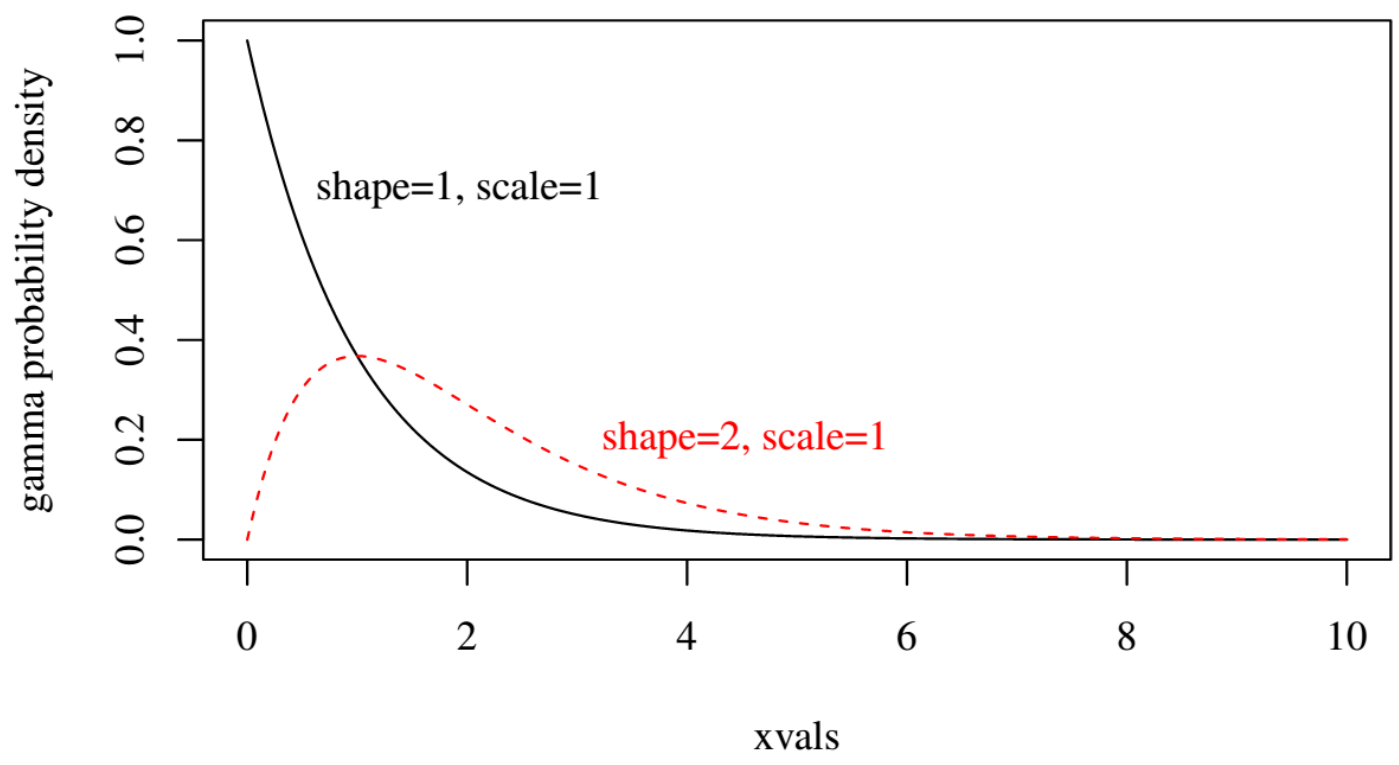

Figure 2-3-3-2 Typical Gamma Distribution curves; adapted from (Johnson, 2013) 

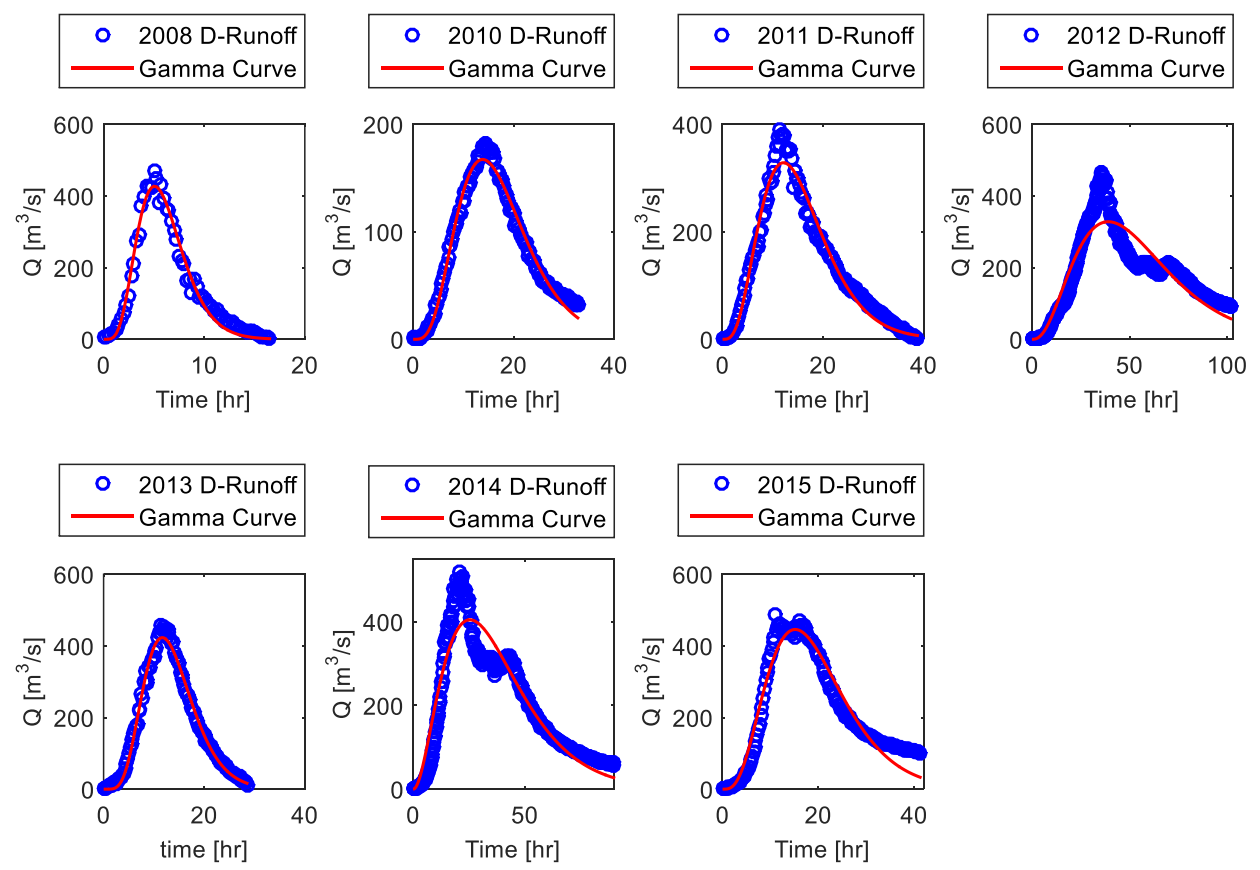

Figure 2-3-3-3 plotted gamma distribution curve on the direct runoff of high flow events

Table 2-3-3-1 $\mathrm{R}^{2}$ between observed direct runoff and gamma function curve

\begin{tabular}{lccccccc}
\hline Year & 2008 & 2010 & 2011 & 2012 & 2013 & 2014 & 2015 \\
\hline $\mathrm{R}^{2}$ & 0.9796 & 0.9861 & 0.9723 & 0.8357 & 0.9911 & 0.8987 & 0.9377 \\
\hline
\end{tabular}

\section{2-3-4 Ordinates of Extreme Event Hydrographs and Hydrograph Shapes}

The ordinates of extreme event hydrographs are derived from the observed hydrographs. Because hydrographs from different years are different in term of peak flow and water volume discharge over time, we divide the direct runoff hydrographs relative to the amount of peak flow (figure 2-3-4-1). According to figure 2-3-4-1, direct runoff hydrographs are discretized into eleven points; five data points are located on rising limb, one is at the peak and the other five situated on recession limb. The points are taken at 
$10 \%, 20 \%, 40 \%, 60 \%, 80 \%$ of peak flow (QP) in both rising and recession limbs and $100 \%$ on peak. The rising time (TR) on rising limb, lowering time (TL) on recession limb and discharge in each flow percentage are tabulated in Table 2-3-4-1 for each high flow events. Finding the non-dimensionalized time ratio by dividing the TR and TL over base time of direct runoff hydrographs for each year TRR and TLR respectively makes work easier. When the averages of these non-dimensionalized factors and multiplied by time base BT (30 hr) of extreme events, the time ordinates of extreme hydrographs will be computed for different percentages of peak value of extreme events. The computed time ordinates are tabulated in Table 2-3-4-2. 
Table 2-3-4-1 Discharge, time rising and time lowering according to different percentages of peak flow for different years

\begin{tabular}{|c|c|c|c|c|c|c|}
\hline \multirow{4}{*}{2008} & $\% \mathrm{QP}$ & 10 & 20 & 40 & 60 & 80 \\
\hline & $\mathrm{TR}[\mathrm{Hr}]$ & 1.64 & 2.25 & 2.84 & 3.40 & 3.77 \\
\hline & $\mathrm{TL}[\mathrm{Hr}]$ & 6.61 & 7.21 & 8.11 & 10.57 & 12.44 \\
\hline & $\mathrm{Q}\left[\mathrm{m}^{3} / \mathrm{s}\right]$ & 47.06 & 94.13 & 188.25 & 282.40 & 376.53 \\
\hline \multirow{4}{*}{2010} & $\% \mathrm{QP}$ & 10 & 20 & 40 & 60 & 80 \\
\hline & $\mathrm{TR}[\mathrm{Hr}]$ & 3.71 & 4.93 & 6.88 & 8.48 & 11.27 \\
\hline & $\mathrm{TL}[\mathrm{Hr}]$ & 17.86 & 20.18 & 23.96 & 31.56 & \\
\hline & $\mathrm{Q}\left[\mathrm{m}^{3} / \mathrm{s}\right]$ & 18.24 & 36.48 & 72.96 & 109.43 & 145.91 \\
\hline \multirow{4}{*}{2011} & $\% \mathrm{QP}$ & 10 & 20 & 40 & 60 & 80 \\
\hline & $\mathrm{TR}[\mathrm{Hr}]$ & 3.17 & 4.18 & 6.29 & 8.25 & 10.26 \\
\hline & $\mathrm{TL}[\mathrm{Hr}]$ & 14.52 & 16.87 & 21.10 & 27.92 & 32.48 \\
\hline & $\mathrm{Q}\left[\mathrm{m}^{3} / \mathrm{s}\right]$ & 38.88 & 77.76 & 155.52 & 233.30 & 311.06 \\
\hline \multirow{4}{*}{2012} & $\% \mathrm{QP}$ & 10 & 20 & 40 & 60 & 80 \\
\hline & $\mathrm{TR}[\mathrm{Hr}]$ & 10.05 & 15.17 & 21.84 & 25.81 & 27.52 \\
\hline & $\mathrm{TL}[\mathrm{Hr}]$ & 39.42 & 45.09 & 74.63 & 102.00 & \\
\hline & $\mathrm{Q}\left[\mathrm{m}^{3} / \mathrm{s}\right]$ & 46.81 & 93.62 & 187.23 & 280.85 & 374.46 \\
\hline \multirow{4}{*}{2013} & $\% \mathrm{QP}$ & 10 & 20 & 40 & 60 & 80 \\
\hline & $\mathrm{TR}$ [Hr] & 4.01 & 4.87 & 6.75 & 7.86 & 9.73 \\
\hline & $\mathrm{TL}[\mathrm{Hr}]$ & 14.53 & 16.33 & 18.80 & 22.49 & 25.58 \\
\hline & $\mathrm{Q}\left[\mathrm{m}^{3} / \mathrm{s}\right]$ & 45.68 & 91.35 & 182.70 & 274.08 & 365.43 \\
\hline \multirow{4}{*}{2014} & $\% \mathrm{QP}$ & 10 & 20 & 40 & 60 & 80 \\
\hline & $\mathrm{TR}[\mathrm{Hr}]$ & 7.31 & 9.09 & 11.83 & 13.68 & 16.70 \\
\hline & $\mathrm{TL}[\mathrm{Hr}]$ & 25.67 & 41.42 & 51.63 & 68.14 & \\
\hline & $\mathrm{Q}\left[\mathrm{m}^{3} / \mathrm{s}\right]$ & 51.90 & 103.81 & 207.62 & 311.46 & 415.27 \\
\hline \multirow{4}{*}{2015} & $\% \mathrm{QP}$ & 10 & 20 & 40 & 60 & 80 \\
\hline & $\mathrm{TR}[\mathrm{Hr}]$ & 4.99 & 6.36 & 7.89 & 8.90 & 10.23 \\
\hline & $\mathrm{TL}[\mathrm{Hr}]$ & 19.43 & 22.29 & 26.67 & 41.50 & \\
\hline & $\mathrm{Q}\left[\mathrm{m}^{3} / \mathrm{s}\right]$ & 48.68 & 97.35 & 194.71 & 292.09 & 389.44 \\
\hline
\end{tabular}




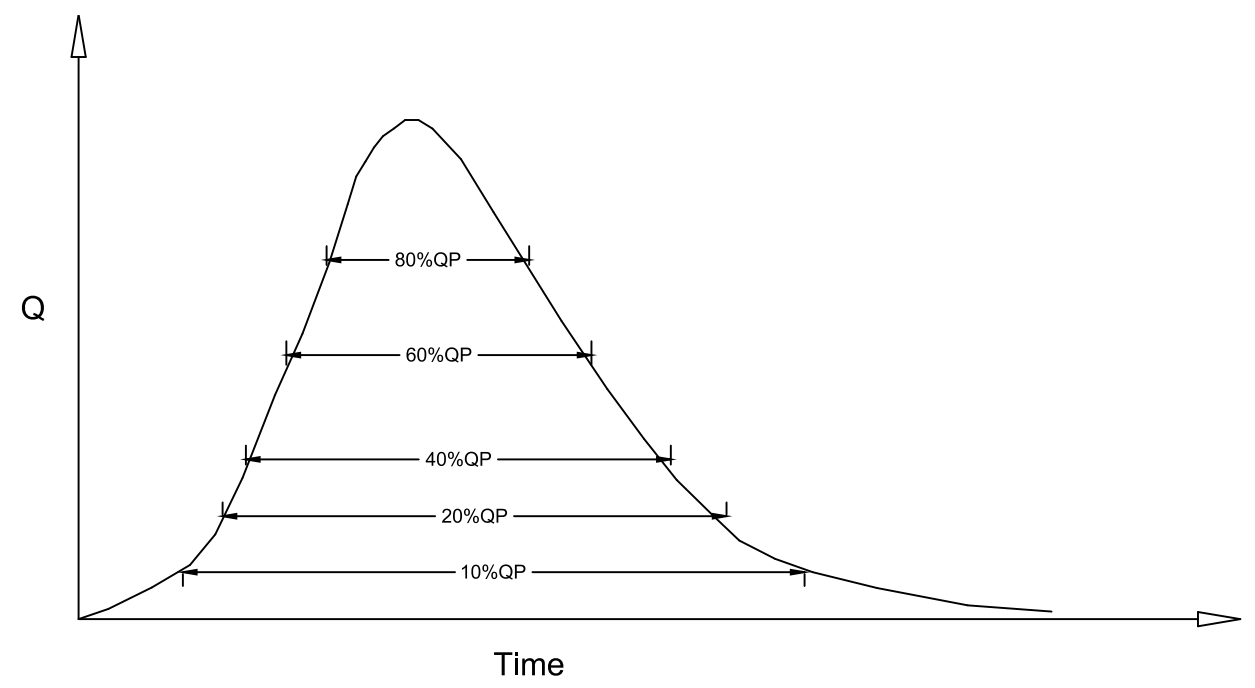

Figure 2-3-4-1 Division of direct runoff hydrograph according to peak flow

Table 2-3-4-2 computed time ordinated for extreme event hydrographs

\begin{tabular}{|c|c|c|c|c|}
\hline $\mathrm{QP} \%$ & \multicolumn{2}{|c|}{ Time Ratio Average } & $\begin{array}{c}\text { Time Ordinates } \\
\text { [Min] }\end{array}$ & $\begin{array}{c}\text { Time Ordinates } \\
{[\mathrm{Hr}]}\end{array}$ \\
\hline & & & 0.0 & 0.0 \\
\hline 10 & \multirow{5}{*}{ TRR } & 0.1055 & 189.9 & 3.2 \\
\hline 20 & & 0.1385 & 249.3 & 4.2 \\
\hline 40 & & 0.1887 & 339.7 & 5.7 \\
\hline 60 & & 0.2258 & 406.4 & 6.8 \\
\hline 80 & & 0.2702 & 486.4 & 8.1 \\
\hline 100 & \multirow{7}{*}{ TLR } & & $\mathrm{TP}$ & $\mathrm{TP}$ \\
\hline 80 & & 0.4254 & 765.7 & 12.8 \\
\hline 60 & & 0.4985 & 897.3 & 15.0 \\
\hline 40 & & 0.6185 & 1113.3 & 18.6 \\
\hline 20 & & 0.8247 & 1484.5 & 24.7 \\
\hline \multirow[t]{2}{*}{10} & & 0.8299 & 1493.8 & 24.9 \\
\hline & & & 1800.0 & 30.0 \\
\hline
\end{tabular}


The time ordinate for the last time ratio is anomalous (24.9 hours) because data points for 2010, 2012, 2014, and 2015 at the $10 \%$ level in recession limb are not available (Table 2-3-4-1, Figure 2-3-1-1). So that the ordinate at the $10 \%$ level is consistent with other data, we assume the time ordinate occurs at 26 hours. Using these result, hydrographs are fitted by Gamma Distribution curve with $\mathrm{R}^{2}=0.9771$, for all floods. The fitted direct runoff hydrographs with the corresponding Gamma Distribution curves are shown in figure 2-3-4-2. To obtain a full hydrograph for each extreme event, the base flow is added to the each direct runoff hydrograph. The full extreme hydrographs of each return period are shown in Figure 2-3-4-3.
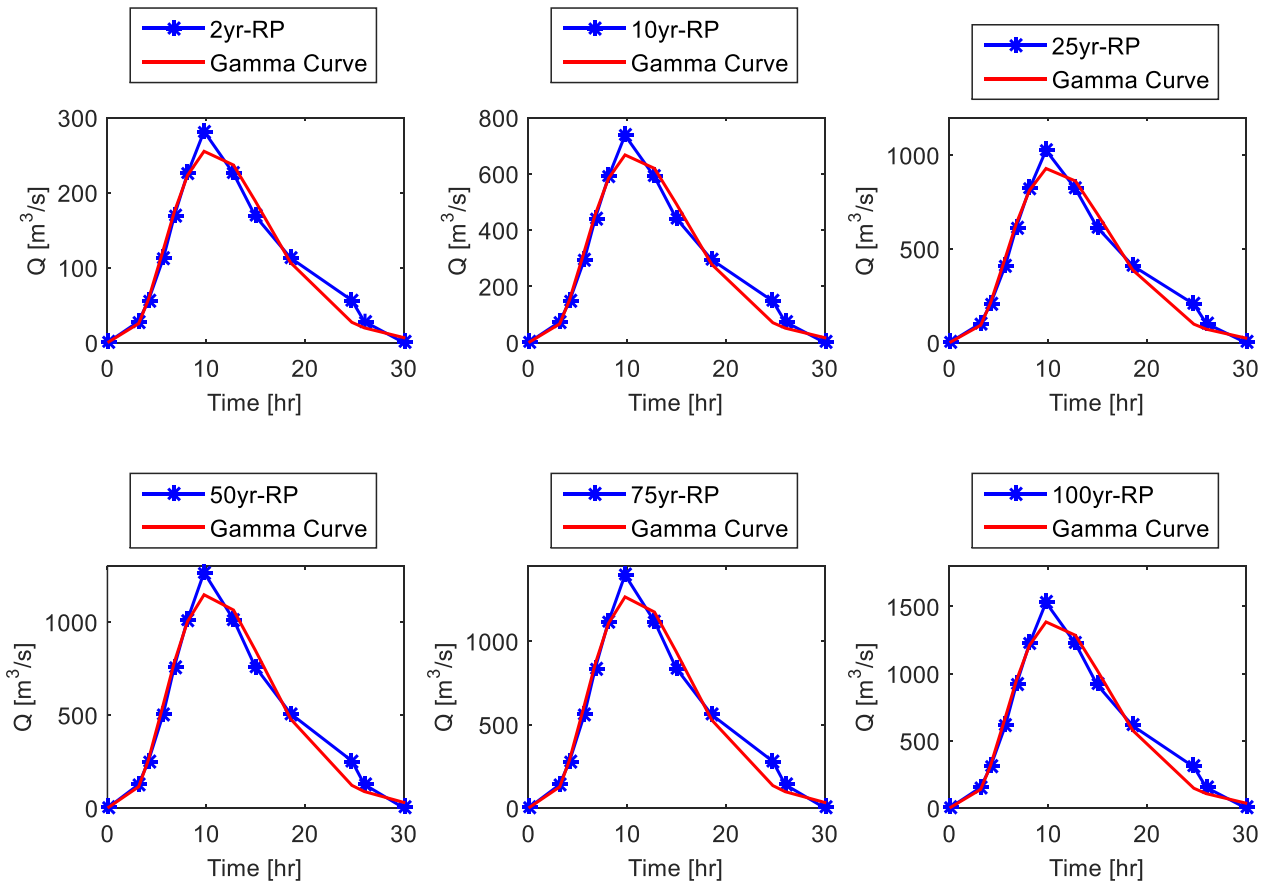

Figure 2-3-4-2 Extreme direct runoff hydrographs for different return periods 
In Summary, the extreme values of selected return periods are calculated by using Log-Pearson Type III distribution. For derivation extreme event hydrograph, we use the collected data in the Sandy River by choosing seven high flood events from the Sandy River discharges after removing the Marmot Dam. Because flood hydrographs are randomly distributed, the shape and volume of water of the hydrograph are taken from observed hydrographs. To examine the shape of derived hydrograph related to the observed hydrographs, we use Gamma distribution curve as a form to fit both observed and derived hydrographs, and it works well with both.

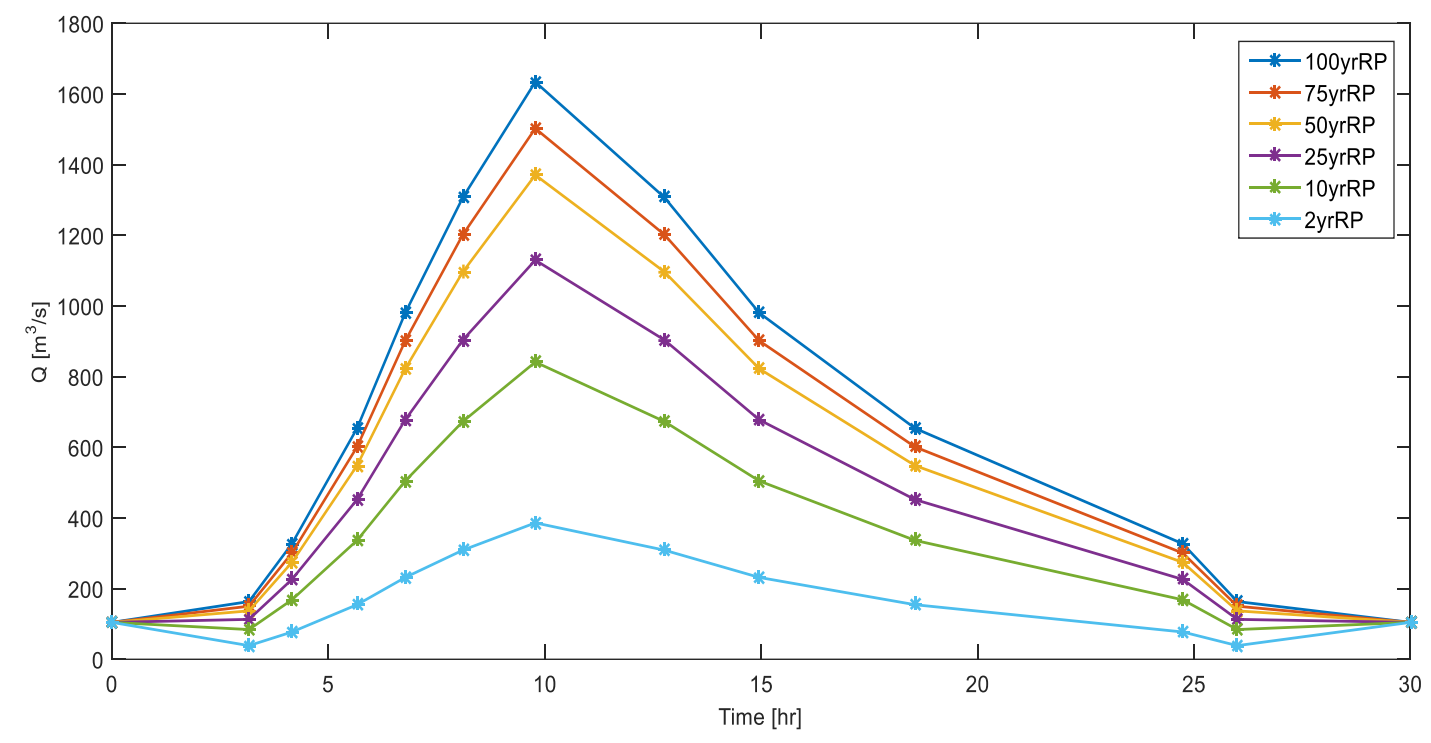

Figure 2-3-4-3 Extreme hydrographs of different return periods 


\section{Chapter 3: Theory of the Numerical Model}

\section{3-1 Introduction}

The equations describing fluid mechanics are complicated and analytical solutions are limited to simple cases. Thus, numerical methods are extensively used for solving these equations. Flow and sediment transport in a natural river are one of the more complex environmental flow phenomena, and these complications make it difficult to determine the actual physics behind transport of flow and sediment and their interactions. Environmental processes in rivers were, before the development of computer (1970s), analyzed by using physical models in the laboratories and/or field investigations. As the computational power of computers grew, numerical methods very widely utilized to solve actual physical problems (Wu, 2007). Computational fluid dynamics (CFD) is applied to many industrial and environmental problems though applications of environmental phenomena were mostly studied later than industrial problems. CFD codes are now very widely used to study riverine environments, as an alternative to classical field and laboratories techniques (Ingham and Ma. 2005). CFD models for river systems are very complex due to spatially and temporally variation in the flow, sediment, bathymetry, planform, and vegetation. The interactions of these physical factors with each other and chemical factors (e.g., contamination) make river systems very complicated, and empirical formulas must be used for describing some of the variables.

The accuracy of numerical methods used to represent river mechanics depends on many factors, for example, expression of natural processes mathematically in the governing equations, accuracy of boundary conditions, precision numerical of 
discretization of the governing equations (finite difference methods, finite volume methods, finite element method), and the correctness of the resulting computer codes. According to $\mathrm{Wu}$, (2007) numerical models of flow and sediment transport can be categorized based on:

1. Dimensions: models may be three-dimensional, depth-averaged two-dimensional, width-averaged two-dimensional, or one-dimensional; each of these has its own applications.

2. Flow condition: models can be classified according to the status of flow as unsteady (varied with time), steady (constant with time), and quasi-steady (by breaking down the hydrograph into segments, each of these may be considered as steady state flow condition).

3. Sediment sizes: the models of sediment transport may be applied for single size or multiple sizes of bed material; multiple sizes sediment matter provide more useful results than the single-size materials, because the natural bed material of rivers consists of a spectrum of sizes.

4. Type of sediment transport: sediment transport models are generally classified as bed-load models, suspended-load models, total-load models, or bed-load and suspended-load models.

5. Numerical technique: models can solve the nonlinear terms in the transport equations by finite difference, finite volume, or finite element. Each of these techniques has many schemes that are used based on the physical phenomenon modeled. 


\section{3-2 Nays2DH}

The model used in this study is called Nays $2 \mathrm{DH}$, a solver included in the iRIC (International River Interface Cooperative) software. Nays $2 \mathrm{DH}$ is a two-dimensional, depth averaged, horizontal, unsteady coupled flow and sediment transport hydrodynamic model that can analysis flow, sediment and hydro-geomorphological change in the bed and banks of a river (Kinze et al, 2015). The Nays2DH and more than ten other solvers are provided by the $i R I C$ package and are free for download from $\underline{i \text {-ric.org. The } i R I C}$ software was created and developed scientists and engineers from different countries. For all solvers, iRIC is the graphical user interface and in Figure 3-2-1provides the general conceptual structure.

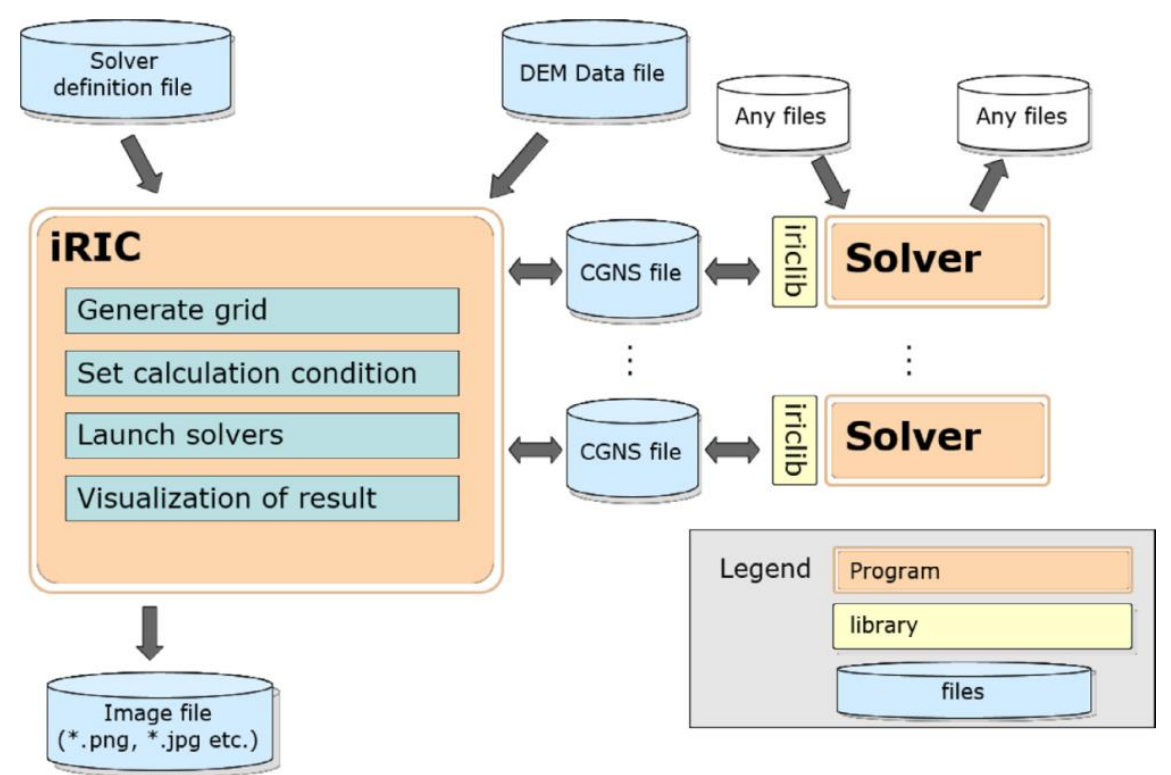

Figure 3-2-1 General structure of iRIC model; retrived from Nelson et al, 2016

Nays2DH was created by combining two previous iRIC solvers: Nays $2 D$ developed by Yasuyuki Shimizu in Hokkaido University in Japan, and Morpho2D 
developed by Hiroshi Takebayashi in Kyoto University in Japan, providing a powerful tool for users (iRIC Software, 2014). Nays2DH was developed by Toshiki Iwasaki at Hokkaido University modified by Kazutake Asahi, Takuya Inoue and Tomoko Kyuka.

Nays2DH utilizes a general curvilinear coordinate system (with moving boundary), suitable for application to complicated river boundaries and riverbed geometry. For solving the advection terms in the momentum equations, Nays $2 \mathrm{DH}$ uses two user-selectable finite difference schemes: an Upwind (first order) scheme, and a Cubic-Interpolated Pseudoparticle (CIP) (high order) scheme. CIP scheme can perform flow problems with high precision especially for local unsteady flow of flow separation or substantial shear. For the pressure computation (assumed hydrostatic), Nays $2 \mathrm{DH}$ uses a successive relaxation technique (Nelson et al, 2016). It also provides three userselectable turbulence closures: constant eddy viscosity, spatially varying eddy diffusivity (zero equation) and a $k-\varepsilon$ model; Manning's $n$ is used to evaluate roughness of the bed of river channels and can be set by the user for individual grid cells or within polygons. Nays $2 \mathrm{DH}$ has ability to compute bed load and suspended load sediment matter with single and multiple grain-size of the bed materials. Performing bank erosion in Nays $2 \mathrm{DH}$ is implemented by bank shifting and bank collapsing models (iRIC Software, 2014).

\section{3-3 Equations of Motion}

The equations of motions in the Nays $2 \mathrm{DH}$ consist of continuity and momentum equations for two dimensional depth-averaged situations; these are:

Continuity equation in two dimensional 


$$
\frac{\partial h}{\partial t}+\frac{\partial(h u)}{\partial x}+\frac{\partial(h v)}{\partial y}=0
$$

Momentum equations in $x$ - and $y$-direction respectively

$$
\begin{aligned}
& \frac{\partial(u h)}{\partial t}+\frac{\partial\left(h u^{2}\right)}{\partial x}+\frac{\partial(h u v)}{\partial y}=-g h \frac{\partial H}{\partial x}-\frac{\tau_{x}}{\rho}+D^{x} \frac{F_{x}}{\rho} \\
& \frac{\partial(v h)}{\partial t}+\frac{\partial(h v u)}{\partial x}+\frac{\partial\left(h v^{2}\right)}{\partial y}=-g h \frac{\partial H}{\partial y}-\frac{\tau_{y}}{\rho}+D^{y} \frac{F_{y}}{\rho} \\
& \frac{\tau_{x}}{\rho}=C_{f} u \sqrt{u^{2}+v^{2}} \\
& 4 \\
& \frac{\tau_{y}}{\rho}=C_{f} v \sqrt{u^{2}+v^{2}} \\
& D^{x}=\frac{\partial}{\partial x}\left[v_{t} h \frac{\partial u}{\partial x}\right]+\frac{\partial}{\partial y}\left[v_{t} h \frac{\partial u}{\partial y}\right] \\
& D^{y}=\frac{\partial}{\partial x}\left[v_{t} h \frac{\partial v}{\partial x}\right]+\frac{\partial}{\partial y}\left[v_{t} h \frac{\partial v}{\partial y}\right] \\
& \frac{F_{x}}{\rho}=\frac{1}{2} C_{d} a_{s} h_{v} u \sqrt{u^{2}+v^{2}} \\
& \frac{F_{y}}{\rho}=\frac{1}{2} C_{d} a_{s} h_{v} v \sqrt{u^{2}+v^{2}} \\
& C_{f}=\frac{g n^{2}}{h^{\frac{1}{3}}} \\
& u_{*}=\frac{n \sqrt{g\left(u^{2}+v^{2}\right)}}{h^{\frac{1}{6}}}
\end{aligned}
$$

Here $h$ is depth of water, $t$ is time, $u$ and $v$ are depth-averaged velocities in $x$ - and $y$ directions respectively, $g$ is gravitational due to acceleration, $H$ is surface water elevation, $\tau_{x}$ and $\tau_{y}$ are the components of the shear stress of bed in $x$ - and $y$-directions respectively, $F_{x}$ and $F_{y}$ are components of drag force due to vegetation in the $x$ - and $y$-direction respectively, $C_{f}$ is the drag coefficient of the bed shear stress, $v_{t}$ is eddy viscosity 
coefficient, $C_{D}$ is drag coefficient of vegetation, $h_{v}$ is minimum value of water depth and height of vegetation, $n$ is Manning's roughness coefficient, $\kappa$ is Karman coefficient (0.4), $u *$ is shear velocity, and $\rho$ is density.

The above equations are in a Cartesian coordinate system and must be transformed to a curvilinear, moving boundary-fitted coordinate (MBFC) system (see Appendix and Figure 3-3-1). The equations of motion in a general curvilinear coordinate system are as follows:
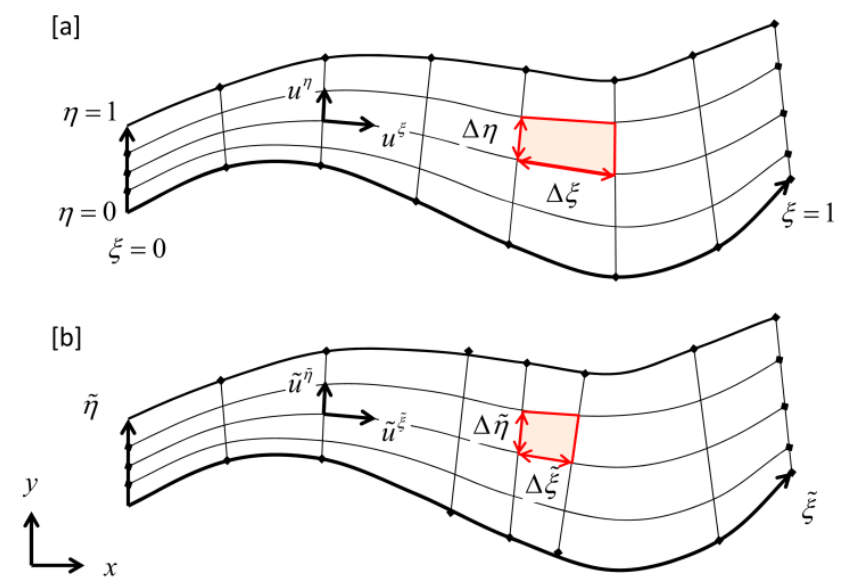

Figure 3-3-1 The horizontal moving boundary-fitted coordinate for non-dimensional ( $\xi$ and $\eta$ ) and dimensional of $\tilde{\xi}$ and $\tilde{\eta}$ coordinates (retrived from Asahi et al., 2013)

Continuity equation

$\frac{\partial}{\partial t}\left(\frac{h}{J}\right)+\frac{\partial}{\partial \xi}\left(\frac{h u^{\xi}}{J}\right)+\frac{\partial}{\partial \eta}\left(\frac{h u^{\eta}}{J}\right)=0$

Momentum equations in $\xi$-and $\eta$-directions respectively 


$$
\begin{aligned}
& \frac{\partial u^{\xi}}{\partial t}+u^{\xi} \frac{\partial u^{\xi}}{\partial \xi}+u^{\eta} \frac{\partial u^{\xi}}{\partial \eta}+\alpha_{1} u^{\xi} u^{\xi}+\alpha_{2} u^{\xi} u^{\eta}+\alpha_{3} u^{\eta} u^{\eta}= \\
& -g\left[\left(\xi_{x}^{2}+\xi_{y}^{2}\right) \frac{\partial H}{\partial \xi}+\left(\xi_{x} \eta_{x}+\xi_{y} \eta_{y}\right) \frac{\partial H}{\partial \eta}\right] \\
& -\left(C_{f}+\frac{1}{2} C_{D} a_{s} h_{v}\right) \frac{u^{\xi}}{h J} \sqrt{\left(\eta_{y} u^{\xi}-\xi_{y} u^{\eta}\right)^{2}+\left(-\eta_{x} u^{\xi}+\xi_{x} u^{\eta}\right)^{2}}+D^{\xi} \\
& \frac{\partial u^{\eta}}{\partial t}+u^{\xi} \frac{\partial u^{\eta}}{\partial \xi}+u^{\eta} \frac{\partial u^{\eta}}{\partial \eta}+\alpha_{4} u^{\xi} u^{\xi}+\alpha_{5} u^{\xi} u^{\eta}+\alpha_{6} u^{\eta} u^{\eta}= \\
& -g\left[\left(\eta_{x} \xi_{x}+\eta_{y} \xi_{y}\right) \frac{\partial H}{\partial \xi}+\left(\eta_{x}^{2}+\eta_{y}^{2}\right) \frac{\partial H}{\partial \eta}\right] \\
& -\left(C_{f}+\frac{1}{2} C_{D} a_{s} h_{v}\right) \frac{u^{\eta}}{h J} \sqrt{\left(\eta_{y} u^{\xi}-\xi_{y} u^{\eta}\right)^{2}+\left(-\eta_{x} u^{\xi}+\xi_{x} u^{\eta}\right)^{2}}+D^{\eta}
\end{aligned}
$$

Terms in Eq. 3-3-11 and 3-3-12 are:

$$
\begin{aligned}
& a_{1}=\xi_{x} \frac{\partial^{2} x}{\partial \xi^{2}}+\xi_{y} \frac{\partial^{2} y}{\partial \xi^{2}} \\
& a_{2}=2\left(\xi_{x} \frac{\partial^{2} x}{\partial \xi \partial \eta}+\xi_{y} \frac{\partial^{2} y}{\partial \xi \partial \eta}\right) \\
& a_{3}=\xi_{x} \frac{\partial^{2} x}{\partial \eta^{2}}+\xi_{y} \frac{\partial^{2} y}{\partial \eta^{2}} \\
& a_{4}=\eta_{x} \frac{\partial^{2} x}{\partial \xi^{2}}+\eta_{y} \frac{\partial^{2} y}{\partial \xi^{2}} \\
& a_{5}=2\left(\eta_{x} \frac{\partial^{2} x}{\partial \xi \partial \eta}+\eta_{x} \frac{\partial^{2} y}{\partial \xi \partial \eta}\right) \\
& a_{6}=\eta_{x} \frac{\partial^{2} x}{\partial \eta^{2}}+\eta_{x} \frac{\partial^{2} y}{\partial \eta^{2}}
\end{aligned}
$$




$$
\begin{aligned}
D^{\xi} & =\left(\xi_{x} \frac{\partial}{\partial \xi}+\eta_{x} \frac{\partial}{\partial \eta}\right)\left[v_{t}\left(\xi_{x} \frac{\partial u^{\xi}}{\partial \xi}+\eta_{x} \frac{\partial u^{\xi}}{\partial \eta}\right)\right] \\
& +\left(\xi_{y} \frac{\partial}{\partial \xi}+\eta_{y} \frac{\partial}{\partial \eta}\right)\left[v_{t}\left(\xi_{y} \frac{\partial u^{\xi}}{\partial \xi}+\eta_{y} \frac{\partial u^{\xi}}{\partial \eta}\right)\right] \\
D^{\eta}= & \left(\xi_{x} \frac{\partial}{\partial \xi}+\eta_{x} \frac{\partial}{\partial \eta}\right)\left[v_{t}\left(\xi_{x} \frac{\partial u^{\eta}}{\partial \xi}+\eta_{x} \frac{\partial u^{\eta}}{\partial \eta}\right)\right] \\
& +\left(\xi_{y} \frac{\partial}{\partial \xi}+\eta_{y} \frac{\partial}{\partial \eta}\right)\left[v_{t}\left(\xi_{y} \frac{\partial u^{\eta}}{\partial \xi}+\eta_{y} \frac{\partial u^{\eta}}{\partial \eta}\right)\right]
\end{aligned}
$$

Equations 3-3-15 and 3-3-16 are diffusion terms of momentum equations. Also,

$$
\begin{aligned}
& \xi_{x}=\frac{\partial \xi}{\partial x}, \xi_{y}=\frac{\partial \xi}{\partial y}, \eta_{x}=\frac{\partial \eta}{\partial x}, \eta_{y}=\frac{\partial \eta}{\partial y} \\
& u^{\xi}=\xi_{x} u+\xi_{y} v, u^{\eta}=\eta_{x} u+\eta_{y} v \\
& J=\frac{1}{x_{\xi} y_{\eta}-x_{\eta} y_{\xi}}
\end{aligned}
$$

When the diffusion terms of the momentum equations in MBFC system are written out, they create a large number of terms. However, these terms can be simplified by assuming that higher order terms are locally equal to zero.

$$
\begin{aligned}
& D^{\xi} \approx \frac{\partial}{\partial \xi}\left(v_{t} \xi_{r}^{2} \frac{\partial u^{\xi}}{\partial \xi}\right)+\frac{\partial}{\partial \eta}\left(v_{t} \eta_{r}^{2} \frac{\partial u^{\xi}}{\partial \eta}\right) \\
& D^{\eta} \approx \frac{\partial}{\partial \xi}\left(v_{t} \xi_{r}^{2} \frac{\partial u^{\eta}}{\partial \xi}\right)+\frac{\partial}{\partial \eta}\left(v_{t} \eta_{r}^{2} \frac{\partial u^{\eta}}{\partial \eta}\right) \\
& \xi_{r}=\frac{\partial \xi}{\partial \xi}=\frac{\Delta \xi}{\Delta \xi}, \eta_{r}=\frac{\partial \eta}{\partial \eta}=\frac{\Delta \eta}{\Delta \eta}
\end{aligned}
$$


Where $\xi$ and $\eta$ are non-dimensionalized MBFC system, $\tilde{\xi}$ and $\tilde{\eta}$ are dimensionalized MBFC system (Figure 3-3-1), $u^{\xi}$ and $u^{\eta}$ are velocity components in $\xi$ and $\eta$ directions respectively, $J$ is Jacobian determinant for transformed coordinates, $\xi_{x}, \xi_{y}, \eta_{x}, \eta_{y}$ are differential metric coefficient between $\xi, \eta$ and $x, y$ coordinates, $\Delta \xi$ and $\Delta \eta$ are grid sizes in non-dimensionalized MBFC system, $\Delta \tilde{\xi}$ and $\Delta \tilde{\eta}$ are grid sizes in dimensionalized MBFC system (figure 3-3-1). Transformation from non-dimensionalized $\xi, \eta$ coordinate to dimensionalized tildes $\xi$, $\eta$ coordinates is performed by using equation $3-3-19$, and transformation of velocity from non-dimensioned $\xi, \eta$ to the dimensionalized $\tilde{\xi}, \tilde{\eta}$ is defined by:

$$
u^{\xi}=\frac{1}{\xi_{r}} u^{\xi}, u^{\eta}=\frac{1}{\eta_{r}} u^{\eta}
$$

\section{3-4 Turbulence Closure}

In this study, we use the Zero-Equation Model. By assuming that turbulent momentum transport is determined by bed roughness velocity and depth, the eddy viscosity coefficient $v_{t}$ is calculated as:

$v_{t}=a \times u_{*} \times h$

Equation 3-4-1

Where $a$ is proportionality constant. Thus, the horizontal and vertical eddy viscosity coefficient $v_{t}$ would be in the same order if depth and roughness are altered slightly in transverse direction. The eddy viscosity coefficient $v_{t}$ can also be presented with Von Kàrmàn coefficient $(\kappa)$.

$v_{t}=\frac{\kappa}{6} A u_{*} h+B$

Equation 3-4-2 
Where $A$ and $B$ are eddy viscosity parameters, $h$ is depth of water,and $u *$ is shear velocity

\section{3-5 Sediment Transport Model Equations}

Nays $2 \mathrm{DH}$ can model sediment transport can be modeled in two different modes: bed-load only or bed-load plus suspended-load. In this study, we utilized the bed-load plus suspended load model.

\section{3-5-1 Shields Number (Non-Dimensioned shear stress)}

Sediment transport is represented as a function of non-dimensional bed stress expressed in Shields form:

$$
\tau_{*}=\frac{h I_{e}}{s_{g} d}
$$

Equation 3-5-

1

$V=\sqrt{u^{2}+v^{2}}$

Equation 3-5-2

Where $h$ is water depth, $I_{e}$ is energy slope, $s_{g}$ is submerged specific gravity of the bed material, and $V$ is composite velocity $d$ grain size diameter. From Manning's equation, $I_{e}$ can be represented as a function of Manning's coefficient $n$, so that the shields number $\tau$ * can be presented as follow

$$
\tau_{*}=\frac{C_{f} V^{2}}{s_{g} g d}=\frac{n^{2} V^{2}}{s_{g} d h^{1 / 3}}
$$

From equation 3-3-11, $\tau *$ can be written as:

$$
\tau_{*}=\frac{u_{*}^{2}}{s_{g} g d}
$$




\section{3-5-2 Bed-Load Transport}

Bed-load transport $q_{b}$ can be determined using two different user-selectable approaches; the Meyer-Peter and Müller, and the Ashida and Michiue formulas. The Ashida and Michiue formula is used in this work for bed-load computation.

A. Meyer-Peter and Müller

$q_{b}=8\left(\tau_{*}-\tau_{*_{c}}\right)^{1.5} \sqrt{s_{g} g d^{3} r_{b}}$

Equation 3-5-5

B. Ashida and Michiue

$$
\begin{aligned}
& q_{b}=17 \tau_{*_{e}}^{1.5}\left(1-K_{c} \frac{\tau_{*_{c}}}{\tau_{*}}\right)\left(1-\sqrt{K_{c} \frac{\tau_{*_{c}}}{\tau_{*}}}\right) \sqrt{s_{g} g d^{3} r_{b}} \\
& \tau_{*_{e}}=\frac{u_{*_{e}}{ }^{2}}{s_{g} g d}
\end{aligned}
$$

Equation 3-5-7

$u_{* e}{ }^{2}=\frac{V^{2}}{\left(6+2.5 \ln \frac{h}{d\left(1+2 \tau_{*}\right)}\right)^{2}}$

Equation 3-5-8

$K_{c}=1+\frac{1}{\mu_{s}}\left[\left(\frac{\rho}{\rho_{s}-\rho}+1\right) \cos \alpha \tan \theta_{x}+\sin \alpha \tan \theta_{y}\right]$

Equation 3-5-9

$\alpha=\arctan \left(\frac{v_{b}}{u_{b}}\right)$

Equation 3-5-10

$\theta_{x}=\arctan \left(\frac{\partial \xi}{\partial x} \frac{\partial z_{b}}{\partial \xi}+\frac{\partial \eta}{\partial x} \frac{\partial z_{b}}{\partial \eta}\right)$

Equation 3-5-11

$\theta_{y}=\arctan \left(\frac{\partial \xi}{\partial y} \frac{\partial z_{b}}{\partial \xi}+\frac{\partial \eta}{\partial y} \frac{\partial z_{b}}{\partial \eta}\right)$

Equation 3-5-12

$r_{b}=1 \quad E_{s d} \geq E_{b e}$

Equation 3-5-13 
$r_{b}=\frac{E_{b}}{E_{b e}} \quad E_{s d} \leq E_{b e}$

Equation 3-5-14

where $\tau *_{c}$ is critical shear stress, $\tau *_{e}$ is effective shear stress, $u *_{e}$ is effective shear velocity, $K_{c}$ is modification function of effect of local bed slope of sediment transport, $\rho$ is the density of water, $\rho_{s}$ density of sediment material, $\alpha$ is angle of deviation of near bed flow, $\mu_{s}$ is static friction coefficient, $\theta_{x}, \theta_{y}$ are bed slope in in $x$ and $y$ direction respectively, $z_{b}$ is the bed elevation, $r_{b}$ is the function of exchange layer thickness, $E_{b}, E_{b e}, E_{s d}$ are bedload layer thickness, equilibrium bedload layer thickness, and sediment layer (cohesive sediment layer in case of multilayer sediment) thickness respectively.

\section{3-5-3 Near Bed Velocity}

The velocity near the bed of the channel is used to calculate shear stress and is computed as a function of the depth average (composite) velocity

$u_{b}^{s}=\beta V$

Equation 3-5-

15

$\beta=3 \frac{1-\sigma}{3-\sigma}$

Equation 3-5-16

$\sigma=\frac{3}{\phi_{0} \kappa+1}, \phi_{0}=\frac{V}{u_{*}}$

Equation 3-5-17

Where $\tilde{u}_{b}^{s}$ is near-bed velocity along streamline of the composite velocity and $\beta$ is velocity coefficient.

\section{3-5-4 Vertical Flux of Suspended Load from River Bed}

The flux from river bed and bed-load layer into the flow generates suspended load transport $q_{s u}$. This is calculated by using two different user-selectable formulas: the 
Itakura and Kishi and the Lane-Kalinske formulas. In this study the Lane- Kalinske formula is used

$q_{s u}=5.55\left[\frac{1}{2} \frac{u_{*}}{w_{f}} \exp \left(-\frac{w_{f}}{u_{*}}\right)\right]^{1.61} w_{f} r_{b}$

Where $q_{s u}$ is suspended sediment upward from bed, $w_{f}$ is settling velocity by Rubey's equation (Rubey, 1933).

\section{3-5-4 Conservation of Suspended Load}

The conservation of suspended concentration load can be expressed as:

$\frac{\partial}{\partial t}\left(\frac{c h}{J}\right)+\frac{\partial}{\partial \xi}\left(\frac{u^{\xi} c h}{J}\right)+\frac{\partial}{\partial \eta}\left(\frac{u^{\eta} c h}{J}\right)=\frac{q_{s u}-w_{f} c_{b}}{J}$

Here $c$ is depth-averaged suspended concentration load, $q_{s u}$ is upward flux of suspended load from bed of the channel, $w_{f}$ is the settling velocity, and $c_{b}$ is the reference suspended concentration load near the bed and it is considered that suspended load has exponential vertical profile within the water column, thus:

$$
c_{b}=\frac{6 w_{f} c}{\kappa u_{*}\left(1-\exp \left(\frac{-6 w_{f}}{\kappa u_{*}}\right)\right)}
$$

\section{3-5-4 Conservation of Sediment load and Exchange with the Bed}

The conservation of sediment transport and its exchange with the bed is often called Exner equation. In a two-dimensional Cartesian coordinate system, it can be expressed as follow: 
$\frac{\partial}{\partial t}\left(c_{b} E_{b}\right)+(1-\lambda) \frac{\partial z_{b}}{\partial t}+\left[\frac{\partial q_{b}^{x}}{\partial x}+\frac{\partial q_{b}^{y}}{\partial y}+q_{s u}-w_{f} c_{b}\right]=0$

Where $z_{b}$ is bed elevation, $\lambda$ is void ratio of bed material, and $q_{b}{ }^{x}$ and $q_{b}{ }^{y}$ are bed-load per unit width in the direction of $x$ and $y$ respectively. In the model setting, if users select only bedload, $q_{s u}, w_{f}$ and $c_{b}$ are zero. The transformed equation for conservation of sediment transport in the MBFC system is:

When $E_{s d} \geq E_{b e} \frac{c_{b}}{1-\lambda}$,

$\frac{\partial}{\partial t}\left(\frac{c_{b} E_{b}}{J}\right)+(1-\lambda) \frac{\partial}{\partial t}\left(\frac{z_{b}}{J}\right)+\left[\frac{\partial}{\partial \xi}\left(\frac{q_{b}^{\xi}}{J}\right)+\frac{\partial}{\partial \eta}\left(\frac{q_{b}^{\eta}}{J}\right)+\frac{q_{s u}-w_{f} c_{b}}{J}\right]=0$

When $E_{s d} \leq E_{b e} \frac{c_{b}}{1-\lambda}$,

$\frac{\partial}{\partial t}\left(\frac{z_{b}}{J}\right)=0$

Equation 3-5-26

$q_{b}^{\xi}$ and $q_{b}{ }^{\eta}$ are bed-load transport in the direction of $\xi$ and $\eta$ respectively.

\section{3-5-5 Bank Erosion Model}

Bank erosion and bed alteration near banks caused by sediment transport is shown conceptually in Figure 3-5-5-1 and can be expressed:

$\operatorname{der}= \pm \frac{1}{1-\lambda} \frac{q_{b}^{\eta}}{\eta_{r} B_{h}} \Delta t+\frac{\Delta z}{\tan \theta_{c}}$

Equation 3-5-27 
Where der is amount of material due to bank erosion (positive for bank erosion), $\Delta z$ is the elevation change of the bed near bank due to bank erosion, $\theta_{c}$ is critical bank slope with horizontal plane. $B_{h}$ is height of the bank, and $\Delta t$ is time step of calculation.
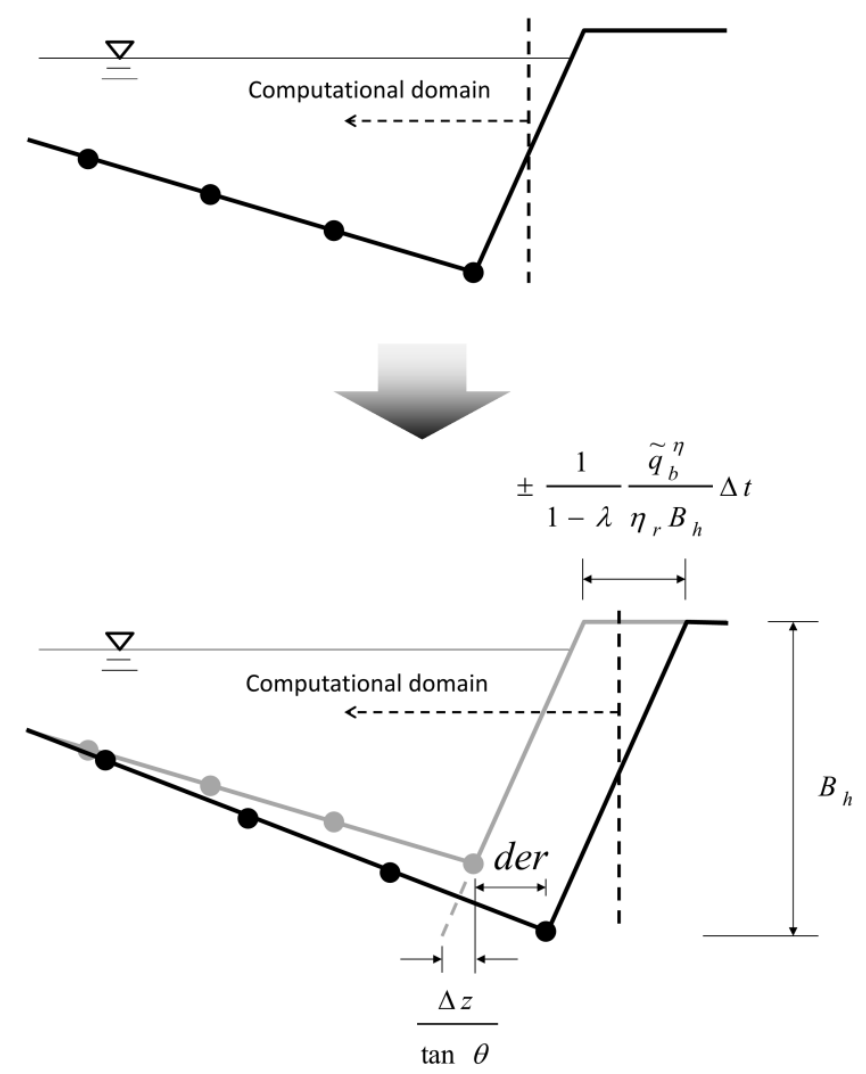

Figure 3-5-5-1 the bank erosion model conceptualized diagram (retrieved from iRIC Software, 2014)

Using the Exner equation (Equation 3-5-21, 3-5-22), it is possible to create an unrealistic bank slope that exceeds the angle of repose. To avoid this, users can define critical angle of repose. When the slope exceeds the critical value, the slope will collapse and correct the angle to the critical value by considering mass balance of the sediment (Figure 3-5-52). 
(1) Bed evolution is calculated by

the continuity equation of bed.

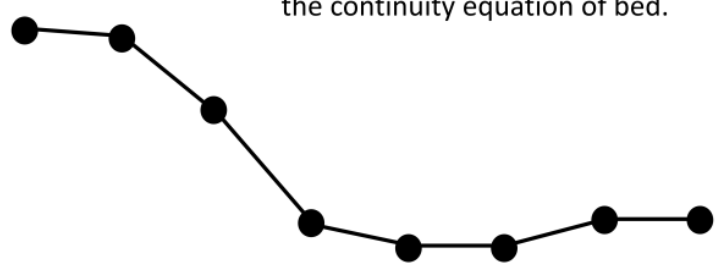

(2) If the angle of bed exceeds the critical angle for slope collapse,
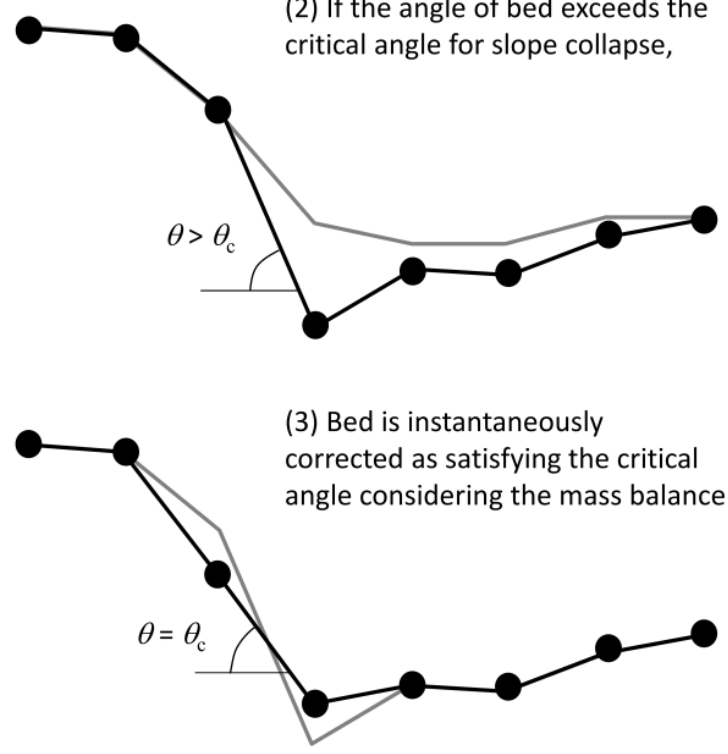

Figure 3-5-5-2 the conceptualized slope collapse model (retrieved from iRIC Software, 2014) 


\section{Chapter 4: Numerical Grid Size Selection}

\section{4-1 Introduction}

There are two main approaches to solving differential equations, analytical and numerical solution. An analytical solution may be exact or derived from a simplified version of the fundamental equations describing system. But analytical solutions become very complicated mathematically as they become more realistic, and many systems cannot be solved with analytical method. Overall, analytical solution to environmental fluid flow equations are limited in scope and apply only to simple geometries. As the computational ability of computers has evolved, numerical solution of equations became most widely approach for solving equations for realistic, complex geometries that cannot readily be treated using analytical approaches. A numerical solution is an approximation that becomes exact only in the unreachable limit of infinitely fine grid resolution, and many different techniques and methodologies have been developed for solving different problem and equations (Popescu. 2014).

The spatial and/or temporal computational domain has to be described for any numerical scheme. In numerical solutions, the domain is discretized into a number of smaller computational cells that cover the original domain. This processes is called grid or mesh grid generation, and a computational grid is the result (Versteeg and Malalasekera. 2007). The equations that describe the physical problem to be solved must be transformed from differential form to a set of algebraic (difference) equations that are applied to each grid cell of the computational domain; these are called the discretized equations and are solved simultaneously by computer (Figure 4-1-1), (Moukalled et al., 
2016; Ferziger and Peric, 2002). Depending on the numerical scheme and computational domain there are different methods of grid generation (figure 4-1-1). The process of solving equations of fluid mechanics by numerical schemes is called Computational Fluid Dynamics (CFD). On the other hand, a new generation of CFD has been developed called mesh free particle hydrodynamics, which solves equations without generating a computational grid. The method defines a domain as a number of moving particles in a Lagrangian system (Shakibaeinia and Jin, 2011). This approach is not applied here, because the Nays2DH model solves Eulerian, not Lagrangian equations.

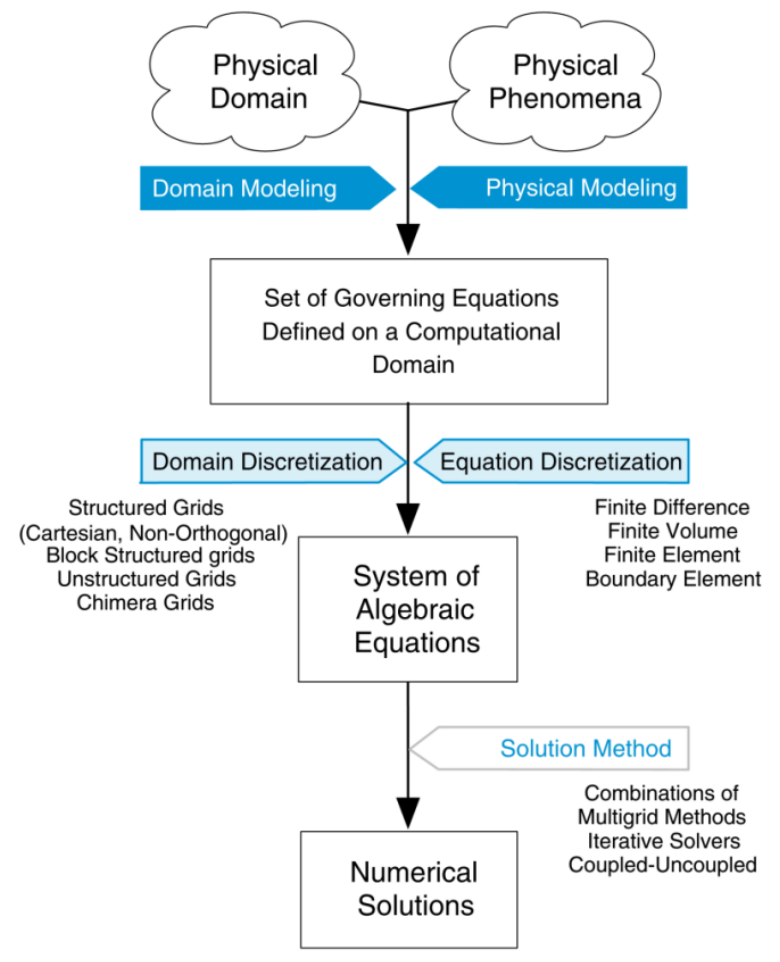

Figure 4-1-1 General outline of computational fluid dynamics. Adapted from (Moukalled et al., 2016) 


\section{4-2 Models for Grid Selection}

An important problem in any modeling application is the choice of grid resolution. The DEM for the reach of Sandy River modeled here (Figure 1-5-2) was used to create five different models to find the optimal spatial grid resolution; i.e., the best possible balance of computational time and process resolution. The computational grid domain, (Figure 4-2-1) $200 \mathrm{~m}$ wide and about $1800 \mathrm{~m}$ long, has a different resolution in each of the five models. Table 4-2-1 tabulates the resolution of each model. The models were run for the same flow and sediment properties, boundary conditions, and initial conditions, aside from grid resolution. The $\{x, y\}$ spacing were respectively, 1.5, 2, 3, 4, and $5 \mathrm{~m}$ for models \#1 to \#5. The models were run for a simple unsteady hydrograph for 10.2 hours that has peak flow $600 \mathrm{~m}^{3} / \mathrm{s}$ or $21188.8 \mathrm{cfs}$, lower than the five year return flow (Figure 2-2-2).

Table 4-2-1 Number of grids and grid resolution of each model

\begin{tabular}{lccccc}
\hline Models & x Space $[\mathrm{m}]$ & y Space $[\mathrm{m}]$ & No. x & No. y & No. Comp. Grid \\
\hline Model \#1 & 1.5 & 1.5 & 1181 & 133 & 157073 \\
Model \#2 & 2 & 2 & 886 & 101 & 89486 \\
Model \#3 & 3 & 3 & 591 & 67 & 39597 \\
Model \#4 & 4 & 4 & 443 & 51 & 22593 \\
Model \#5 & 5 & 5 & 335 & 41 & 14555 \\
\hline
\end{tabular}




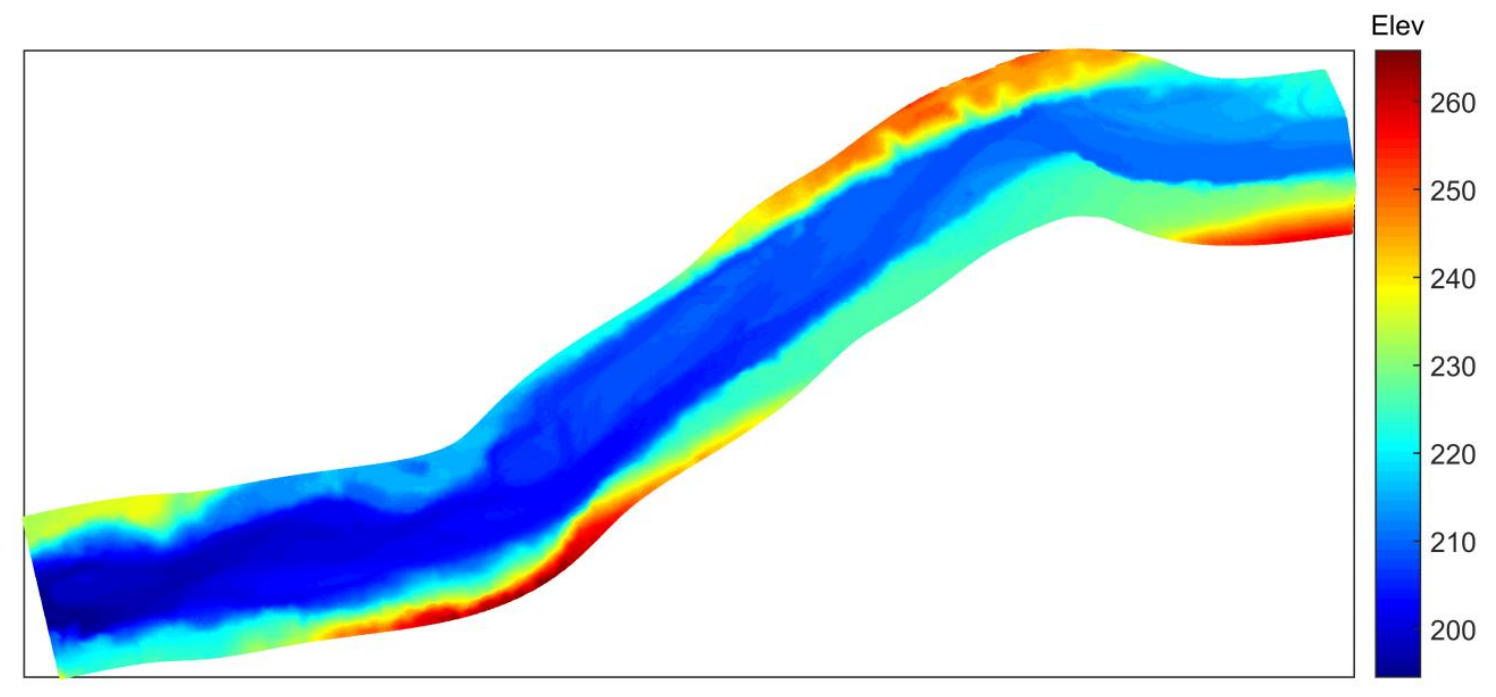

Figure 4-2-1 the computational domain of the five models

Manning's $n$ is defined by three polygons two for floodplains, riparian area and the third for the river channel. Manning's was taken as 0.1 for floodplains and 0.045 for the river channel (Figure 4-2-3) selected based on (Coon. 1998). A uniform Sediment particles diameter of $45 \mathrm{~mm}$ was selected because the Sandy River is a coarse-gravel river. Ashida and Michiue formula is used for bed-load formula, along with the bank erosion model. The zero equation model was selected for the turbulence closure. The downstream flow boundary condition is uniform flow and takes its slope from channel slope at that section. The upstream velocity is uniform and slope is taken from the bed elevation. Sediment transport and bed deformation begin from the initiation of the model running. The time step of calculation was 0.01 second (which the stability criterion for all grids), the time step for visualization result was 100 seconds, and the maximum number of iterations for water surface computation was 10 . 


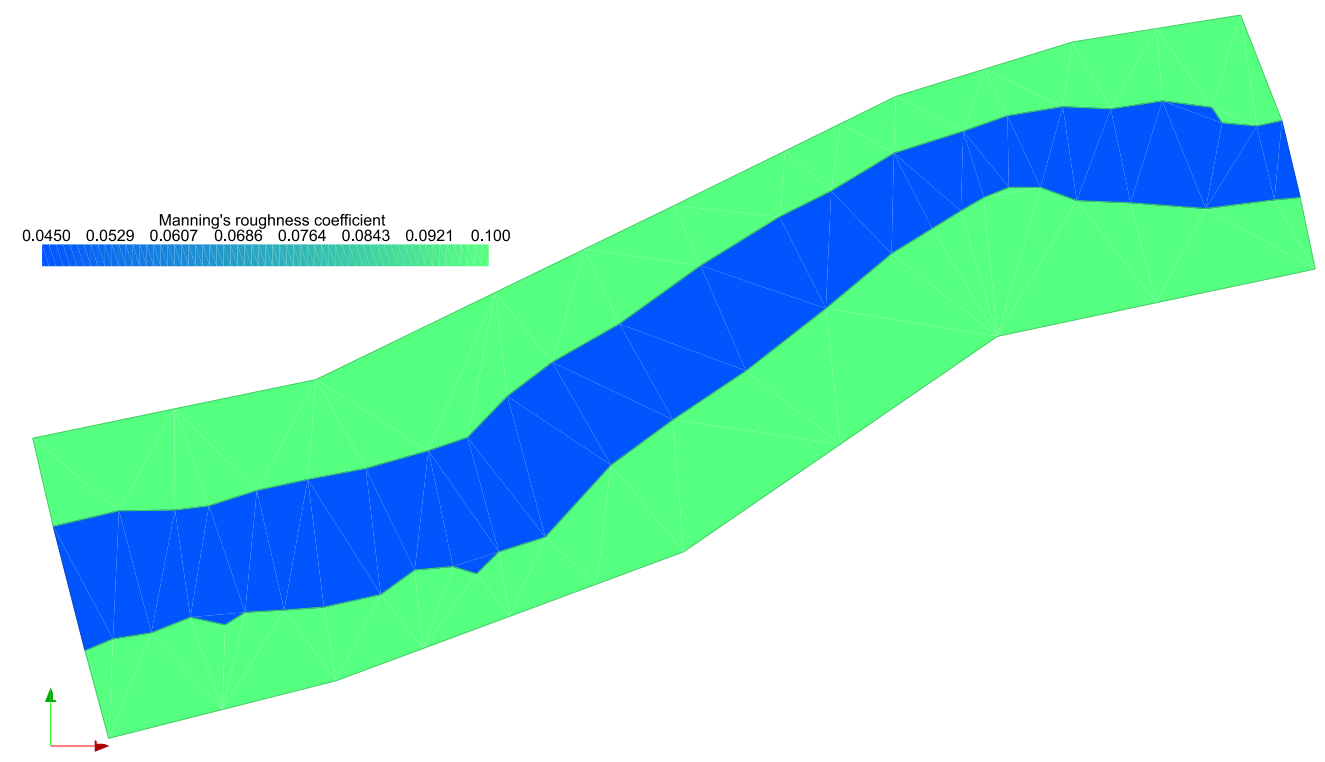

Figure 4-2-2 Manning's coefficient in the river channel and riparian area

\section{4-3 Grid Selection Models’ Result}

After running the model for all grid resolutions, the model results were analyze during peak flow and at the end of the event. The depth of water at peak flow and at the end of the event is shown in Figure 4-3-1. The change in bathymetry at peak flow and at the end of the event is shown in Figure 4-3-2. These results are complex and do not, by themselves, provide an obvious way to choose grid resolution. Therefore, an integral measure was selected. 

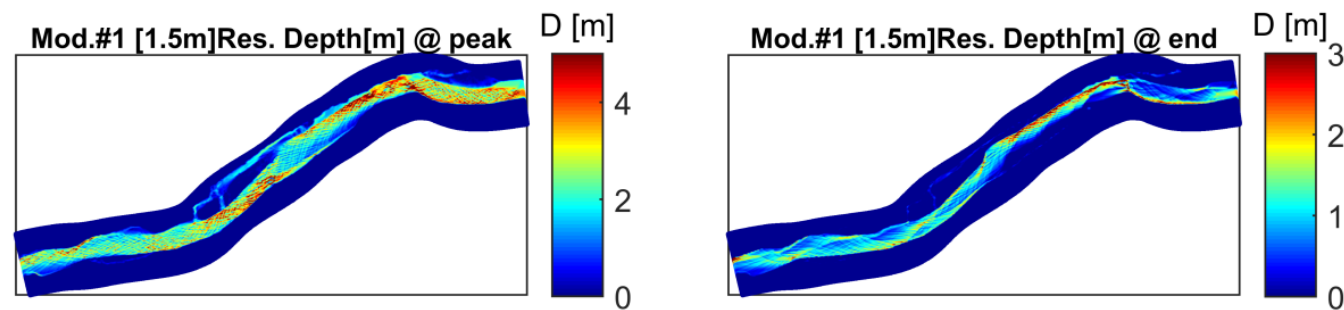

Mod.\#2 [2m]Res. Depth[m] @ peak
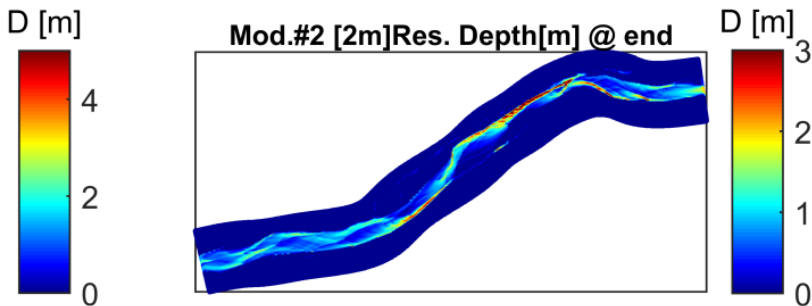

Mod.\#3 [3m]Res. Depth[m] @ peak
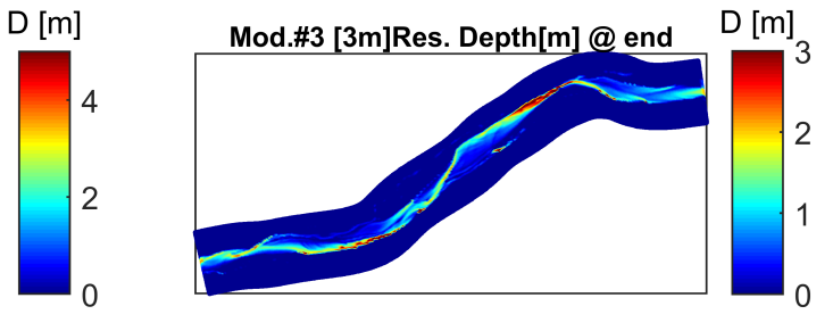

Mod.\#4 [4m]Res. Depth[m] @ peak

$D[m]$
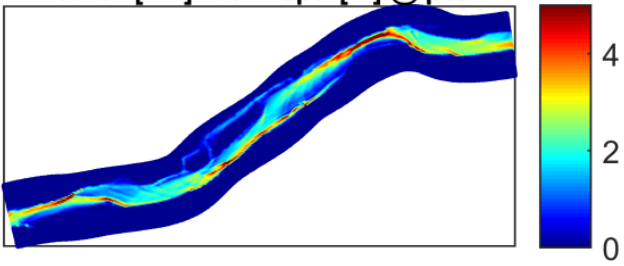

Mod.\#4 [4m]Res. Depth[m] @ end

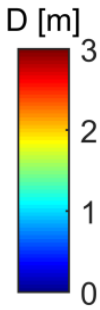

Mod.\#5 [5m]Res. Depth[m] @ peak

$\mathrm{D}[\mathrm{m}]$
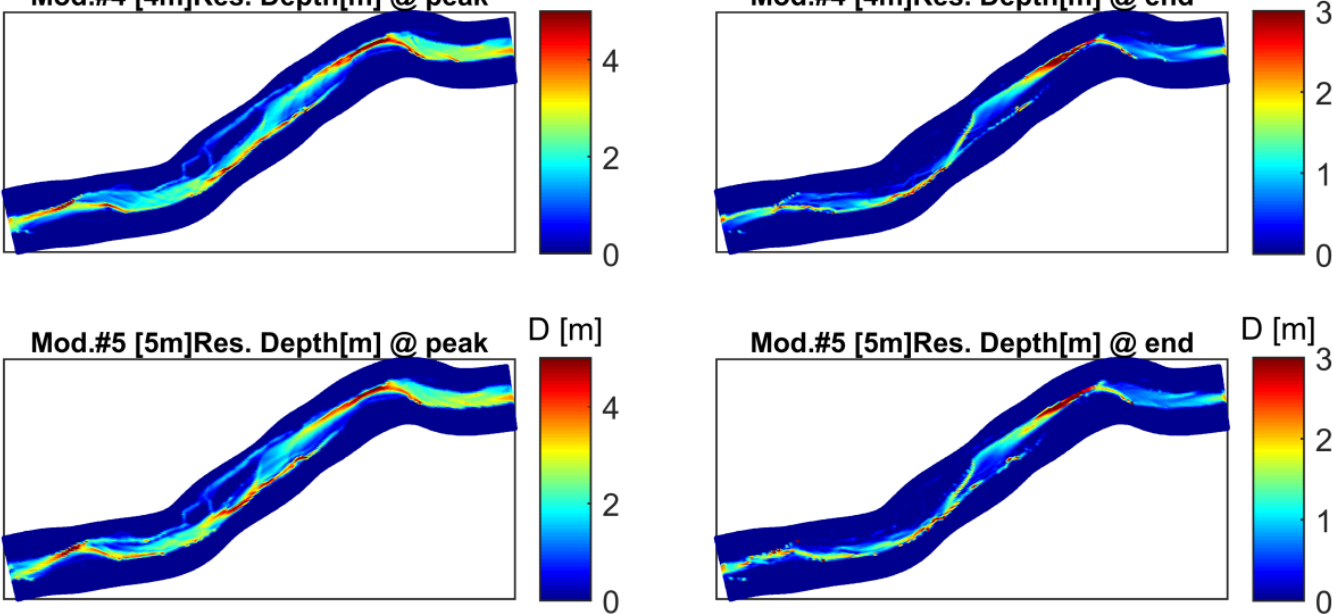

Figure 4-3-1 Depth of water at the time of peak flow and at the end of the event 

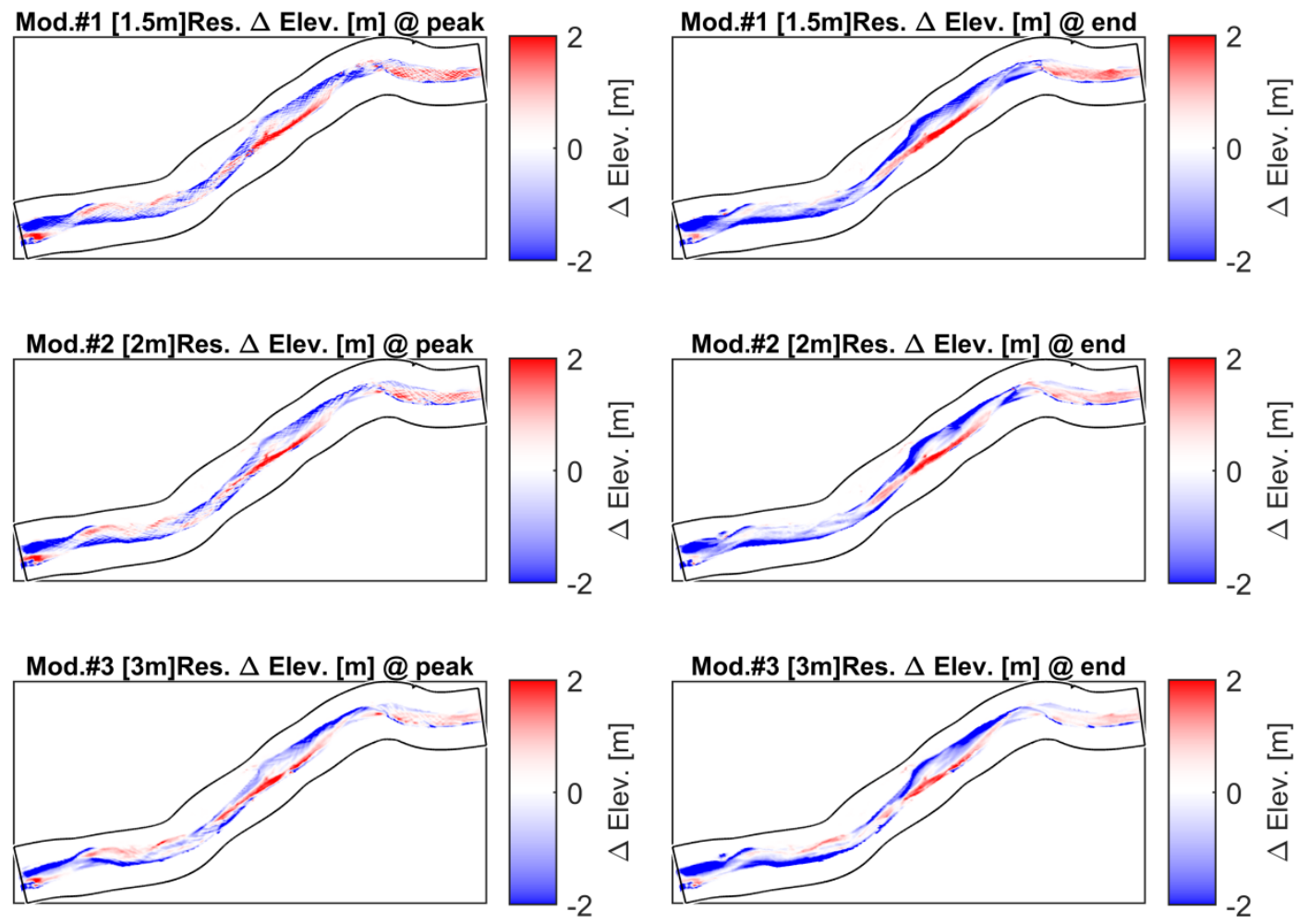

Mod.\#3 [3m]Res. $\Delta$ Elev. [m] @ end
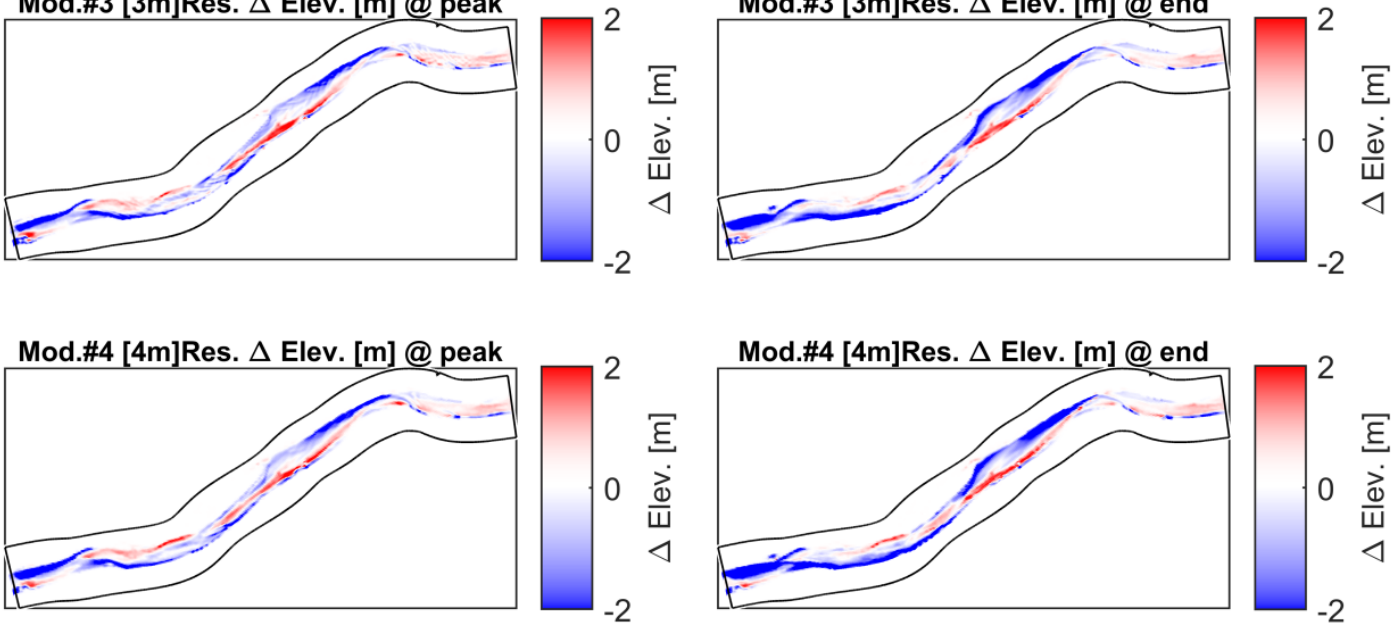

Mod.\#4 [4m]Res. $\Delta$ Elev. [m] @ end
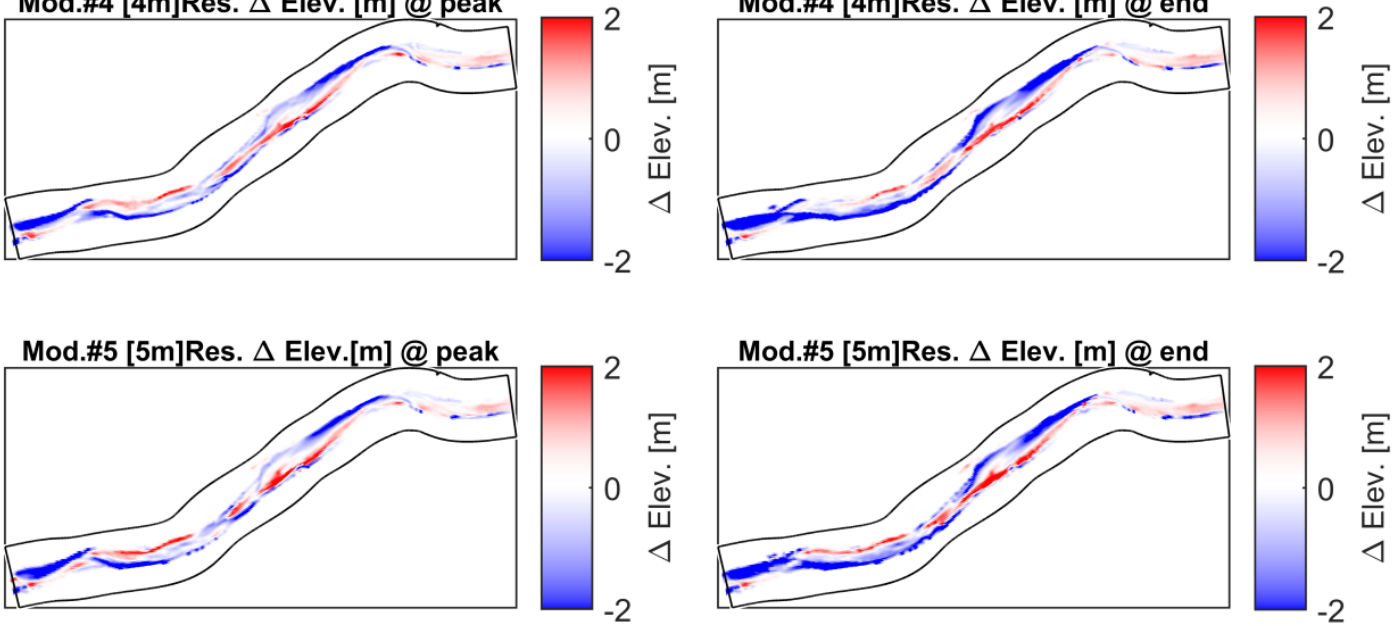

Mod.\#5 [5m]Res. $\Delta$ Elev. $[\mathrm{m}] @$ end

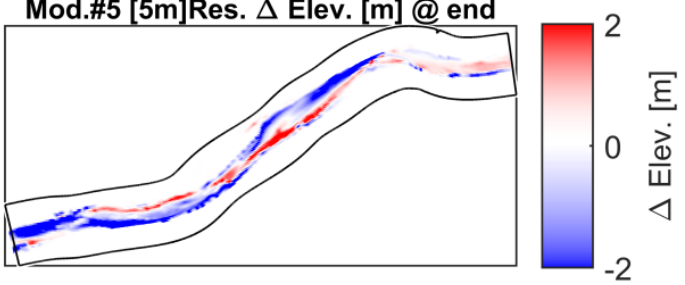

Figure 4-3-2 Alteration of bathymetry at the time of peak flow and at the end of the event 
The distribution of bed elevation change for all models and for both flow situations (peak flow and the end of the event) was used as an integral measure of the model behavior (Figure 4-3-3). The histograms shown in Figure 4-3-3 were fitted to the normal distribution, with the assumption that minimum erosion and deposition changes are $2 \mathrm{~cm}$. The grid selection criterion was convergence; i.e., the coarsest grid was selected that was consistent with the idea that grid resolution should be refined until the results remain relatively stable. 

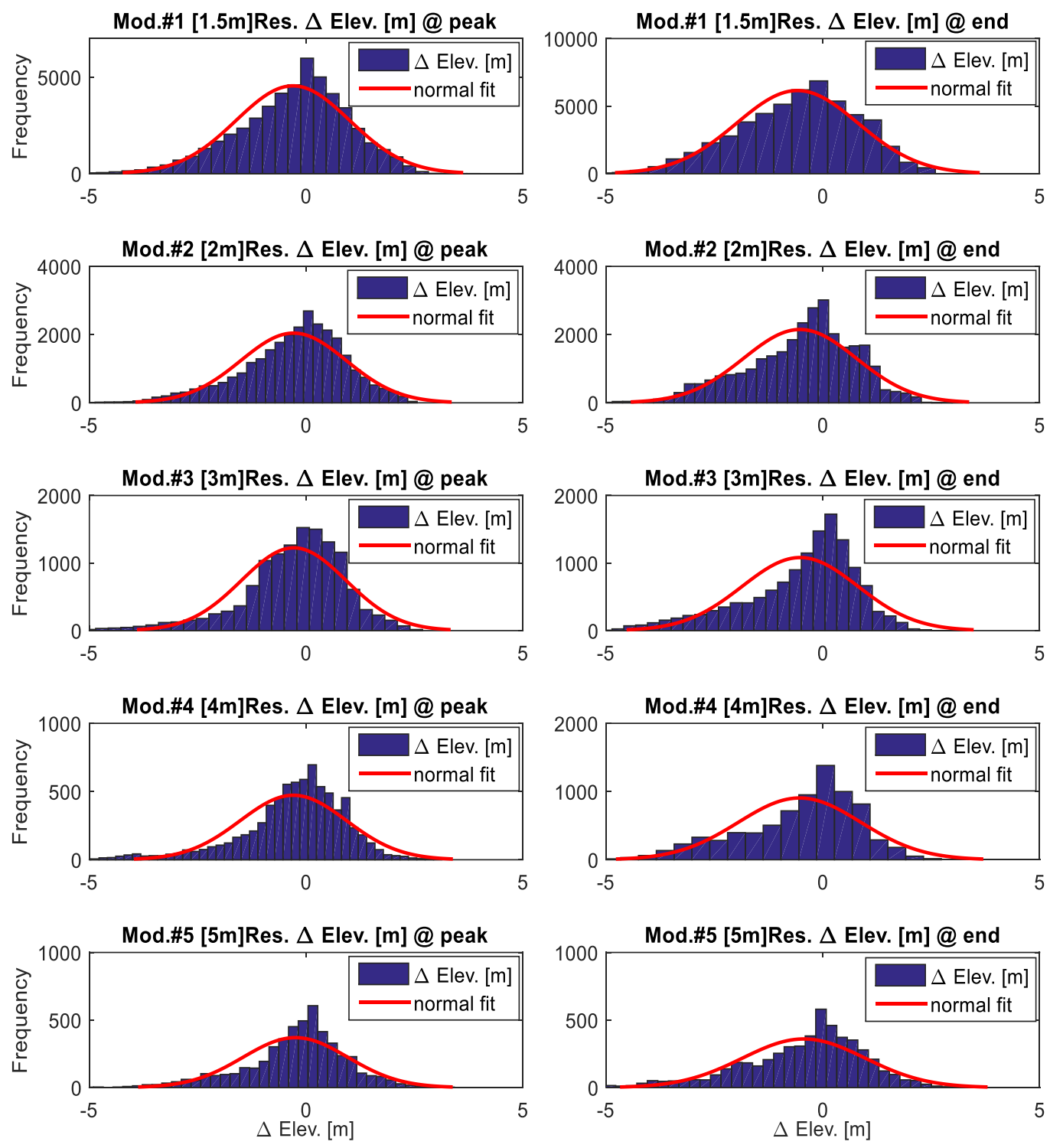

Figure 4-3-3 Histograms of distribution the bed elevation alteration for different model and flow situation (peak flow and the end of the event)

Figures 4-3-1 and 4-3-2 show an overall general view of the processes but the detail of depth of water, evolution of the bed level or any other hydraulic and geomorphic properties of the study area should also be presented for sections typical of the system. 
For this purpose four representative cross-sections are chosen (Figure 4-3-4) within the study area (Table 4-3-1)

Table 4-3-1 the location of the cross-sections on the grids of the models

\begin{tabular}{lcccccc} 
& & \multicolumn{5}{c}{ Grid Resolution [m] } \\
\cline { 3 - 6 } & & 1.5 & 2 & 3 & 4 & 5 \\
\hline Cross-sec No. & Distance from U/S & \multicolumn{5}{c}{ Grid No. (i) from U/S } \\
\hline 1 & 300 & 200 & 150 & 100 & 75 & 60 \\
2 & 600 & 400 & 300 & 200 & 150 & 120 \\
3 & 900 & 600 & 450 & 300 & 225 & 180 \\
4 & 1200 & 800 & 600 & 400 & 300 & 240 \\
\hline
\end{tabular}

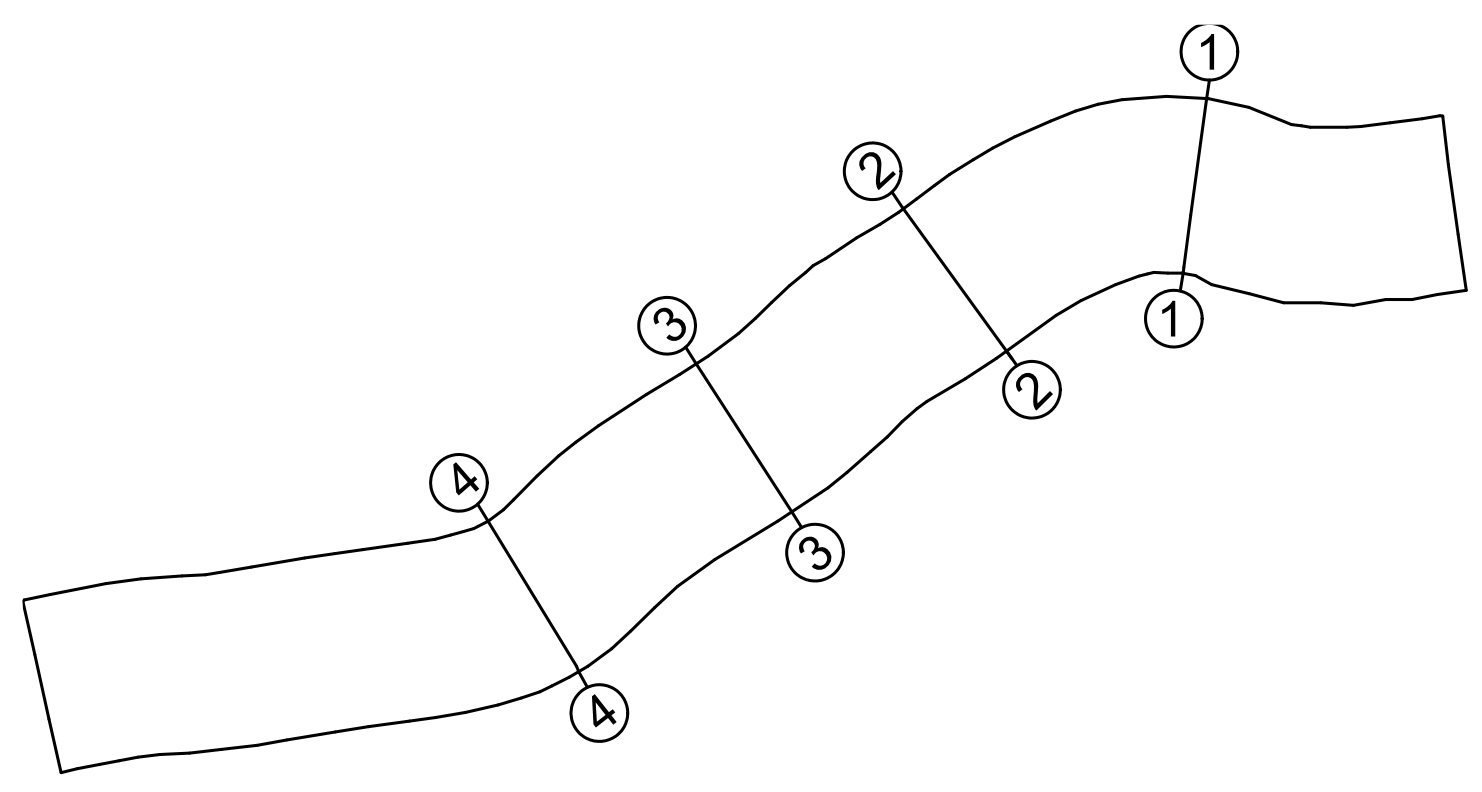

Figure 4-3-4 Locations of the cross-sections used for convergence evaluation

Reach cross-sections are taking from right to left. Figures 4-3-5, to 4-3-9 show the crosssectional evolutions of the models with $1.5,2,3,4$, and $5 \mathrm{~m}$ resolution, respectively. The notations on the figures are: BE for bed elevation, WSE for water surface elevation, IniE 
for initial bed elevation and XS cross-section. As shown in the figures, WSE and BE are plotted for both flow situations (peak and end of the event).
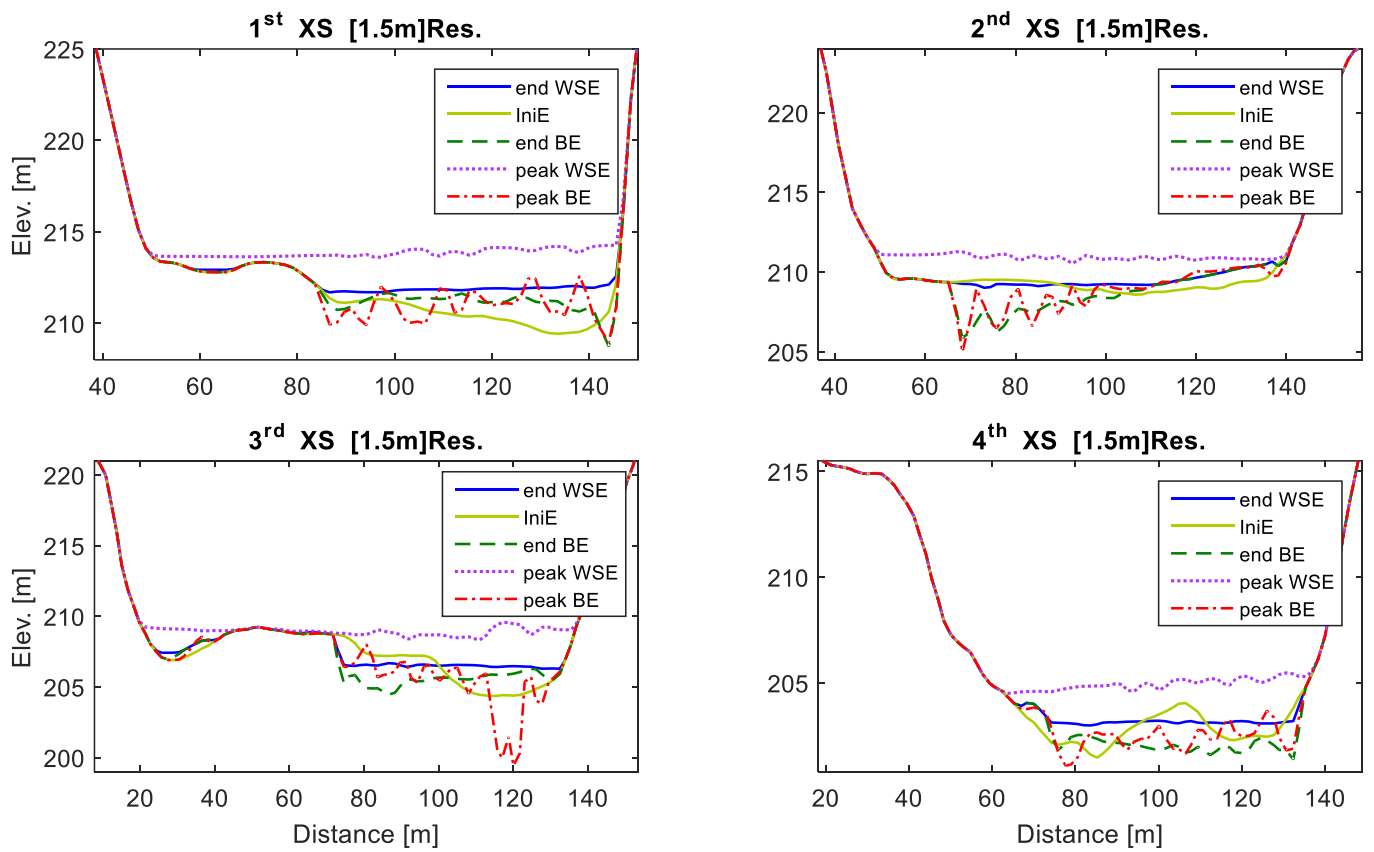

Figure 4-3-5 1.5 m resolution grid cross-sections looking upstream of initial bed elevation, water surface elevation, and evolution of bed elevation at peak flow and the end of the event flow condition. Crosssection locations are shown in Figure 4-3-4

At the end of the event for the $1.5 \mathrm{~m}$ grid size, the bed elevation (Figure 4-3-5) of the cross-sections has changed differently among cross-sections. The first cross-section is occupied by deposition except near the left bank location; the second and third crosssections have both erosion and deposition but the fourth one is dominated by erosion. In the peak flow condition, the bed evolution is highly irregular especially in second and third cross-sections. At the end of the event of the $2 \mathrm{~m}$ grid resolution, (Figure 4-3-6) the situation similar to $1.5 \mathrm{~m}$ grid resolution result but the bed elevation at the peak flow is not undulating as in the $1.5 \mathrm{~m}$ case, even considering the somewhat lower resolution. 
$1^{\text {st }}$ XS [2m]Res.
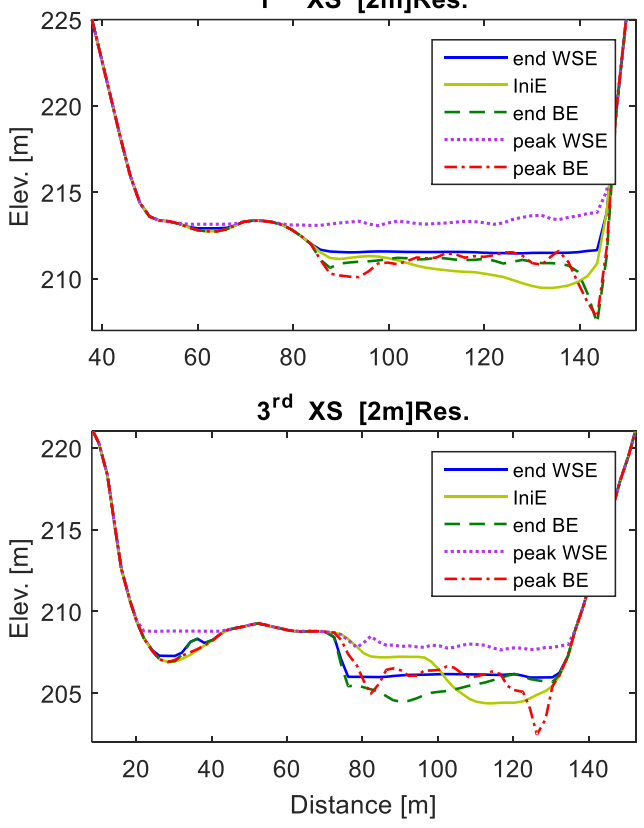

$2^{\text {nd }} \times S$ [2m]Res.
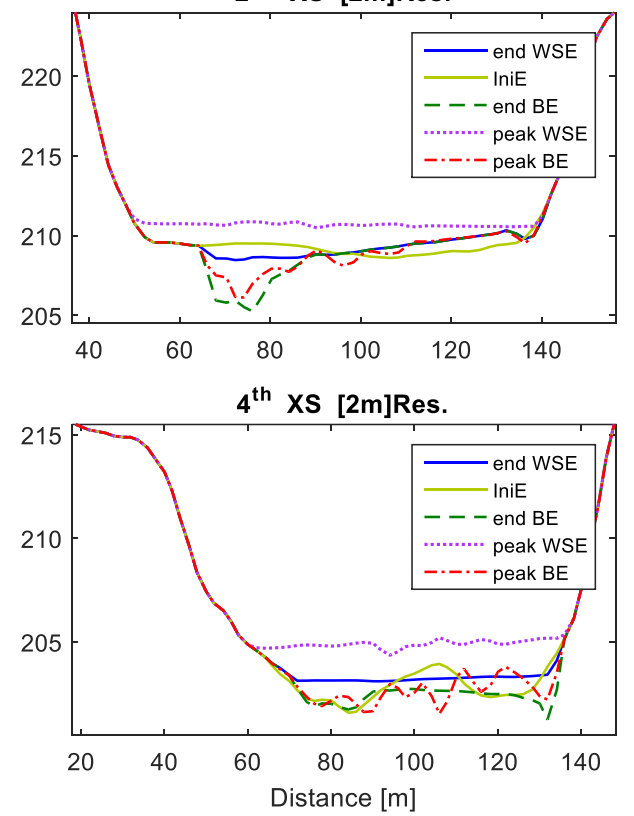

Figure 4-3-6 As in Figure 4-3-5, but for the $2 \mathrm{~m}$ grid resolution model
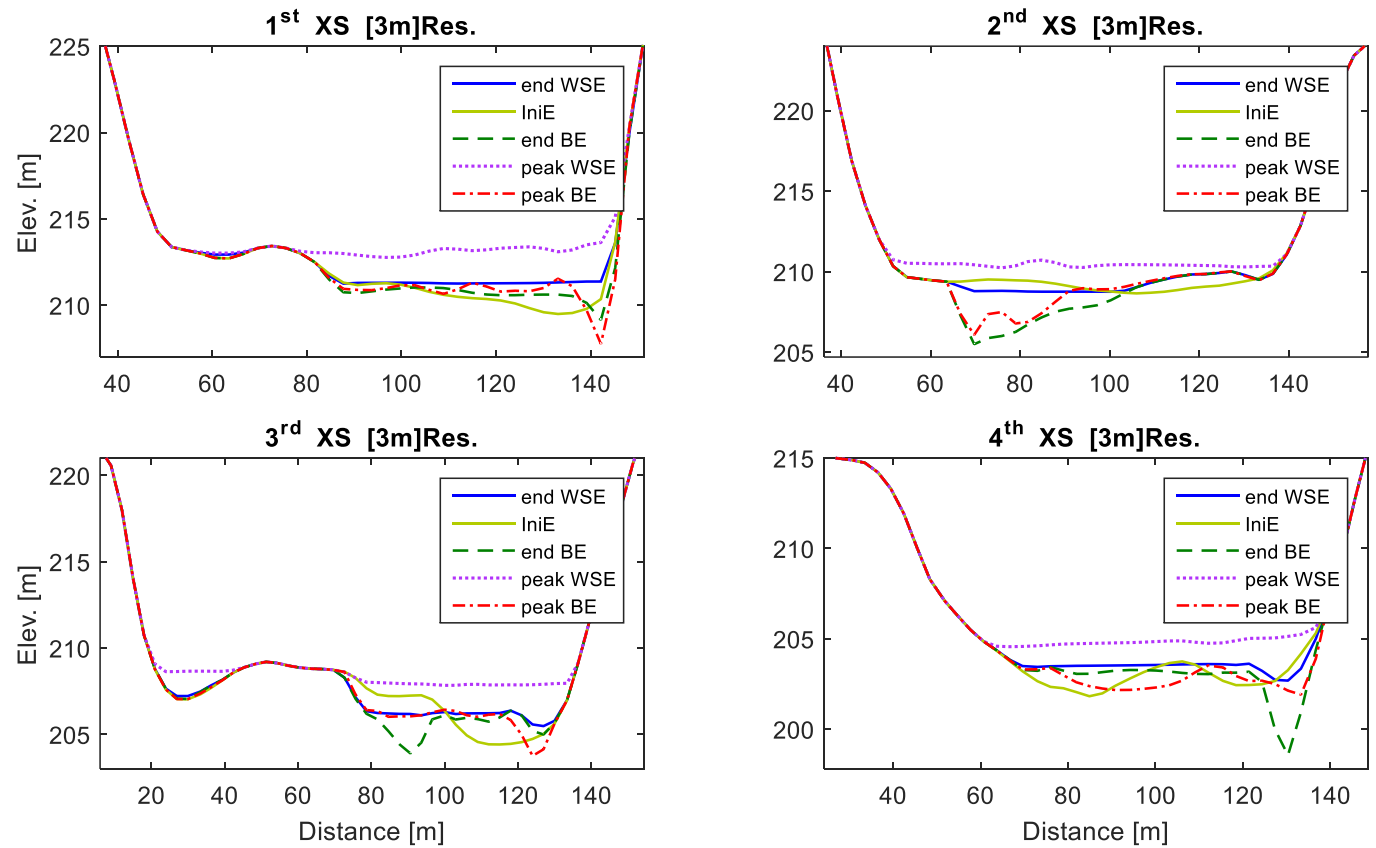

Figure 4-3-7 As in Figure 4-3-5, but for the $3 \mathrm{~m}$ grid resolution model 

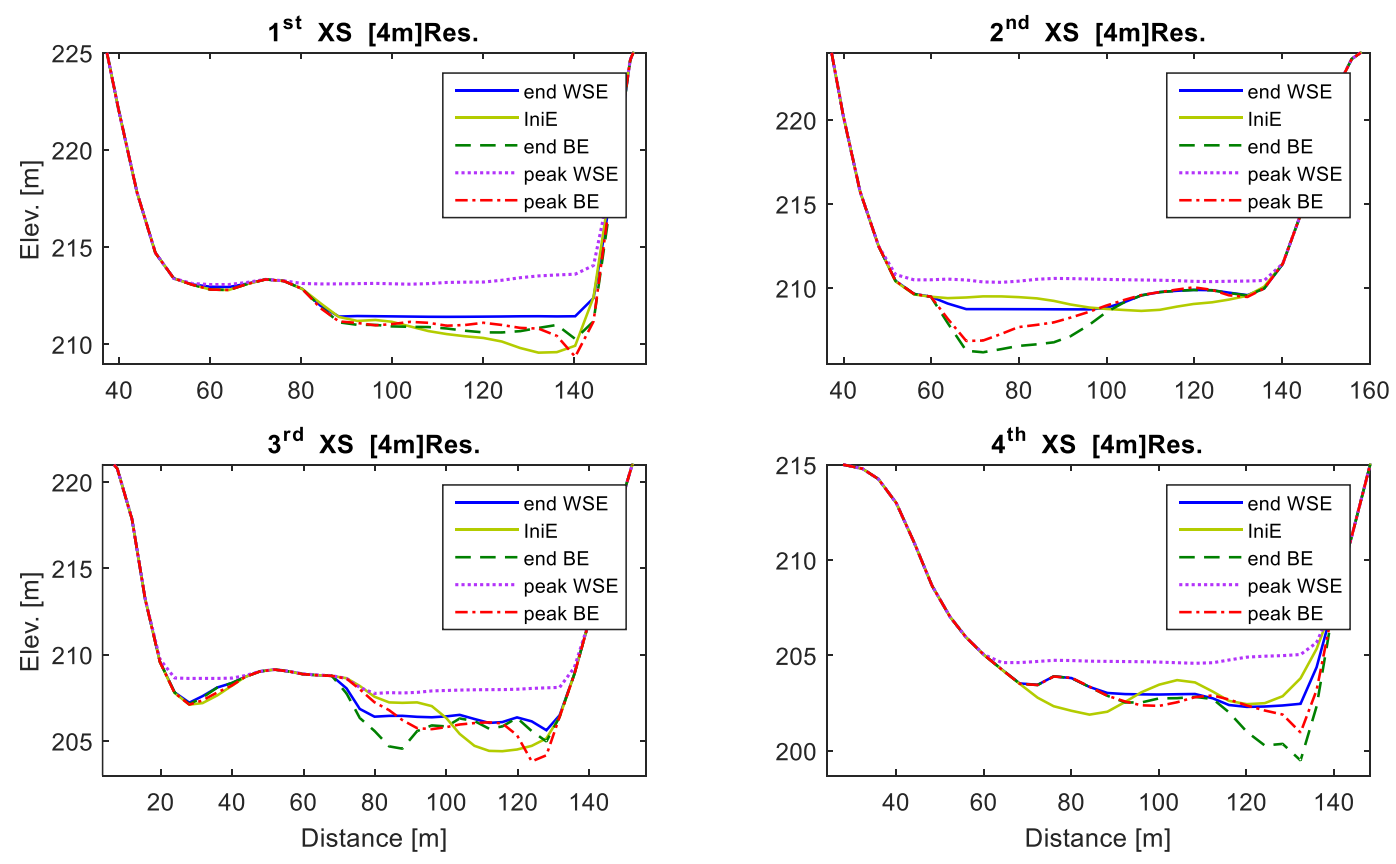

Figure 4-3-8 As in Figure 4-3-5, but for the $4 \mathrm{~m}$ grid resolution model

$1^{\text {st }}$ XS [5m]Res.
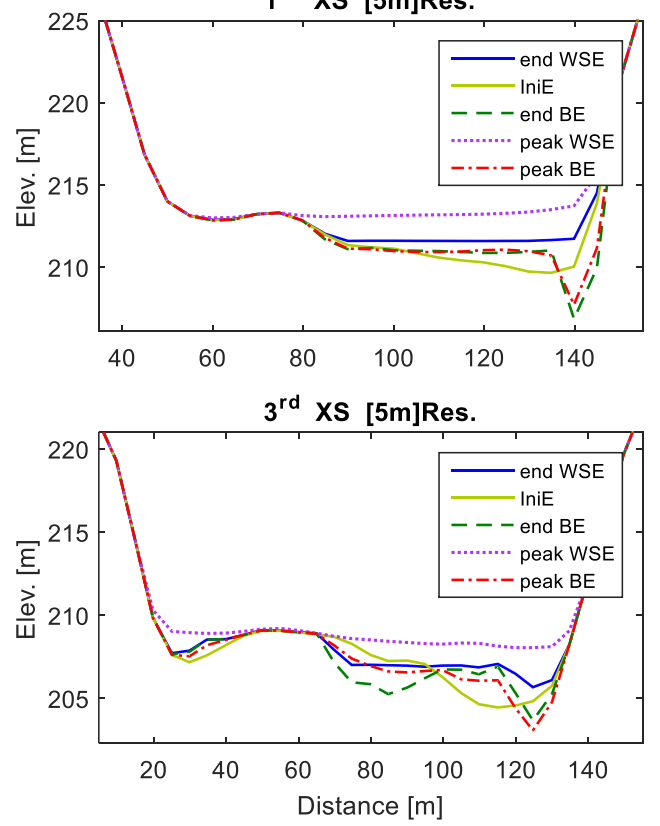

$2^{\text {nd }}$ XS $[5 \mathrm{~m}]$ Res.

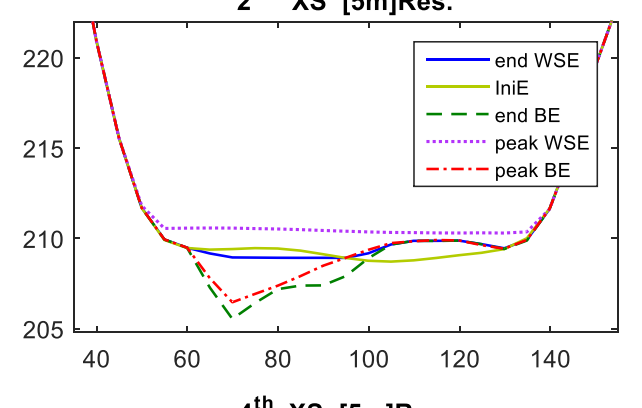

$4^{\text {th }}$ XS $[5 \mathrm{~m}]$ Res.

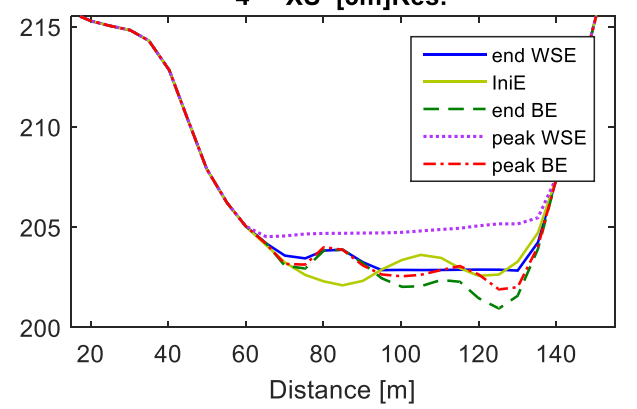

Figure 4-3-9 As in Figure 4-3-5, but for the $5 \mathrm{~m}$ grid resolution model 
The first three cross-sections of end of the event of the $3 \mathrm{~m}$ grid resolution (Figure 4-3-7) resemble the $2 \mathrm{~m}$ grid resolution. But the fourth cross-section has more erosion near the right bank. In the peak flow condition, the erosion and deposition of all sections in average are similar to the $2 \mathrm{~m}$ grid. In the grid resolution $4 \mathrm{~m}$ (Figure 4-3-8), the bed elevation change for both flow situations is quite similar to the $3 \mathrm{~m}$ grid case. The general shape and direction of bed elevation alteration for the $5 \mathrm{~m}$ grid resolution cross-sections (Figure 4-3-9) are similar to those for the $4 \mathrm{~m}$ grid case but the erosion is a little deeper, and the bed topography is considerably smoother.

\section{4-4 Grid Resolution Selection}

Selection of grid resolution for a numerical model is always a complicated decision because several factors need to be considered: the scale of processes in the physical environment, convergence of the solution as the grid is refined, the numerical scheme, the scale of the model, computational time, and available computer resources. In this study, the grid size was chosen in a simple manner, based on average of the elevation change over (Figure 4-4-1). As is obvious in the Figure 4-3-1, the highest elevation change occurs with the $1.5 \mathrm{~m}$ grid resolution, perhaps because it can capture the initial topography better and cover local altered geometry. The $1.5 \mathrm{~m}$ grid resolution does not choose because the $45 \mathrm{~mm}$ size particle is relatively large with compared grid resolution. Because of discontinuity of the mesh grid, $1.5 \mathrm{~m}$ may not be sufficient for movement of $45 \mathrm{~mm}$ sediment size. Also, the $1.5 \mathrm{~m}$ needs very long time for run the model (table 4-41). The lowest elevation alteration occurs with the $5 \mathrm{~m}$ resolution. The result for the 2,3 , and $4 \mathrm{~m}$ grid are similar (located almost in a straight line in the Figure 4-4-1). Table 4-4-1 
tabulates the average elevation change for each grid size with $5 \%$ and $95 \%$ confidence intervals.

Table 4-4-1 shows that the model is very computationally intensive due in part to the small time step, and computation time increases with the square of grid size. Thus, realistic model runs are time consuming. The $4 \mathrm{~m}$ grid was selected accordingly, as the best trade-off between resolution and computational feasibility. The models have run by Lenovo computer supplied by $2.6 \mathrm{GHz}$ quad-core with Intel Core i7 processor, and 16 GB of memory.
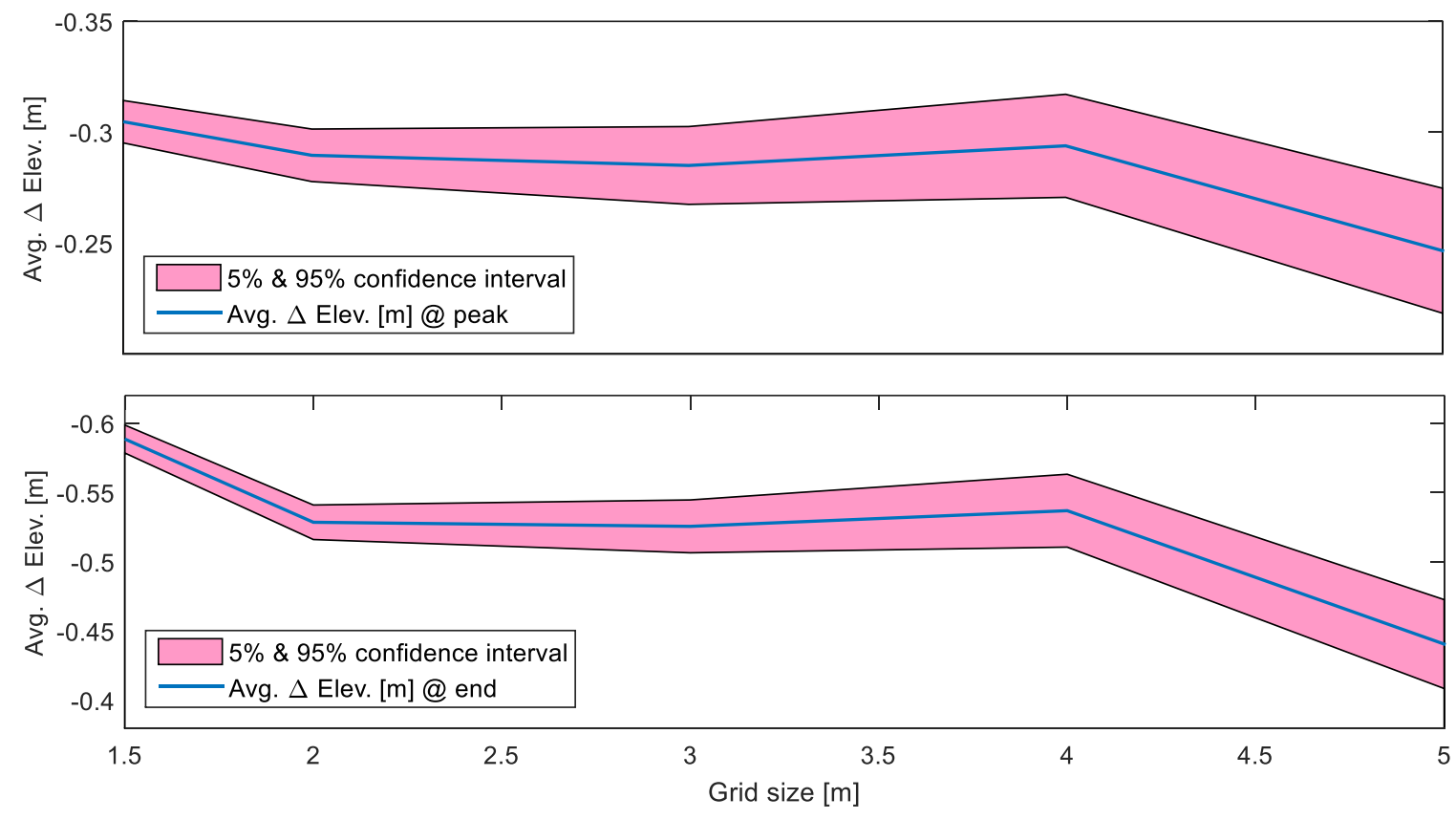

Figure 4-4-1 The average elevation change of the entire domain for all grid sizes 
Table 4-4-1 The requested time and average, 5\% and 95\% confidence interval of elevation change of the study domain of all models

\begin{tabular}{cccccccc}
\hline & Time to & \multicolumn{3}{c}{$\Delta$ Elev. at peak of event } & \multicolumn{3}{c}{$\Delta$ Elev. at end of event } \\
\cline { 3 - 8 } Res. & run [Hr] & Avg. & 5\% Conf. & 95\% Conf. & Avg. & 5\% Conf. & 95\% Conf. \\
\hline 1.5 & 30.33 & -0.305 & -0.314 & -0.295 & -0.589 & -0.599 & -0.578 \\
2 & 18.3 & -0.290 & -0.301 & -0.278 & -0.529 & -0.541 & -0.516 \\
3 & 7.17 & -0.285 & -0.303 & -0.267 & -0.526 & -0.545 & -0.507 \\
4 & 4.03 & -0.294 & -0.317 & -0.271 & -0.537 & -0.563 & -0.511 \\
5 & 2.24 & -0.247 & -0.275 & -0.218 & -0.441 & -0.473 & -0.409 \\
\hline
\end{tabular}

\section{4-5 Model Specification for Extreme Events}

The model that is used for running flood hydrograph simulations is $\mathrm{Nays} 2 \mathrm{DH}$, and its formulation and implementation were discussed in Chapter 3. To summarize, the grid resolution for all models is $4 \mathrm{~m}$, and the domain size is $250 \mathrm{~m}$ width (to ensure that the flow does not pass through the boundary of the computational domain for extreme events) and about $1800 \mathrm{~m}$ length. There are 63 computational mesh cells in the lateral direction and 438 in the longitudinal direction, for a total of 27594 cells. The computational cell roughness (Manning's $n$ ) is defined as shown in the Figure 4-2-2, and the fixed and movable bed portions of the domain are shown in Figure 4-5-1. The numerical approach is the CIP scheme, and the model is used to calculate for both bedload and suspended-load. The Ashida and Michiue formula is used for calculating the bed-load transport; while the Lane and Kalinske formula is applied to estimate the upward flux of suspended sediment from the bed of the river and for implementation of the bank erosion model. 
As noted in the previous sections, the downstream boundary condition is uniform water surface and its slope is taken from bed topography. The velocity at upstream boundary is uniform; the slope of uniform flow take from bed topography and the extreme hydrographs apply on the upstream face of the domain. The computational time step is 0.01 second and the visualization time is 120 seconds. The sediment material is assumed to be uniform with a size of $45 \mathrm{~mm}$ size.

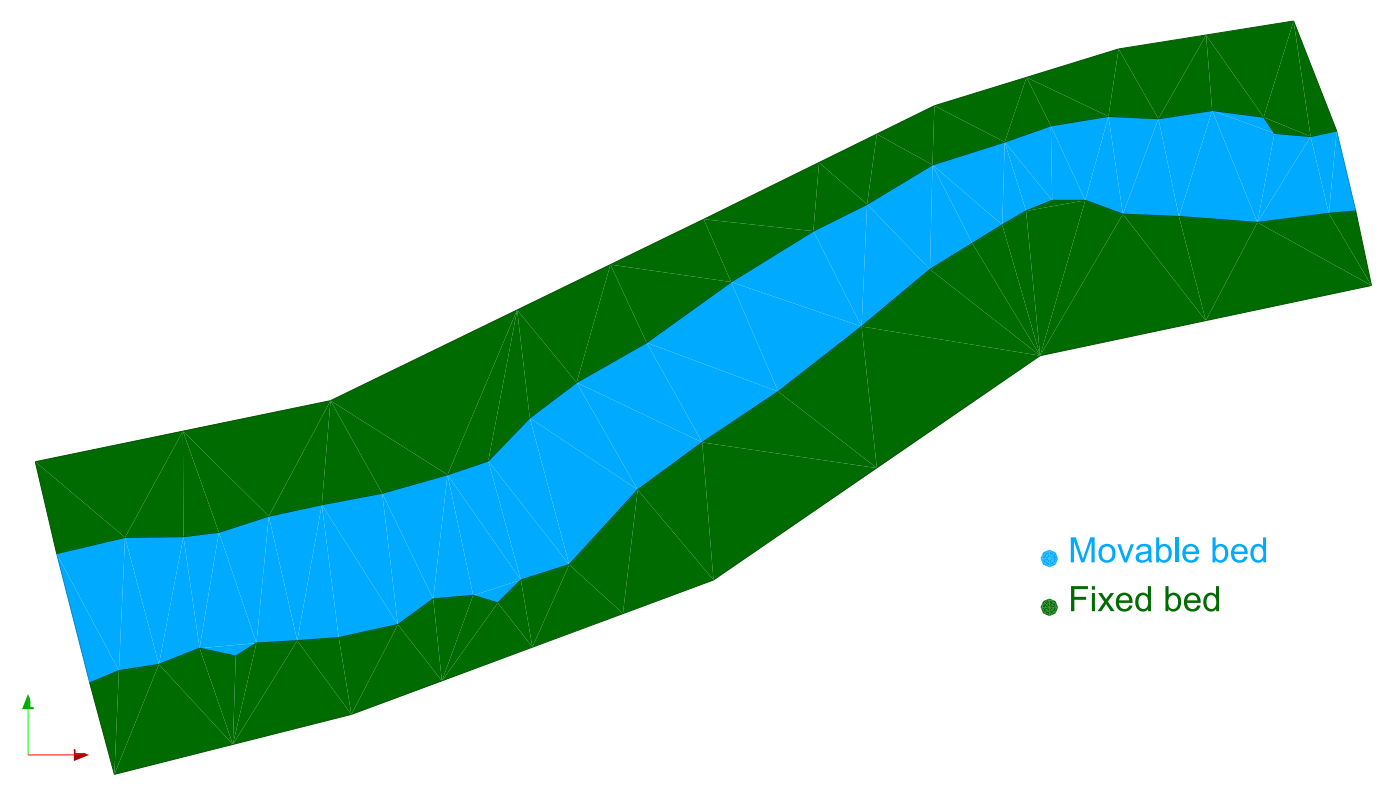

Figure 4-5-1 Movable and fixable bed of the domain. 


\section{Chapter 5: The Result}

\section{5-1 Introduction}

The basic idea supporting geomorphological science is that the earth's topographical formation is result of the alteration by geophysical processes acting over time on the earth's surface. The question as to whether channels and valleys precede the presence of flow, or are the consequence of flow passing flow them, can be answered by fluvial geomorphology (Costa and O'Connor, 1995). The word "fluvial" comes from the Latin fluvius that means river (Charlton, 2008). In the fluvial systems, geomorphology has been defined in two different ways: a) as the interaction between river forming forces acting on the river system on different of time and space scales (Charlton, 2008), and b) the amount of sediment transport that alter the vertical form of a river channel over a defined time scale (Costa and O'Connor, 1995). Except in supply limited streams, the amount of sediment movement is a direct function of the amount of flow passing through the specific river channel, because large flows usually creates higher force acting in the river bed and banks.

The river ecosystem is a challenging field for investigation, because river systems are influenced by nonlinear phenomena like sediment transport, bedform and sand bar formation, and meandering. Comprehending river planform and bed deformation is crucial for management urbanization and monitoring ecosystem because it affects entire dynamics of the system (Iwasaki et al., 2016). High flood events are usually the most influential factor that alter the river bed and bank geometry, and cause rapid meandering (Asahi et al., 2013). The Sandy River is believed to be typical in this regard. 
Therefore, in this study, we deal with how the big flood events will alter the river geometry.

\section{5-2 The Models Result}

In Chapter 2, six different extreme event hydrographs have been derived and the Nays2DH model was run for those six flood scenarios. Each hydrograph represents an independent, extreme event. The hydrographs approximate the 2-year, 10-year, 25-year, 50-year, 75-year, and 100-year return period hydrographs. The result of each model is analyzed for two flow conditions: peak flow and the end of the event. The peak flow is important because at peak flow, the system faces the maximum force that can alter the geometry and characteristics of the system. At the end of the event, the system has returned to the original flow condition, and the evolution of the system caused by the event can be determined. Two methods have been used to visualize the result: a) eight evenly spaced cross-sections are examined, and b) the computational domain is viewed from above. The cross-sections are distributed from upstream to the downstream over the computational domain and oriented normal to the channel (Figure 5-2-1). The spatial distribution distance of cross-sections from upstream to downstream is listed in the Table 5-2-1. The depth of water and changes in flow velocity between the two flow situations show the hydro-geomorphic evolution for each event (Figure 5-2-2 and Figure 5-2-3).

Table 5-2-1 The spatial distribution of the cross-sections from upstream

\begin{tabular}{lcccccccc}
\hline Cross-sections & A & B & C & D & E & F & G & H \\
Distance from U/S [m] & 200 & 400 & 600 & 800 & 1000 & 1200 & 1400 & 1600 \\
\hline
\end{tabular}




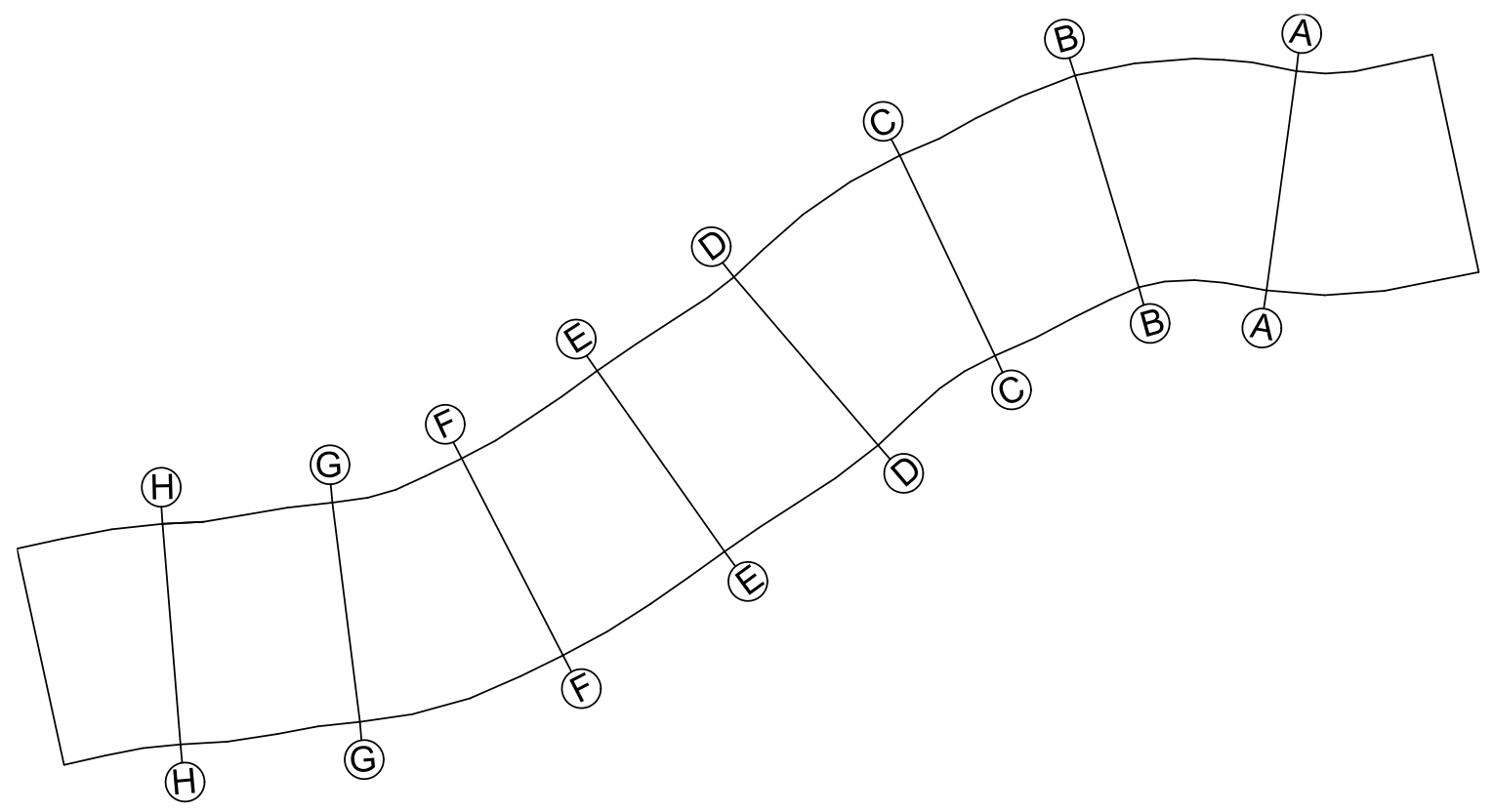

Figure 5-2-1 The spatial distribution of the cross-sections over the computational domain.

Figures 5-2-2 and 5-2-3 show the changes due to the high flow during the extreme events, especially for the in 75 and 100 year return periods. It is clear that the high flow have moved the channel from left to right (looking downstream) in the central portion of the river reach (end of the event 2 year and end of the event of the 100 year). The changes in flow direction take place due to erosion and deposition of the river channel (Wu, 2007) which is caused by the flows. Thus, erosion and deposition of the river reach demonstrate hydro-geomorphic response of the river reach to flood events. 

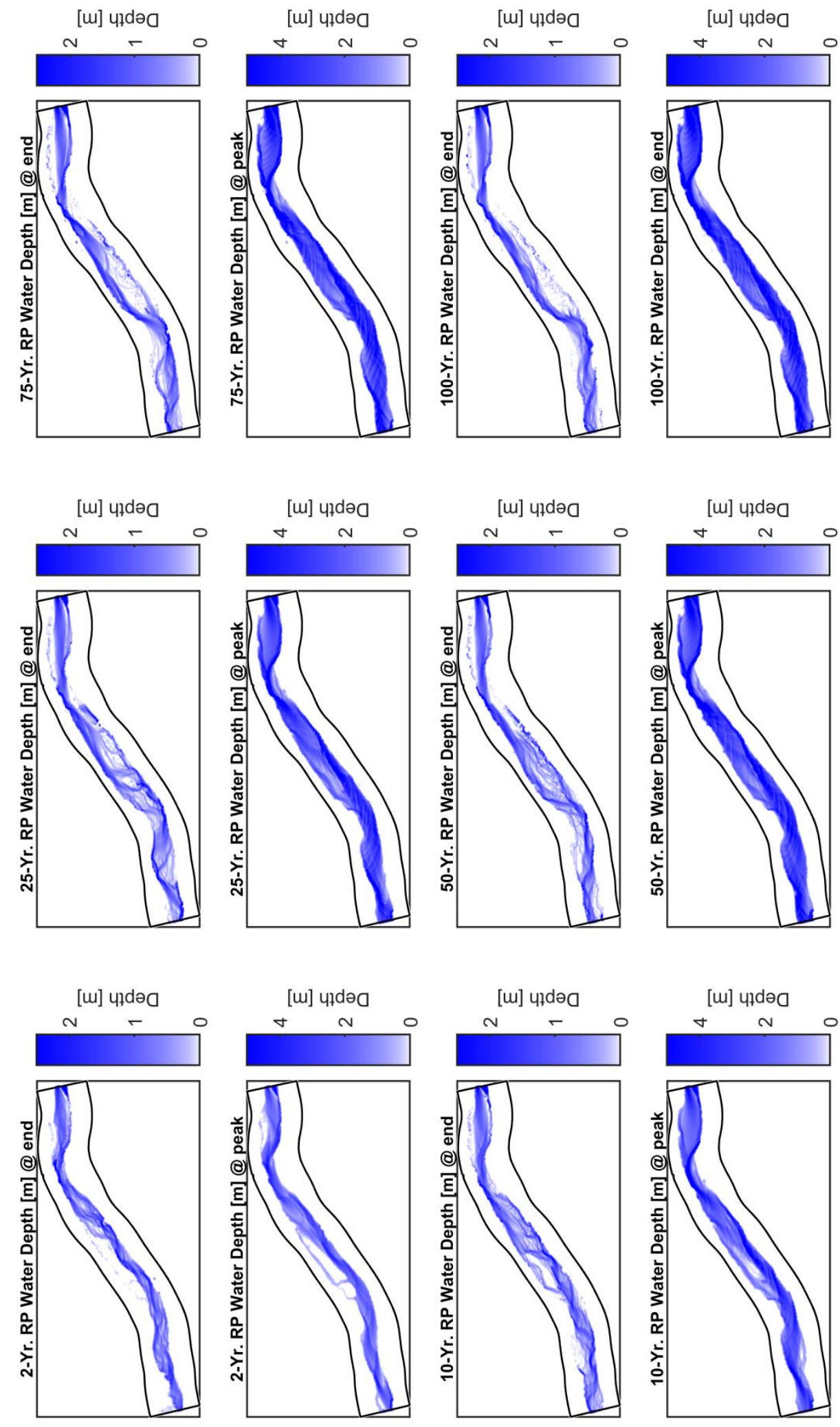

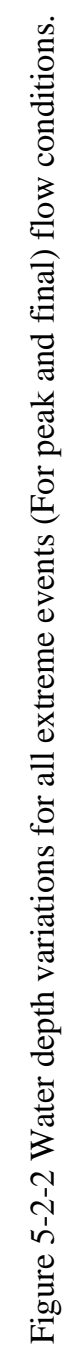




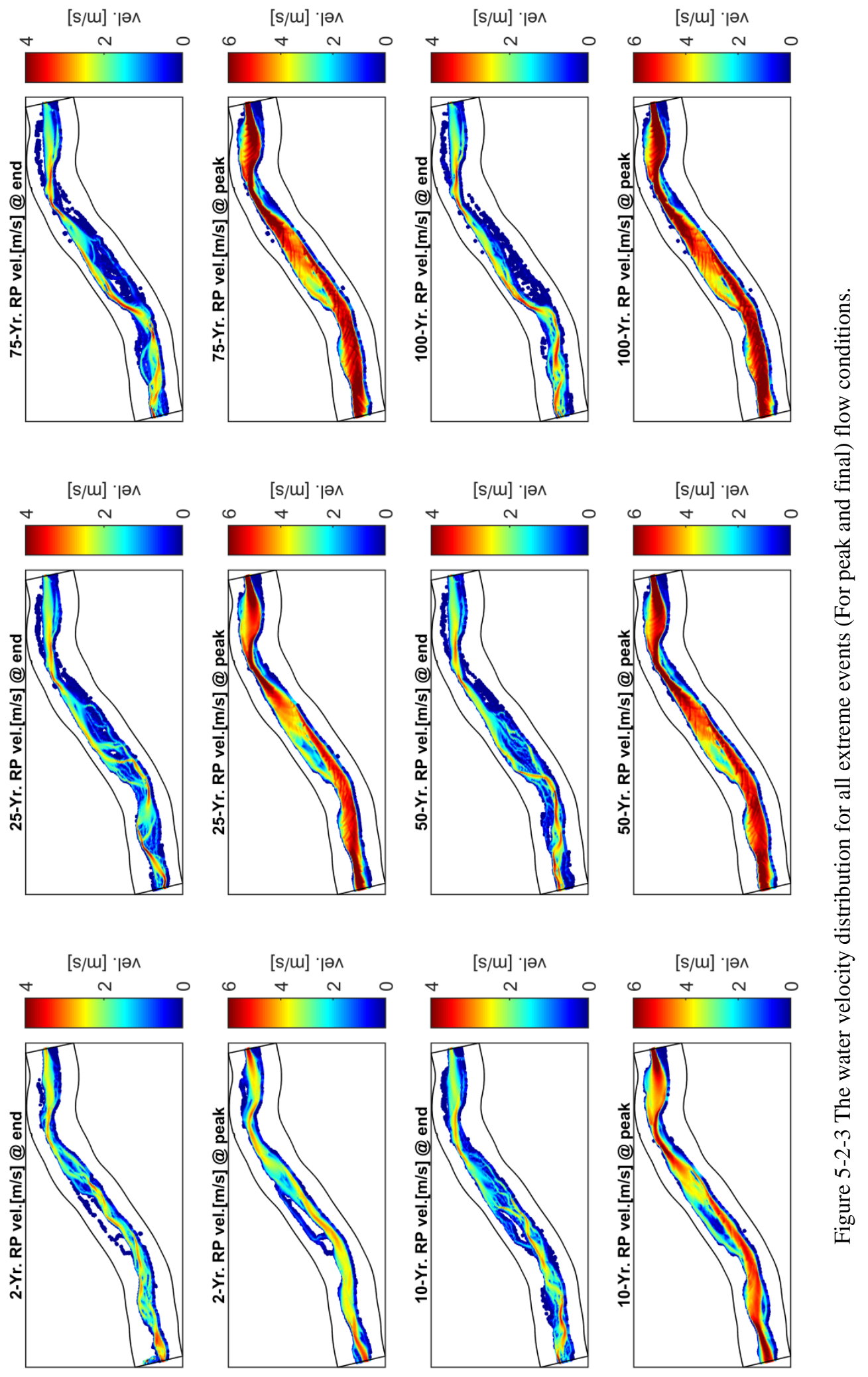


The bed and bank evolution (due to erosion and deposition) is very complex because it reflects and interacts with many hydrological and geological factors. Erosion of the banks and beds of river channel and floodplain during extreme floods increases the rate of sediment transport and alters river geometry parameters like the width and depth of the river channel (Griffin and Smith, 2004). Elevation change for all flood events is shown in the Figure 5-2-4 for both flow conditions. Generally, the deposition and erosion rate increases with increasing peak flow; the highest alteration takes place for the 100year return period and lowest for 2-year return period. Changes at the cross-sections defined in Figure 5-2-1illustrate precisely the complex evolution of the bed and banks of the study area. To make clear the bed and bank evolution through the cross-sections, the active part of cross-section (altered portion of the cross-sections) is taken. Figures 5-2-5, 5-2-6, 5-2-7, 5-2-8, 5-2-9, and 5-2-10 show the cross-sectional variation of the bed and bank elevation change and water surface elevation for both flow condition of 2, 10, 25 , 50, 75, and 100-years return periods, respectively. In these figures, it is clear that the more intense floods cause the bank erosion rate to increases, as expected. Also, erosion of the higher elevation parts of the banks is due to erosion at lower elevation; when lower elevation banks erode, the higher elevation collapse, and the bank adjusts its profile to stability (Dulal et al., 2010, Asahi et al., 2013). The processes of bank erosion reduced with assumption that the banks are vegetated, because vegetation provides more stability to the banks, but in this study we do not model for vegetated banks. 

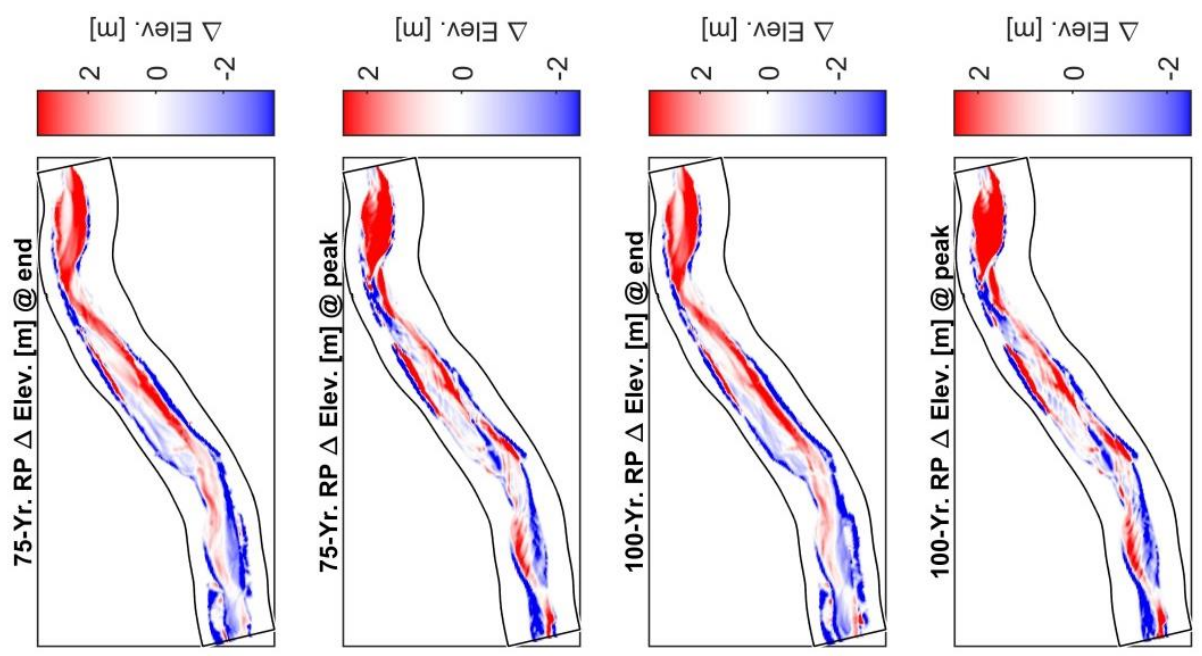

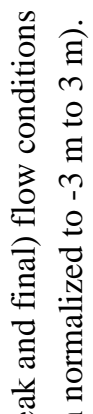
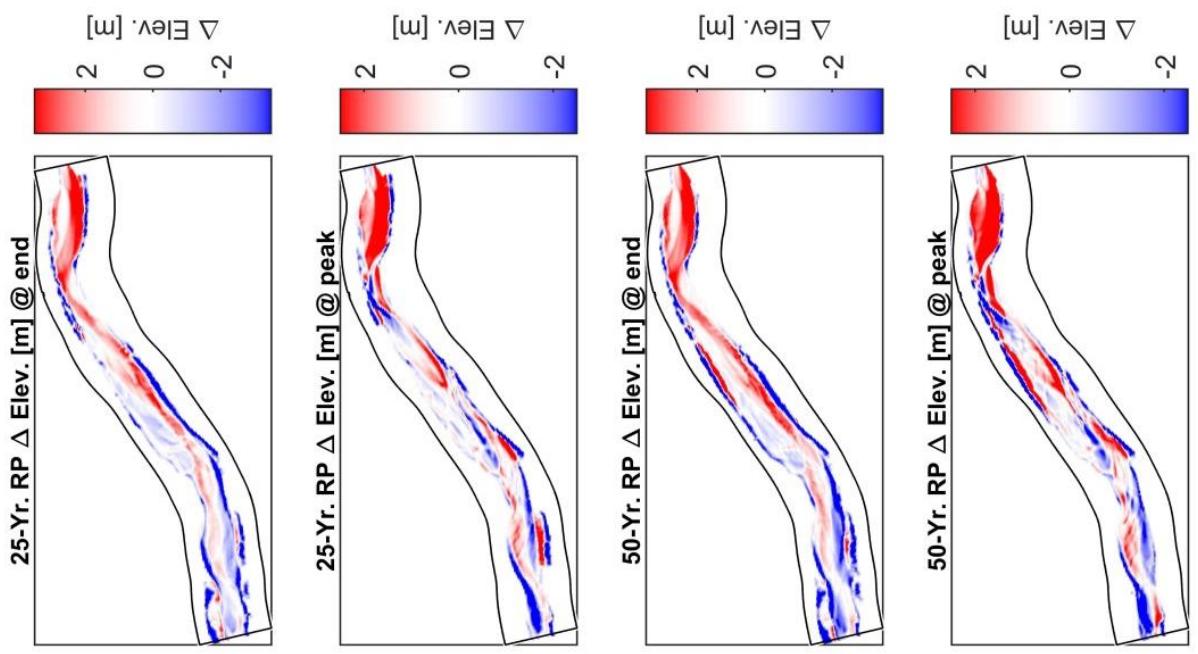

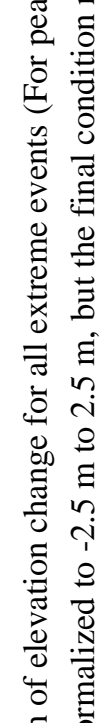
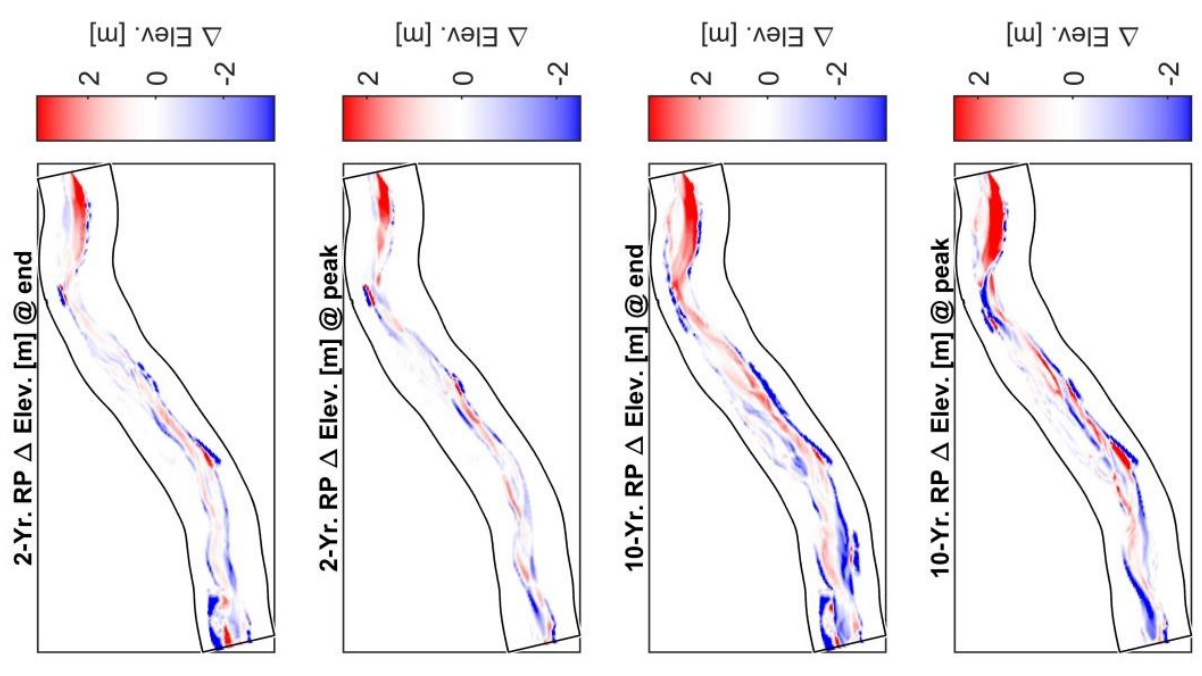

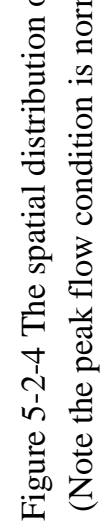



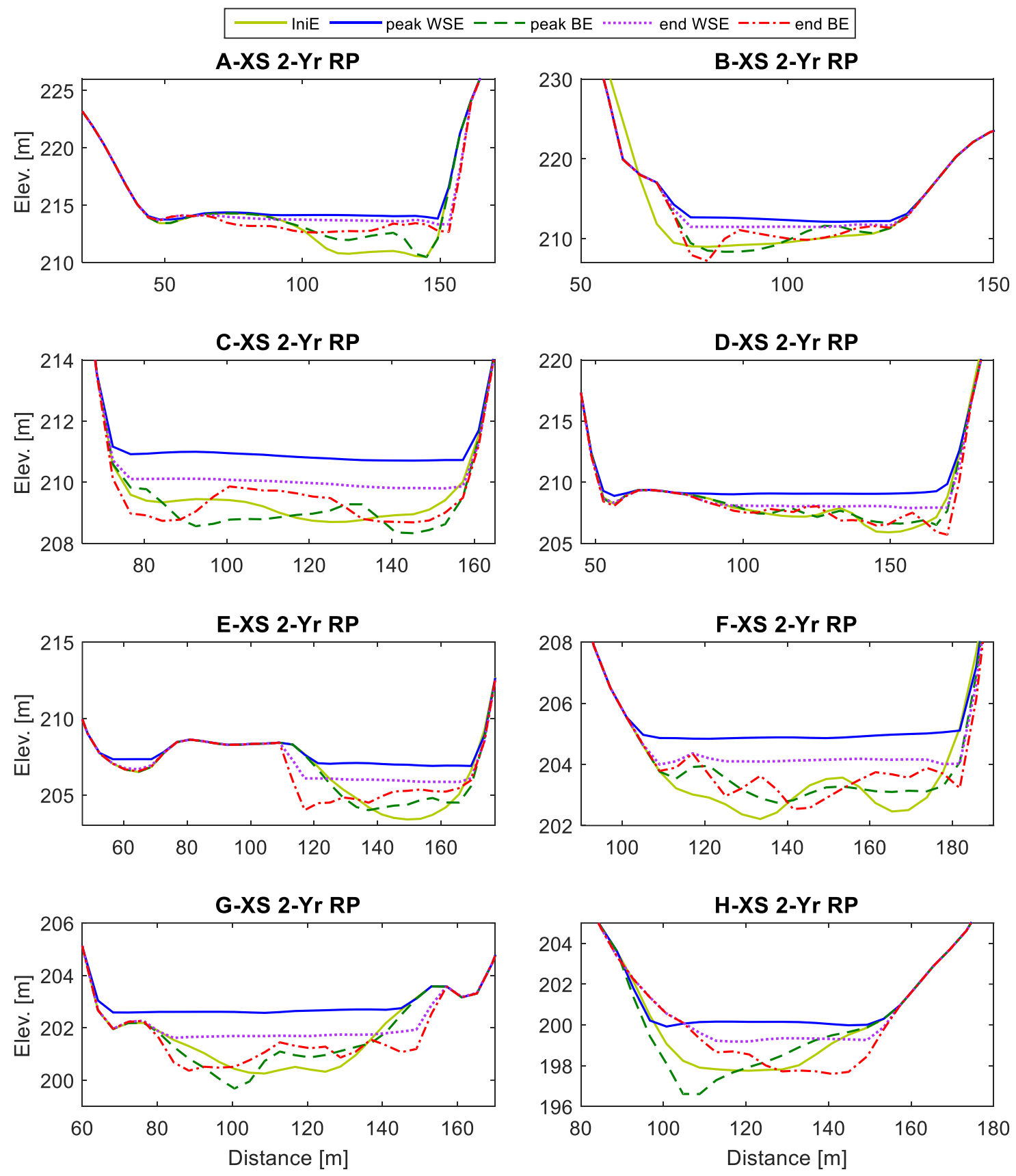

Figure 5-2-5 The cross-sectional variation of bed and bank evolution with water surface elevation for the 2year event (For peak and final) flow conditions. IniE is initial elevation, peak WSE is water surface elevation at peak flow, peak BE is the bed elevation condition at peak flow, end WSE is the water surface elevation at the end of the event, end BE is the bed elevation at the end of the event, and XS is crosssection. 


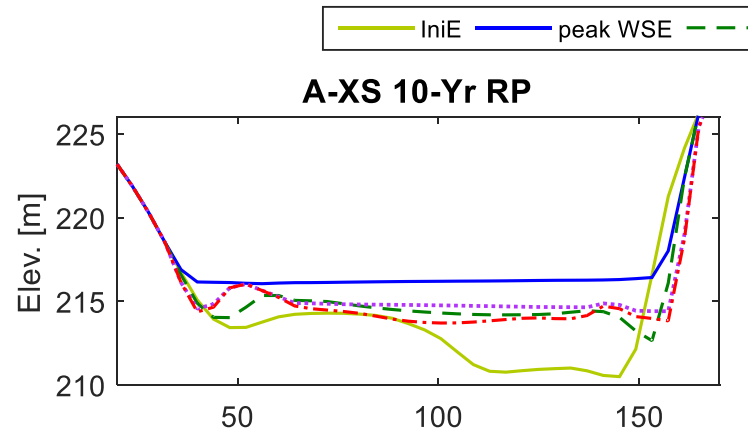

- peak BE $\cdots \ldots \ldots . . . \cdot$ end WSE $-\cdot-\cdot-$ end BE
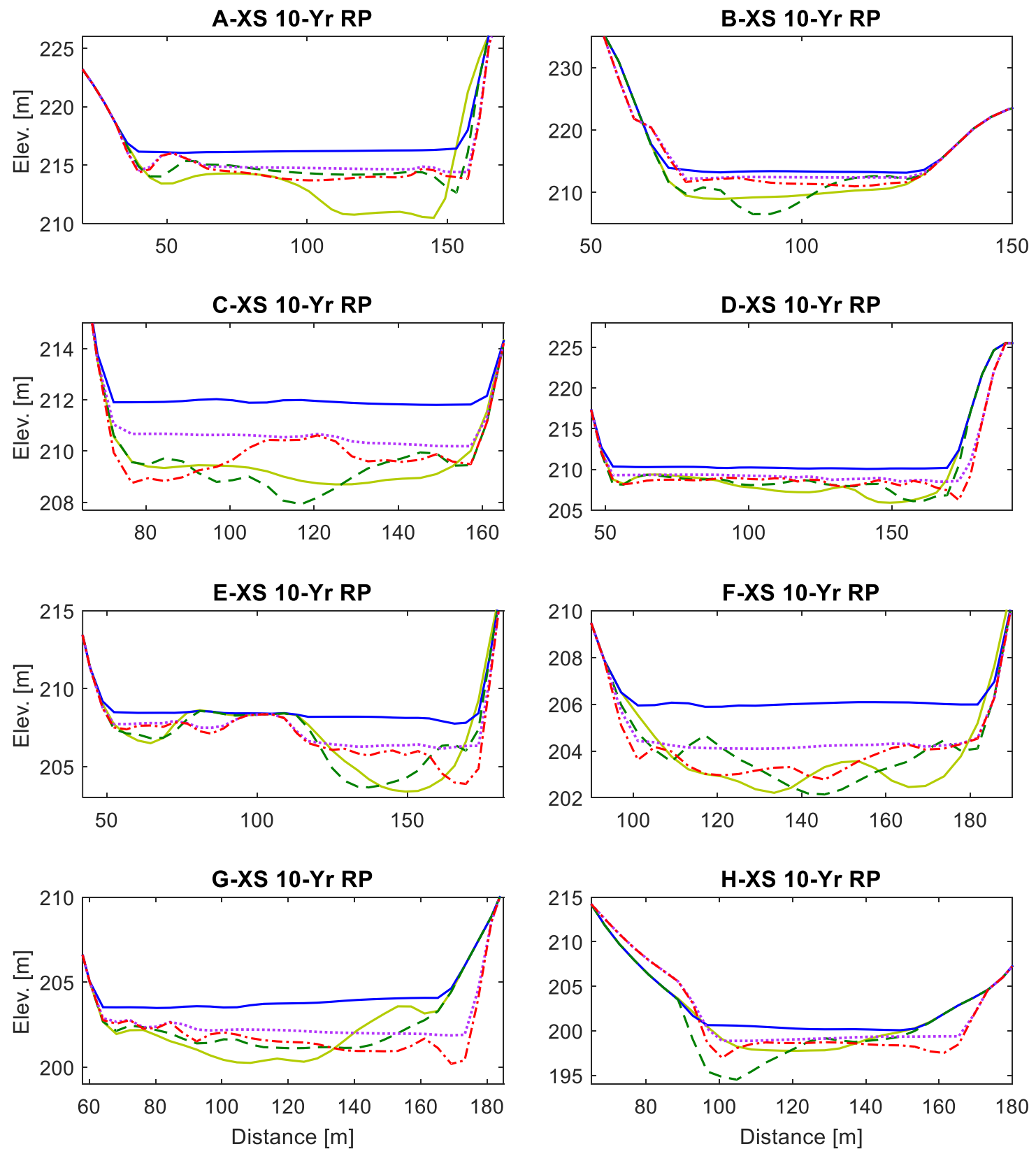

Figure 5-2-6 As in Figure 5-3-5, but for the 10-year event 


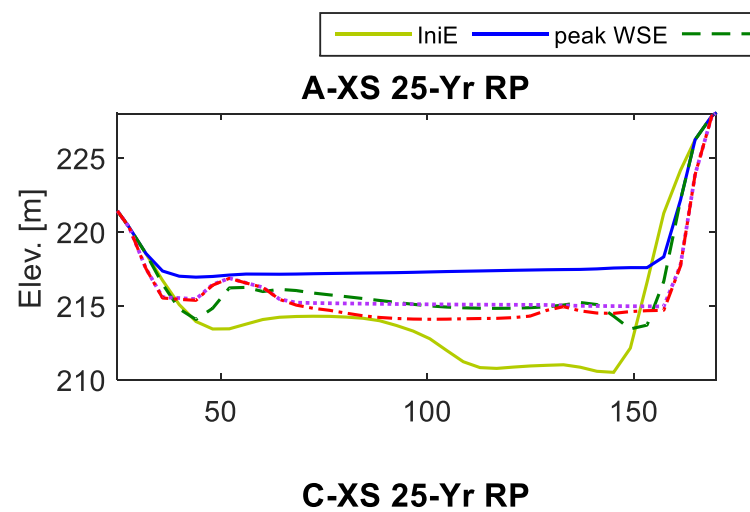

peak BE $\cdots \cdots \cdots \cdots$ end WSE $-\cdot-\cdot-$ end BE
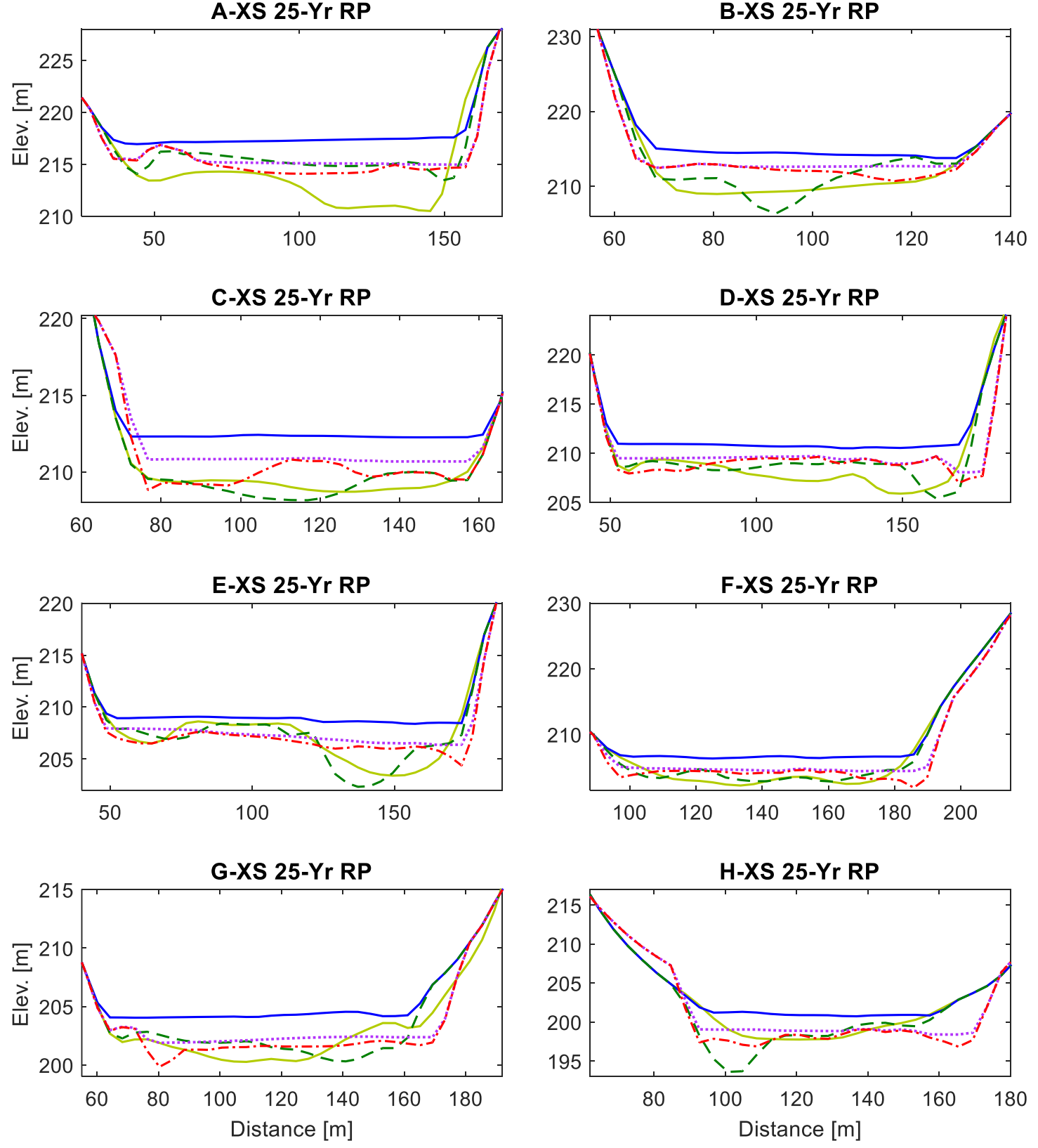

Figure 5-2-7 As in Figure 5-3-5, but for the 25-year event 

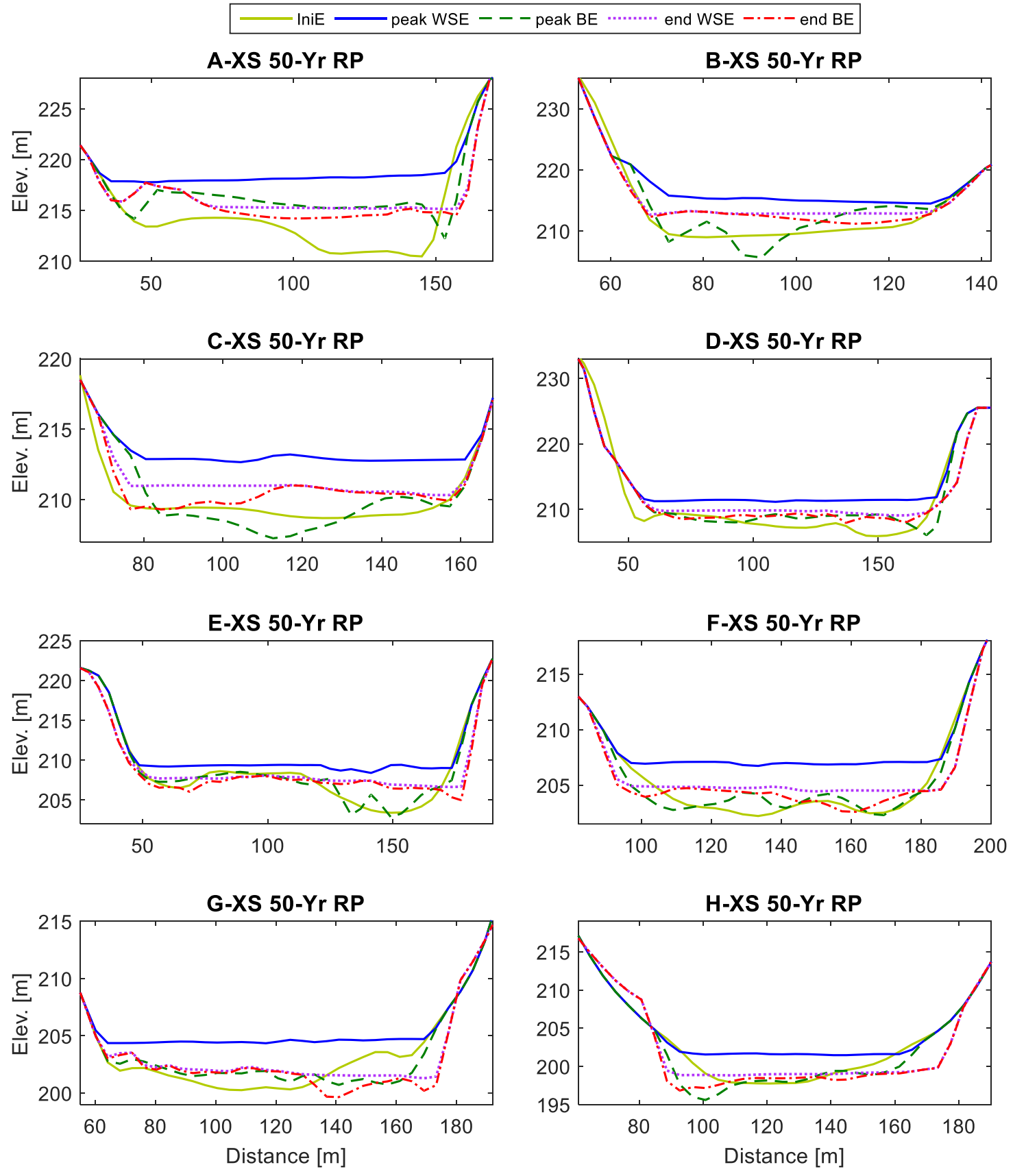

Figure 5-2-8 As in Figure 5-3-5, but for the 50-year event 


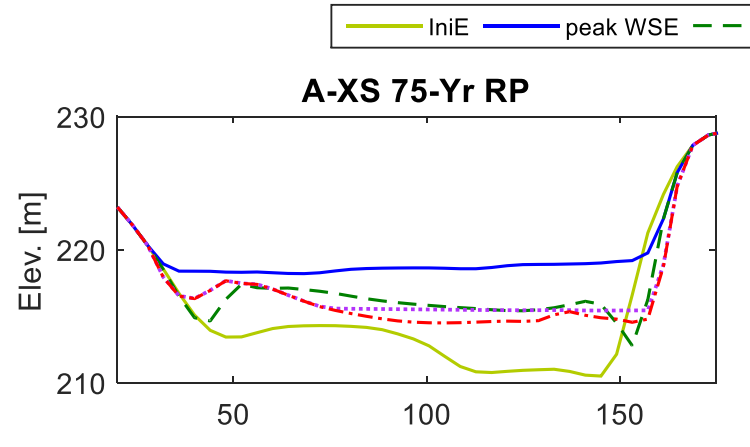

- peak BE $\cdots . . . . . .$. end WSE $-\cdot-\cdot-$ end BE
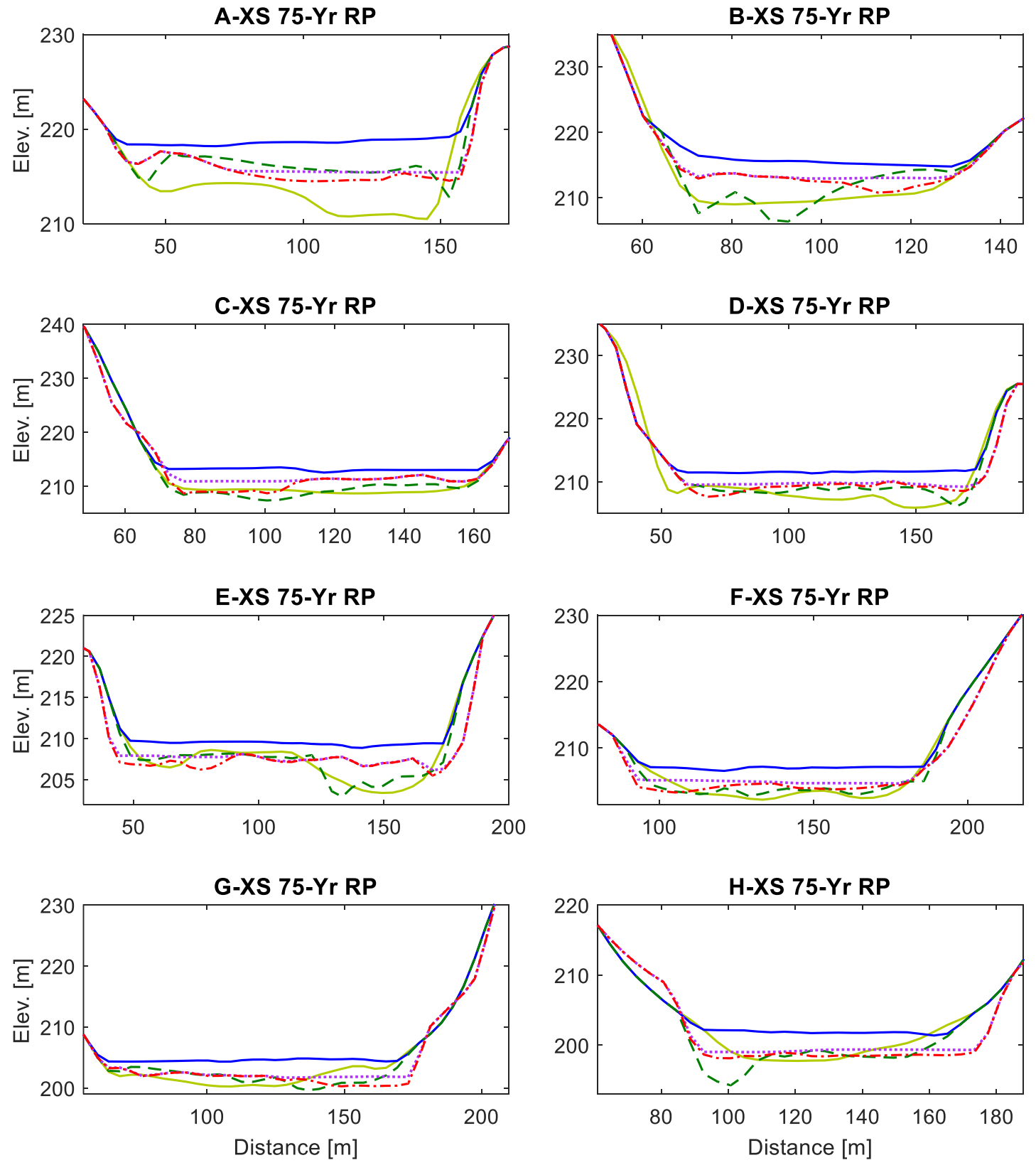

Figure 5-2-9 As in Figure 5-3-5, but for the 75-year event 

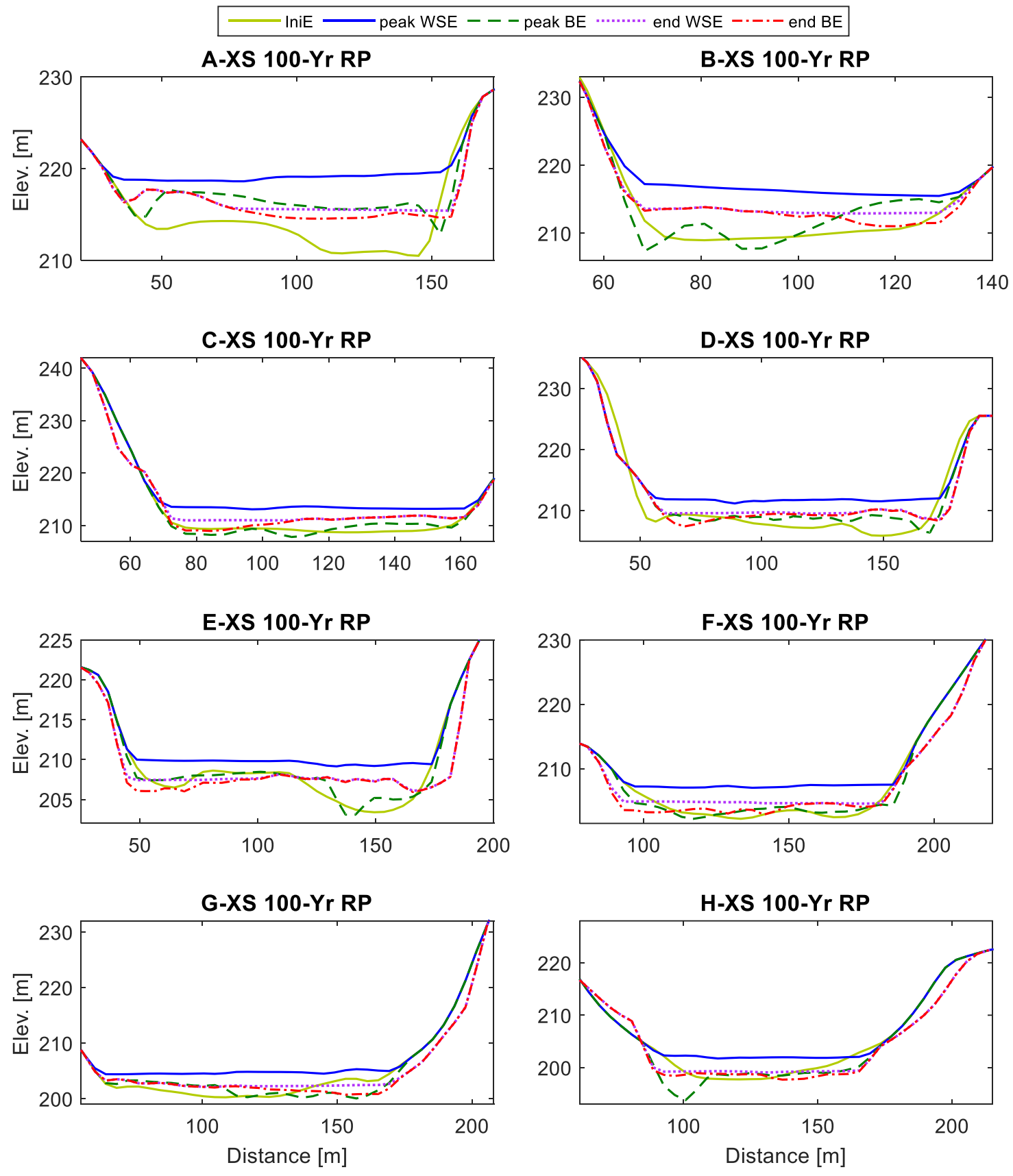

Figure 5-2-10 As in Figure 5-3-5, but for the 100-year event 

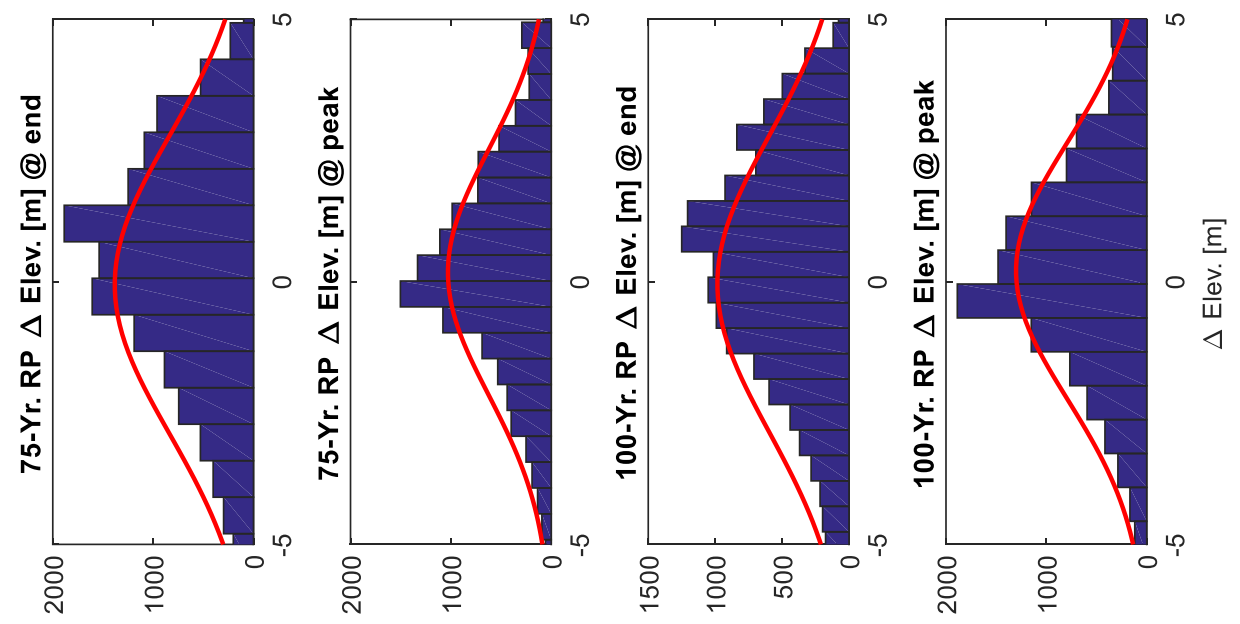

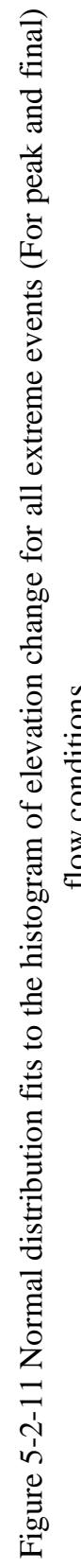
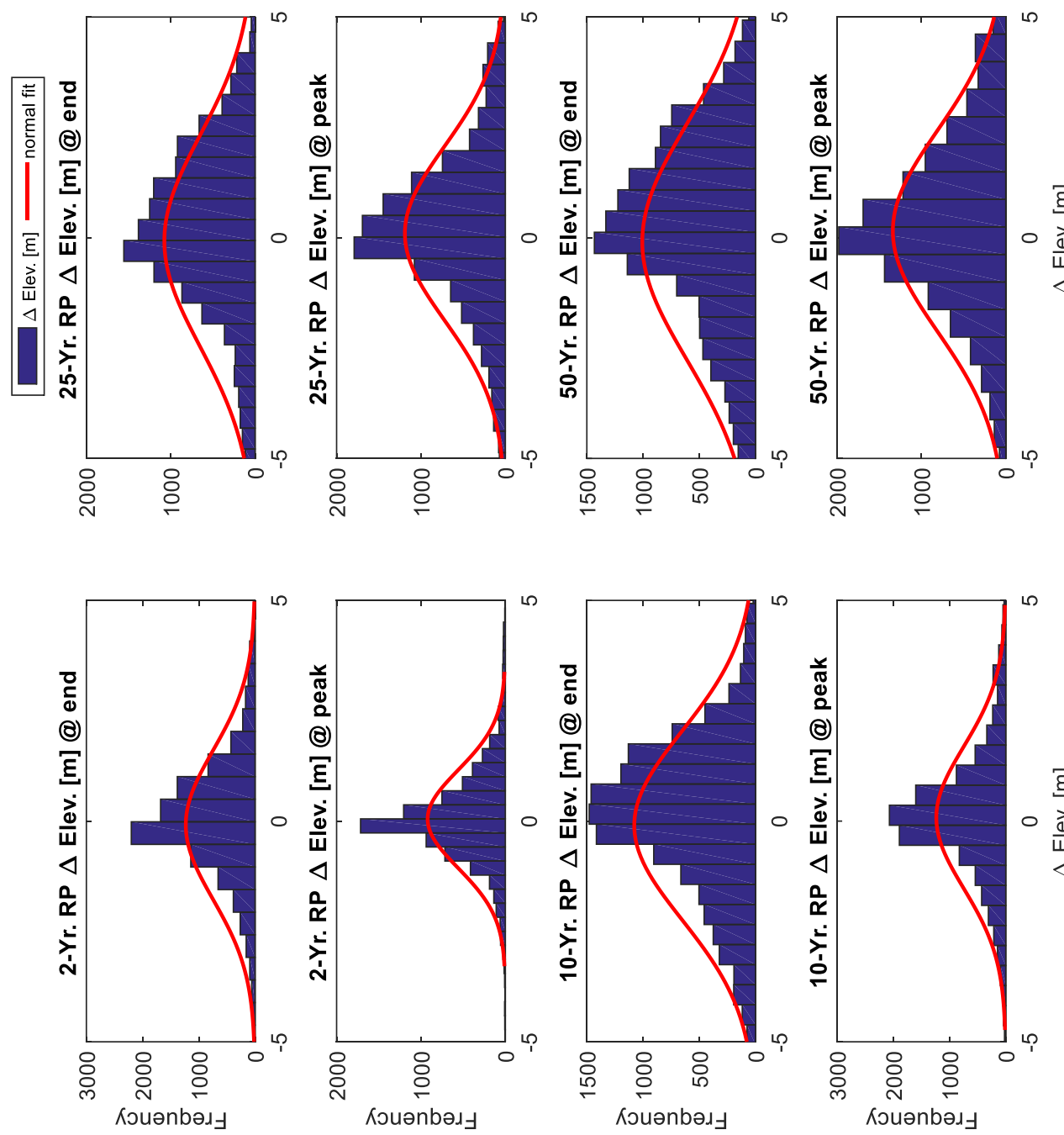
The statistical distribution of elevation changes for all extreme events is shown for both the peak and final flow condition in the Figure 5-2-11; each histogram is fitted to normal distribution to show how each of erosion and deposition depth is takes place.

\section{5-3 Sediment transport result}

The model predicts two components of sediment transport, bed-load, and suspended load for the size class of sediment used, with diameter $45 \mathrm{~mm}$. The bed-load transport has a substantial role in changing hydro-geomorphology of rivers (Wu, 2007). The sediment particles start to move when the shear stress exceeds its critical value, which is $37.15 \mathrm{~Pa}$ for the sediment considered here. The distribution of shear stress of the bed is shown in Figure 5-3-1 and the non-dimensional shear stress (Shields Number) in Figure 5-3-2. The bed-load and suspended load are shown in figure 5-3-3 and 5-3-4 respectively.

The bed-load and velocity horizontal profiles are plotted together for each cross-section separately for all return periods and flow conditions in Figures 5-4-5, to 5-4-16. These profiles suggest that there is a relationship between the bed-load flux and water velocity, as expected form of the bedload model used (equation 3-5-6). This is illustrated in Figure 5-4-17, which shows bed-load flux vs. flow speed for the entire domain and for both flow condition (peak and the end of the event).there is an exponential relation between these two. The fit of an exponential curve to the bedload data is tabulated in Table 5-3-1. 


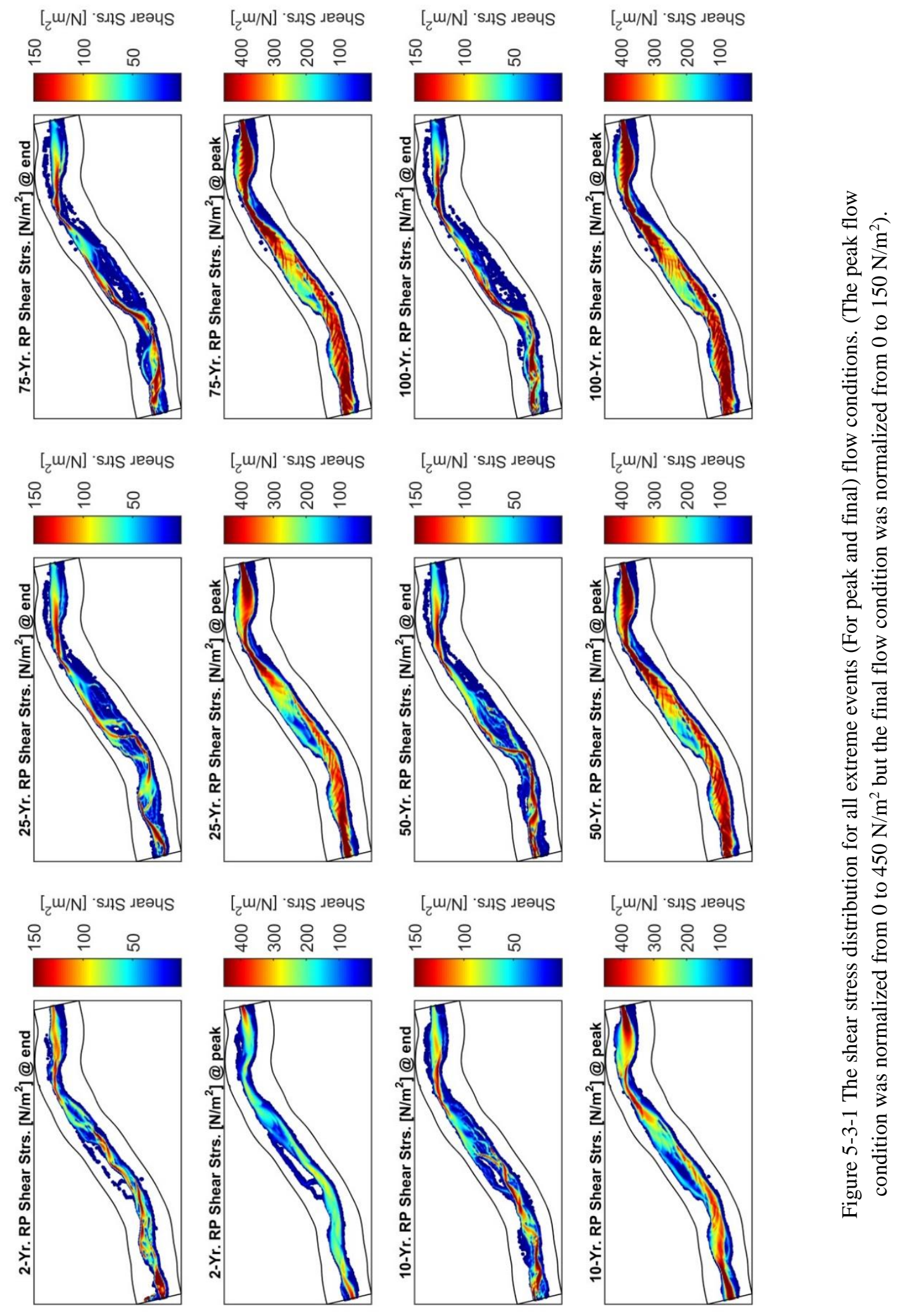



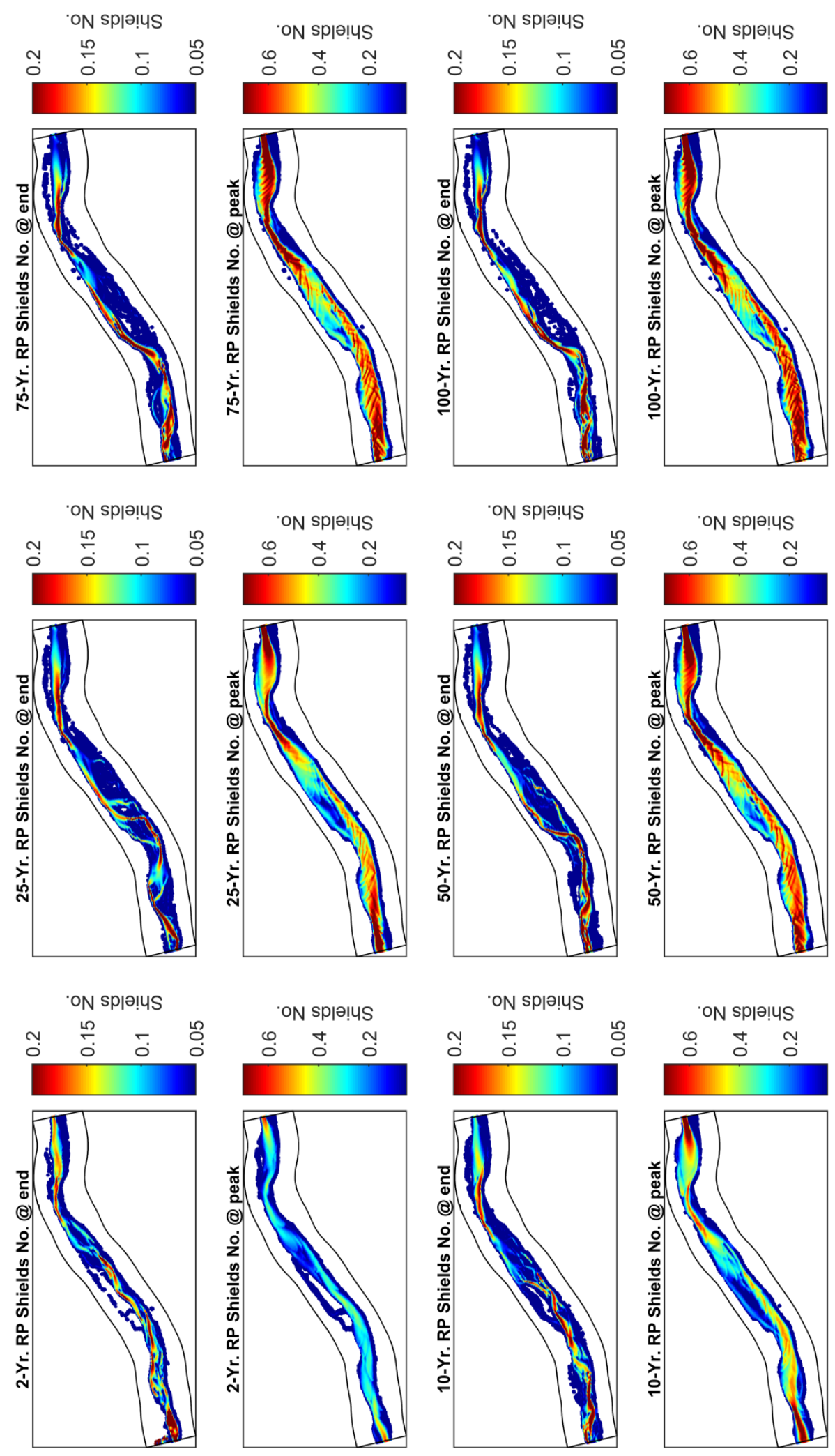

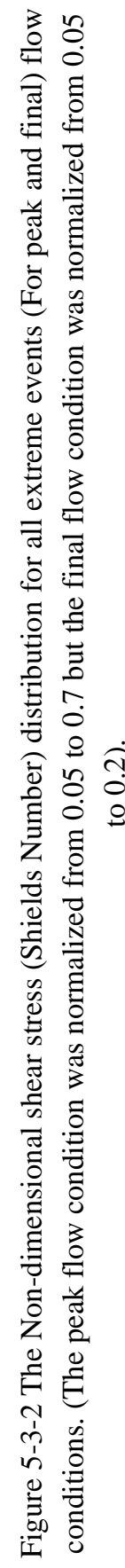



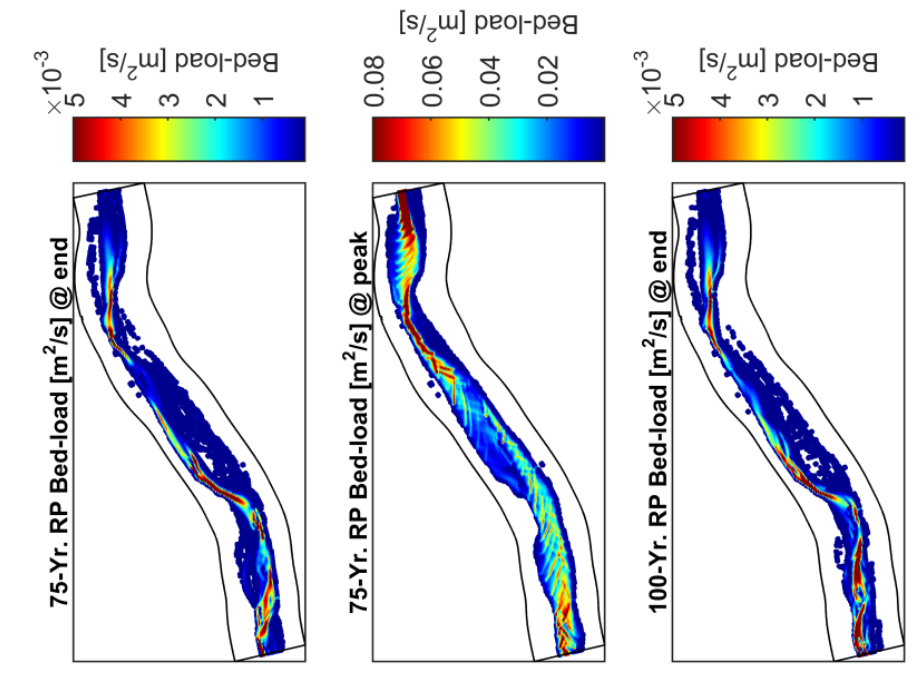

[s/zw] peol-pәg
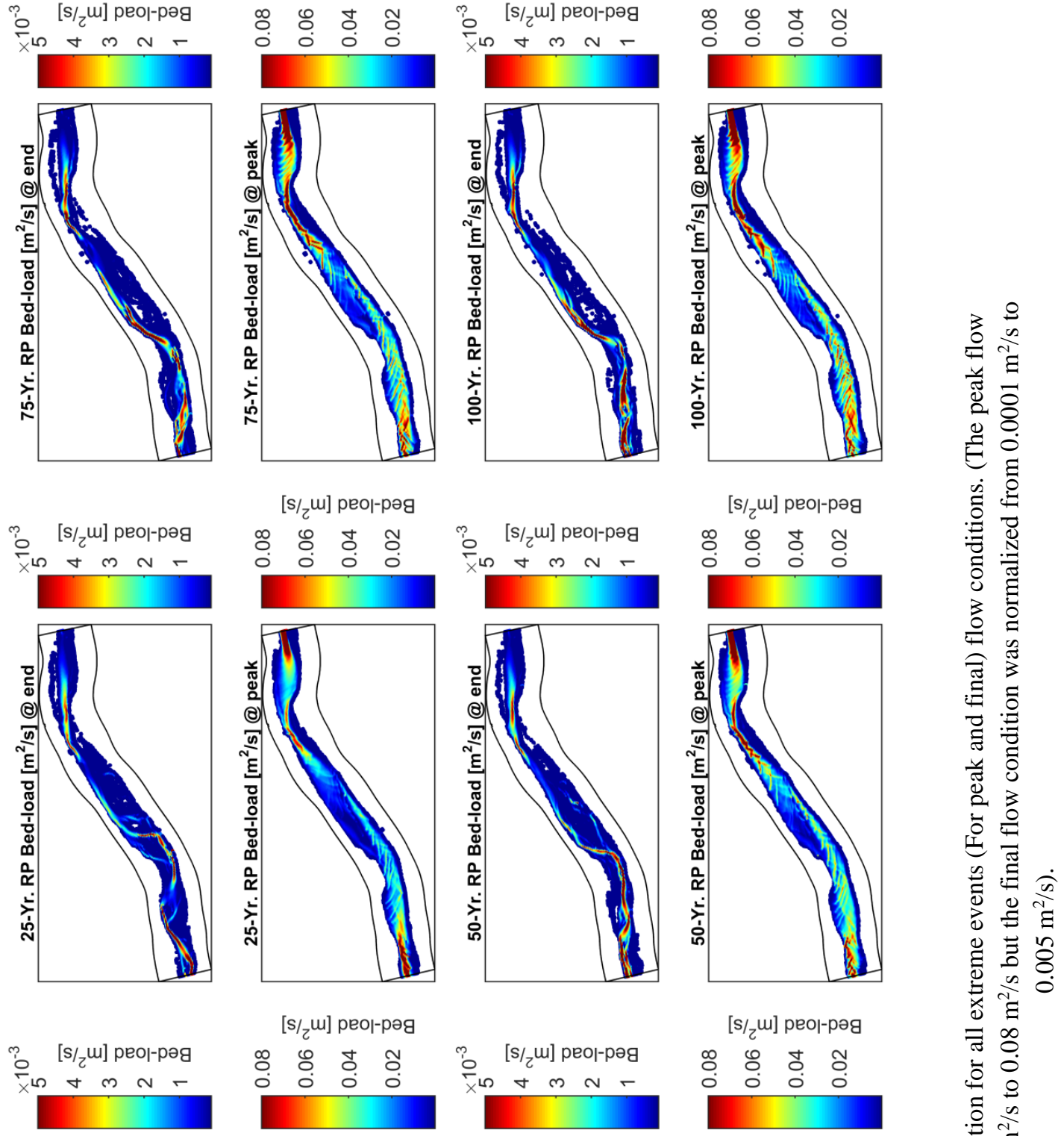

$$
\text { [s/zw] peol-pəg }
$$
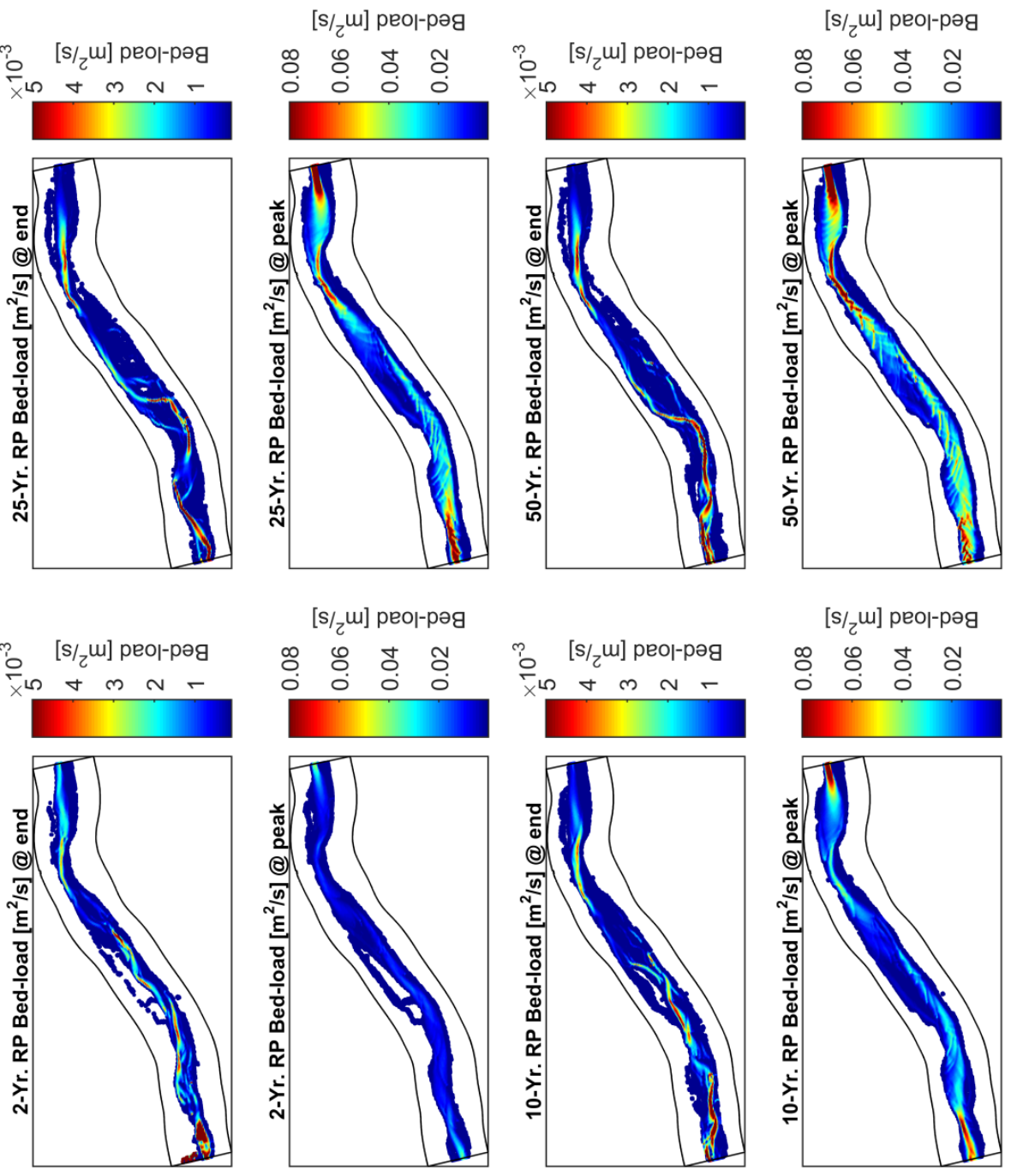

[s/zw] peol-pәg

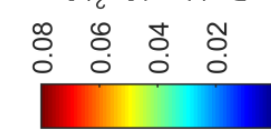

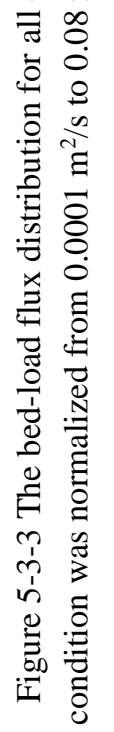



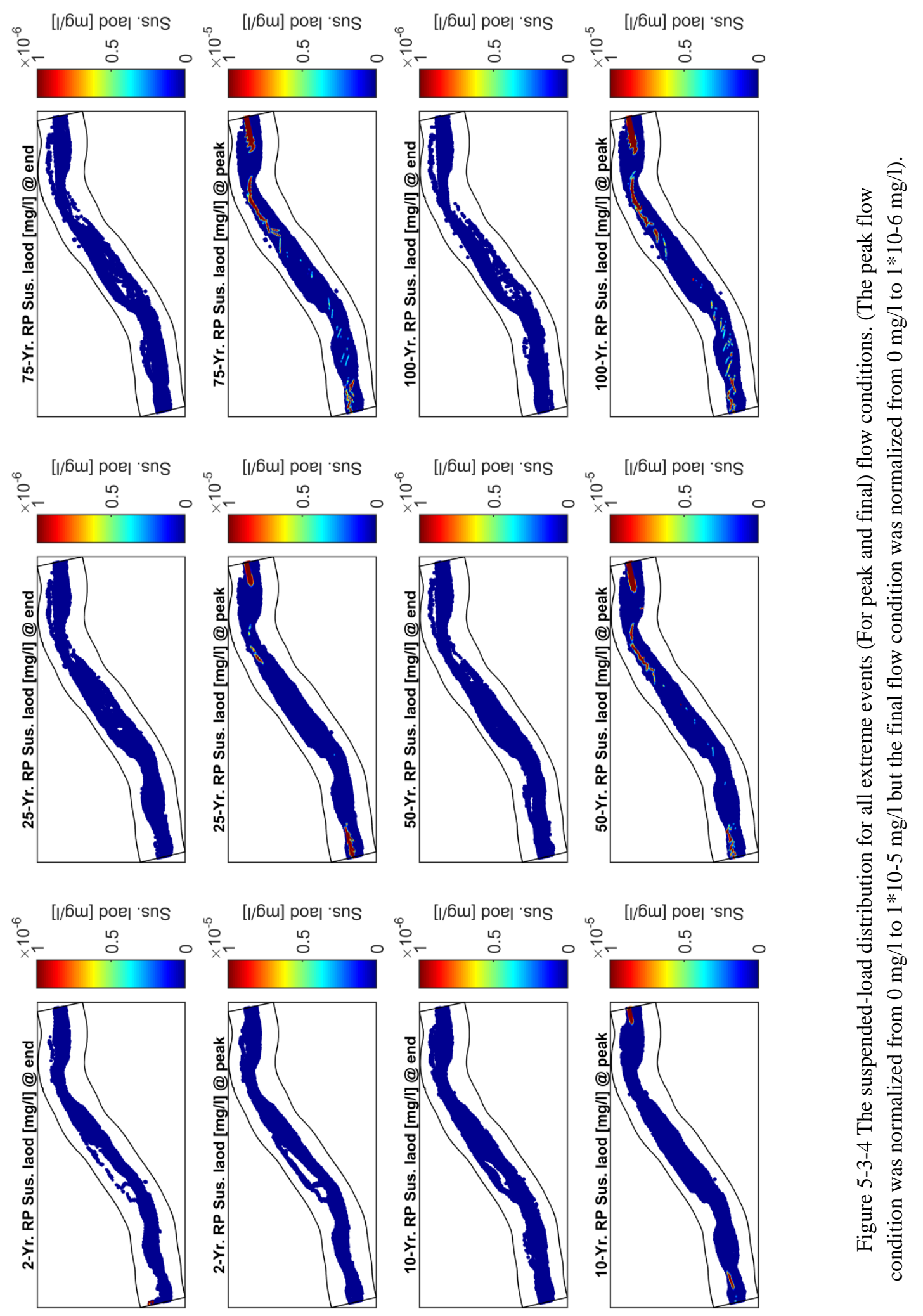

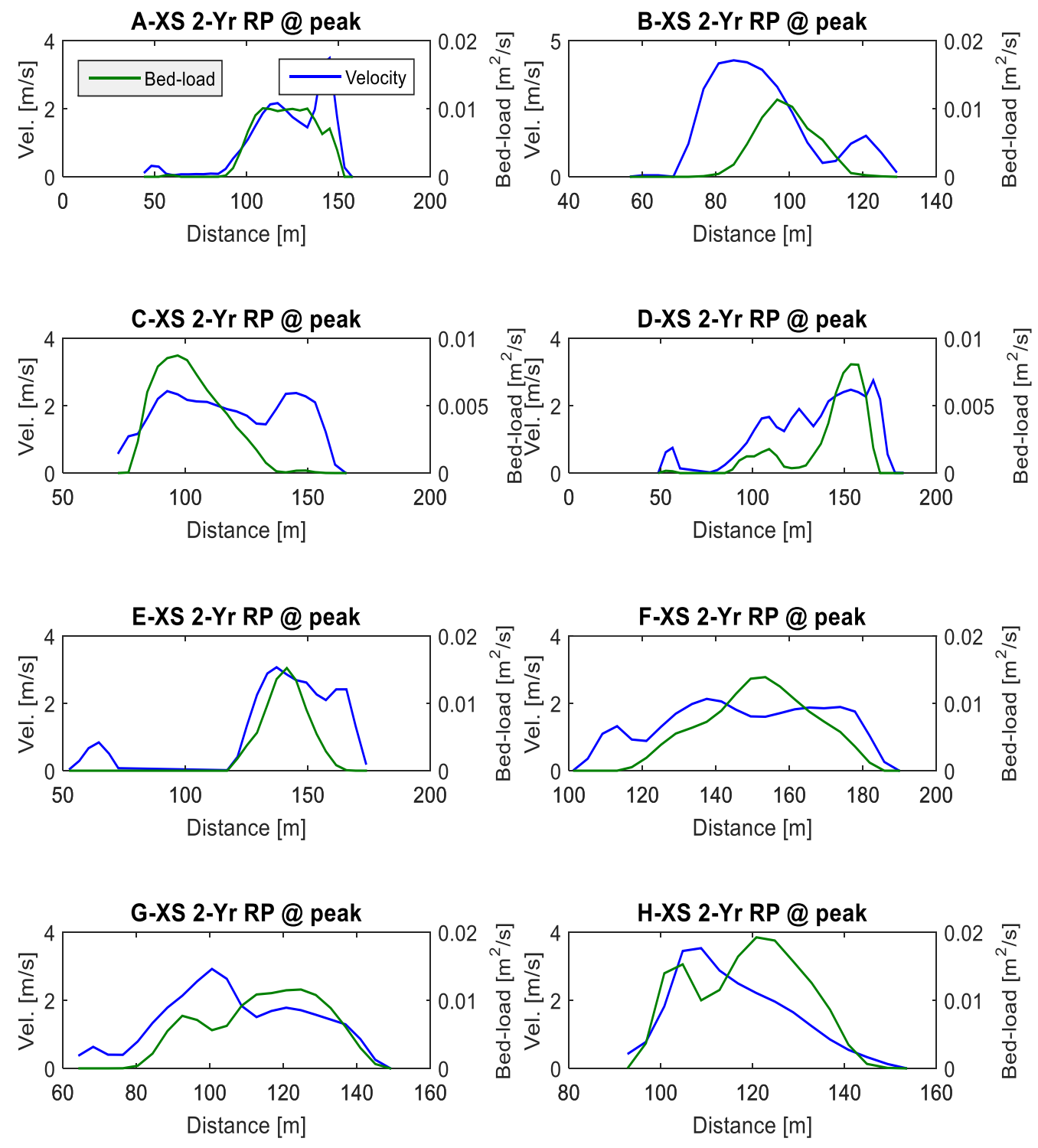

Figure 5-3-5 Cross-sections of horizontal velocity and bedload transport for the 2-year return period, for the peak flow condition. 

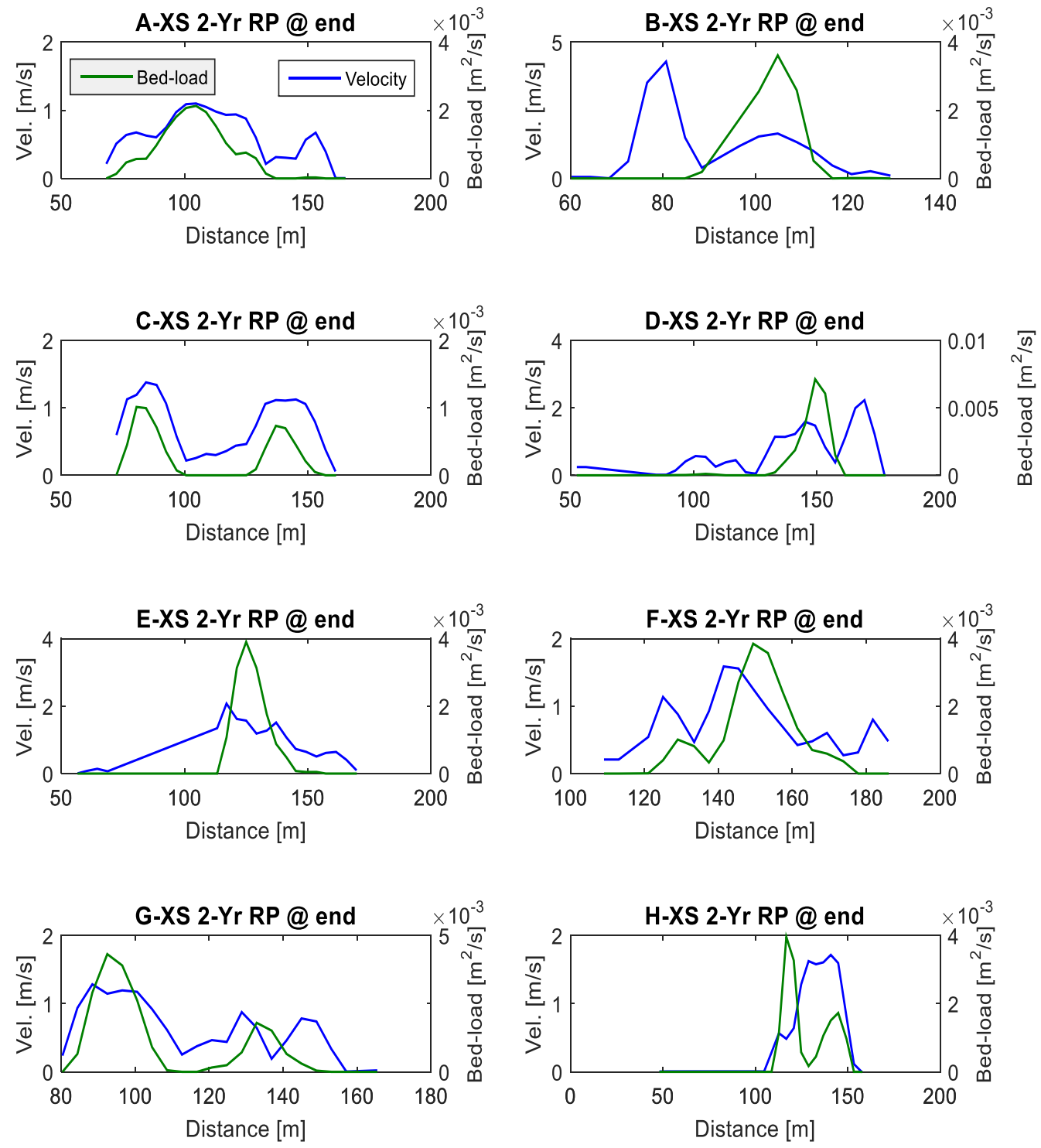

Figure 5-3-6 As in Figure 5-3-5, but for the final flow condition. 

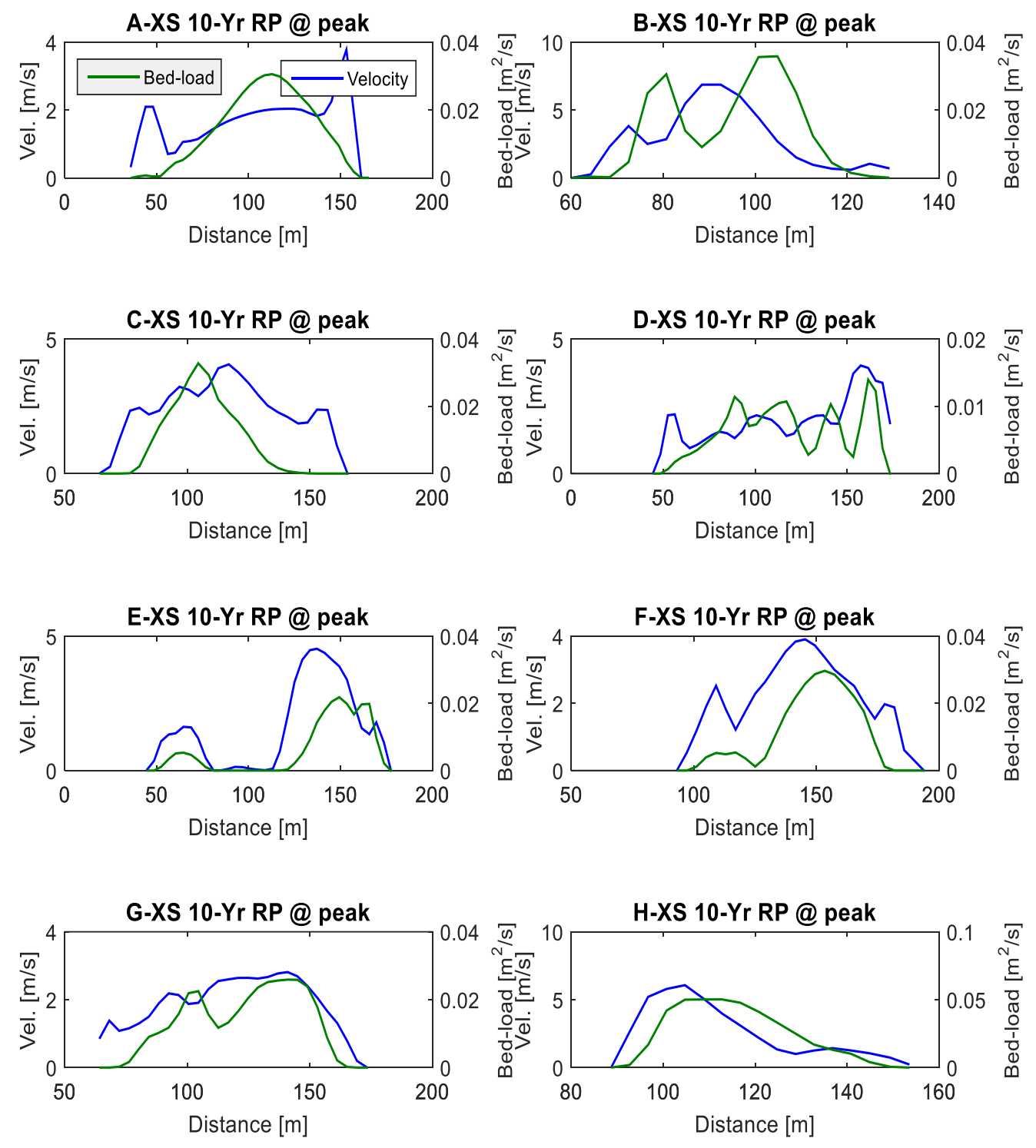

Figure 5-3-7 As in Figure 5-3-5, but for the 10-year event. 

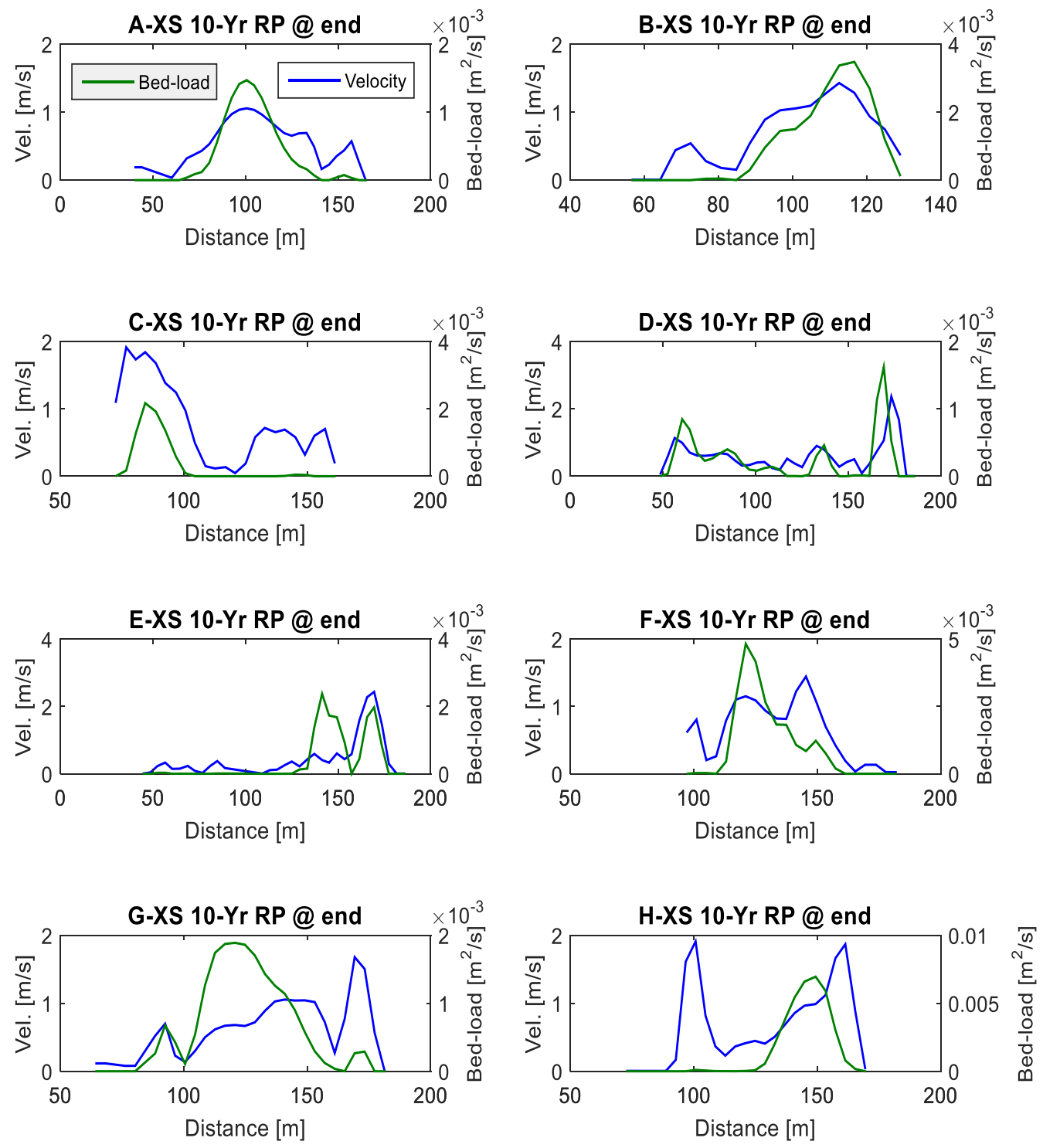

Figure 5-3-8 As in Figure 5-3-5, but for the 10-year event, the final flow condition. 

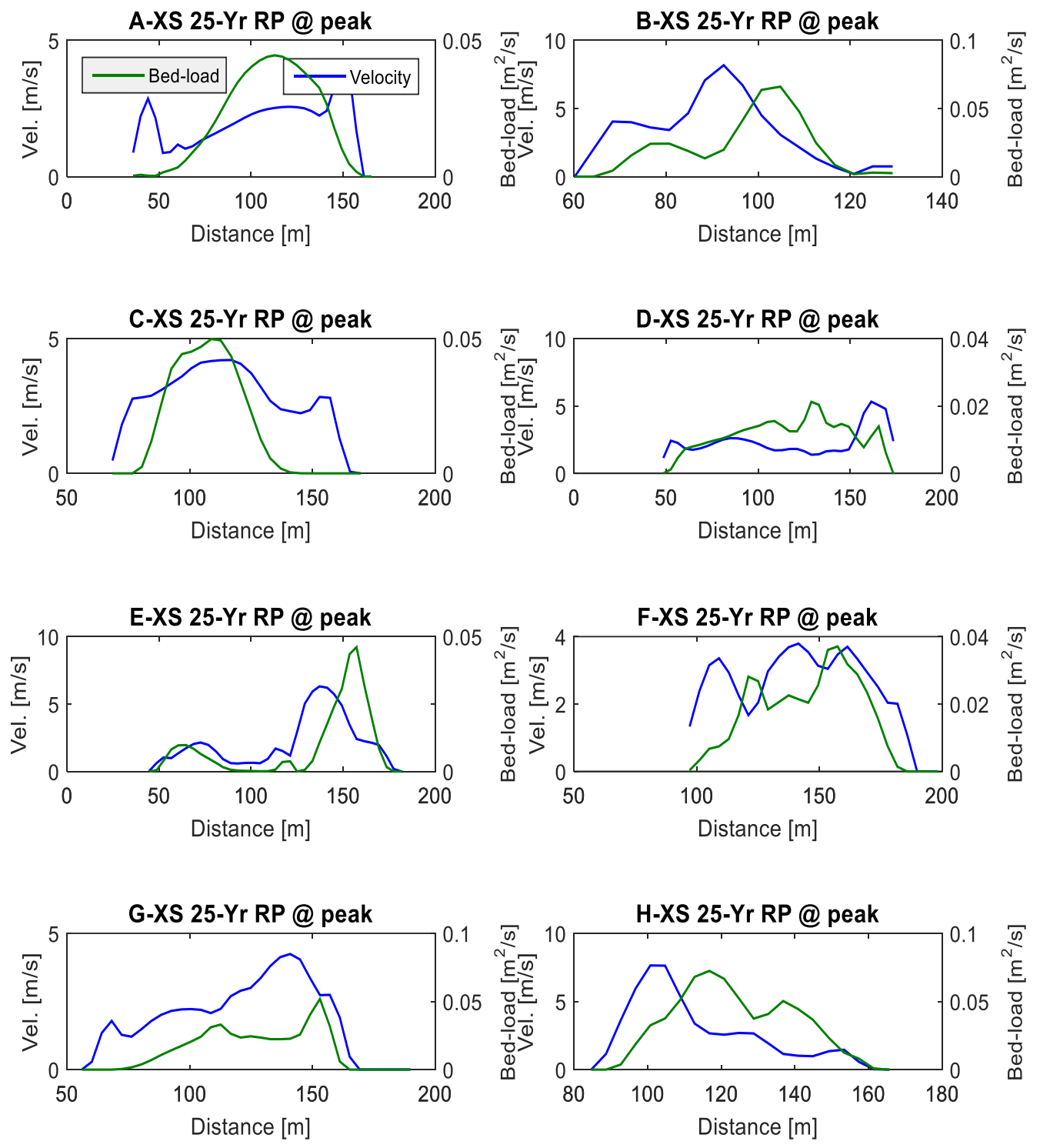

Figure 5-3-9 As in Figure 5-3-5, but for the 25-year event. 

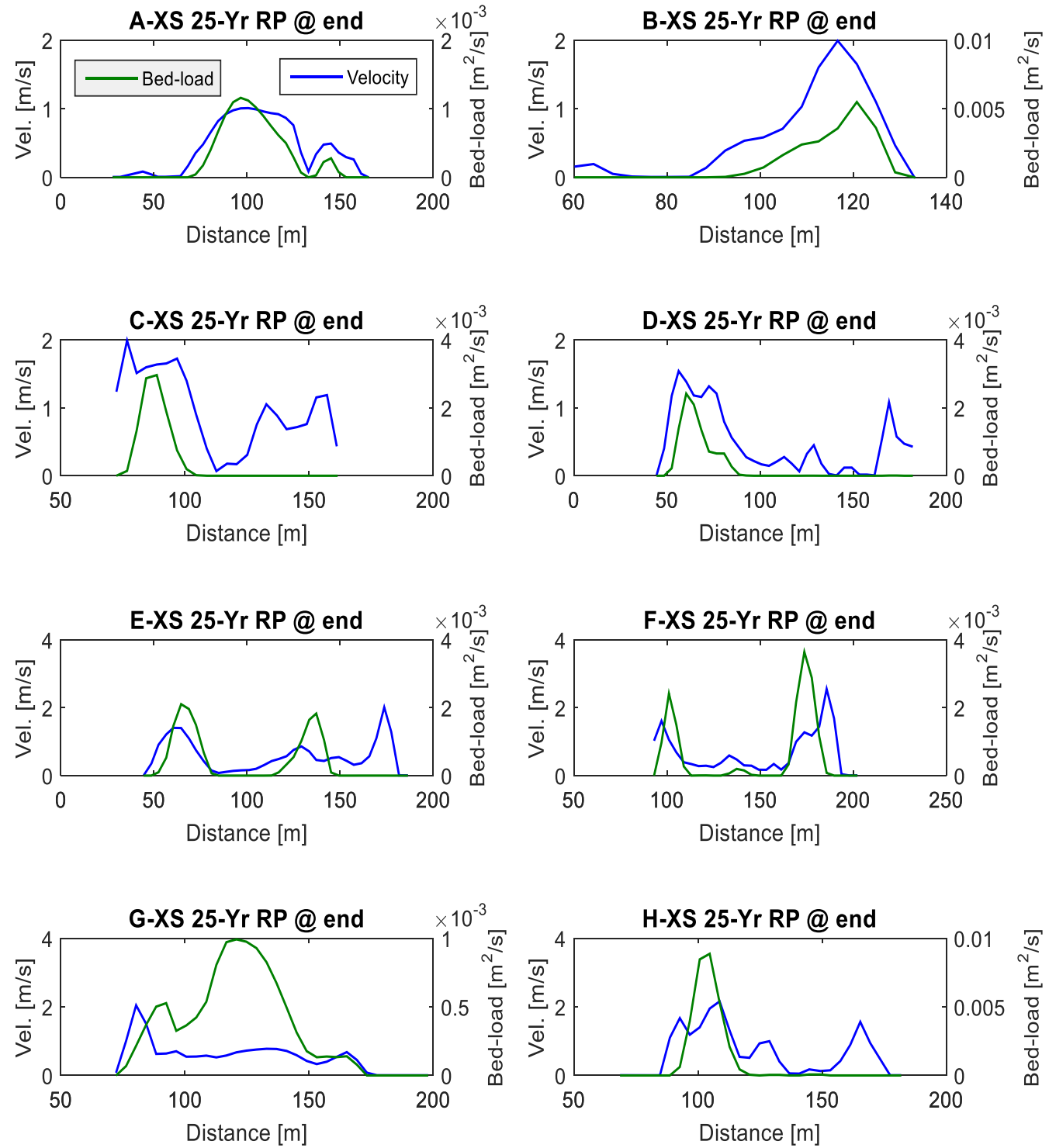

Figure 5-3-10 As in Figure 5-3-5, but for the 25-year event, the final flow condition. 

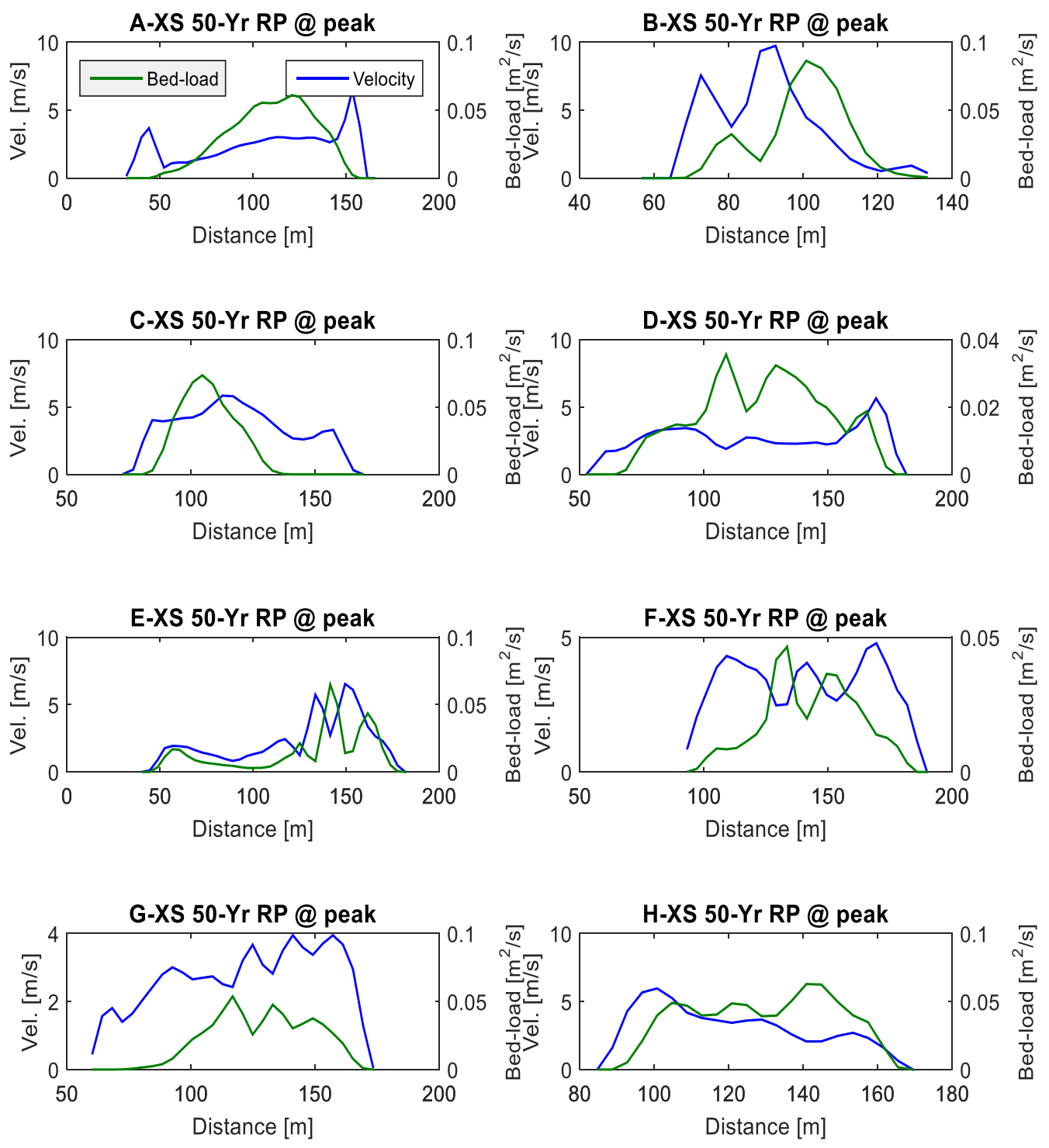

Figure 5-3-11 As in Figure 5-3-5, but for the 50-year event. 

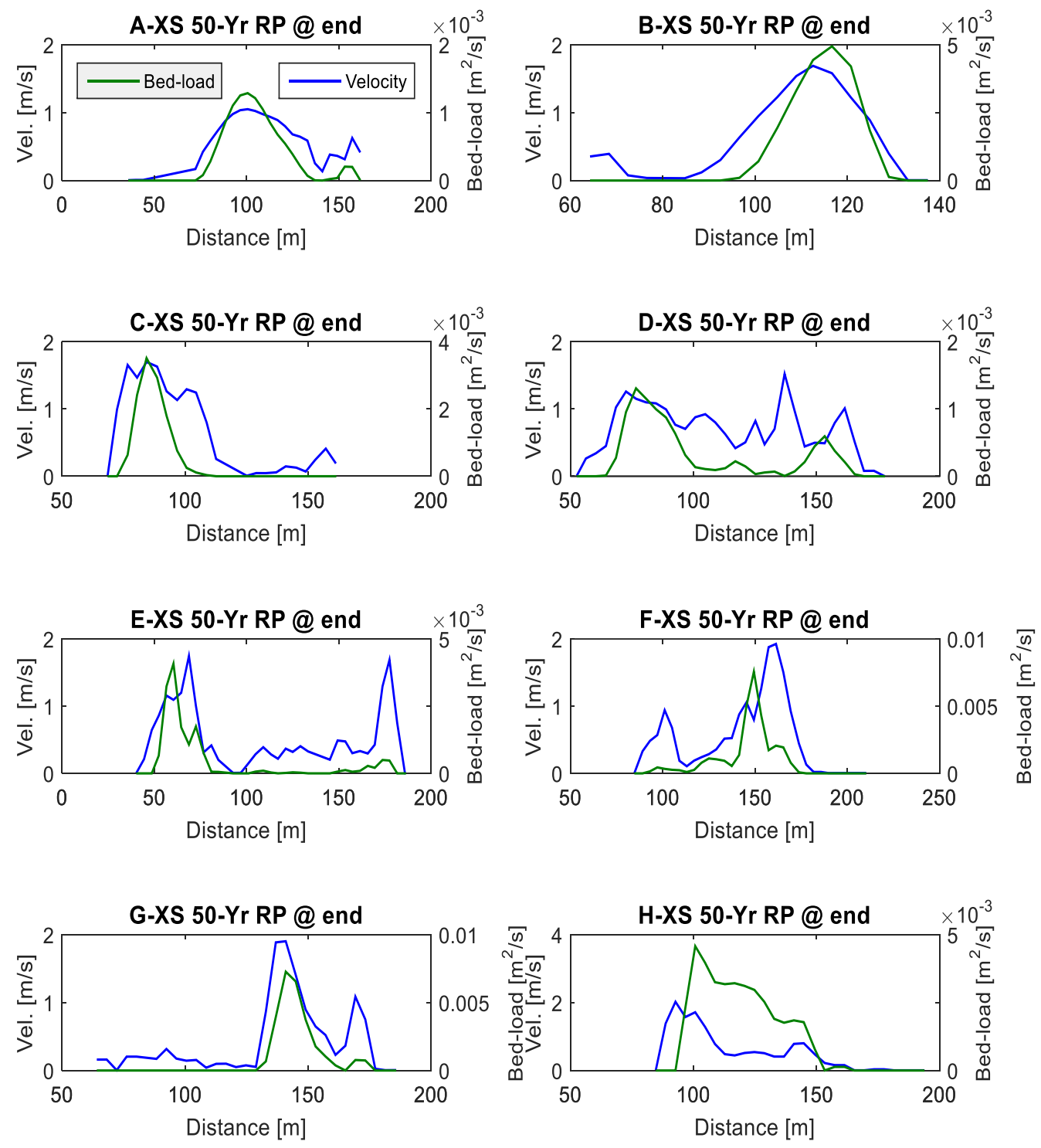

Figure 5-3-12 As in Figure 5-3-5, but for the 50-year event, the final flow condition. 

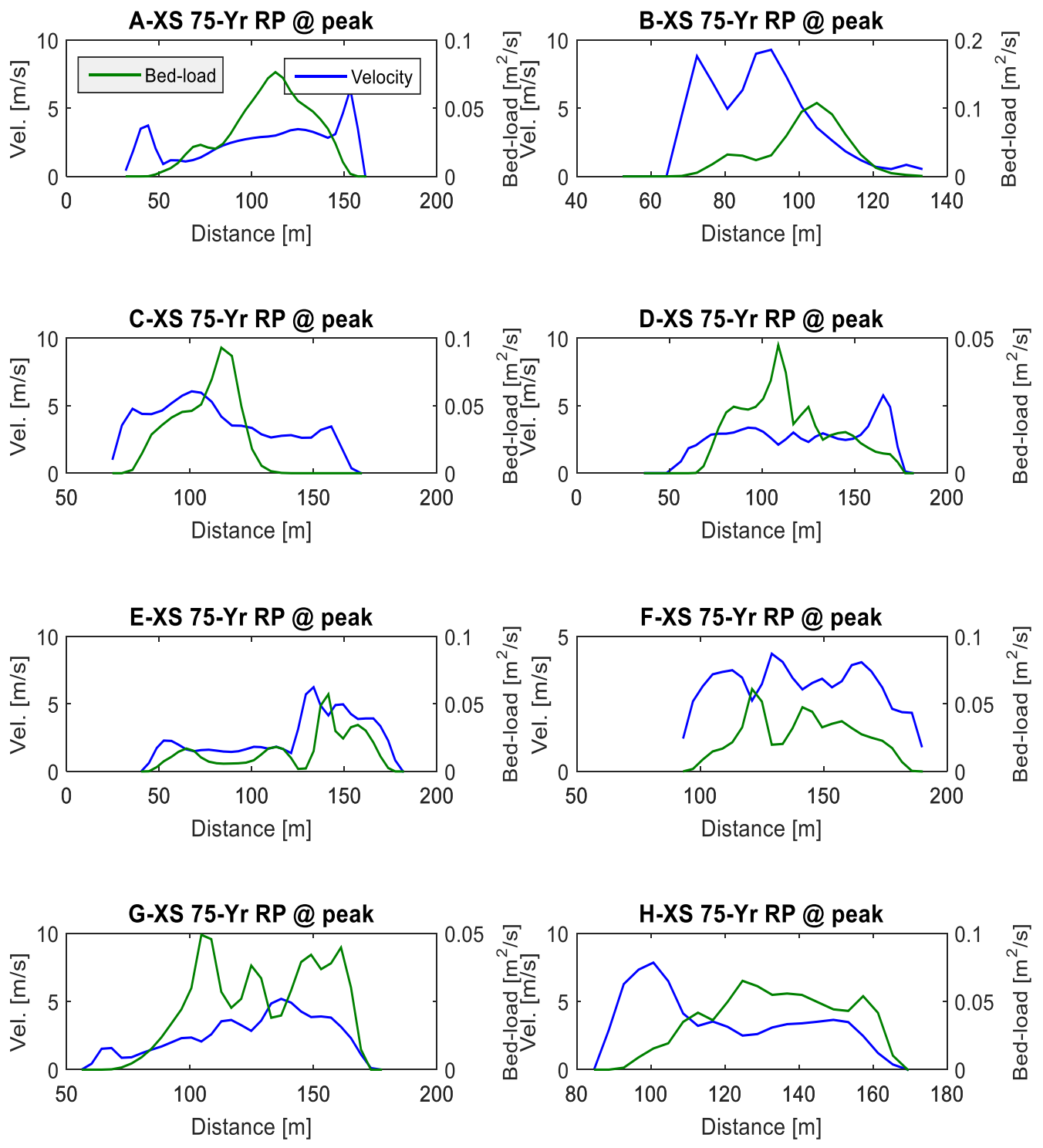

Figure 5-3-13 As in Figure 5-3-5, but for the 75-year event. 

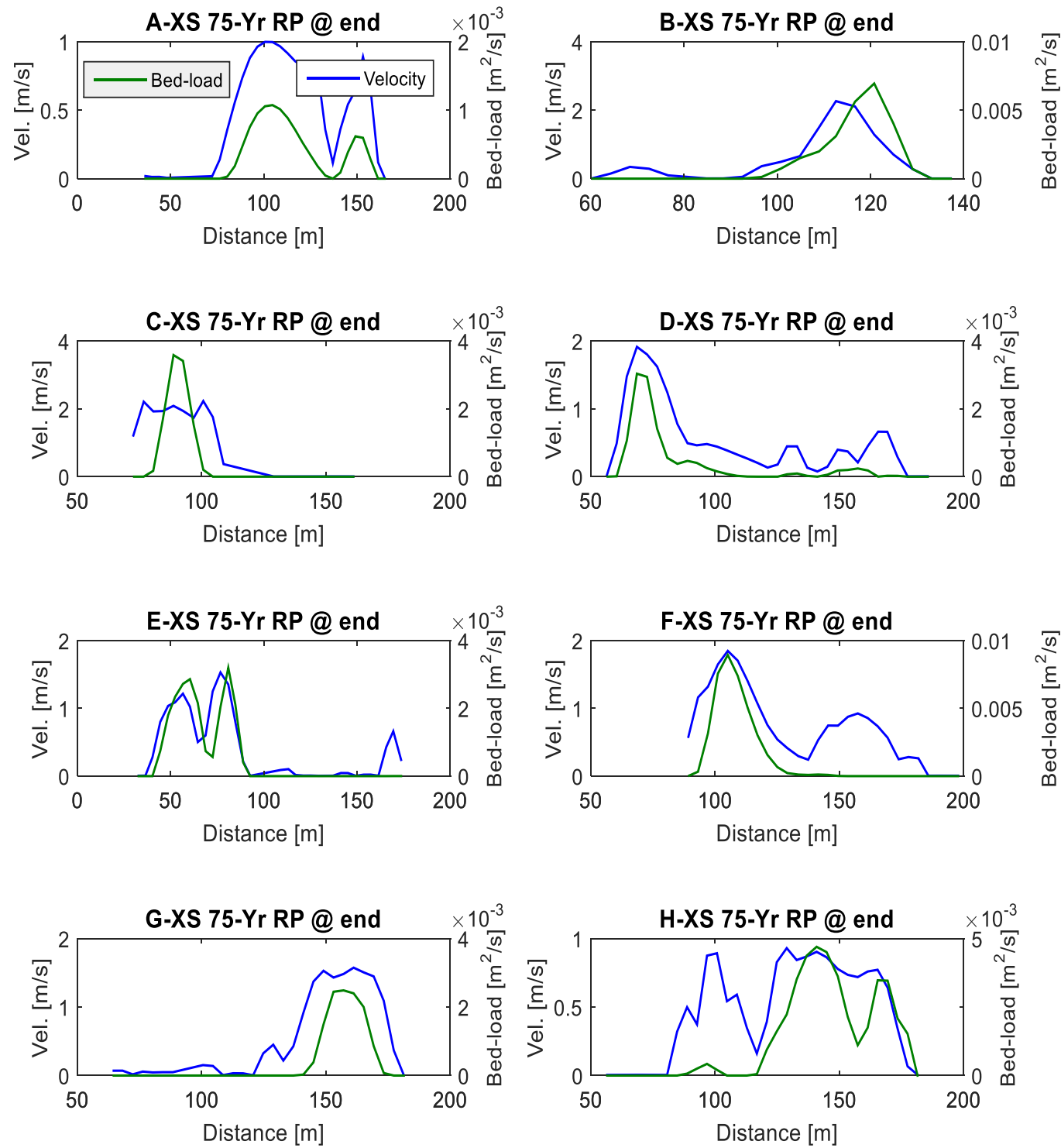

Figure 5-3-14 As in Figure 5-3-5, but for the 75-year event, the final flow condition. 

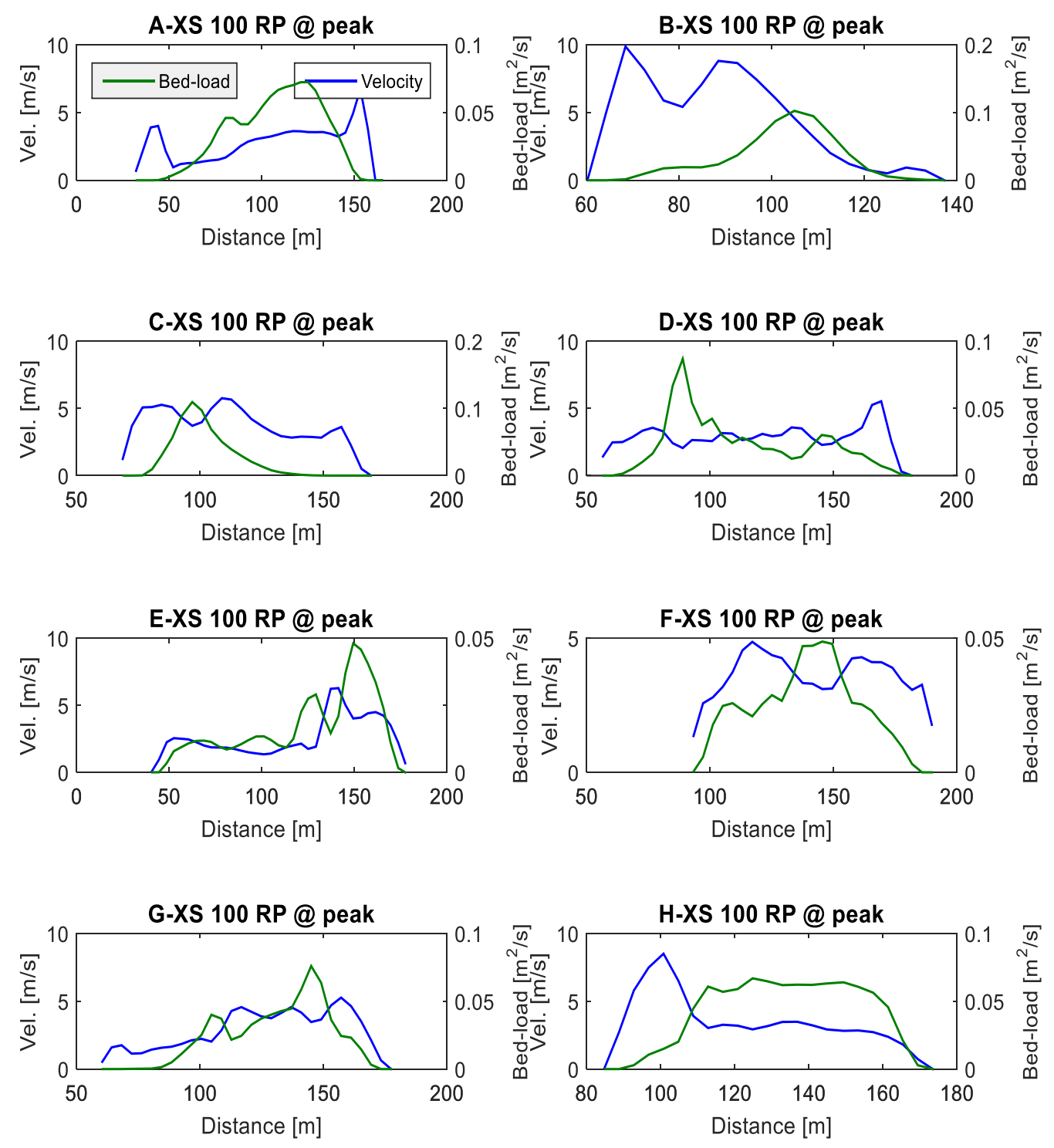

Figure 5-3-15 As in Figure 5-3-5, but for the 100-year event. 

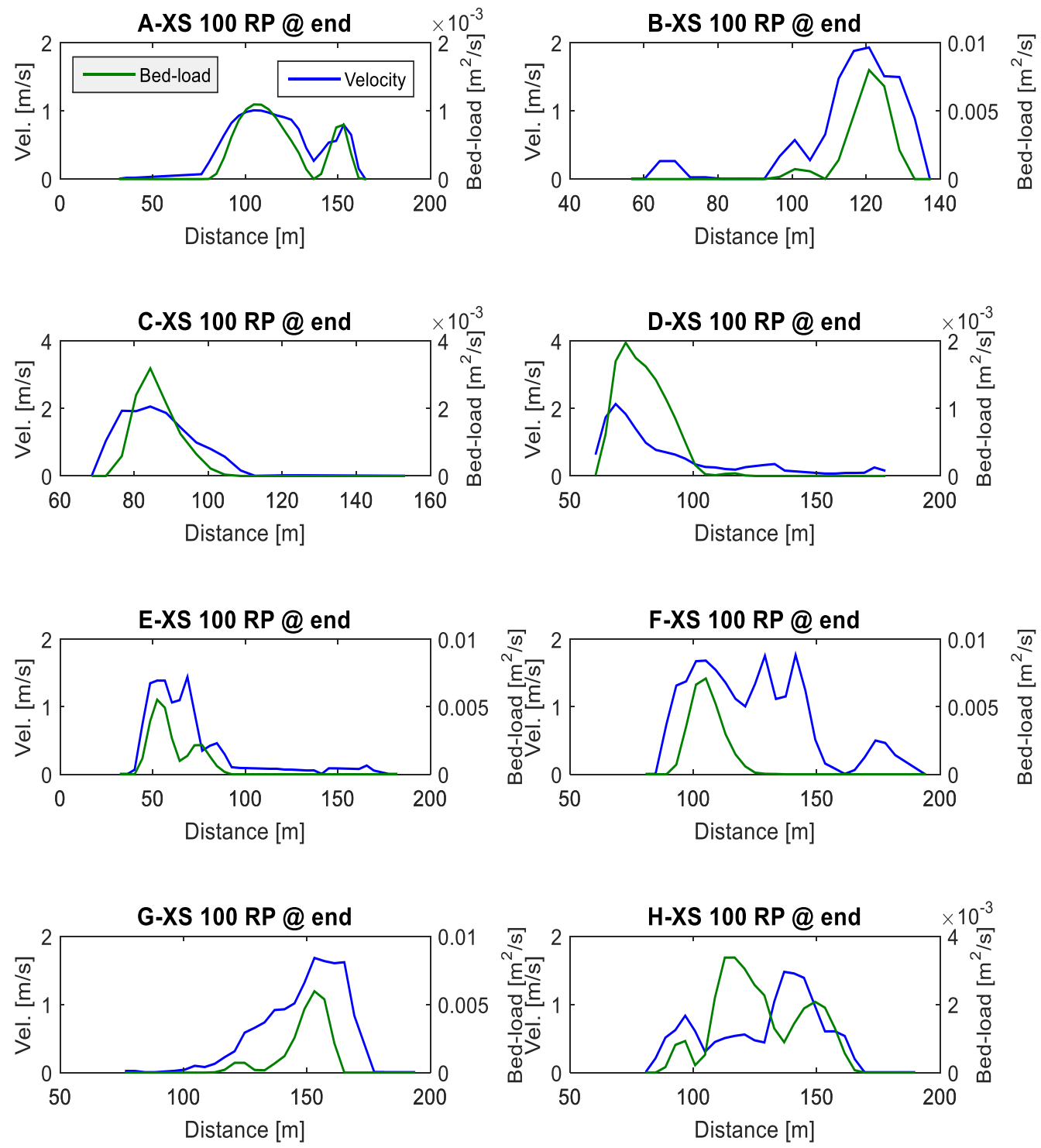

Figure 5-3-16 As in Figure 5-3-5, but for the 100-year event, the final flow condition. 

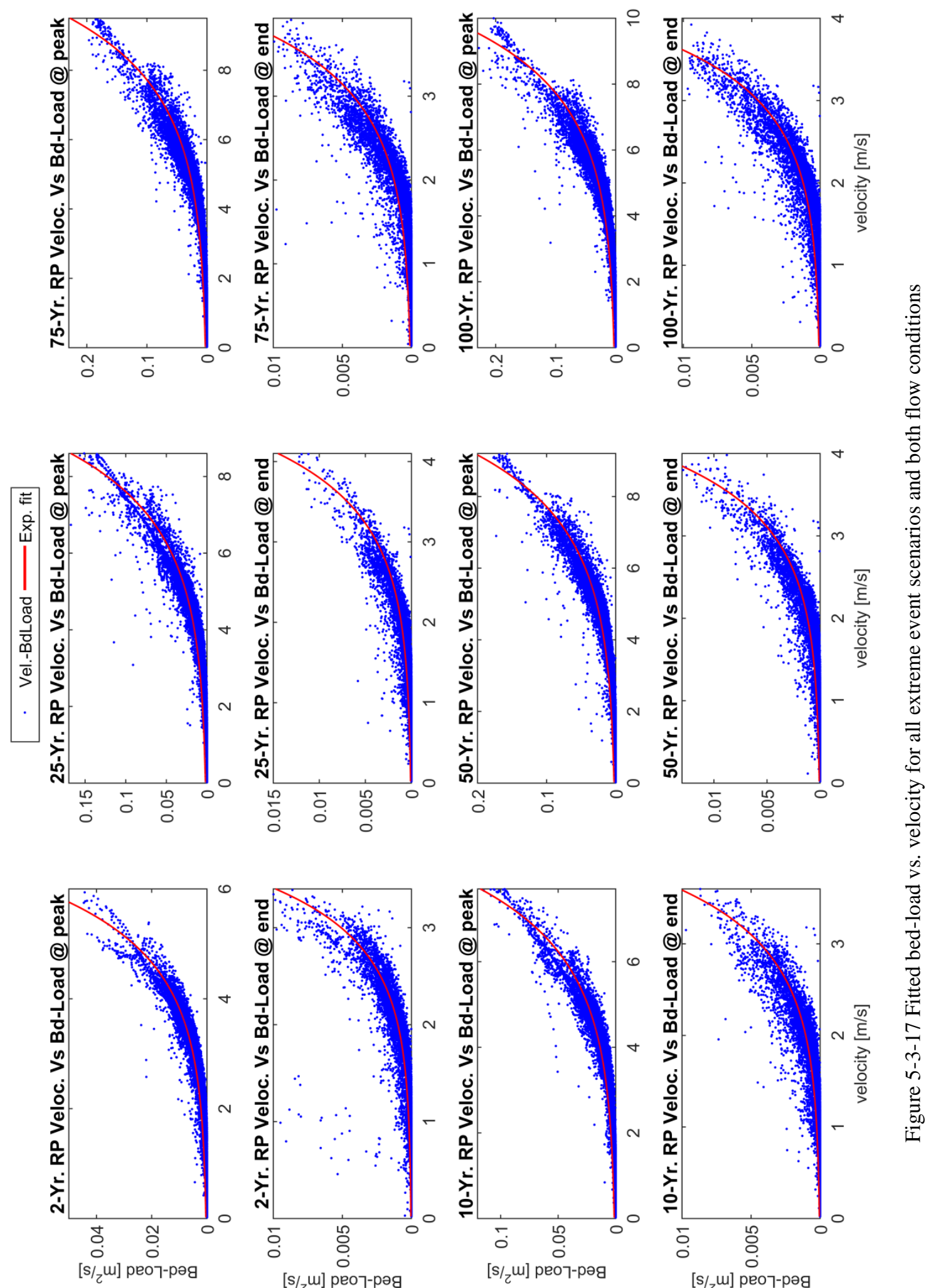
Table 5-3-1 Relations between bed-load and velocity

\begin{tabular}{clll}
\hline $\begin{array}{c}\text { Return } \\
\text { Periods }\end{array}$ & Flow & $\begin{array}{c}\text { Relation between } \\
\text { velocity and Bed-load }\end{array}$ & $\mathrm{R}^{2}$ \\
\hline \multirow{2}{*}{2} & Peak Flow & $B L=0.000414 e^{0.8324 \mathrm{Vel}}$ & 0.906 \\
& End of Event & $B L=3.62 * 10^{-5} e^{1.648 \mathrm{Vel}}$ & 0.787 \\
\multirow{2}{*}{10} & Peak Flow & $B L=0.00131 e^{0.584 \mathrm{Vel}}$ & 0.910 \\
& End of Event & $B L=6.078 * 10^{-5} e^{1.422 \mathrm{Vel}}$ & 0.824 \\
\multirow{2}{*}{25} & Peak Flow & $B L=0.00194 e^{0.518 \mathrm{Vel}}$ & 0.893 \\
& End of Event & $B L=9.576^{-5} 0^{1.224 \mathrm{Vel}}$ & 0.848 \\
50 & Peak Flow & $B L=0.00247 e^{0.48 \mathrm{Vel}}$ & 0.895 \\
& End of Event & $B L=8.92 * 10^{-5} e^{1.295 \mathrm{Vel}}$ & 0.861 \\
75 & Peak Flow & $B L=0.0028 e^{0.464 \mathrm{Vel}}$ & 0.882 \\
& End of Event & $B L=0.000113 e^{1.207 \mathrm{Vel}}$ & 0.829 \\
\multirow{2}{*}{100} & Peak Flow & $B L=0.002915 e^{0.4574 \mathrm{Vel}}$ & 0.882 \\
& End of Event & $B L=9.34 * 10^{-5} e^{1.294 \mathrm{Vel}}$ & 0.856 \\
\hline
\end{tabular}

\section{5-4 Predictions of Erosion and Deposition}

Erosion and deposition are major controls on the geomorphology of river channels and floodplain. Their values depend on the flow and geological or geotechnical features of the locations modeled. The latter factors vary on small spatial scales. In this study, the erosion and deposition mean values are assumed to predict how the depth of each of erosion and deposition is changed with changing flow condition. These are assumed to be representative of geomorphological change associated with each event and depend on the magnitude of the flow itself, or the return period of the flow. Because the geomorphic response of a river channel and floodplain is the local phenomena dependent on factors other than flow, it is very hard to predict regionally. The best integral measure of geomorphic change in the model domain are the spatial means of the erosion depth and deposition depth, given in Table 5-4-1. 
Table 5-4-1 Mean erosion and deposition depth of the river reach for each return period and both flow conditions

\begin{tabular}{ccccc}
\hline \multirow{2}{*}{$\begin{array}{c}\text { Return Period } \\
\text { [Year] }\end{array}$} & \multicolumn{2}{c}{ Mean Erosion Depth [m] } & \multicolumn{2}{c}{ Mean Deposition Depth [m] } \\
\cline { 2 - 5 } & peak & end & peak & end \\
\hline 2 & -0.677 & -1.164 & 0.845 & 1.037 \\
10 & -1.067 & -1.782 & 1.114 & 1.321 \\
25 & -1.432 & -1.890 & 1.376 & 1.558 \\
50 & -1.615 & -2.262 & 1.656 & 1.721 \\
75 & -1.685 & -2.407 & 1.759 & 1.883 \\
100 & -1.717 & -2.392 & 1.879 & 1.936 \\
\hline
\end{tabular}

Predicted erosion and deposition vary almost linearly with peak flow, as is shown in Figure 5-4-1 and 5-4-2. The relationships shown in Figure 5-4-1and 5-4-2 have high correlation parameters and their relations and correlation coefficients are as follow:

Avg.Ero. ${ }_{\text {Peak }}=-8.8 \times 10^{-4} Q p-0.36$

$R^{2}=0.981$

Avg.Dep $\cdot_{\text {Peak }}=8.55 \times 10^{-4} Q p+0.46$

$R^{2}=0.986$

Interestingly, mean erosion and deposition depth at the end of the various events vary nonlinearly with return period. Thus the have been fit using a power low in Figure 5-4-3 and 5-4-4 show the mean erosion and deposition at the end of the events with their 95\% confidence intervals respectively which are fitted with power function. The resulting relationships are:

$\operatorname{Avg.Ero~}_{\text {End }}=-1.11 R P^{0.175}$

$R^{2}=0.965$ 
$A v g$. Dep $_{\cdot_{\text {End }}}=0.917 R P^{0.1634}$

$R^{2}=0.998$

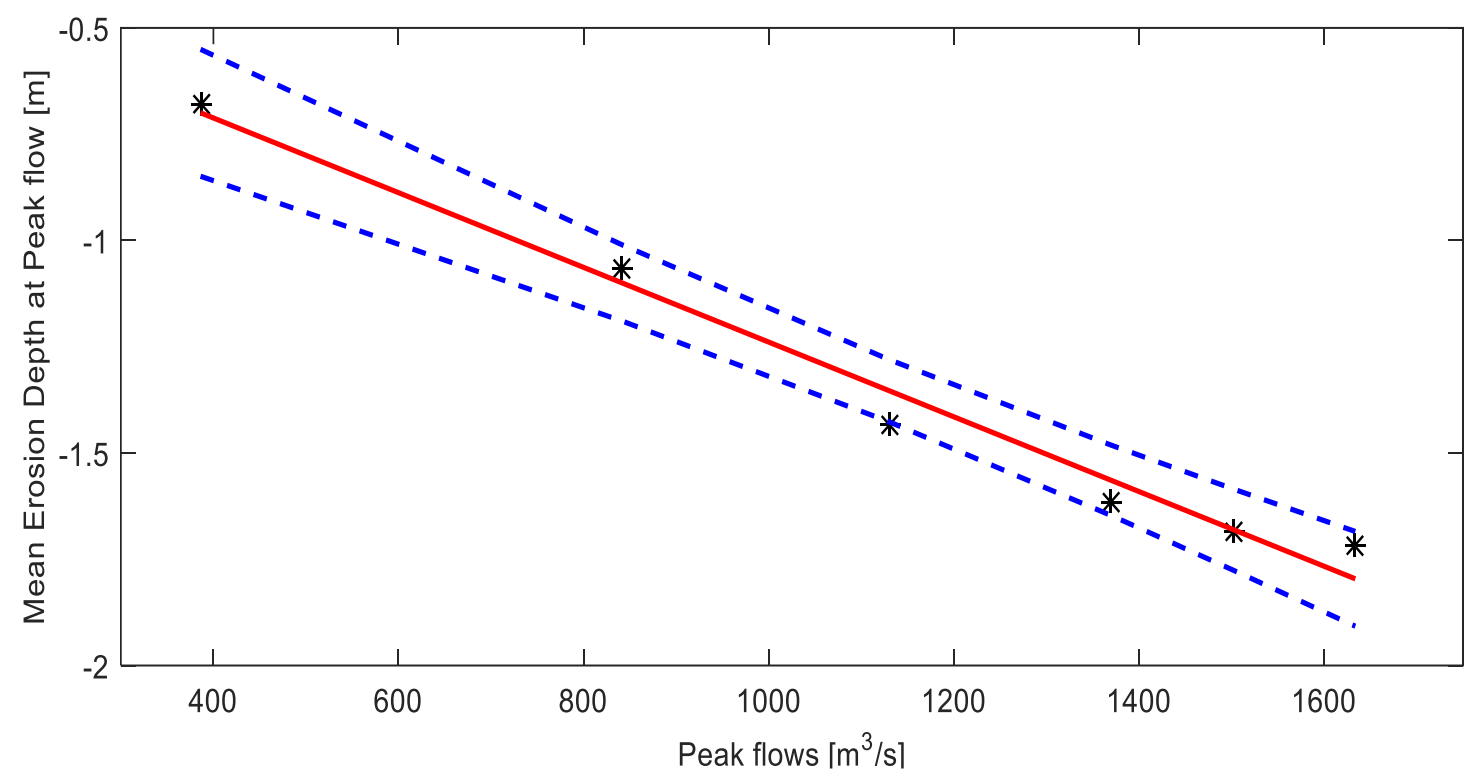

Figure 5-4-1 Mean erosion depth for the peak flow condition

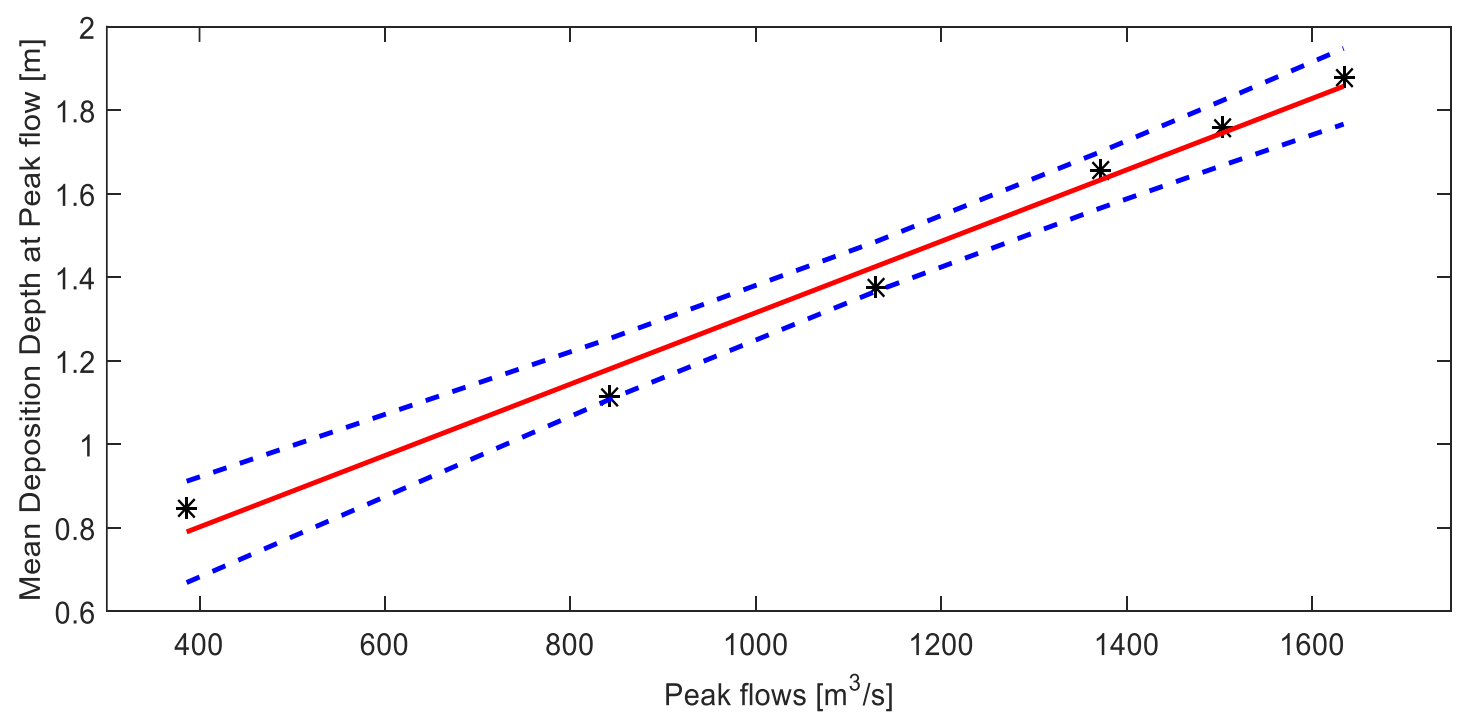

Figure 5-4-2 Mean deposition depth at peak flow condition 


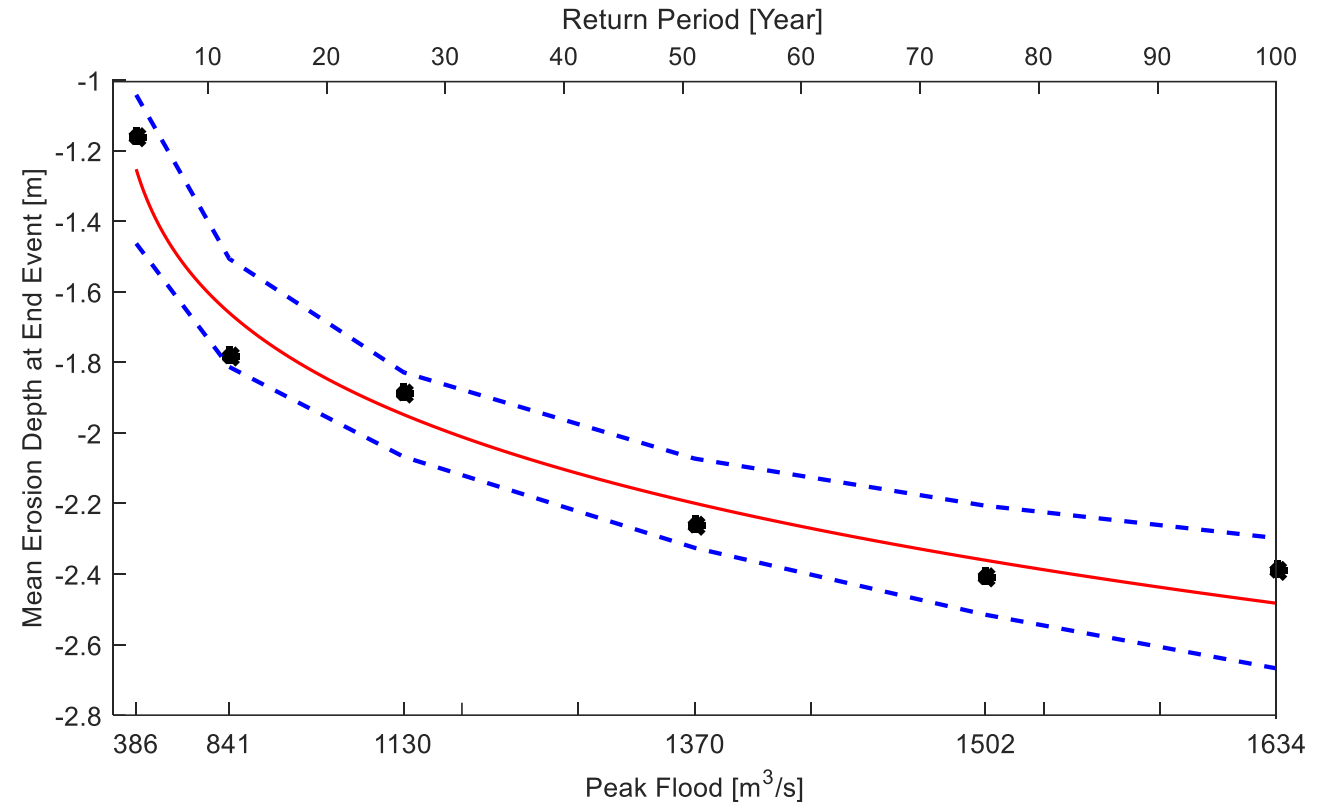

Figure 5-4-3 Mean erosion depth at end of the events flow condition (return periods)

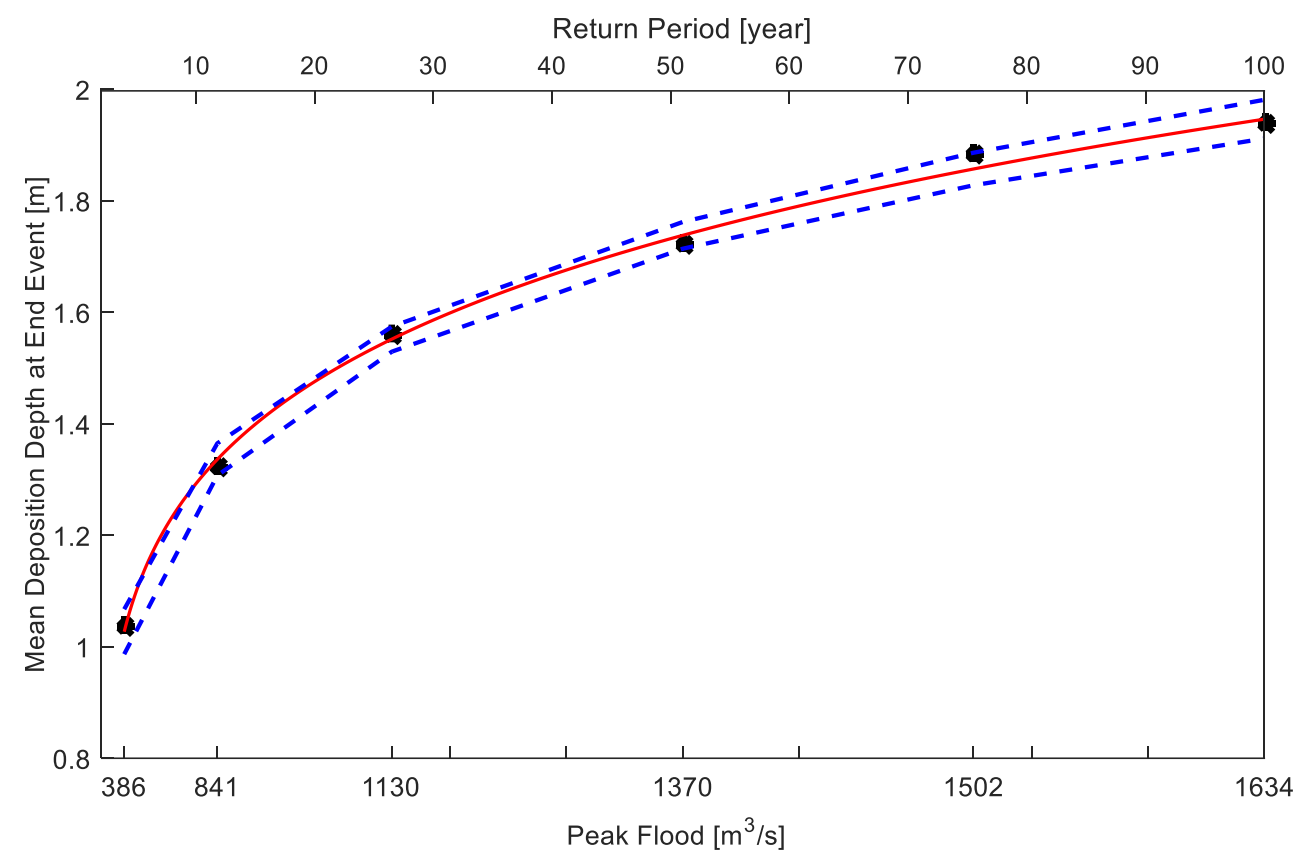

Figure 5-4-4 Mean deposition depth at end of the events flow condition (return periods) 


\section{5-5 the 100-Year Event with M-P M Formula}

The bed-load formula used to sediment transport model is Ashida and Michiue formula; but Nays2DH also implements the Meyer-Peter and Müller formula for bed-load transport. The 100 year return period was also run by using the Meyer-Peter and Müller formula and the results of the elevation change for event peak and final flow conditions and, spatial distribution of the erosion and deposition are shown in Figures 5-5-1 and 5-52 respectively.
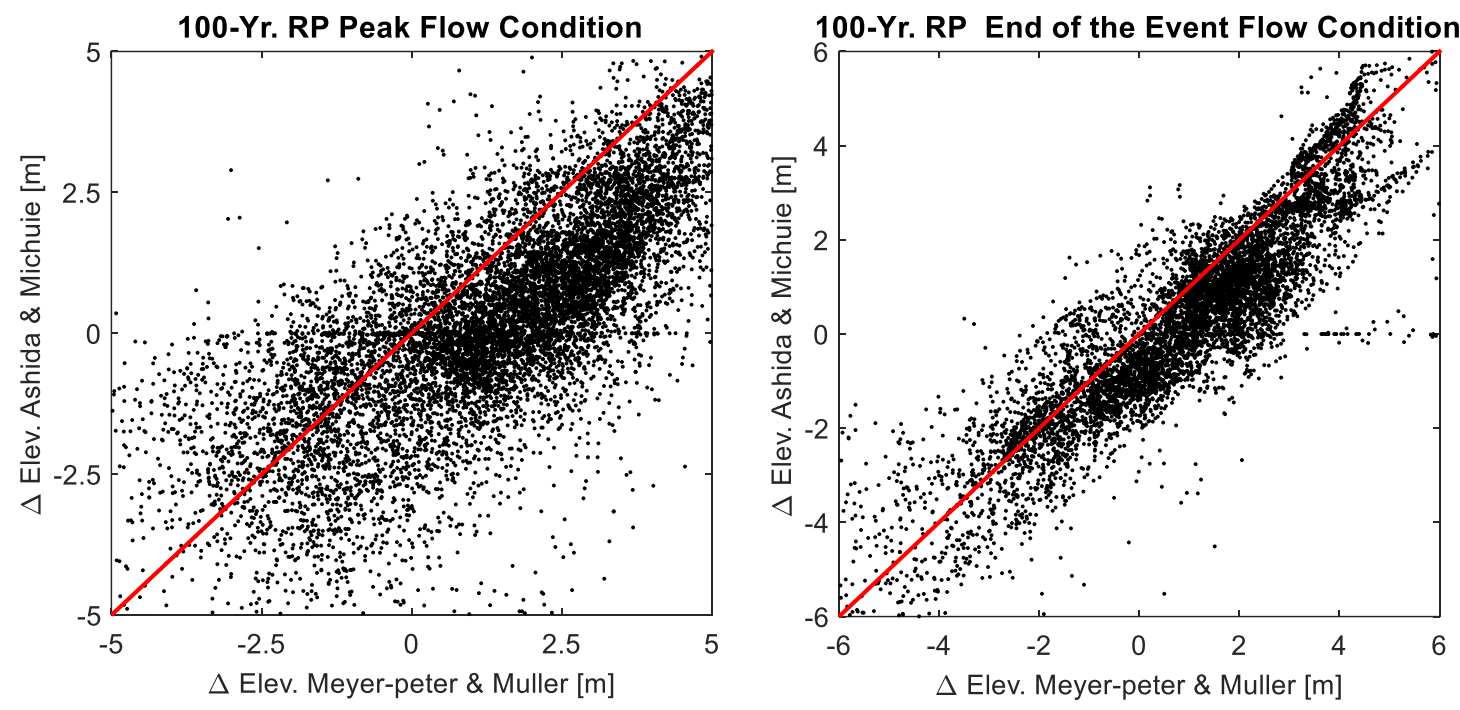

Figure 5-5-1 Elevation change of 100 year return period for both Ashida and Michiue formula and MeyerPeter and Müller formula at peak and end of the event flow condition 

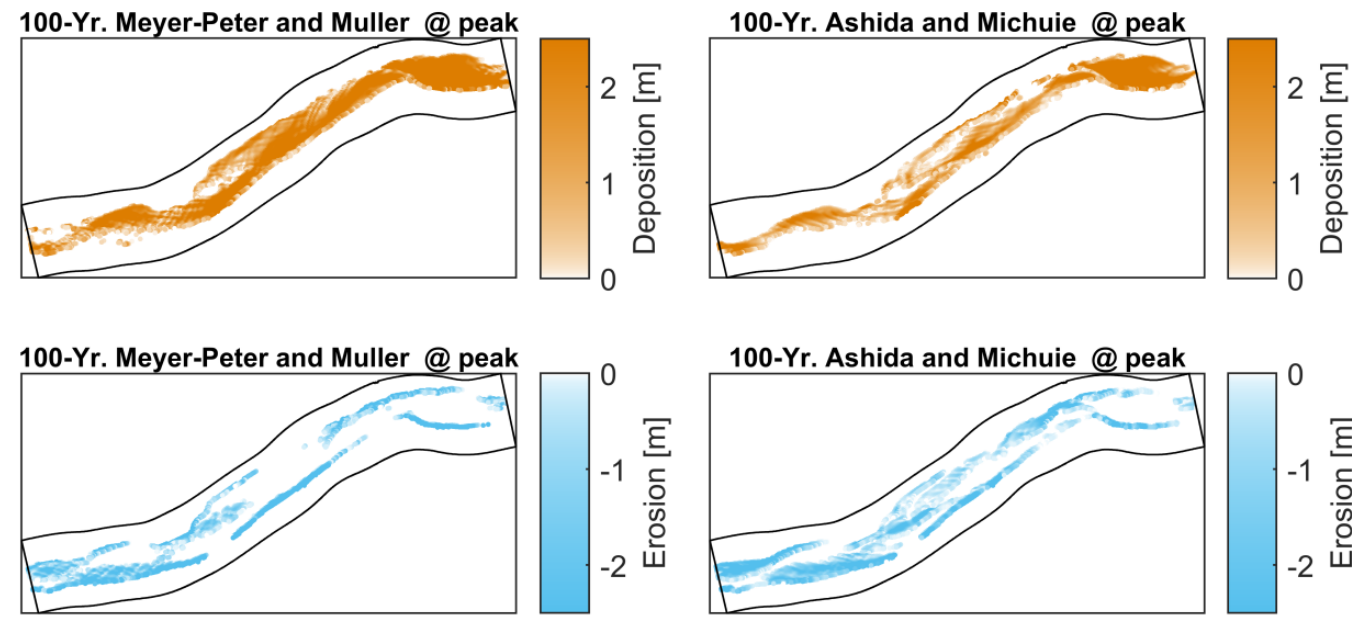

100-Yr. Ashida and Michuie@ @ peak

100-Yr. Meyer-Peter and Muller @ end
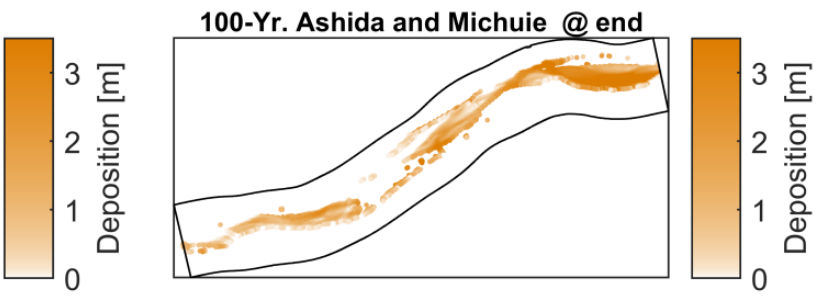

100-Yr. Meyer-Peter and Muller @ end
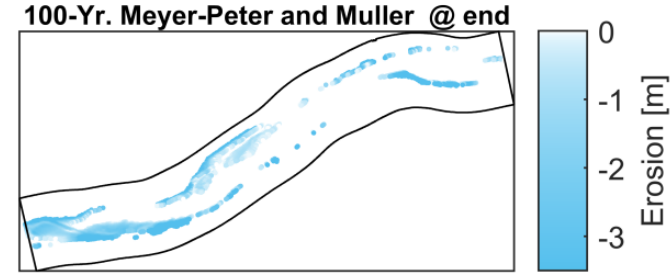

100-Yr. Ashida and Michuie @ end

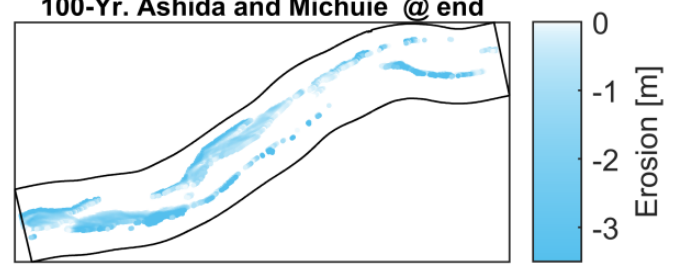

Figure 5-5-2 The erosion and the deposition spatial distribution for the 100 year return period scenario for the Ashida and Michiue formula and the Meyer-Peter and Müller formula, for peak and final flow condition 


\section{Chapter 6: Conclusion and Discussion}

\section{6-1 Conclusion and Summary}

This study examines hydro-geomorphological evolution due to multiple flood event scenarios for a reach of the Sandy River, using two-dimensional flow and sediment transport model, Nays $2 \mathrm{DH}$. The study area is moderately sinuous and is locate downstream of the former Marmot Dam (removed in 2007). A Log-Pearson Type III distribution was used to model extreme event values with different return periods. The highest peak discharge hydrographs in 2008, 2010, 2011, 2012, 2013, 2014, and 2015 were used to simulate extreme event hydrographs; both simulated and observed flood hydrographs were summarized using a Gamma distribution curve function.

Floods in the Sandy River are a major problem. Picture of past floods illustrate the potential danger of the floods to the people and property that are located near the bank of the river; see Figures 6-1-1 to 6-1-3 for examples of high water, bank erosion, and major property damage.

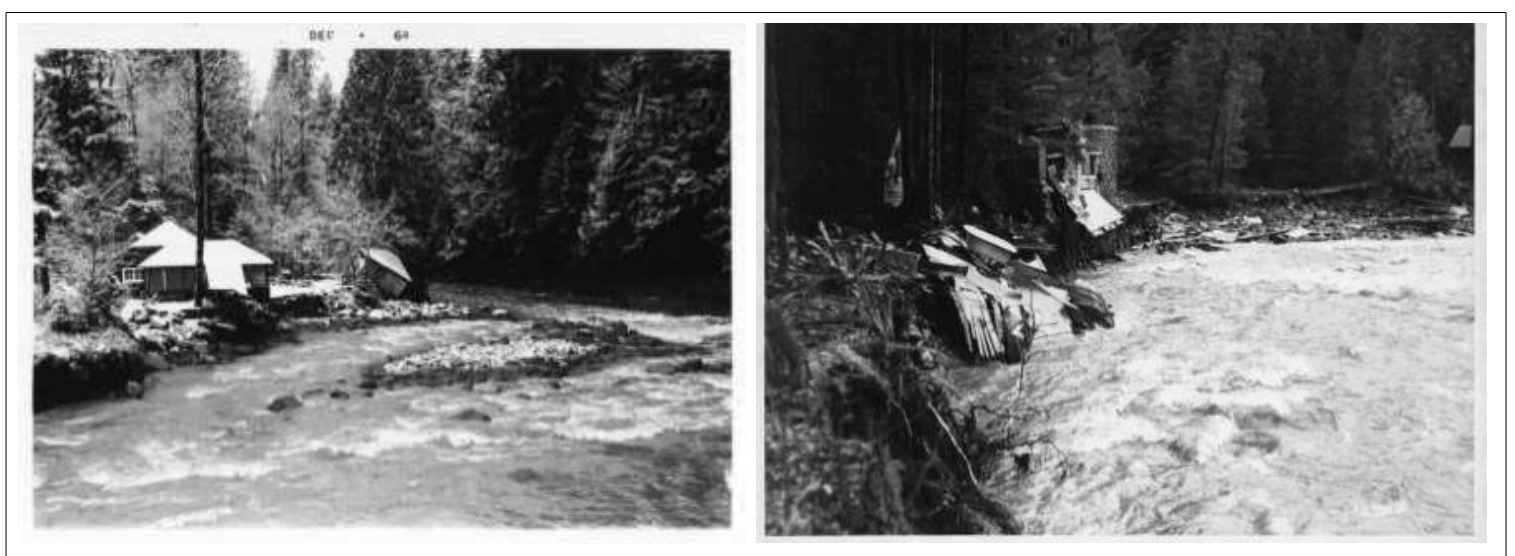

. Figure 6-1-1 1964 flood in the Sandy at the upstream of the study area 


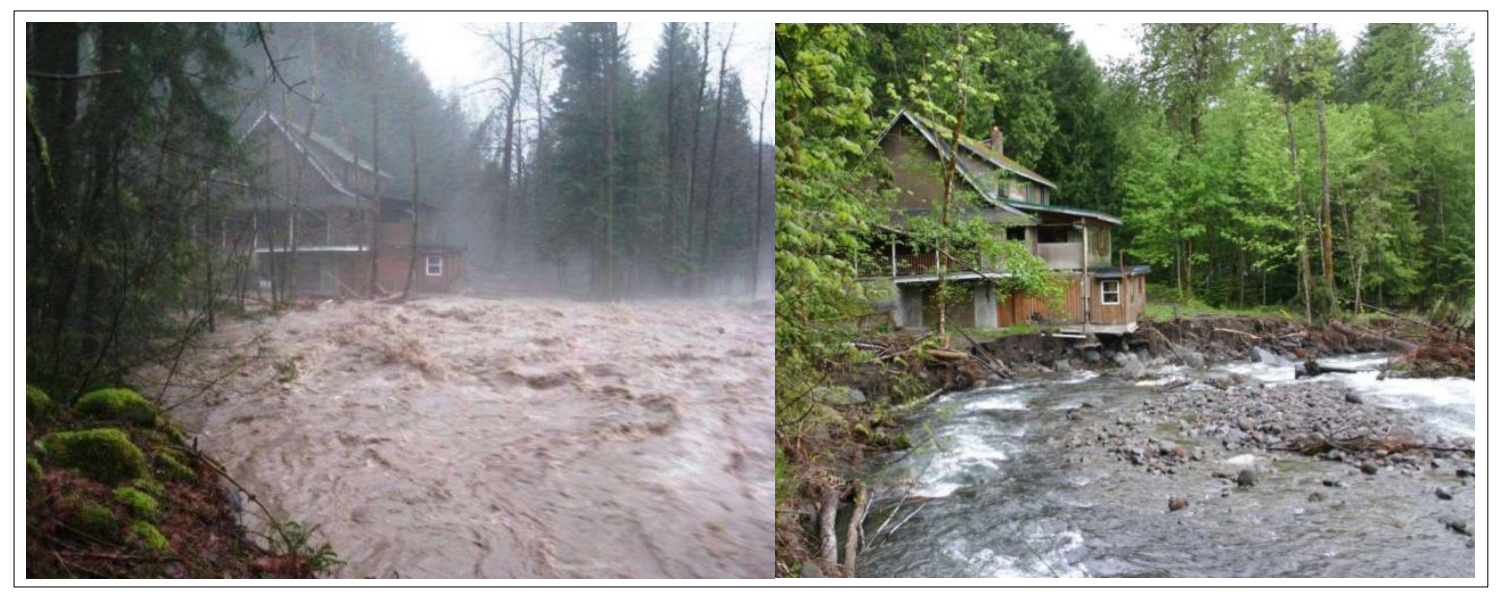

Figure 6-1-2 2011 flood, same location in two different times

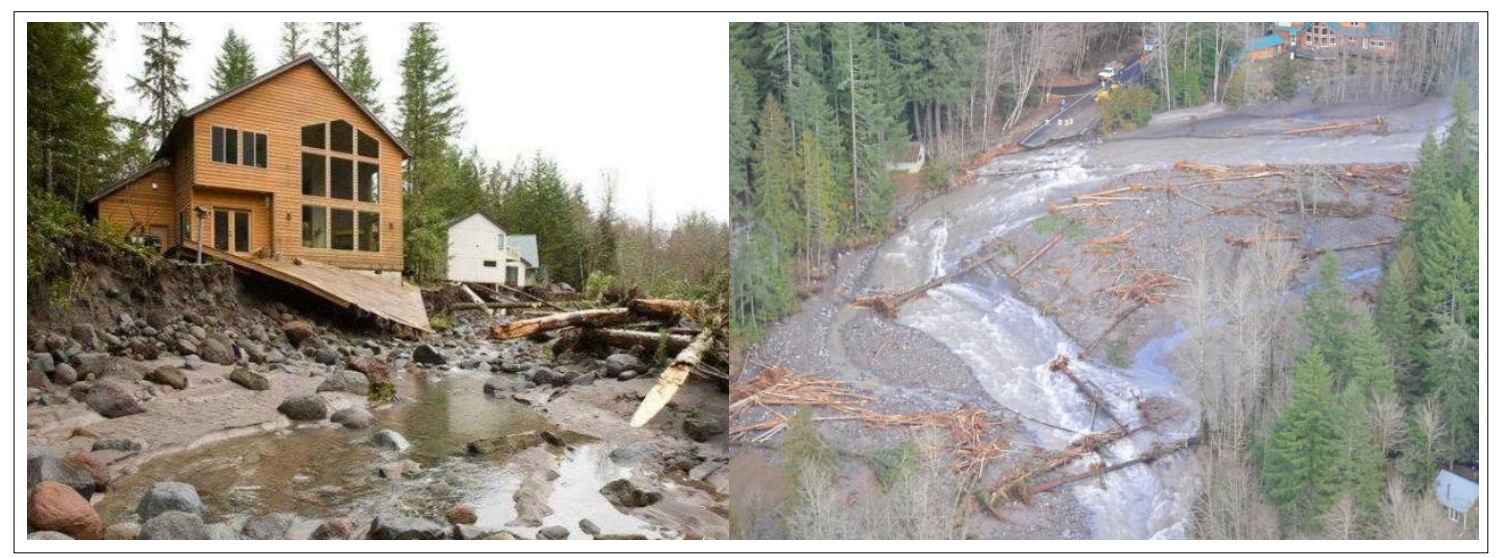

Figure 6-1-3 2011 flood in other locations

If we assume the floodplain on both sides of the river to be $100 \mathrm{~m}$ in the middle section after the bend in Figure 6-1-1 and 6-1-2, the river migrated about $14 \mathrm{~m}$ to the left side of the river (watching to downstream) for 100 year flood (Figure 6-1-1) and about $10.4 \mathrm{~m}$ with 50 year flood (Figure 6-1-2). This changes especially 100 year flood event is 
considered as long term change in the topography of the riparian areas because the direction of the river pass will totally change and the features of the riverine environment alter as well. These photos emphasize the need to model and understand flood-induced erosion and deposition in steep systems like the Sandy River.

Realistic fluvial sediment transport computations are, however, computationally intensive, so a careful compromise between grid resolution and computational intensity is needed. Convergence of the Nays $2 \mathrm{DH}$ model as a function of spatial grid resolution was checked using 1.5, 2, 3, 4, and $5 \mathrm{~m}$ grid resolution. Based on convergence of the spatially averaged the geomorphic response of the study area, a $4 \mathrm{~m}$ resolution was for modeling purposes as the coarsest grid that provided good results, very similar to grid with 2 and 3 $\mathrm{m}$ resolution. This model was run for six different scenarios, representing flood return periods of 2, 10, 25, 50, 75, 100 years. The result of scenario analyses and interpretation of physical parameter (depth, velocity, bed-load, and suspended-lad) variations was presented. The average morphodynamics of the river reach as a function peak flows and return periods was analyzed.

The Nays2DH model was used to represent the morphodynamics of a reach of the Sandy River for flood scenarios with return flows between 2 and 100 years. Each scenario has its own impacts on the system in term of geomorphic response. Because the floods of 100 year and 75 years return periods are very large and cause obvious bed and bank evolution, they could cause long term changes in the morphology of the system (e.g., Figures 5-2-2 and 5-2-3). Erosion and deposition increase during the rising limb of 
hydrograph, and land accretion occurs in the falling limb, especially in the bend of the river, as is obvious in the Figures 5-2-2 and 5-2-3.These processes locally change the direction and channel location of the river.

These changes in morphology are also connected to another prominent phenomenon: flow-sediment transport hysteresis. Figures (6-1-4 and 6-1-5) show the cross-sectional bed and suspended load hysteresis for 100 and 10 years return periods in the $450 \mathrm{~m}$ from upstream face of the study area. In the both cases, the peak of transport for both of the suspended and bed-load are occurs after the peak discharge. This hysteresis is mainly forced by depth of the water, bedform, bedslope, shear stress, flow discharge and sediment layering (Kleinhans et al, 2007). In cases where sediment supply is limited, peak sediment transport typically occurs before peak flow. In this case, there is ample sediment to move, and peak transport occurs here after the peak of the flow, possibly as a result of the cumulative bank erosion that occurs around the time of peak flow. Alternatively, the peak flow may have reduced bed armoring that occurred early in the flood, resulting in a sudden increase in transport. 


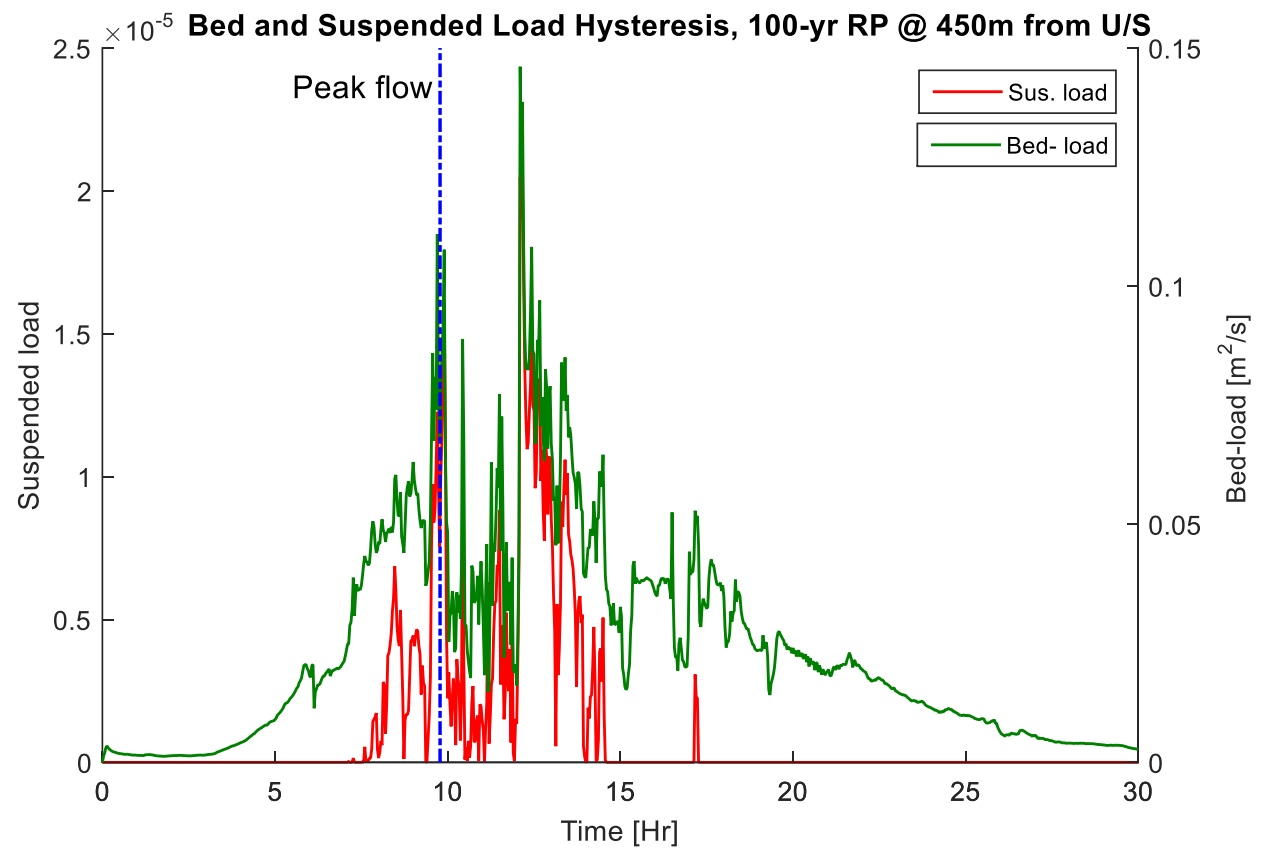

Figure 6-1-4 Cross-sectional hysteresis of suspended and bed-load for 100 year flood return period which is taken from $450 \mathrm{~m}$ from upstream face of the study area

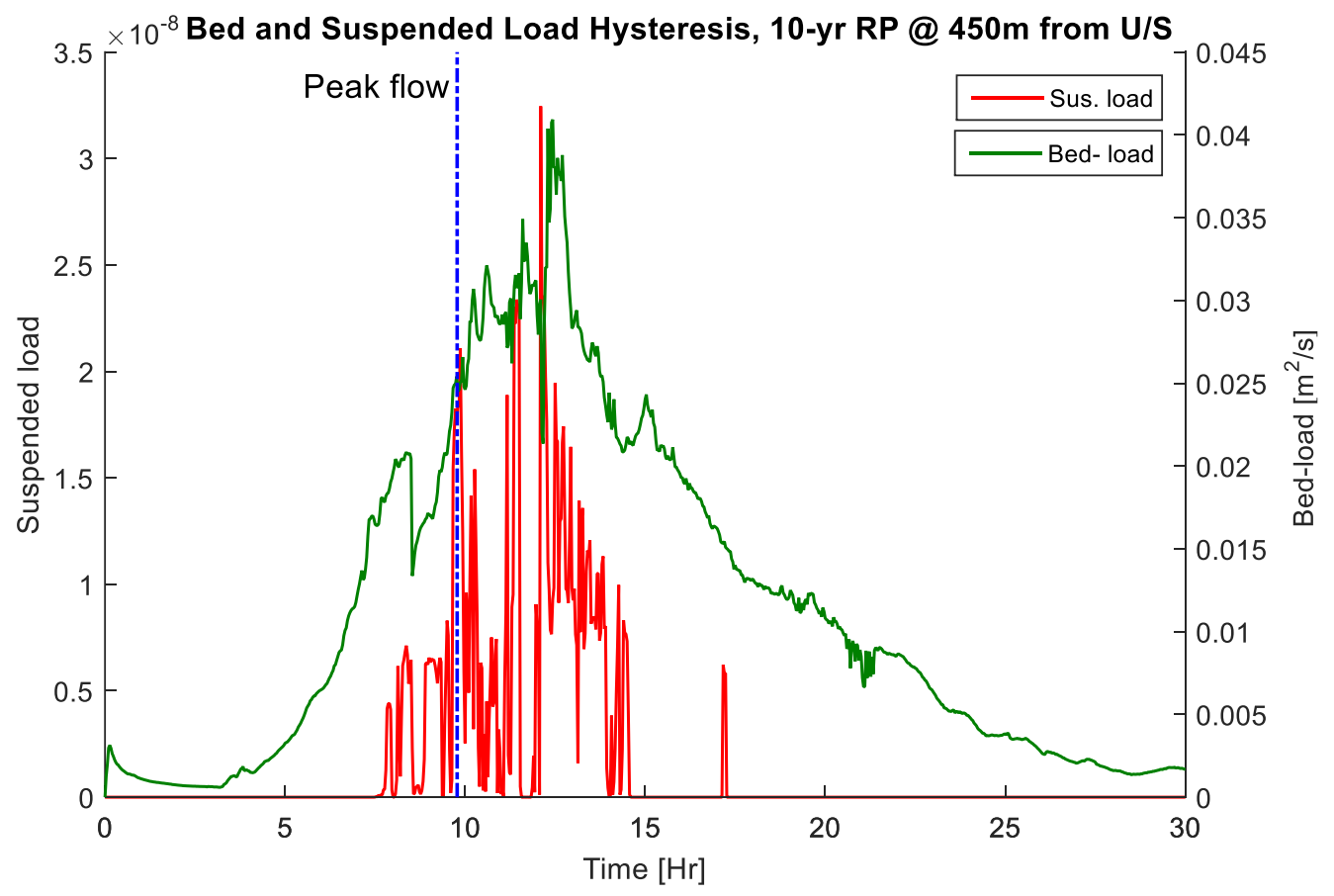

Figure 6-1-5 Cross-sectional hysteresis of suspended and bed-load for 10 year flood return period which is taken from $450 \mathrm{~m}$ from upstream face of the study area 
The bed slope of the river reach is the function of the shear stress and the depth of the water; neglecting accelerations, $\tau=\rho_{w} d S g$. Where, $\tau$ is the bed shear stress, $\rho_{w}$ is the density of water, $S$ is bedslope, and $\mathrm{g}$ is gravity due to acceleration. The bed slope affects the total transport in the system. Changing slope versus time for the same cross-section is shown in the figure 6-1-6 for the 100 and 10 years return periods. The increasing bed slope shown in Figure 6-1-6 may be one of the reasons for the sediment-flow hysteresis shown in Figure 6-1-5. By increasing slope of the bed, the sediment transport increased that means the erosion process increased as well.
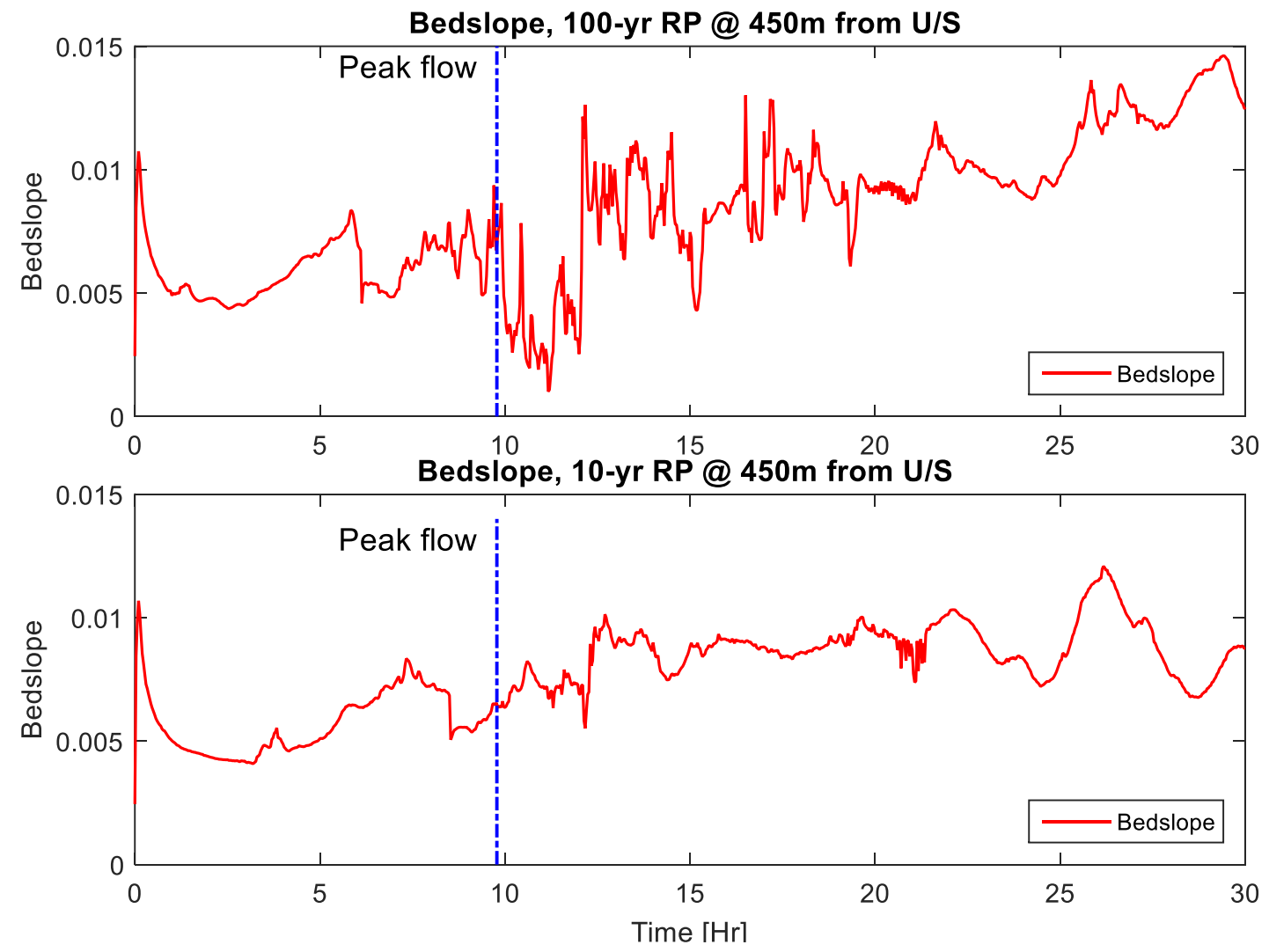

Figure 6-1-6 Cross-sectional bedslope change with time for 100 and 10 years flood return periods which are taken from $450 \mathrm{~m}$ from upstream face of the study area 


\section{6-2 Future Climate Impacts}

Climate change has had extraordinary influence on glaciers on Mt Hood and elsewhere. Many glaciers are shrinking and thinning due to global warming (Dalton et al., 2013). According Hamlet et al, (2013) for climatic scenarios A1B and B1 for the Columbia River basin, the Sandy River basin projected to change from transition (snowrainfall dominated) to rainfall-dominant from the 2020s forward (Figure 6-2-1). This transformation will occur due to shrinking of Mount Hood glaciers, higher average temperatures, and heavier storms. Thus, the river discharge will be increased in winter and reduced in summer. As a result, wild fire risk will increase due to drier and higher temperature in the summer and lead to less forestation in the basin. 


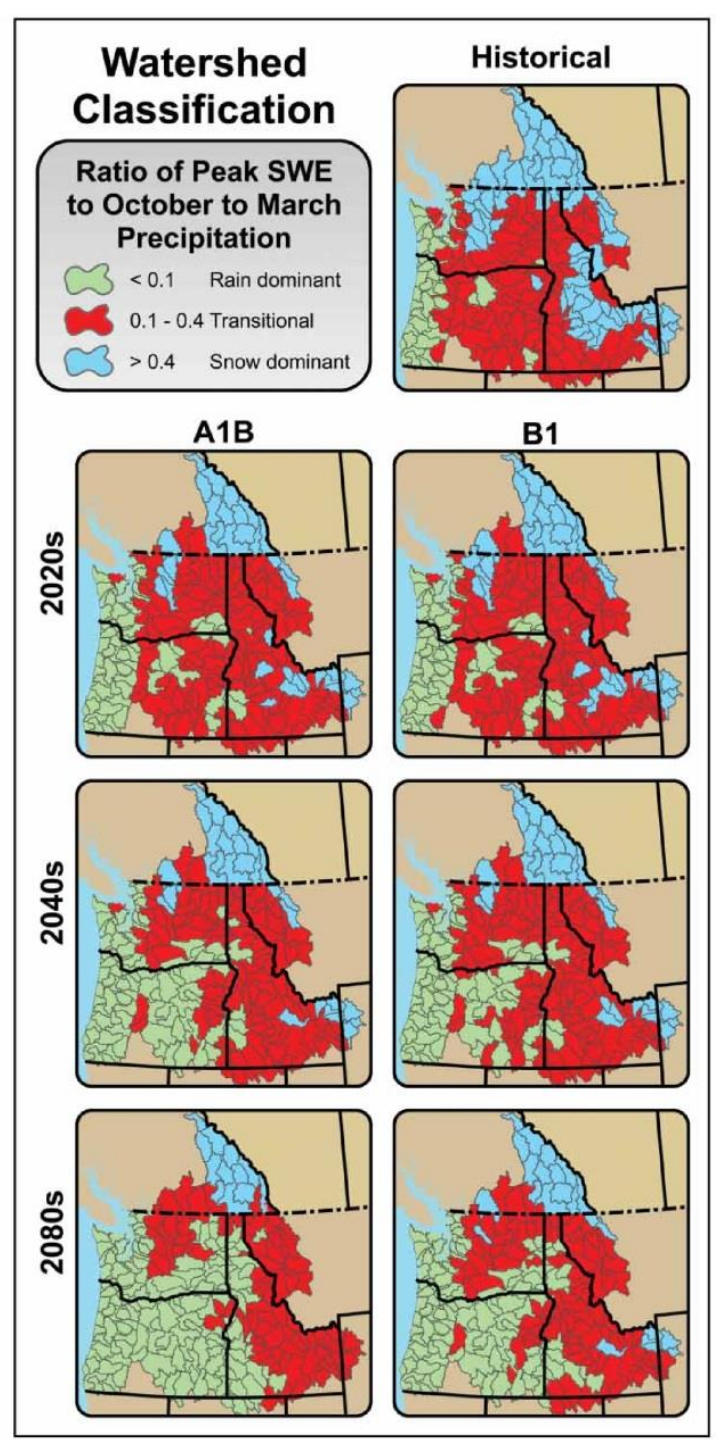

Figure 6-2-1 Watersheds of Columbia River basin for projected climate change scenarios (retrieved Hamlet et al, 2013)

\section{6-3 Discussion of Model Limitation and Recommendations}

The geomorphic response of rivers to extreme events is very important to riverine environments, because they are major factors driving changes in the system, will happen again in the future, and may become larger in the Pacific Northwest as the climate 
warms. The morphologic response of a river affects all aspects of the system, e.g.,, management of the river, vegetation of the riparian area, fish habitat, water quality, the future sediment budget, and hydraulic characteristics of the river (e.g. flood inundation). Whenever the geomorphology of a river changed, it affects aquatic habitat, causing fish and other aquatic organisms to experience a somewhat environment. The Sandy River's most fish of greatest interest to humans is the Steelhead salmon (Sandy River Fishing. 2001). Major flood events can affect salmonid eggs and migration of Steelhead. More extreme floods might more take place because of the effect of climate change and global warming (IPCC, 2007). In particular, the Sandy River basin will transform to rainydominant; whatever precipitates, passes through the river channel and it makes big flood. It is unclear what affect this will have on salmonids.

The particle size distribution of the Sandy River at river miles 39.65 and 40.3 have D80s (80\% of particle are passed) of about $130 \mathrm{~mm}$ and $260 \mathrm{~mm}$ respectively. These particles have critical shear stresses for erosion of $113 \mathrm{~Pa}$ for $130 \mathrm{~mm}$ and $225 \mathrm{~Pa}$ for $260 \mathrm{~mm}$, values that are in the range of applied bed shear stress during flood events. The computational domain for this study is relatively small, about $1.8 \mathrm{~km}$ in the downstream of the Marmot Dam. If the computational domain were to be increased to include a longer reach, there are two options: either reduce the spatial resolution of the mesh grid or increase the computational power. The latter is expensive, because the model is computationally very intensive. The Sandy River reach used for this study is curved, and flow in curved channel is very complicated because secondary flow comes to play and this sort of phenomena should, in principle, be simulated by three-dimensional model 
(Duan and Julien, 2010). Secondary flow at bends influence sediment erosion and transport, and the direction of sediment transport. Secondary flow tends to erode the outer bank and cause deposition on the inner bank of bends. Though secondary flow is treated by imperial relationship in the Nays2DH, a three-dimensional model is needed to fully represent it (Garcia, 2008). There are many three-dimensional hydrodynamic models that can simulate morphodynamics of the rivers and estuaries, like TELEMAC-3D, FLESCOT, SUTRENCH-3D, CH3D-SED, RMA-10, MIKE 3, FAST3D, and Delft3D. Each of these models has its own assumptions and characteristics, and some of them are not stable for the supercritical flow (Froude Number $>1$ ) that occurs in steep channel like the Sandy River (Spasojevic and Holly, 2008). Another constraint is the DEM based on the data collected in 2012; because the Sandy River is a very active river with extensive sediment transport even for the 2-year flood event, its bed changes rapidly. This is especially the case because the system is still adjusting after removal of Marmot Dam. Thus, the morphology changes after each flood, new elevation and bathymetry data are needed to get precise model result. However, no more current bed elevation data were available.

Roughness is another very sensitive factor in hydrodynamic modeling that should be calibrated, because it varies widely. The roughness of rivers is influenced by topography of bed, sediment particle sizes, vegetation, and channel geometry (parahi et al., 2012). In our study, we use just two values of Manning's roughness coefficient, one for river channel and other for floodplain. 
The normal (without high flood events) morphodynamic response of rivers takes place slowly and usually requires several years to show an obvious response. As mentioned before, the Nays2DH is very intensive computationally, so long-term morphodynamic modeling with this model was not feasible in this project. While one-dimensional models are available (Spasojevic and Holly, 2008), they would not provide any detail regarding channel migration. Instead, the model was run for 30 hours flood which can be considered as short term hydrographs. These modeled floods move a large amount of sediment in a short time, so a significant and observable effect could be obtained.

Another simplification in the modeling was the use of a uniform grain size of sediment. This is an approximation, because a river beds always consist of multiple size sediment, and because the Sandy River bed is poorly sorted, as it is downstream of an active glacier that provides a wide range of sediment sizes. Because the model needed to simulate high flow events, the banks adjusted due to erosion by impacts of high flows. Nays2DH is not able to simulate bank erosion with multiple sizes, and multiple sizes also require more computational power, so we decided to use single size with bank erosion model. Sediment material size is very important for the sediment transport, because each size has its own critical shear stress and larger particle are much more difficult to move. When floods occur, smaller size will (in the absence of armoring of the bed) move initially, then larger and larger will move as flow velocity increases, according to the Shields curve (Figure 6-3-1), again in the absence of bed armoring. 


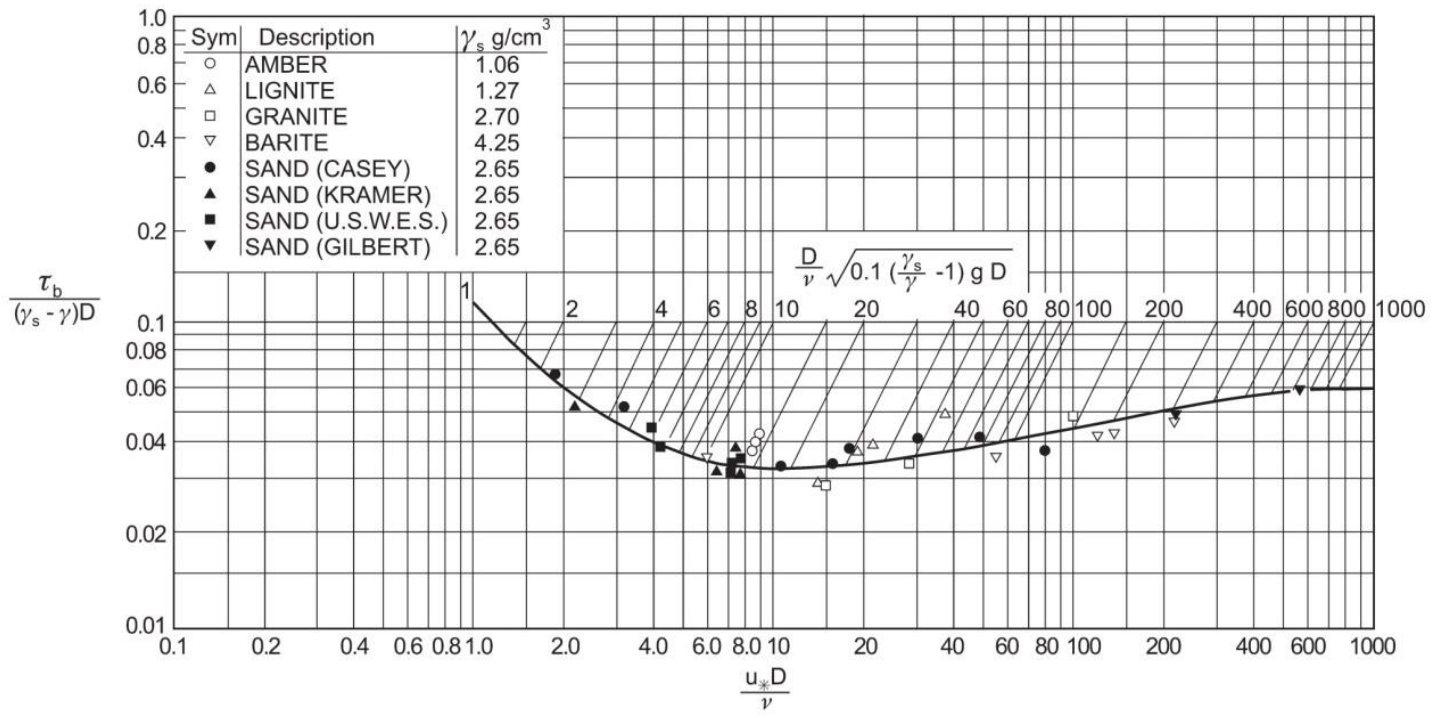

Figure 6-3-1 Shields diagram for initiation of sediment particle movement (retrieved Garcia, 2008)

The effects of vegetation on flow and sediment transport were also not modeled because of a lack of information regarding the type, density, and height of the local vegetation. Though the understanding of interaction of vegetation with flow and sediment transport is not well developed, recent studies have been conducted to analyze the effects of spatial density and height of vegetation (e.g., Iwasaki et al., 2016). Vegetation can vary the flow and sediment transport, for example, un-vegetated model runs typically results more depth, velocity and shear stress, especially at the peak flow condition (Iwasaki et al., 2016). Thus, including realistic vegetation would likely change the results presented here.

Another limitation for this this work is the upstream sediment supply. Upstream inflow sediment was not included in the model, which affects the quantity of transported matter in the model domain, and the amounts of predicted erosion and deposition. An 
upstream boundary with sediment supply (at the equilibrium sediment transport rate) may show relatively balanced erosion and deposition, but without sediment supply this equilibrium is disrupted - the amount of the deposition is reduced compared with the erosion (Kinzel et al. 2015).

Validating models natural systems is difficult, because data collection is time consuming and expensive, and it may be logistically impossible to observed extreme events. We use the amount of gravel accumulated in the reservoir of the former Marmot Dam for validating the result of the coarse sediment in the Sandy River, by making a simple comparison of the amount of sediment accumulated in the reservoir and released in 2007. The amount of sediment accumulated in the reservoir was about 730,000 $\mathrm{m} 3$ of sand and gravel, with 300,000-400,000 tons of sand and 200,000-300,000 tons of gravel (Major et al. 2012). Making use of the flow history, we assume that the Sandy River experienced different flood return periods, and with each flood had a different width of the river channel, based on the inundated area (Table 6-3-1). The columns in Table 6-3-1: Occ. is occurrence of the floods with return periods in column 1, Width is the width of water in the river, $\mathrm{Vol} / \mathrm{m}$ is the volume of sediment transport per meter width, U/S distance is the distance from calculated cross-section to the upstream face of the study area, and U/S River length is the distance from cross section to the head water of Sandy River. 
Table 6-3-1 calculation of the amount of gravel accumulated inside the reservoir

\begin{tabular}{cccccccc}
\hline $\begin{array}{c}\text { Return } \\
\begin{array}{c}\text { Period } \\
\text { [year] }\end{array}\end{array}$ & Occ. & $\begin{array}{c}\text { Width } \\
{[\mathrm{m}]}\end{array}$ & $\begin{array}{c}\text { Vol/m } \\
{[\mathrm{m} 3 / \mathrm{m}]}\end{array}$ & $\begin{array}{c}\text { U/S } \\
\text { distance } \\
{[\mathrm{m}]}\end{array}$ & $\begin{array}{c}\text { U/S River } \\
\text { length }[\mathrm{m}]\end{array}$ & $\begin{array}{c}\text { Specific } \\
\text { gravity }\end{array}$ & $\begin{array}{c}\text { Total } \\
\text { Mass } \\
\text { [ton] }\end{array}$ \\
\hline 100 & 1 & 112 & 0.724 & 450 & 42000 & 2.65 & 20064 \\
25 & 4 & 107 & 0.511 & 450 & 42000 & 2.65 & 54094 \\
10 & 10 & 100 & 0.341 & 450 & 42000 & 2.65 & 84385 \\
2 & 30 & 85 & 0.104 & 450 & 42000 & 2.65 & 65590 \\
\hline
\end{tabular}

Column four is taken from Figure (6-3-2) by integration of the bedload area under the curves. The total amount of gravel accumulated (modeled) is about 224,000 ton which is in the range of measured gravel in the reservoir. While this is not a conclusive result because the historic system before logging was different from the modern system, and the material deposited has a wide variety of sizes (rather than the single size modeled), it is encouraging 

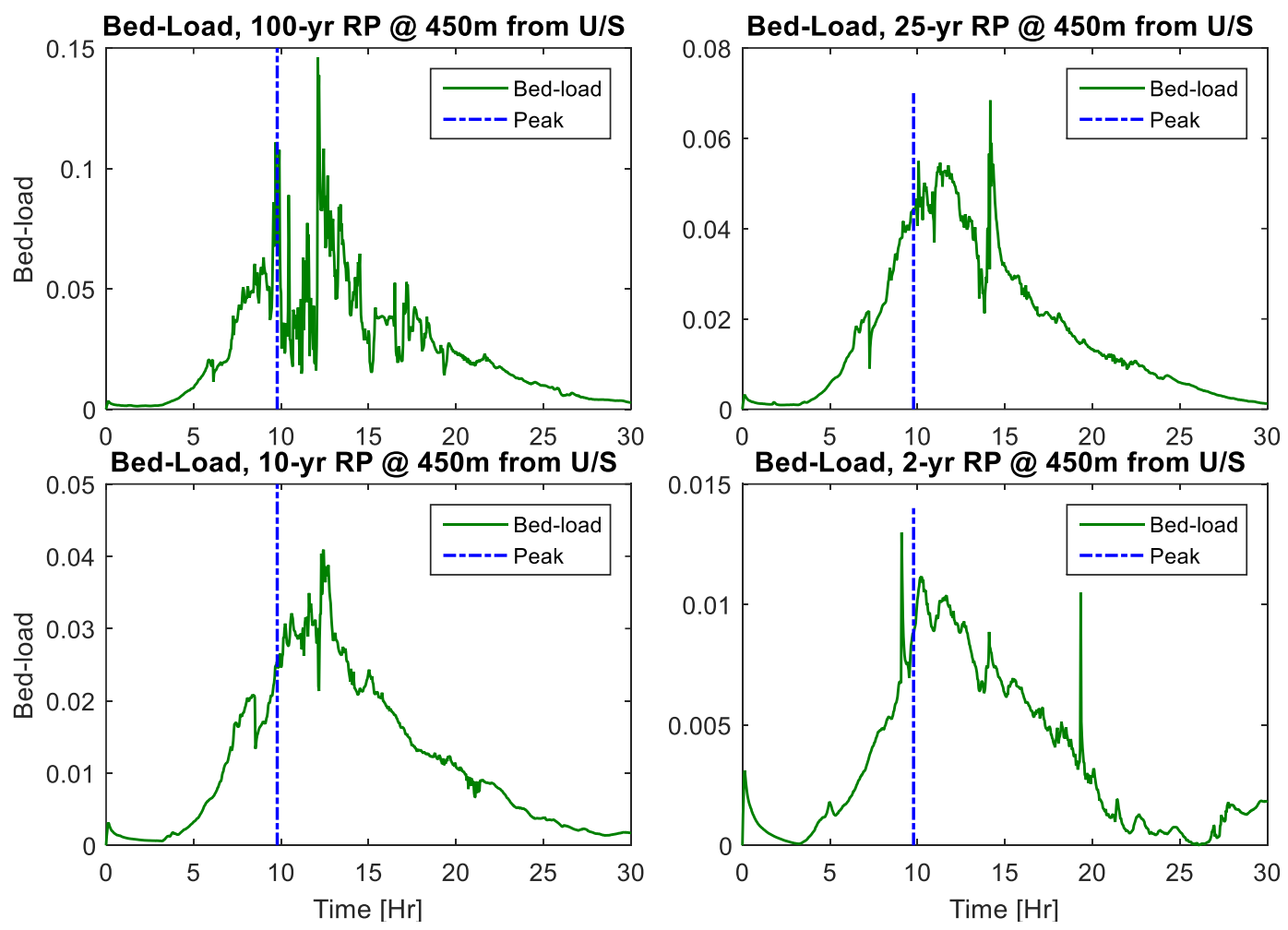

Figure 6-3-2 the bed-load hysteresis of different return period floods

There are also some restrictions in the Nays $2 \mathrm{DH}$ that affect the model performance and output. For example, the model distributes the inflow at upstream boundary of the model domain over the entire inflow cross-section inlet, no matter how small the flow is. This problem was dealt with by deleting DEM on the shoulders of the flow inlet. When the mesh is generated over the deleted points, iRIC makes deleted area into a (barrier) in the domain, causing the inflow to be restricted to the channel (Figure 63-3). Another constraint of the model is bed-load formula; when the user selects the Meyer-Peter and Müller formula for bed-load computation, it must use uniform sediment size. While the more flexible Ashida and Michiue algorithm was used, multiple sediment sizes were not implemented because of the bank erosion model and lack of computational 
resources. Also, there is restriction for bank erosion model with Nays2DH; it cannot model bank erosion with non-uniform sediment size. This is an important limitation, as sediment on the banks may be either coarser or finer than sediment in the channel or channels, and bank erosion is obviously very important in the Sandy River, as shown in Figures 6-1-1 to 6-1-3.

It would be useful for the Nays2DH developers to eliminate the restrictions described in the previous paragraph in future model updates. Even with the existing model, some improvements could be made in a future study. These include:

1. Modeling a longer reach.

2. Using a three-dimensional curvilinear grid.

3. Using newer elevation and bathymetry data, if those are collected.

4. Including multiple sediment sizes with recent particle size distribution of the river reach.

5. Conduct field surveys to obtain a dataset for numerical model calibration.

6. Use more computational power.

7. Consideration the effects of vegetation.

8. Study effects of geomorphic response on the aquatic habitat.

9. Include inflow from rainfall over the domain during the flood events. 

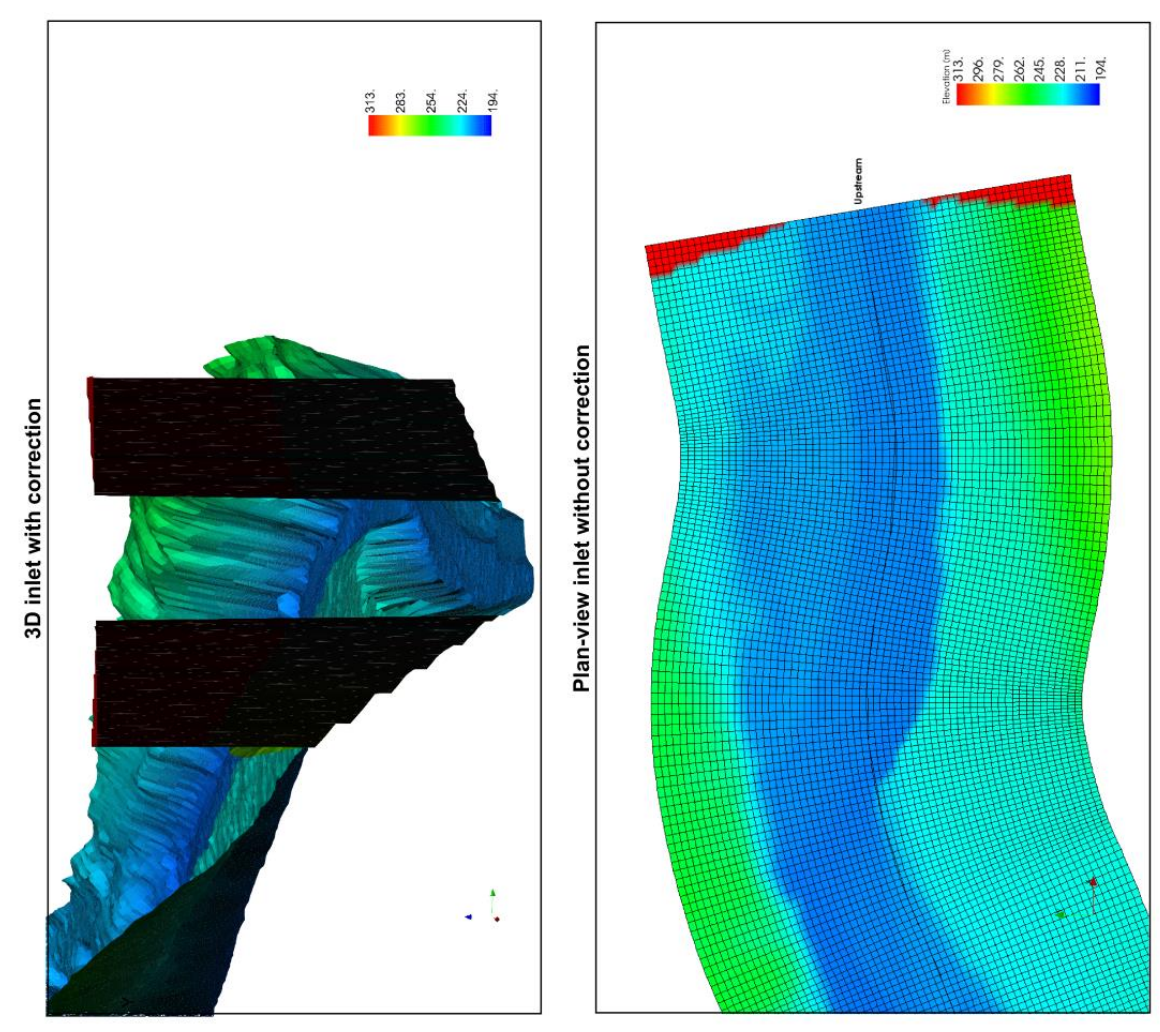

(3)
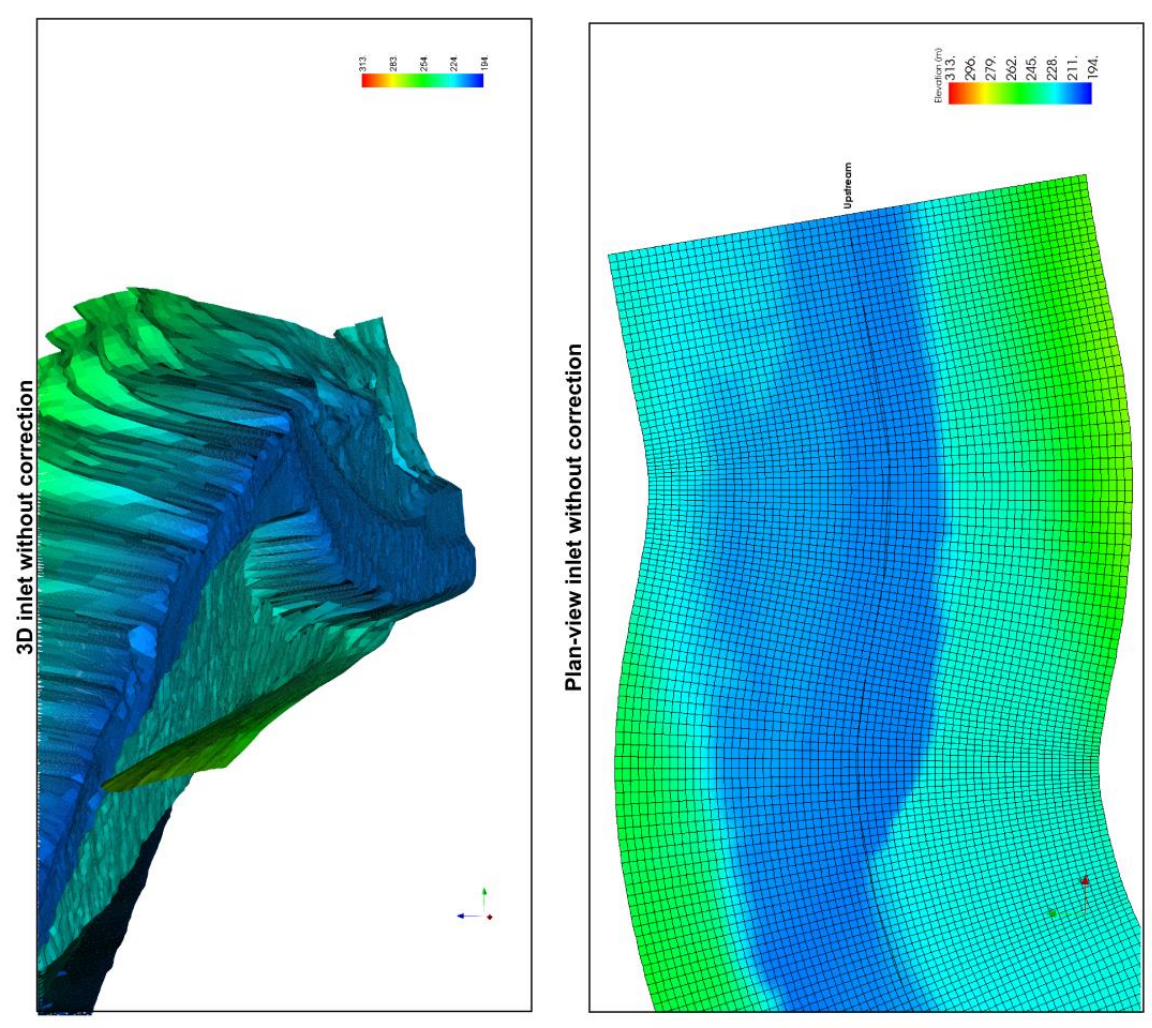

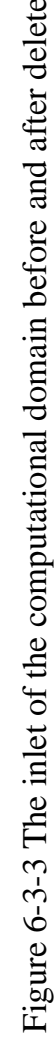




\section{Reference List}

Dalton, M. M., Mote, P. W., \& Snover, A. K. (2013). Climate Change in the Northwest Implications for Our Landscapes, Waters, and Communities. ISLAND PRESS.

Aron, G., \& White, E. (1982). Fitting a Gamma Distribution Over a Synthetic Unit Hydrograph. JAWRA Journal of the American Water Resources Association, 9598.

Asahi, K., Shimizu, Y., Nelson, J., \& Parker, G. (2013). Numerical Simulation of River Meandering with Self-Evolving Banks. Journal of Geophysical Research: Earth Surface, 1-22.

Ashida, K., \& Michiue, M. (1972). Study on Hydraulic Resistance and Bedload Transport Rate in Alluvial Streams. Journal of Japan Society of Civil Engineers, 59-69.

Bhunya, P. K., Berndtsson, R., Singh, P. K., \& Hubert, P. (2008). Comparison Between Weibull and Gamma Distributions to Derive Synthetic Unit Hydrograph Using Horton Ratios. Water Resources Research (AGU), 1-17.

Bhunya, P. K., Mishra, S. K., \& Berndtsson, R. (2003). Simplified Two-Parameter Gamma Distribution for Derivation of Synthetic Unit Hydrograph. Journal of Hydrologic Engineering ASCE, 226-230.

Bobée, B. (1975). The Log-Pearson Type 3 Distribution and Its Application in Hydrology. Water resources Research (AGU), 681-689.

Brandt, J. P., Morgan, T. A., Dillon, T., Lettman, G. J., Keegan, C. E., \& Azuma, D. L. (2006). Oregon's Forest Products Industry and Timber Harvest, 2003. Washington, DC: United States Department of Agriculture, Forest Service, Pacific Northwest Research Station.

Brekke, L., Kuepper, B., \& Vaddey, S. (2010). Climate and Hydrology Datasets for Use in the RMJOC Agencies' Longer-Term Planning Studies: Part I - Future Climate and Hydrology Datasets. U.S. Department of the Interior, U.S. Army Corps of Engineers, Bonneville Power Administration.

Burkey, J. (2009, December 02). Log-Pearson Flood Flow Frequency using USGS 17 B. Retrieved from MATLAB Central File Exchange: https://www.mathworks.com/matlabcentral/fileexchange/22628-log-pearsonflood-flow-frequency-using-usgs-17b 
Charlton, R. (2008). Fundamentals of Fluvial Geomorphology. New York: Routledge.

Chow, V. T., Maidment, D. R., \& Mays, L. W. (1988). Applied Hydrology. Singapore: McGraw-Hill.

Coe, M. T., Latrubesse, E. M., Ferreira, M. E., \& Amsler, M. L. (2011). The Effects of Deforestation and Climate Variability on the Streamflow of the Araguaia River, Brazil. Biogeochemistry, 119-131.

Cooley, D. (2013). Chapter 4: Return Periods and Return Levels Under Climate Change. In A. AghaKouchak, D. Easterling, K. Hsu, S. Schubert, \& S. Sorooshian, Extremes in a Changing Climate: Detection, Analysis and Uncertainty (pp. 97114). Dordrecht: Springer.

Coon, W. F. (1998). Estimation of Roughness Coefficients for Natural Stream Channels with Vegetated Banks. U.S. Geological Survey, U.S. Department of the Interior.

Dingman, S. L. (2015). Physical Hydrology. Long Grove, Illinois: Waveland Press.

Duan, J. G., \& Julien, P. Y. (2010). Numerical Simulation of Meandering Evolution. Journal of Hydrology, 34-46.

Dulal, K. P., \& Shimizu, Y. (2008). Investigation of the Cohesive Sediments Influence on the Meandering Channel Development. In Proceedings of 8th ICHE 2008.

Dulal, K. P., Kobayashi, K., Shimizu , Y., \& Parker, G. (2010). Numerical Computation of Free Meandering Channels with the Application of Slump Blocks on the Outer Bends. Journal of Hydro-environment Research , 239-246.

Ferziger, J. H., \& Peric, M. (2002). Computational Methods for Fluid Dynamics. Springer.

Grant, G., Marr, J., Hill, C., Johnson, S., Campbell, K., Mohseni, O., et al. (2008). Experimental and Field Observations of Breach Dynamics Accompanying Erosion of Marmot Cofferdam, Sandy River, Oregon. World Environmental and Water Resources Congress 2008 (pp. 1-10). Honolulu, Hawaii: Environmental and Water Resources Institute (EWRI) of the American Society of Civil Engineers (ASCE).

Griffin, E. R., \& Smith, J. D. (2004). Floodplain Stabilization by Woody Riparian Vegetation During an Extreme Flood. In S. J. Bennett , \& A. Simon, Riparian 
Vegetation and Fluvial Geomorphology (pp. 221-236). Wiley-American Geophysical Union.

Griffis, V. W., \& Stedinger, J. R. (2007). Log-Pearson Type 3 Distribution and Its Application in Flood Frequency Analysis. I: Distribution Characteristics. Journal of Hydrologic Engineering ASCE, 482-491.

Hingray, B., Picouet, C., \& Musy, A. (2015). Hydrology A Science for Engineers. CRC Press Taylor \& Francis Group.

Ingham, D. B., \& Ma, L. (2005). Fundamental Equations for CFD in River Flow Simulations. In P. D. Bates, S. N. Lane, \& R. I. Ferguson, Computational Fluid Dynamics: Applications in Environmental Hydraulics (pp. 19-50). John Wiley \& Sons.

Intergovernmental Panel on Climate Change (IPCC ). (2007). IPCC Fourth Assessment Report: Climate Change 2007. Retrieved from IPCC: https://www.ipcc.ch/publications_and_data/ar4/wg2/en/ch3s3-4-3.html

Intergovernmental Panel on Climate Change (IPCC ). (2013, June 18). What is a GCM? Retrieved from IPCC: http://www.ipcc-data.org/guidelines/pages/gcm_guide.html

iRIC Software. (2014). Nays2DH Solver Manual.

Iwasaki, T., Shimizu, Y., \& Kimura, I. (2016). Numerical Simulation of Bar and Bank Erosion in a Vegetated Floodplain: A Case Study in the Otofuke River. Advances in Water Resources, 118-134.

Ji, P. (2011). Reservoir Re-operation, Risk, and Levee Failure Analysis: Mokelumne River Case. Retrieved from https://watershed.ucdavis.edu/shed/lund/students/JiThesis.pdf: University of Calefornia Davis (Doctoral Dissertation).

John E. Costa, J. E. (1995). Chapter 3: Geomorphically Effective Floods. (A. J. John E. Costa, Ed.) Natural and Anthropogenic Influences in Fluvial Geomorphology, 4556.

Kay, W. M., Donoghue, E. M., Charnley, S., \& Moseley, C. (2007). Socioeconomic Monitoring of the Mount Hood National Forest and Three Local Communities. Washington, DC: United States Department of Agriculture, Forest Service, Pacific Northwest Research Station. 
Keith, M. K. (2012). Reservoir Evolution Following the Removal of Marmot Dam on the Sandy River, Oregon. Portland: Portland State University.

Keller, T. (2010, October 28). What PGE Learned While Removing Marmot Dam. Retrieved from Daily Journal of Commerce:

http://www.djc.com/news/ae/12023010.html?action=get\&id=12023010\&printmo de=true

Kinze, P. J., Logan, B. L., \& Nelson, J. M. (2015). Effects of Upstream Sediment Supply and Flow Rate on the Initiation and Topographic Evolution of Sandbars in Laboratory and Numerical Channels. Proceedings of the Joint 10th Federal Interagency Sedimentation Conference and 5th Federal Interagency Hydrologic Modeling Conference.

Kleinhans, M. G., Wilbers, A. E., \& ten Brinke, W. M. (2007). Opposite Hysteresis of Sand and Gravel Transport Upstream and Downstream of a Bifurcation During a Flood in the River Rhine, the Netherlands. Netherlands Journal of Geosciences, 273-285.

Knighton, D. (1998). Fluvial Forms and Processes: A New Perspective. Hodder Arnold.

Lucía, A., Recking, A., Martín-Duque, J. F., Storz-Peretz, Y., \& Laronne, J. B. (2013). Continuous Monitoring of Bedload Discharge in a Small, Steep Sandy Channel. Journal of Hydrology, 37-50.

Major, J., Apicer, K., \& Collins, R. (2010). Time-Lapse Imagery of the Breaching of Marmot Dam, Oregon, and Subsequent Erosion of Sediment by the Sandy RiverOctober 2007 to May 2008. Reston, Virginia: U.S. Geological Survey, Data Series 521.

Major, J., O’Connor, J., Podolak, C., Keith, M., Grant, G., Spicer, K., et al. (2012). Geomorphic Response of the Sandy River, Oregon, to Removal of Marmot Dam. Reston, Virginia: U.S. Geological Survey Professional Paper 1792.

Major, J., Spicer, K., Rhode, A., O’Connor, J., Bragg, H., Tanner, D., et al. (2008). Initial Fluvial Response to the Removal of Oregon's Marmot Dam. EOS, Transactions American Geophysical Union, 241-252.

Mantua, N. J., Hare, S. R., Zhang, Y., Wallace, J. M., \& Francis, R. C. (1997). A Pacific Interdecadal Climate Oscillation with Impacts on Salmon Production. Bulletin of the American Meteorological Society, 1069-1079. 
Matheussen, B., Kirschbaum, R. L., Goodman, I. A., O'Donnell, G. M., \& Lettenmaier, D. P. (2000). Effects of Land Cover Change on Streamflow in the Interior Columbia River Basin (USA and Canada). Hydrological Processes, 867-885.

Meylan, P., Favre, A.-C., \& Musy, A. (2011). Predictive Hydrology: A Frequency Analysis Approach. CRC Press Taylor \& Francis Group.

Moukalled, F., Mangani, L., \& Darwish, M. (2016). The Finite Volume Method in Computational Fluid Dynamics: An Advanced Introduction with OpenFOAM® and Matlab®. Springer International Publishing Switzerland .

Nelson, J. M., Shimizu, Y., Abe, T., Asahi, K., Gamou, M., Inoue, T., et al. (2016). The International River Interface Cooperative: Public Domain Flow and Morphodynamics Software for Education and Applications. Advances in Water Resources, 62-74.

NOAA. (n.d.). Glossary of Hydrologic Terms. Retrieved from National Oceanic and Atmospheric Administration (NOAA): http://www.nws.noaa.gov/om/hod/SHManual/SHMan014_glossary.htm

Oregon Climate Change Research Institute. (n.d.). Potential Impacts of Climate Change Water Resources. Retrieved from occri.net: http://occri.net/climatescience/potential-impacts-of-climate-change/water-resources

Parhi, P. K., Sankhua, R. N., \& Roy, G. P. (2012). Calibration of Channel Roughness for Mahanadi River, (India) Using HEC-RAS Model. Journal of Water Resource and Protection, 847-850.

Popescu, I. (2014). Computational Hydraulics: Numerical Methods and Modelling. London: IWA Publishing.

Ronen-Eliraz, G., Ginat, H., Dody, A., Blumberg, D., \& Dahan, O. (2016). Flood Hydrograph Reconstruction From the Peak Flow Value in Ephemeral Streams Using a Simplified Robust Single-Parameter Model. Hydrological Processes, DOI: 10.1002/hyp.10831.

Sade, M. (2011). A Gamma Distribution Unit Hydrograph for Flat Terrain Watersheds. World Water Congress 2001 (pp. 1-7). American Society of Civil Engineers (ASCE).

Sandy River Fishing. (2001, January 1). Fishing on the Sandy River in Oregon. Retrieved from Sandy River Fishing: http://sandyriverfishing.com/ 
Shakibaeinia, A., \& Jin, Y.-C. (2011). MPS-Based Mesh-Free Particle Method for Modeling Open-Channel Flows. Journal of Hydraulic Engineering (ASCE), 13751384.

Shankland, A. (2005). Sandy River Basin Characterization Report. Sandy River Basin Partners.

Spasojevic, M., \& Holly, F. M. (2008). Two- and Three-Dimensional Numerical Simulation of Mobile-Bed Hydrodynamics and Sedimentation. In M. H. García, ASCE Manuals and Reports on Engineering Practice No. 110: Sedimentation Engineering: Processes, Measurements, Modeling, and Practice (pp. 683-762). American Society of Civil Engineers (ASCE).

Stillwater Sciences . (2000b). Numerical Modeling of Sediment Transport in the Sandy River, OR Following Removal of Marmot Dam. Portland, Oregon: Portland General Electric Company.

Stillwater Sciences . (2002b). Sediment Transport Modeling Following the Removal of Marmot Dam with 125,000 and 300,000 Cubic Yards of Dredging Prior to Dam Removal. Portland, Oregon: Portland General Electric.

Subramanya, K. (2013). Engineering Hydrology. New Delhi: McGraw-Hill Education .

U.S. Geological Survey. (2016, July 15). National Water Information System. Retrieved from waterdata.usgs.gov:

http://waterdata.usgs.gov/nwis/inventory/?site_no=14137000\&agency_cd=USGS

U.S. Water Resources Council. (1982). Guidelines for Determining Flood Flow Frequency. Washington D.C: Bulletin 17B Hydrology Committee.

Versteeg, H. K., \& Malalasekera, W. (2007). An Introduction to Computational Fluid Dynamics: The Finite Volume Method. Pearson Education.

Vogel, R. M., \& Wilson, I. (1996). Probability Distribution of Annual Maximum, Mean, and Minimum Streamflows in the United States. Journal of Hydrologic Engineering, ASCE, 69-76.

Wu, W. (2007). Computational River Dynamics. London: Taylor \& Francis Group.

Xiao, Y., Guo, S., Liu, P., Yan, B., \& Chen, L. (2009). Design Flood Hydrograph Based on Multicharacteristic Synthesis Index Method. Journal of Hydrologic Engineering ASCE, 1359-1364. 
Xue, Q., Som, S., Senecal, P. K., \& Pomraning, E. (2013). A Study of Grid Resolution and SGS Models for LES under Non-reacting Spray Conditions. 25th Annual Conference on Liquid Atomization and Spray Systems. Pittsburgh: Institute for Liquid Atomization and Spray Systems (ILASS) Americas.

Yue, S., Ouarda, T. B., Bobée, B., Legendre, P., \& Bruneau, P. (2002). Approach for Describing Statistical Properties of Flood Hydrograph. Journal of Hydrologic Engineering ASCE, 147-153. 


\section{Appendix: Coordinate system transformation from a Cartesian coordinate system}

\section{to a general curvilinear coordinates system.}

The purpose of this Appendix is to explain coordinate system transformation from Cartesian $(x, y)$ to a general curvilinear $(\xi, \eta)$ or moving boundary -fitted coordinate (MBFC) system which is used to model complex boundaries in systems with sediment transport.

Assume:

$\xi=\xi(x, y)$

$\eta=\eta(x, y)$

In differential form,

$$
\begin{aligned}
& \frac{\partial}{\partial x}=\frac{\partial \xi}{\partial x} \frac{\partial}{\partial \xi}+\frac{\partial \eta}{\partial x} \frac{\partial}{\partial \eta} \\
& \frac{\partial}{\partial y}=\frac{\partial \xi}{\partial y} \frac{\partial}{\partial \xi}+\frac{\partial \eta}{\partial y} \frac{\partial}{\partial \eta}
\end{aligned}
$$

Arranging A-1, and A-2 in the matrix formation,

$$
\left(\begin{array}{c}
\frac{\partial}{\partial x} \\
\frac{\partial}{\partial y}
\end{array}\right)=\left(\begin{array}{ll}
\frac{\partial \xi}{\partial x} & \frac{\partial \eta}{\partial x} \\
\frac{\partial \xi}{\partial y} & \frac{\partial \eta}{\partial y}
\end{array}\right)\left(\begin{array}{c}
\frac{\partial}{\partial \xi} \\
\frac{\partial}{\partial \eta}
\end{array}\right)
$$

$$
\left(\begin{array}{c}
\frac{\partial}{\partial x} \\
\frac{\partial}{\partial y}
\end{array}\right)=\left(\begin{array}{ll}
\xi_{x} & \eta_{x} \\
\xi_{y} & \eta_{y}
\end{array}\right)\left(\begin{array}{c}
\frac{\partial}{\partial \xi} \\
\frac{\partial}{\partial \eta}
\end{array}\right)
$$

The (Eqn. A-4) is called the matrix of transformation 
where,

$$
\xi_{x}=\frac{\partial \xi}{\partial x}, \xi_{y}=\frac{\partial \xi}{\partial y}, \eta_{x}=\frac{\partial \eta}{\partial x}, \eta_{y}=\frac{\partial \eta}{\partial y}
$$

Similarly,

$$
\begin{aligned}
& \frac{\partial}{\partial \xi}=\frac{\partial x}{\partial \xi} \frac{\partial}{\partial x}+\frac{\partial y}{\partial \xi} \frac{\partial}{\partial y} \\
& \frac{\partial}{\partial \eta}=\frac{\partial x}{\partial \eta} \frac{\partial}{\partial x}+\frac{\partial y}{\partial \eta} \frac{\partial}{\partial y}
\end{aligned}
$$

Arranging A-6, and A-7 in the matrix formation,

$$
\begin{aligned}
& \left(\begin{array}{c}
\frac{\partial}{\partial \xi} \\
\frac{\partial}{\partial \eta}
\end{array}\right)=\left(\begin{array}{ll}
x_{\xi} & y_{\xi} \\
x_{\eta} & y_{\eta}
\end{array}\right)\left(\begin{array}{c}
\frac{\partial}{\partial x} \\
\frac{\partial}{\partial y}
\end{array}\right) \\
& x_{\xi}=\frac{\partial x}{\partial \xi}, x_{\eta}=\frac{\partial x}{\partial \eta}, y_{\xi}=\frac{\partial y}{\partial \xi}, y_{\eta}=\frac{\partial y}{\partial \eta}
\end{aligned}
$$

From A-4 and A-8,

$$
\left(\begin{array}{c}
\frac{\partial}{\partial \xi} \\
\frac{\partial}{\partial \eta}
\end{array}\right)=\left(\begin{array}{cc}
\xi_{x} & \eta_{x} \\
\xi_{y} & \eta_{y}
\end{array}\right)^{-1}\left(\begin{array}{c}
\frac{\partial}{\partial x} \\
\frac{\partial}{\partial y}
\end{array}\right) \rightarrow\left(\begin{array}{cc}
x_{\xi} & y_{\xi} \\
x_{\eta} & y_{\eta}
\end{array}\right)=\left(\begin{array}{cc}
\xi_{x} & \eta_{x} \\
\xi_{y} & \eta_{y}
\end{array}\right)^{-1}
$$

Because the inverse in $2 \times 2$ matrix is,

$$
\left(\begin{array}{ll}
a & b \\
c & d
\end{array}\right)=\frac{1}{a d-b c}\left(\begin{array}{cc}
d & -b \\
-c & a
\end{array}\right)
$$

Then,

$$
\left(\begin{array}{ll}
\xi_{x} & \eta_{x} \\
\xi_{y} & \eta_{y}
\end{array}\right)^{-1}=\frac{1}{\xi_{y} \eta_{y}-\xi_{x} \eta_{x}}\left(\begin{array}{cc}
\eta_{y} & -\eta_{x} \\
-\xi_{y} & \xi_{x}
\end{array}\right)
$$




$$
\begin{aligned}
& \left(\begin{array}{c}
\frac{\partial}{\partial \xi} \\
\frac{\partial}{\partial \eta}
\end{array}\right)=\frac{1}{\xi_{y} \eta_{y}-\xi_{x} \eta_{x}}\left(\begin{array}{cc}
\eta_{y} & -\eta_{x} \\
-\xi_{y} & \xi_{x}
\end{array}\right)\left(\begin{array}{l}
\frac{\partial}{\partial x} \\
\frac{\partial}{\partial y}
\end{array}\right)=\left(\begin{array}{cc}
x_{\xi} & y_{\xi} \\
x_{\eta} & y_{\eta}
\end{array}\right)\left(\begin{array}{c}
\frac{\partial}{\partial x} \\
\frac{\partial}{\partial y}
\end{array}\right) \\
& J=\xi_{x} \eta_{y}-\xi_{y} \eta_{x}
\end{aligned}
$$

Where $J$ is the Jacobian of Transformation

$$
\frac{1}{J}\left(\begin{array}{cc}
\eta_{y} & -\eta_{x} \\
-\xi_{y} & \xi_{x}
\end{array}\right)=\left(\begin{array}{cc}
x_{\xi} & y_{\xi} \\
x_{\eta} & y_{\eta}
\end{array}\right)
$$

From the above relationships we get,

$$
\begin{aligned}
& x_{\xi}=\frac{1}{J} \eta_{y}, x_{\eta}=-\frac{1}{J} \xi_{y}, \quad y_{\xi}=-\frac{1}{J} \eta_{x}, \quad y_{\eta}=\frac{1}{J} \xi_{x} \\
& \eta_{y}=J x_{\xi}, \quad \xi_{y}=-J x_{\eta}, \quad \eta_{x}=-J y_{\xi}, \quad \xi_{x}=J y_{\eta} \\
& J=\xi_{x} \eta_{y}-\xi_{y} \eta_{x}=J y_{\eta} \times J x_{\xi}-\left(-J x_{\eta} \times-J y_{\xi}\right) \\
& J=J^{2}\left(x_{\xi} y_{\eta}-x_{\eta} y_{\xi}\right) \\
& J=\frac{1}{x_{\xi} y_{\eta}-x_{\eta} y_{\xi}}
\end{aligned}
$$

Assume the components of velocity $(u)$ are $\left(u^{\xi}, u^{\eta}\right)$ in the $\xi, \eta$ direction

$u^{\xi}=\xi_{x} u+\xi_{y} v$

$u^{\eta}=\eta_{x} u+\eta_{y} v$

In the matrix form

$$
\begin{aligned}
& \left(\begin{array}{l}
u^{\xi} \\
u^{\eta}
\end{array}\right)=\left(\begin{array}{ll}
\xi_{x} & \xi_{y} \\
\eta_{x} & \eta_{y}
\end{array}\right)\left(\begin{array}{l}
u \\
v
\end{array}\right) \\
& \left(\begin{array}{l}
u \\
v
\end{array}\right)=\frac{1}{J}\left(\begin{array}{cc}
\eta_{y} & -\xi_{y} \\
-\eta_{x} & \xi_{x}
\end{array}\right)\left(\begin{array}{l}
u^{\xi} \\
u^{\eta}
\end{array}\right)
\end{aligned}
$$


Example: Transform two-dimensional transport equation $\frac{\partial \psi}{\partial t}+u \frac{\partial \psi}{\partial x}+v \frac{\partial \psi}{\partial y}=0$ from the orthogonal coordinate system to general curvilinear coordinate system.

$$
\begin{aligned}
& \frac{\partial \psi}{\partial t}+u \frac{\partial \psi}{\partial x}+v \frac{\partial \psi}{\partial y}=0 \\
& \frac{\partial \psi}{\partial x}=\frac{\partial \xi}{\partial x} \frac{\partial \psi}{\partial \xi}+\frac{\partial \eta}{\partial x} \frac{\partial \psi}{\partial \eta} \\
& \frac{\partial \psi}{\partial y}=\frac{\partial \xi}{\partial y} \frac{\partial \psi}{\partial \xi}+\frac{\partial \eta}{\partial y} \frac{\partial \psi}{\partial \eta} \\
& \frac{\partial \psi}{\partial t}+u \frac{\partial \xi}{\partial x} \frac{\partial \psi}{\partial \xi}+u \frac{\partial \eta}{\partial x} \frac{\partial \psi}{\partial \eta}+v \frac{\partial \xi}{\partial y} \frac{\partial \psi}{\partial \xi}+v \frac{\partial \eta}{\partial y} \frac{\partial \psi}{\partial \eta}=0 \\
& \frac{\partial \psi}{\partial t}+u \xi_{x} \frac{\partial \psi}{\partial \xi}+u \eta_{x} \frac{\partial \eta}{\partial x} \frac{\partial \psi}{\partial \eta}+v \xi_{y} \frac{\partial \psi}{\partial \xi}+v \eta_{y} \frac{\partial \psi}{\partial \eta}=0 \\
& \frac{\partial \psi}{\partial t}+\left(u \xi_{x}+v \xi_{y}\right) \frac{\partial \psi}{\partial \xi}+\left(u \eta_{x}+v \eta_{y}\right) \frac{\partial \psi}{\partial \eta}=0 \\
& u \xi_{x}+v \xi_{y}=u . \nabla \xi, u \eta_{x}+v \eta_{y}=u . \nabla \eta \\
& \frac{\partial \psi}{\partial t}+u . \nabla \xi \frac{\partial \psi}{\partial \xi}+u . \nabla \eta \frac{\partial \psi}{\partial \eta}=0 \quad \text { Multiply by } 1 / J \\
& \frac{1}{J} \frac{\partial \psi}{\partial t}+u . \nabla \xi \frac{1}{J} \frac{\partial \psi}{\partial \xi}+u . \nabla \eta \frac{1}{J} \frac{\partial \psi}{\partial \eta}=0 \\
& \text { But } \frac{1}{J} u . \nabla \xi=u^{\xi} \text { and } \frac{1}{J} u . \nabla \eta=u^{\eta} \\
& \frac{1}{J} \frac{\partial \psi}{\partial t}+u^{\xi} \frac{\partial \psi}{\partial \xi}+u^{\eta} \frac{\partial \psi}{\partial \eta}=0
\end{aligned}
$$




$$
\begin{aligned}
& \frac{1}{J} \frac{\partial \psi}{\partial t}+\frac{\partial}{\partial \xi}\left(u^{\xi} \psi\right)-\psi \frac{\partial u^{\xi}}{\partial \xi}+\frac{\partial}{\partial \eta}\left(u^{\eta} \psi\right)-\psi \frac{\partial u^{\eta}}{\partial \eta}=0 \\
& \frac{1}{J} \frac{\partial \psi}{\partial t}+\frac{\partial}{\partial \xi}\left(u^{\xi} \psi\right)+\frac{\partial}{\partial \eta}\left(u^{\eta} \psi\right)-\psi \underbrace{\left(\frac{\partial u^{\xi}}{\partial \xi}+\frac{\partial u^{\eta}}{\partial \eta}\right)}_{\text {Continuity Eqn. }=0}=0 \\
& \frac{1}{J} \frac{\partial \psi}{\partial t}+\frac{\partial}{\partial \xi}\left(u^{\xi} \psi\right)+\frac{\partial}{\partial \eta}\left(u^{\eta} \psi\right)=0
\end{aligned}
$$

